FERNANDA SCARAMAL MADRONA

\title{
PRESSÕES EM SILOS ESBELTOS COM DESCARGA EXCÊNTRICA
}

Dissertação apresentada à Escola de Engenharia de São Carlos da Universidade de São Paulo, como parte dos requisitos para obtenção do Título de Mestre em Engenharia de Estruturas.

Orientador: Prof. Titular Carlito Calil Junior.

\section{SÃO CARLOS}

2008 
FOLHA DE JULGAMENTO

Candidata: Engenheira FERNANDA SCARAMAL MADRONA

Dissertação defendida e julgada em 11/07/2008 perante a Comissão Julgadora:

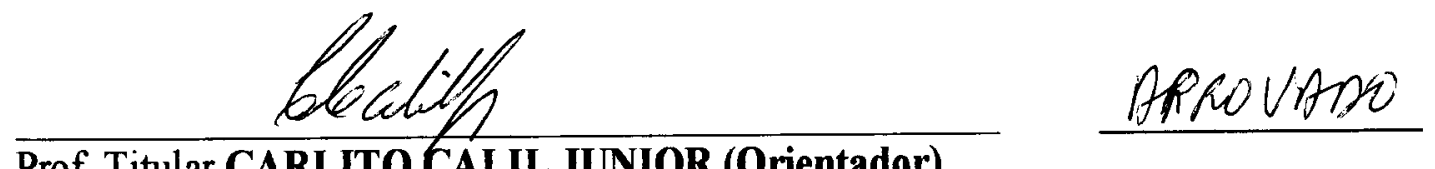

Prof. Titular CARLITO CALIL JUNIOR (Orientador)

(Escola de Engenharia de São Carlos/USP)

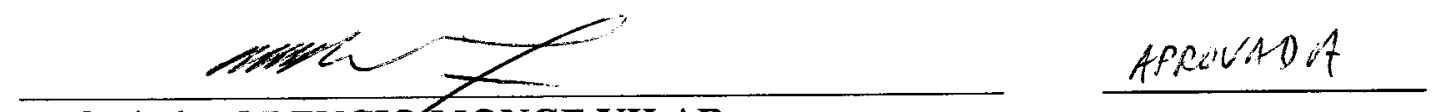

Prof. Titular ORENCIO MONGE VILAR

(Escola de Engenharia de São Carlos/USP)

$$
\operatorname{men} 01,
$$

Prof ${ }^{\mathrm{n}}$. Associada MARIA CECILIA AMORIM TEIXEIRA DA SILVA

(Universidade Estadual de Campinas/UNICAMP)
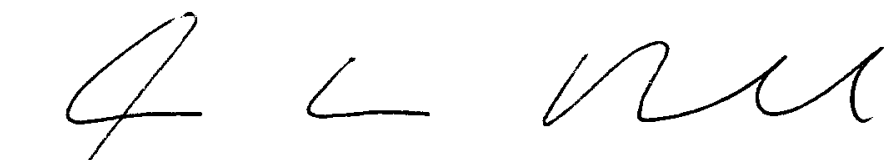

Prof. Associado MARCIO ANTONIO RAMALHO

Coordenador do Programa de Pós-Graduação em

Engenharia Civil (Engenharia de Estruturas) e

Vice-Presidente da Comissão de Pós-Graduação da EESC,

Em Exercício 
A meus pais: Angela e Gilberto que não mediram esforços para me garantir uma boa formação e sempre apoiaram no meu caminho.

Às minhas irmãs Grasiele e Bianca pela amizade e carinho.

Ao meu amado Renato pelo amor, companheirismo, compreensão, amizade $e$ paciência durante os nove anos que estivemos juntos. Você é o colorido da minha vida. 


\section{AGRADECIMENTOS}

Agradeço primeiramente a Deus, que é luz para o meu caminho e a força maior para prosseguir.

Ao professor Titular Carlito Calil Junior, pela orientação, pela confiança, incentivo e apoio durante a realização deste trabalho.

Aos amigos e colegas do departamento de estruturas, em especial Érica, Karla, Camila, Marcela, Aquino, Marlos, Dênis, Jesus, Jonatas, Raimundo, João Cezar e Dorival pela amizade. Também Fernando, Pedro César, Saulo e Ronaldo, que me ajudaram na análise numérica.

Às amigas Ana Carina, Larissa, Mariana, Karenina, Mariana Almeida, Lívia e lara. Estou levando um pouquinho de cada uma de vocês dentro de mim. Todos os bons momentos que passamos juntas serão lembrados.

À Escola de Engenharia de São Carlos pelos serviços de apoio à pesquisa e a pós-graduação;

À Universidade Estadual de Maringá pela formação acadêmica;

À Fundação de Amparo à Pesquisa do Estado de São Paulo (FAPESP), pela concessão da bolsa de mestrado. 



\section{RESUMO}

MADRONA, F. S. Pressões em silos esbeltos com descarga excêntrica. 2008. 178 f .

Dissertação (Mestrado) - Escola de Engenharia de São Carlos, Universidade de São Paulo, 2008.

A maioria dos silos existentes no mundo não apresenta condições ideais de operação devido ao insuficiente conhecimento das pressões exercidas pelo produto armazenado principalmente na situação de descarga. A descarga excêntrica é comum em cooperativas e indústrias pois facilita o acesso na descarga do produto armazenado em trens e caminhões. Em contrapartida, nesta situação surgem pressões assimétricas que são a maior causa de acidentes e colapsos em silos. Até mesmo em silos concêntricos, as pressões assimétricas podem ocorrer. Ainda faltam muitas respostas com relação ao comportamento das pressões na descarga excêntrica, por isso, a maioria das normas internacionais recomenda a adoção de pressões adicionais para levar em conta os efeitos das pressões assimétricas, sendo que, estas recomendações variam muito de uma norma para outra e muitas vezes não são claras em suas afirmações. Este trabalho teve por objetivo principal o estudo teórico e numérico das pressões devidas ao produto armazenado em silos verticais com descarga excêntrica. Os resultados obtidos mostram que para a determinação das ações em silos esbeltos para o armazenamento de produtos de fluxo livre uma boa solução é a utilização dos métodos recomendados pelas normas EUROCODE e DIN, com algumas ressalvas: pressão no fundo do silo segundo a AS, estabelecimento de coeficiente de sobrepressão mínimo de 1,2 e porcentagem mínima de variabilidade das propriedades dos produtos, mesmo quando elas forem obtidas por meio de testes experimentais.

Palavras-chave: Pressões, silos, esbeltos, descarga excêntrica, estruturas de armazenamento. 
Most of the silos do not meet the ideal requirements for operation ought to many factors. One of the main factors is related to the lack of knowledge about the pressure imposed by the stored material, especially during discharge. In this work, the discharge done through eccentric silos is investigated, which is commonly employed by cooperatives and factories once they facilitate the access of trains and trucks to the discharged product. In those situations there is the occurrence of asymmetric pressure, which is the major cause of collapses and accidents in silos. There are still many pending answers regarding the pressure behavior in eccentric discharge; therefore, most international standards recommend the adoption of additional pressures in order to consider the effects of asymmetric pressures. The recommendations, however, are very diverse and not always clear. The results obtained show that, in order to determine the actions in slim silos for free flow product storage, it is important to use the methods recommended by the EUROCODE and DIN standards, with some exceptions: refer to the AS regarding to the pressure on the bottom of the silo, define the minimum underpressure coefficient as 1.2 , and minimum percentage of product property variability, even if they are achieved through experimental tests.

Keywords: pressures, slim silos, eccentric discharge, storage structures. 


\section{LISTA DE FIGURAS}

Figura 1.1 - Silos com descarga excêntrica. 8

Figura 2.1 - Tipos de fluxo em silos com descarga concêntrica. Fonte: EUROCODE (2002). _ 13 Figura 2.2 - Tipos de fluxo em silos com descarga excêntrica. Fonte: EUROCODE (2002). _ 13 Figura 2.3 - Silo muito esbelto. Fonte: EUROCODE (2002). 14

Figura 2.4 - Determinação gráfica do tipo de fluxo. Fonte: AS 3774 (1996).

Figura 2.5 - Determinação gráfica do tipo de fluxo. Fonte: DIN 1055-6 (2005), EUROCODE 1 (2002).

Figura 2.6 - Zonas de fluxo. Fonte: Deutsh e Clyde (1967).

Figura 2.7 - Canal de fluxo em uma tremonha concêntrica e excêntrica em um silo com

fluxo de funil. Fonte: Carson e Jenkyn (1993).

Figura 2.8 - Estado de tensão no silo. Fonte: Cheung e Calil (2005).

Figura 2.9 -Tipos de obstruções de fluxo. Fonte: Palma (2005).

Figura 2.10 - Amostra de um produto granular submetida à compressão. Fonte: Schulze (1996).

Figura 2.11 - (a) densidade (b) função fluxo dos materiais A, B e C e D. Fonte: Schulze (1996).

Figura 2.12 - Curvas de função fluxo com o tempo para diferentes períodos de

armazenamento.

Figura 2.13 - Estado de tensão para várias condições da amostra. Fonte: Schulze (1996).

Figura 2.14 - Aparelho de cisalhamento de Jenike, vista superior e vista lateral.

Figura 2.15 - Detalhe da célula de cisalhamento de Jenike.___ 26

Figura 2.16 - Etapas do teste de cisalhamento direto para a obtenção do lugar geométrico

de deslizamento. Fonte: Palma (2005).

Figura 2.17 - Determinação do atrito com a parede na célula de Jenike. Fonte: Jenike

(1964).

Figura 2.18 - Dimensões das paredes corrugadas. Fonte: EUROCODE (2002) e DIN (2005)._ 29

Figura 3.1 - Pressões atuantes e notações adotadas para silo com descarga concêntrica e excêntrica.

Figura 3.2 - Pressões verticais e horizontais no silo 2 segundo Petrov e Kovtum (1959). Fonte: Gallego (2006).

Figura 3.3 - Ensaios com descarga excêntrica segundo Pieper e Wagner para a areia. Fonte:

Calil (1984).

Figura 3.4 - Ensaios com descarga excêntrica feitos por Pieper e Wagner para o arroz. Fonte: Calil (1984).

Figura 3.5 - Forças na camada elementar de altura dz adotada por Janssen (1895).

Figura 3.6 - Evolução das pressões horizontais de acordo com o estado de tensão atuante no silo.

Figura 3.7 - Pressões verticais no caso estático (a) e na descarga (b) para silo com fluxo de massa.

Figura 3.8 - Indicação do ângulo formado entre o canal de fluxo com a vertical, num silo com fluxo de funil.

Figura 3.9 - Forças numa faixa elementar da tremonha (Walker, 1966).

Figura 3.10 - Pressões dinâmicas na descarga excêntrica adotada por Safarian. Fonte: Calil (1984).

Figura 3.11 - (a) Parâmetros geométricos (b) distribuição de pressões. Fonte: Rotter (1986). 56

Figura 4.1 - Simulação do contato por meio de elementos intermediários: elementos de contato.

Figura 4.2 - Distribuição de pressões horizontais estáticas ( $t=0$ segundos) e dinâmicas ( $t=1$ segundo) para um silo de fundo plano e descarga excêntrica. Fonte: Rombach e Eibl (1995).

Figura 4.3 - Pressões horizontais para $t=0$ segundo, $t=0,1$ segundo e $t=0,2$ segundo em um silo de fundo plano e descarga excêntrica. Fonte: Rombach e Neumann (2004). 
Figura 4.4 - Comparação com as normas de pressões horizontais dinâmicas em um silo de fundo plano e descarga excêntrica. Fonte: Rombach e Neumann (2004).

Figura 4.5 - Modelo numérico híbrido com MEF e MED. Fonte: Lu et al. (1997). 65 Figura 4.6-Modelo de descarga para fluxo de massa utilizado por Ayuga (2001). __ 67 Figura 4.7 - Modelo numério e modelo real. Fonte: Ayuga et al. (2006). _ 69 Figura 4.8 - Resultados das pressões horizontais estáticas na parede silo. FONTE: Ayuga (2006).

Figura 5. 1 - Distribuição da pressão adicional para silos cilíndricos de paredes finas. 69 Figura 5.2 - Distribuição de pressões para silos com fluxo excêntrico. Fonte: EUROCODE (2002).

Figura 5.3 - Distribuição de pressões nas tremonhas pelo método alternativo. Fonte: EUROCODE (2002).

Figura 5.4 - Distribuição de pressões para fluxo excêntrico. Fonte: AS 3774 (1996).

Figura 6.1 - Dimensões, em milímetros, da parede adotada. 74 Figura 6.2- Desenho esquemático e dimensões, em metros, do silo de fundo plano. 76 Figura 6.3- Desenho esquemático e dimensões, em metros, do silo com tremonha concêntrica.

Figura 6.4- Desenho esquemático e dimensões, em metros, do silo com tremonha excêntrica.

Figura 6.5 - Aparelho para medidas de umidade, temperatura e peso específico. Figura 6.6- Aparelho utilizado no ensaio granulométrico.__ 92 Figura 6.7 - Curva granulométrica do farelo de milho. Figura 6.8- Equipamento de Jenike modelo TSG 70-140 e o ploter a ele conectado.___ 93 Figura 6.9 - Ensaio de cisalhamento direto com a parede com o aparelho de Jenike modelo TSG 70-140.

Figura 6.10 - Modelo de comportamento elastoplástico perfeito. 94 Figura 6.11-Representação espacial do critério de ruptura de Mohr-Coulomb. __ 100 Figura 6.12 - Representação espacial do critério de ruptura de Drucker-Prager. —_ 100 Figura 6.13 - Efeito da dilatância do produto nas linhas de deslizamento. 101 Figura 6.14 - Características elemento finito PLANE42. 102 Figura 6.15 - Características do elemento finito SOLID45._ 103 Figura 6.16 - Características do elemento finito BEAM3.__ 103 Figura 6.17 - Características do elemento finito SHELL63._ 104 Figura 6.18 - Variação da densidade da malha do silo com fundo plano. __ 105 Figura 6.19 - Variação da densidade da malha do silo com tremonha. Figura 6.20 - Características dos elementos finitos CONTA 171 e TARGE 169.109 Figura 6.21 - Interação entre os elementos finitos CONTACT 173 e TARGET 170. Figura 6.22 - Deslocamento imposto na área canal de fluxo. 112 Figura 7.1 - Influência do FKN nas pressões estáticas normais às paredes do silo com fundo plano considerando comportamento elástico para o farelo de milho (a) e a soja (b).__ 113 Figura 7.2 - Influência do FKN no estudo das pressões estáticas normais às paredes do silo com fundo plano considerando comportamento elastoplástico para o farelo de milho (a) e a soja (b).

Figura 7.3 - Penetração no contato segundo FKN, com comportamento elástico para o farelo de milho (a) e a soja (b).

Figura 7.4 - Penetração no contato segundo FKN, considerando comportamento elastoplástico para o farelo de milho (a) e a soja (b). 115 Figura 7.5 - Influência do FKN nas pressões estáticas verticais no fundo do silo com fundo plano considerando comportamento elástico para o farelo de milho (a) e a soja (b). Figura 7.6 - Influência do FKN nas pressões estáticas normais às paredes (silo com tremonha concêntrica), considerando comportamento elástico para o farelo de milho (a) e a soja (b).

Figura 7.7 - Influência do FKN nas pressões estáticas normais às paredes do silo com 117 tremonha concêntrica considerando comportamento elastoplástico para o farelo de milho (a) e a soja (b). 118 Figura 7.8 - Quantidade de penetração no contato considerando o produto com comportamento elástico para o farelo de milho (a) e a soja (b). 
Figura 7.9 - Influência do coeficiente de Poisson ( $v$ ) na distribuição das pressões estáticas normais às paredes do silo com fundo plano para o farelo de milho (a) e a soja (b). __ 120 Figura 7.10 - Pressão estática vertical para o farelo de milho (a) e a soja (b) simulados com FKN 10.

Figura 7.11 - Pressão estática vertical no produto em kPa para o farelo de milho (a) e a soja

(b) com o modelo bidimensional axissimétrico FKN 10.

Figura 7.12 - Pressão estática vertical kPa para o farelo de milho com o modelo

tridimensional.

Figura 7.13 - Pressão estática vertical no fundo do silo para o farelo de milho (a) e a soja (b).

Figura 7.14 - Pressão estática normal simétrica mais pressão estática adicional segundo as normas EUROCODE e DIN para silos de classes 2 e 3 para farelo de milho (a) e a soja (b). 125 Figura 7.15 - Pressão estática normal à parede para farelo de milho (a) e a soja (b) com $\theta=0^{\circ}$.

Figura 7.16 - Valores dos coeficientes K para o farelo de milho (a) e a soja (b).___ 127

Figura 7.17 - Pressão estática de atrito para o farelo de milho (a) e a soja (b). __ 128

Figura 7.18 - Pressão dinâmica normal à parede para o farelo de milho.

Figura 7.19 - Pressão dinâmica normal à parede para o farelo de milho.

Figura 7.20 - Pressão dinâmica normal à parede para a soja.

130

Figura 7.21 - Pressão dinâmica normal à parede para a soja.

Figura 7.22 - Distribuição assimétrica da pressão dinâmica normal à parede para o farelo de

milho (a) e a soja (b) segundo as normas EUROCODE e DIN para silos de classe 2._ 132

Figura 7.23 - Distribuição assimétrica da pressão dinâmica normal à parede para o farelo de

milho (a) e a soja (b) segundo as normas EUROCODE e DIN para silos de classe 3.__ 133

Figura 7.24 - Distribuição assimétrica da pressão dinâmica normal à parede para o farelo de

milho (a) e a soja (b) segundo a norma AS.

Figura 7.25 - Pressão dinâmica normal à parede para o farelo de milho (a) e a soja (b) de acordo com altura do silo e ângulo $\theta$, calculada de acordo com a teoria de Safarian.

Figura 7.26 - Pressão dinâmica horizontal para o farelo de milho.

Figura 7.27 - Pressão dinâmica horizontal para a soja.

Figura 7.28 - Distribuição assimétrica da pressão dinâmica de atrito, calculada pelas normas

EUROCODE e DIN para silos de classe 2 para farelo de milho (a) e a soja (b).

Figura 7.29 - Distribuição assimétrica da pressão de atrito, calculada pelas normas

EUROCODE e DIN para silos de classe 3 para o farelo de milho (a) e a soja (b).

Figura 7.30 - Pressão dinâmica de atrito para o farelo de milho.

Figura 7.31 - Pressão dinâmica de atrito para a soja.

Figura 7.32 - Pressão estática normal para o soja considerando produto elástico. _ 141

Figura 7.33 - Pressão estática normal à parede para o farelo de milho (a) e a soja (b). _ 142

Figura 7.34 - Pressão estática normal às paredes de acordo com as normas EUROCODE e

DIN para silos da segunda e terceira classe de confiabilidade para o farelo de milho (a) e a

soja (b).

Figura 7.35 - Valores dos coeficientes K para o farelo de milho (a) e a soja (b).___ 144

Figura 7.36 - Pressão estática de atrito para o farelo de milho (a) e a soja (b).

Figura 7.37 - Pressão dinâmica normal à parede para o farelo de milho (a) e a soja (b)._ 146

Figura 7.38 - Pressão dinâmica normal à parede de acordo com as normas EUROCODE e

DIN para silos da segunda e terceira classe de confiabilidade para o farelo de milho (a) e a

soja (b).

Figura 7.39 - Pressão dinâmica normal à parede de acordo com a norma ISO para silos da segunda e terceira classe de confiabilidade para o farelo de milho (a) e a soja (b).___ 148 Figura 7.40 - Pressão dinâmica de atrito para o farelo de milho (a) e a soja (b). ___ 149 Figura 7.41 - Pressão estática normal para o soja considerando produto elástico. __ 150 Figura 7.42 - Pressão estática normal à parede para farelo de milho. 151

Figura 7.43 - Pressão estática normal à parede para a soja.__ 152

Figura 7.44 - Pressão estática de atrito para o farelo de milho. __ 153

Figura 7.45 - Pressão estática de atrito para a soja. __ 153

Figura 7.46 - Pressão dinâmica normal à parede para o farelo de milho.__ 154

Figura 7.47 - Pressão dinâmica normal à parede para a soja. __ 155 
Figura 7.48 - Pressão dinâmica de atrito para o farelo de milho. 156

Figura 7.49 - Pressão dinâmica de atrito para a soja. 157 Figura 7.50 - Pressão estática normal à parede de acordo com a relação eo/D para o farelo de milho. 158 Figura 7.51 - Pressão estática normal à parede de acordo com a relação eo/D para a soja. 159 Figura 7.52 - Pressão estática de atrito de acordo com a relação eo/D para o farelo de milho.

Figura 7.53 - Pressão estática de atrito de acordo com a relação eo/D para a soja. 160 160 


\section{LISTA DE TABELAS}

Tabela 2.1 - Classificação da capacidade de fluxo dos produtos segundo JENIKE (1964). _ 23 Tabela 2.2 - Classificação dos produtos de acordo com a granulometria. Fonte: Calil (1984).

Tabela 3.1 -Limite superior e inferior das propriedades físicas do produto. Fonte: AS 3774

(1996).

Tabela 3.2 - Características dos silos de concreto ensaiados por Petrov e Kovtum (1959). _ 40

Tabela 5.1 - Classificação dos silos em classes de confiabilidade.

Tabela 5.2 - Classificação dos silos de acordo com a esbeltez. ___ 72

Tabela 5.3 - Classificação dos silos conforme AS 3774 . ___ 80

Tabela 5.4 - Classificação dos silos de acordo com a esbeltez segundo a norma ISO 11697

(1995).

Tabela 6.1 - Características e dimensões do silo de fundo plano (silo 1).

Tabela 6.2 - Características e dimensões do silo com tremonha (silo 2).

Tabela 6.3 - Características e dimensões do silo com tremonha (silo 2).

Tabela 6.4 - Resultados do teste de granulometria com o farelo de milho.

Tabela 6.5 - Níveis de carregamentos utilizados nos ensaios com o produto armazenado. 94

Tabela 6.6 - Resultados experimentais do teste de cisalhamento direto com o farelo de milho $\left(U=12,4 \%\right.$ e $\left.T=25,7^{\circ} \mathrm{C}\right)$ e com a soja $\left(U=10,7 \%\right.$ e $\left.T=24,7^{\circ} \mathrm{C}\right)$.

Tabela 6.7 - Resultados experimentais do teste de cisalhamento com a parede do farelo de

milho ( $U=12,4 \%$ e $T=25,7^{\circ} \mathrm{C}$ ) e da soja $\left(U=10,7 \%\right.$ e $\left.T=24,7^{\circ} \mathrm{C}\right)$.

Tabela 6.8 - Resultados médios das propriedades físicas do farelo de milho $\left(U=12,4 \%\right.$ e $T=25,7^{\circ}$

C) e da soja (U=10,7\% e $\left.T=24,7^{\circ} \mathrm{C}\right)$.

Tabela 6.9 - Resultados médios do ensaio de cisalhamento com a parede com o farelo de

milho $\left(U=12,4 \%\right.$ e $\left.T=25,7^{\circ} \mathrm{C}\right)$ e com a soja $\left(U=10,7 \%\right.$ e $\left.T=24,7^{\circ} \mathrm{C}\right)$. 95

Tabela 6.10 - Valores inferiores, médios e superiores das propriedades físicas. _ 96

Tabela 6.11 - Propriedades físicas dos produtos utilizados na simulação numérica. __ 101

Tabela 6.12 - Propriedades físicas do aço da parede utilizados na simulação numérica. _ 103

Tabela 6.13 - Geometrias analisadas e seus respectivos modelos em M.E.F. _ 104

Tabela 7.1 - Variação do coeficiente de Poisson ( v) com o coeficiente K. 120

Tabela 7.2 - Comparação entre as pressões adicionais dinâmicas, em kPa, para silos concêntricos e excêntricos e ambos os produtos. 156

Tabela 8.1 - Coeficientes de sobrepressão para silos concêntricos e pressão adicional. _ 166 Tabela 8.2 - Coeficientes de sobrepressão para silos de pequena excentricidade e pressão adicional. 


\section{LISTA DE ABREVIATURAS E SIGLAS}
AS
Australian Standard
DIN
Deutsche Industrie Norm
ENV EUROCODE - European Committee for Standardization
$\mathrm{ff} \quad$ Fator fluxo da tremonha
FF Fator fluxo do produto
ISO International Organization for Standardization 


\section{LISTA DE SÍMBOLOS}

\section{LETRAS ROMANAS MAIÚSCULAS}

A Área da sessão transversal do silo

$\mathrm{A}_{c} \quad$ Área da sessão transversal do canal de fluxo na descarga excêntrica

$A_{s} \quad$ Área da sessão transversal da célula de cisalhamento

B relação entre a tensão vertical na parede e a tensão de cisalhamento na parede pela teoria de Walker

$B_{e} \quad$ Coeficiente de majoração da pressão adicional para considerar a excentricidade de descarga segundo a ISO 11697 (1995)

C Coeficiente de majoração das pressões

$\mathrm{C}_{\mathrm{h}} \quad$ Coeficiente de majoração aplicado às pressões horizontais iniciais para obtenção de das pressões horizontais de desgarga

$\mathrm{C}_{\mathrm{pe}} \quad$ Coeficiente de sobrepressão para obtenção das pressões adicionais finais

$\mathrm{C}_{\mathrm{pf}}$ Coeficiente de sobrepressão para obtenção das pressões adicionais iniciais

$\mathrm{C}_{\mathrm{op}} \quad$ Coeficiente do produto

D Diâmetro da seção transversal do silo

D' Fator de distribuição da Teoria de Walker (1966)

E Relação entre a excentricidade do canal de fluxo $\left(\mathrm{e}_{\mathrm{o}}\right)$ e o diâmetro do silo

$E_{p} \quad$ Módulo de elasticidade efetivo do produto

$\mathrm{E}_{\mathrm{w}} \quad$ Módulo de elasticidade da parede do silo

F Razão entre a pressão normal na parede da tremonha e a tensão vertical principal no sólido

Fe Razão entre a pressão normal na parede da tremonha e a tensão vertical principal no sólido durante a descarga

$F_{f} \quad$ Razão entre a pressão normal estática (após o carregamento) na parede da tremonha e a tensão vertical principal estática no sólido

$\mathrm{F}_{\mathrm{pe}} \quad$ Força horizontal resultante devido à pressão adicional em silos circulares de paredes finas durante a descarga

$\mathrm{F}_{\mathrm{pf}} \quad$ Força horizontal resultante devido à pressão adicional em silos circulares de paredes finas após o carregamento

$\mathrm{F}_{\mathrm{r}} \quad$ Força horizontal resultante devido à pressão adicional em silos

G Relação entre o raio do canal de fluxo e o raio do silo circular

$\mathrm{H}$ Peso do pendural 
K Razão entre as pressões horizontal e vertical (valor característico) [1]

$\mathrm{K}_{\mathrm{a}} \quad$ Coeficiente de empuxo ativo de Rankine [1]

$\mathrm{K}_{\mathrm{p}} \quad$ Coeficiente de empuxo passivo de Rankine [1]

$\mathrm{K}^{\prime} \quad$ Razão entre a pressão normal à parede da tremonha e a tensão [1] vertical principal no sólido

$\mathrm{K}_{\mathrm{m}} \quad$ Razão entre as pressões horizontal e vertical (valor médio)

$\mathrm{K}_{\circ} \quad$ Razão entre as pressões principais horizontais e verticais medidas [1] sem deformação

$P_{\text {we }} \quad$ Força de compressão resultante na parede vertical por unidade de perímetro no esvaziamento

$P_{w f} \quad$ Força de compressão resultante na parede vertical por unidade de perímetro após o enchimento do silo

$\mathrm{R} \quad$ Raio do silo [L]

$S \quad$ Fator geométrico da tremonha (=2 para tremonhas cônicas) [1]

$S_{p} \quad$ Força de cisalhamento no pré-cisalhamento da amostra [F]

$\mathrm{S}_{\mathrm{s}} \quad$ Força máxima resistente de cisalhamento obtida na falha da amostra [F]

$\mathrm{S}_{\mathrm{w}} \quad$ Força resistente de cisalhamento no teste de cisalhamento com a parede $\quad[\mathrm{F}]$

U Perímetro da seção transversal da parede [L]

$\mathrm{U}_{\mathrm{sc}} \quad$ Comprimento do perímetro do canal de fluxo em contato com o [L] produto estacionário durante a descarga excêntrica

$\cup_{\mathrm{wc}} \quad$ Comprimento do perímetro do canal de fluxo em contato com a [L] parede durante a descarga excêntrica

$V_{b} \quad$ Volume da base da célula de cisalhamento [ $\left.\mathrm{L}^{3}\right]$

$V_{r} \quad$ Volume do anel de cisalhamento [ $\left.\mathrm{L}^{3}\right]$

$\mathrm{V}_{\mathrm{t}} \quad$ Volume total da célula de cisalhamento (somatório de $\mathrm{V}_{\mathrm{r}}$ e $\mathrm{V}_{\mathrm{b}}$ ) [ $\left.\mathrm{L}^{3}\right]$

$W_{b} \quad$ Peso da base da célula de cisalhamento [F]

$W_{1} \quad$ Peso da tampa da célula de cisalhamento [F]

$\mathrm{W}_{\mathrm{m}} \quad$ Peso do material da parede $\quad$ [F]

$W_{p} \quad$ Peso suspenso no pendural no pré-cisalhamento [F]

$W_{r} \quad$ Peso do anel de cisalhamento [F]

$W_{s} \quad$ Peso suspenso no pendural durante o cisalhamento da amostra [F]

$W_{t} \quad$ Peso total da célula de cisalhamento incluindo o produto [F]

$\mathrm{W}_{\mathrm{w}} \quad$ Peso suspenso no pendural durante o teste de cisalhamento da parede [F]

$W_{w t}$ Peso total da célula de cisalhamento com a parede incluindo o produto [F]

\section{LETRAS ROMANAS MINÚSCULAS}

b Dimensão da boca de saída para silos retangulares 
c Coesão do produto

d Diâmetro da célula de cisalhamento

$d_{p} \quad$ Tamanho ou diâmetro característico das particulas granulares do produto

$\mathrm{e}_{\mathrm{c}} \quad$ Excentricidade do centro do canal de fluxo

$e_{f} \quad$ Excentricidade de enchimento

$e_{o} \quad$ Excentricidade do centro da boca de saída

$e_{o, c r} \quad$ Máxima excentricidade da boca de saída para a qual processos de cálculo simplificados podem ser aplicados $\left(e_{o, c r}=0,25 d\right)$

g Aceleração da gravidade $\left(g=8,91 \mathrm{~m} / \mathrm{s}^{2}\right)$

h Altura efetiva do silo (da boca de saída até a superfície equivalente)

$\mathrm{h}_{\mathrm{c}} \quad$ Altura do corpo do silo, da transição até a superfície equivalente

$h_{h} \quad$ Altura do cone da tremonha, do seu eixo até a transição

$h_{\text {tp }} \quad$ Altura do cone da cobertura

$\mathrm{n} \quad$ Número de testes com o mesmo valor de $\mathrm{W}_{\mathrm{p}}$

p Pressão

$\mathrm{p}_{\mathrm{h}} \quad$ Pressão horizontal normal à parede do corpo do silo devido ao produto armazenado

phae Pressão estática horizontal na parede próxima à saída excêntrica

$\mathrm{p}_{\text {hce }} \quad$ Pressão estática horizontal no canal de fluxo durante à descarga excêntrica

phco Pressão horizontal no canal de fluxo na altura ótima durante à descarga excêntrica

$p_{\text {he }} \quad$ Pressão horizontal durante a descarga

phe,u Pressão horizontal durante a descarga calculada pelo método simplificado

Phe,f Pressão horizontal após o carregamento

$\mathrm{p}_{\mathrm{hfb}} \quad$ Pressão horizontal após o carregamento na base da parede vertical

$\mathrm{p}_{\mathrm{hf}, \mathrm{u}} \quad$ Pressão horizontal após o carregamento calculada pelo método simplificado

Phse Pressão horizontal estática na parede distante do canal de fluxo para silos com excentricidade da boca de saída

$\mathrm{p}_{\mathrm{n}} \quad$ Pressão normal à parede da tremonha devido ao produto armazenado

$\mathrm{p}_{\text {ne }} \quad$ Pressão normal à parede da tremonha durante o esvaziamento do silo

$\mathrm{p}_{\mathrm{nf}} \quad$ Pressão normal à parede da tremonha após o enchimento do silo

$\mathrm{p}_{\mathrm{p}} \quad$ Pressão adicional

$\mathrm{p}_{\mathrm{pe}} \quad$ Pressão adicional durante a descarga

$\mathrm{p}_{\text {pei }} \quad$ Pressão adicional complementar durante a descarga $\quad\left[\mathrm{FL}^{-2}\right]$

$\mathrm{p}_{\mathrm{pf}} \quad$ Pressão adicional após o enchimento do silo 
$\mathrm{p}_{\mathrm{pfi}} \quad$ Pressão adicional complementar após o enchimento do silo [FL $\left.{ }^{-2}\right]$

$p_{\text {pes }} \quad$ Pressão adicional em coordenadas cilíndricas $(\theta)$ para silos circulares de $\quad\left[\mathrm{FL}^{-2}\right]$ paredes finas durante o esvaziamento

$\mathrm{p}_{\mathrm{pfs}} \quad$ Pressão adicional adicional em coordenadas cilíndricas $(\theta)$ para silos circulares de paredes finas após o enchimento

$\mathrm{p}_{\mathrm{t}} \quad$ Pressão tangencial de atrito na parede da tremonha

$\mathrm{p}_{\mathrm{te}} \quad$ Pressão tangencial de atrito na parede da tremonha durante o esvaziamento do silo

$\mathrm{p}_{\mathrm{tf}} \quad$ Pressão tangencial de atrito na parede da tremonha após enchimento do silo

$\mathrm{p}_{\mathrm{v}} \quad$ Pressão vertical no produto armazenado

$p_{\text {vf }} \quad$ Pressão vertical no produto armazenado após o enchimento do silo

$p_{\text {vft }} \quad$ Pressão vertical no produto armazenado na transição parede tremonha

$p_{\text {vho }} \quad$ Pressão vertical na base da pilha

$\mathrm{p}_{\mathrm{vhp}} \quad$ Pressão geostática vertical na base da pilha de topo

$\mathrm{p}_{\mathrm{w}} \quad$ Pressão tangencial à parede vertical

$\mathrm{p}_{\text {wae }} \quad$ Pressão tangencial no sólido estático adjacente ao canal de fluxo durante a descarga excentrica

$p_{\text {wce }} \quad$ Pressão de atrito na parede em contato com o canal de fluxo durante durante a descarga excêntrica

$\mathrm{p}_{\mathrm{we}} \quad$ Pressão de atrito na parede durante a descarga

$\mathrm{p}_{\mathrm{we}, \mathrm{u}} \quad$ Pressão de atrito na parede durante a descarga obtida pelo método simplificado

$\mathrm{p}_{\mathrm{wf}} \quad$ Pressão de atrito na parede após o enchimento

$\mathrm{p}_{\mathrm{wf}, \mathrm{u}} \quad$ Pressão de atrito na parede após o enchimento obtida pelo método simplificado

$\mathrm{p}_{\mathrm{wse}} \quad$ Pressão de atrito na parede do sólido estático adjacente ao canal de fluxo durante a descarga excêntrica

$r_{c} \quad$ Raio do canal de fluxo excêntrico

$r_{0} \quad$ Raio do a abertura da boca de saída

s Comprimento do lado onde deve ser aplicada a pressão adicional

$x \quad$ Coordenada vertical na tremonha com origem no eixo do cone da tremonha enchimento máximo do silo

$\mathrm{z}_{\mathrm{p}} \quad$ Comprimento da superfície equivalente até o centro da pressão adicional 


\section{LETRAS GREGAS MINÚSCULAS}

$\alpha \quad$ Ângulo de inclinação da parede da tremonha com a horizontal

$\alpha_{f} \quad$ Âgulo de inclinação do canal de fluxo com a vertical para silos com fluxo de funil

$\alpha_{i} \quad$ Âgulo de inclinação da parede da tremonha com a horizontal (valor inferior)

$\alpha_{s} \quad$ Âgulo de inclinação da parede da tremonha com a horizontal (valor superior)

$\beta \quad$ Ângulo de inclinação da parede da tremonha com a vertical

$\beta_{\mathrm{i}} \quad$ Ângulo de inclinação da parede da tremonha com a vertical (valor inferior)

$\beta_{\mathrm{s}} \quad$ Ângulo de inclinação da parede da tremonha com a vertical (valor superior)

$\beta_{0} \quad$ Ângulo de inclinação do canal de fluxo com a vertical

$\beta_{0} \quad$ Ângulo de inclinação do canal de fluxo com a parede da tremonha

$\gamma_{i} \quad$ Valor inferior do peso específico do produto

$\gamma_{s} \quad$ Valor superior do peso específico do produto

$\theta \quad$ Coordenada no sistema cilíndrico

$\theta_{c} \quad$ Ângulo de contato do fluxo de canal excêntrico com a parede

$\psi \quad$ Ângulo de dilatância

$\delta \quad$ Ângulo medido do centro do canal de excêntrico até o ângulo de contato do fluxo com a parede

$\mu_{\text {eff }} \quad$ Coeficiente de atrito efetivo com a parede

$\mu_{\mathrm{h}} \quad$ Coeficiente de atrito da parede da tremonha

$\mu_{\mathrm{i}} \quad$ Valor inferior do coeficiente de atrito da parede com o produto

$\mu_{\mathrm{m}} \quad$ Valor médio do coeficiente de atrito da parede com o produto

$\mu_{\mathrm{s}} \quad$ Valor superior do coeficiente de atrito da parede com o produto

$\mu_{\mathrm{sc}} \quad$ Coeficiente de atrito do sólido estático com o canal de fluxo em silos com descarga excêntrica

$\mu_{\mathrm{w}} \quad$ Coeficiente de atrito característico da parede vertical

$\mu_{\mathrm{wc}} \quad$ Coeficiente de atrito do o canal de fluxo com a parede em silos com descarga excêntrica

u Coeficiente de Poisson do produto

$u_{w} \quad$ Coeficiente de Poisson da parede

$\phi_{\mathrm{i}} \quad$ Ângulo de atrito interno do produto

$\phi_{\text {ii }} \quad$ Valor inferior do ângulo de atrito interno do produto

$\phi_{\text {im }} \quad$ Valor médio do ângulo de atrito interno do produto 
$\phi_{\mathrm{e}} \quad$ Ângulo de atrito efetivo do produto

$\phi_{\mathrm{ei}} \quad$ Valor inferior do ângulo de atrito efetivo do produto

$\phi_{\mathrm{em}} \quad$ Valor médio do ângulo de atrito efetivo do produto

$\phi_{\text {es }} \quad$ Valor superior do ângulo de atrito efetivo do produto

$\phi_{\mathrm{r}} \quad$ Ângulo de repouso do produto

$\phi_{\text {wi }} \quad$ Valor inferior do ângulo de atrito do produto com a parede

$\phi_{\mathrm{wm}} \quad$ Valor médio do ângulo de atrito do produto com a parede

$\phi_{\text {ws }} \quad$ Valor superior do ângulo de atrito do produto com a parede

$\sigma \quad$ Tensão normal

$\sigma_{\mathrm{h}} \quad$ Tensão horizontal no produto

$\sigma_{\mathrm{v}} \quad$ Tensão vertical no produto

$\sigma_{1} \quad$ Tensão principal vertical

$\sigma_{1^{\prime}} \quad$ Tensão principal vertical na tremonha

$\sigma_{2} \quad$ Tensão principal horizontal

$\sigma_{\mathrm{c}} \quad$ Resistência inconfinada do produto

$\sigma_{\mathrm{p}} \quad$ Tensão normal de pré-cisalhemento da amostra

$\bar{\sigma}_{p} \quad$ Valor médio da tensão normal de pré-cisalhemento

$\sigma_{\mathrm{s}} \quad$ Tensão normal aplicada no momento de cisalhamento da amostra

$\tau \quad$ Tensão de cisalhamento

$\tau_{\mathrm{s}} \quad$ Tensão de cisalhamento máxima resistente do produto no teste de cisalhamento com a parede

$\tau_{\mathrm{p}} \quad$ Tensão de pré- cisalhamento

$\bar{\tau}_{p} \quad$ Valor médio da tensão de pré-cisalhamento

\section{LISTA DE ÍNDICES}

e Final, dinâmico, descarregamento

f Inicial, estático, enchimento

v Vertical

h Horizontal

w Parede

i Inferior

m Médio

s Superior 


\section{SUMÁRIO}

1. Introdução

1.1 Considerações Iniciais ______ 5

1.2 Objetivo ___ 7

1.3 Justificativa ___ 8

2.Fuxo e Propriedades Físicas dos Produtos Amazenados

2.1 Propriedades físicas e sua relação com o fluxo ___ 11

2.2 estado de tensão e o fluxo ___ 18

2.3 Propriedades dos produtos amazenados___ 20

2.3.1 Teste de cisa lhamento com o produto ___ 26

2.3.2 Teste de cisalhamento com a parede 28

2.3.3 Granulometria__ 30

2.4 O coeficiente $K$

2.5 Considerações sobre o capítulo _____ 33

3. Pressões Exerc idas pelos Produtos Amazenados ___ 35

3.1 Considerações iniciais e notações ___ _ _ 35

3.2 Histórico ___ 39

3.3 Teoria de Janssen (1895) ___ 44

3.4 Teoria de Jenike etal. (1973)

3.4.1 Silos com fluxo de massa ___ 49

3.4.2 Silos com fluxo de funil — 50

3.5 Teoria de Walker (1966) ___ 52

3.6 Teoria de Safarian (1969) ___ 54

3.7 Teoria de Rotter (1986) ___ 55

3.8 Recomendações de Ravenet (1974)____ 59

3.9 Considerações finais sobre o capítulo ___ 60

4. Métodos Numéric os no Estudo dos Silos___ 61

4.1 Evolução dos modelos numéric os no estudo dos silos ___ 63

4.2 Considerações finais sobre o capítulo ___ 70

5. Recomendações das Nomas Intemacionais Analisadas___ 71

5.1 EUROCODE ENV 1991-4 (2002) e DIN 1055-6 (2005) ___ 71

5.1.2 Classific ação dos silos__ 71

5.1.3 Pressões estátic as nas pa redes vertic a is de silos esbeltos ___ 73

5.1.4 Pressões dinâmic as nas pa redes vertic a is de silos esbeltos_

5.1.5 Pressões na tremonha__ 78

5.2 Noma australiana AS 3774 (1996) 79

5.2.1 Propriedades dos produtos armazenados___ 79

5.2.2 Classificação dos silos_ 79

5.2.3 Pressões estátic as nas pa redes vertic a is de silos esbeltos ___ 81

5.2.4 Pressões dinâmic as nas pa redes vertic a is de silos esbeltos 
5.2.5 Pressões na tremonha

5.2.6 Considerações sobre desc arga excêntrica ___ 82

5.3 Intemational Standard ISO 11697 (1995)____ 83

5.3.1 Considerações inicia is___ 83

5.3.2 Classificação 84

5.3.3 Pressões estátic as nas paredes vertic a is de silos esbeltos___ 84

5.3.4 Pressões dinâ mic as nas paredes vertic a is de silos esbeltos ___ 84

5.3.5 Pressões na tremonha 85

5.3.6 Considerações sobre desc arga excêntric a _ 85

5.4 Considerações finais sobre o capítulo ___ _ 85

6. Análise Numérica____ 87

6.1 Geometrias dos silos estudados ___ 87

6.2 Determinação das propriedades físicas dos produtos ___ 91

6.2.2 Ensaio de granulometria __ 91

6.2.4 Ensaio de cisalhamento com a parede___ 94

6.3 Modelos e parâmetros numéricos___

6.3.1 Produtos amazenados 97

6.3.2 Parede 103

6.3.3 Dimensões dos modelos simulados 104

6.3.4_ 104

6.4 Densidade das malhas adotadas___ 104

6.5 Simulação do contato produto-parede ___ 106

6.5.1 Modelagem do conta to ___ 106

6.5.2 Rigidez do conta to e algoritmo de solução empregado___ 107

6.6 Modelo de descarregamento para obtenção das pressões dinâmicas_111

7.Resultados e Análisedos Resultados__ 113

7.1 Aspectos da modelagem numérica ___ 113

7.1.1 Influência do fator de rigidez nomal do contato (FKN) e do modelo de

comportamento do produto

7.2 Análise das pressões no silo com fundo plano____

7.2.1 Pressão estática vertical no produto ___ 121

7.2.2 Pressão estática vertical no fundo do silo __ 123

7.2.3 Pressão estática nomalà parede__ 124

7.2.4 Pressão estátic a de atrito 127

7.2.5 Pressão dinâ mica normal à parede __ 128

7.2.6 Pressão dinâ mica de atrito___ 137

7.3 Pressões no silo com tremonha concêntrica

7.3.1 Pressão estática nomal à parede___ 141

7.3.2 Pressão estática de atrito 144

7.3.3 Pressão dinâmica nomal à parede __ 146

7.3.4 Pressão dinâ mica de atrito____ 149

7.4 Silo com tremonha excêntrica $\left(e_{o} / D=\mathbf{2 5 \%}\right) \ldots 150$

7.4.1 Pressão estática normal à parede___ 150

7.4.2 Pressão estática de a trito __ 152

7.4.3 Pressão dinâmica nomal à parede_ 154

7.4.4 Pressão dinâmica de atrito à pa rede_ 156

7.5 Análise da excentricicade nas pressões estáticas____ 157

7.5.1 Pressão estática nomalà parede___ 157 
7.5.2 Pressão estátic a de a trito 159

8. Disc ussões e Conclusões

163

8.1.1 A interação produto-parede

163

8.1.2 Comporta mento do produto a mazenado 163

8.2.1 Pressõ es estátic as no corpo dos silos

164

8.2.2 Pressões estátic as na tremonha 165

8.2.3 Pressões dinâ mic as no como dos silos 166

8.2.4 Pressões dinâmicas na tremonha 168 



\section{INTRODUÇÃO}

\subsection{Considerações Iniciais}

A produção de grãos como a soja, o milho, o trigo e o arroz, entre outros, constitui um dos principais segmentos do setor agrícola em todo o mundo. Após a colheita, a safra de grãos precisa ser direcionada a um destino, que gera durante este processo, a necessidade de armazenar os produtos em construções específicas de armazenamento, ou seja, os silos.

A demanda por silos é explicada, portanto, pela necessidade das cooperativas, produtores e indústrias de armazenar grandes quantidades de produtos em espaços reduzidos. Além disso, a estocagem torna-se importante em termos econômicos na medida em que permite o controle do escoamento da safra e abastecimento, reduzindo a necessidade de importação e também das especulações de mercado.

No Brasil, a ampliação da rede armazenadora se torna cada vez mais necessária, tendo em vista a representatividade da produção brasileira de grãos, com um volume de 131,7 milhões de toneladas na safra 2006/2007 (CONAB, 2007), com a previsão estimada pela própria CONAB em 140,8 milhões na safra 2007/08. A capacidade estática de armazenamento é hoje de apenas 120 milhões de toneladas e permanece estagnada, enquanto a produção agrícola cresce em média $6 \%$ ao ano desde 1990.

Para que novas unidades de armazenamento sejam projetadas com segurança, economia e eficiência é essencial o correto conhecimento das máximas pressões capazes de atuar sobre as paredes do silo durante sua vida operacional. Desde o século XIX numerosas teorias têm sido desenvolvidas para avaliar as pressões exercidas sobre as paredes dos silos. Contudo, muitos parâmetros de 
cálculo ainda não foram corretamente determinados, principalmente quando se trata de pressões relacionadas com a descarga excêntrica.

A descarga excêntrica é interessante porque permite a otimização do uso de transportadores e facilita o acesso de caminhões e trens no descarregamento do produto. A desvantagem é que nesta situação, surgem pressões não uniformes ao longo do perímetro do silo, consideradas a maior causa de colapsos em silos (MOLENDA et al., 2001).

De acordo com Rotter (1999) o principal problema da distribuição não uniforme de pressões devido ao fluxo excêntrico é o surgimento de momentos fletores nas paredes do silo. No caso de silos metálicos com seção circular as pressões assimétricas não somente causam momentos locais, mas afetam todo o silo com tensões de membrana dado que são estruturas de casca.

Ravenet (1974) afirma que a descarga excêntrica em cilíndricos metálicos deve ser analisada com muito cuidado porque durante a descarga ocorrem altas sobrepressões seguidas de depressões que, atuando em conjunto, produzem deformações na parede do silo devido à sua elevada esbeltez.

Segundo Bucklin et al. (1990) não existe um método de predição das pressões para a descarga excêntrica que seja considerado aceito e confiável. Por isso, muitos pesquisadores recomendam evitar o emprego da descarga excêntrica sempre que possível. Desta forma, o desconhecimento da intensidade e variabilidade das pressões assimétricas é uma limitação para o emprego da descarga excêntrica. Inúmeras tentativas foram feitas pelos pesquisadores no intuito de desenvolver expressões matemáticas que quantificassem o fenômeno da descarga excêntrica, mas ainda existem muitos aspectos que permanecem indefinidos (GUAITA et al. 2003).

O método de previsão das pressões dinâmicas adotado pela maioria das normas internacionais consiste em determinar as pressões estáticas em silos concêntricos, calculados pela teoria de Janssen (1895) e posteriormente corrigir os resultados por meio da adoção de coeficientes multiplicadores denominados coeficientes de sobrepressão, que simulam o descarregamento do silo.

Dado a dificuldade de determinar de forma precisa a distribuição de pressões de descarga excêntrica, o conceito de pressões adicionais tem sido introduzido por algumas normas internacionais para cobrir incertezas a respeito de assimetrias de pressões durante a descarga. 
- De acordo com Song e Teng (2003), a especificação das pressões adicionais é inadequada para representar o efeito real das pressões de descarga excêntrica. Gillie e Rotter (2002) acrescentam que esta especificação, tem sido realizada sem uma avaliação rigorosa das suas conseqüências estruturais, principalmente em silos metálicos. Sendo que, os poucos estudos existentes têm sido baseados em análises lineares por elementos finitos.

Mais recentemente, um novo método de predição de pressões em silos de saída excêntrica foi incorporado pelas normas DIN 1055-6 (2005) e EUROCODE 1 (2002). Este novo método foi desenvolvido por Rotter (1986) e consiste na adoção de uma distribuição assimétrica de pressões, consideração mais coerente com a realidade da descarga excêntrica.

$\mathrm{Na}$ atualidade, com os sofisticados métodos de cálculo surge uma nova alternativa para o estudo das pressões nas paredes dos silos: a análise numérica por meio do método dos elementos finitos (MEF).

\subsection{Objetivo}

Dando continuidade as pesquisas desenvolvidas no Departamento de Engenharia de Estruturas, este trabalho tem por finalidade apresentar uma introdução ao estudo teórico e numérico da distribuição de pressões e seu aumento para a condição de descarga em silos verticais com descarga excêntrica. Para isso torna-se necessário:

- avaliar as principais teorias sobre o assunto;

- analisar as recomendações constantes nas principais normas internacionais: AS 3774 (1996), DIN 1055-6 (2005), EUROCODE 1-Part 4 (2002) e ISO - 11697 (1995);

- desenvolver uma metodologia de cálculo para este tipo de situação;

Com base no estudo realizado, propor recomendações para a previsão das pressões devidas ao produto armazenado em silos esbeltos e excêntricos, tornando o Brasil mais competitivo no setor de armazenamento internacional e contribuir para a elaboração da futura norma brasileira ainda inexistente. 


\subsection{Justificativa}

É prática comum em muitas cooperativas e indústrias, adotar uma boca de descarga excêntrica nas unidades de armazenamento (Figura 1.1). Entretanto, a maioria dos silos excêntricos existentes não apresenta condições ideais de operação e seus projetos ainda são complexos e rodeados de incertezas. Isso explica a grande quantidade de acidentes e colapsos em silos com descarga excêntrica.

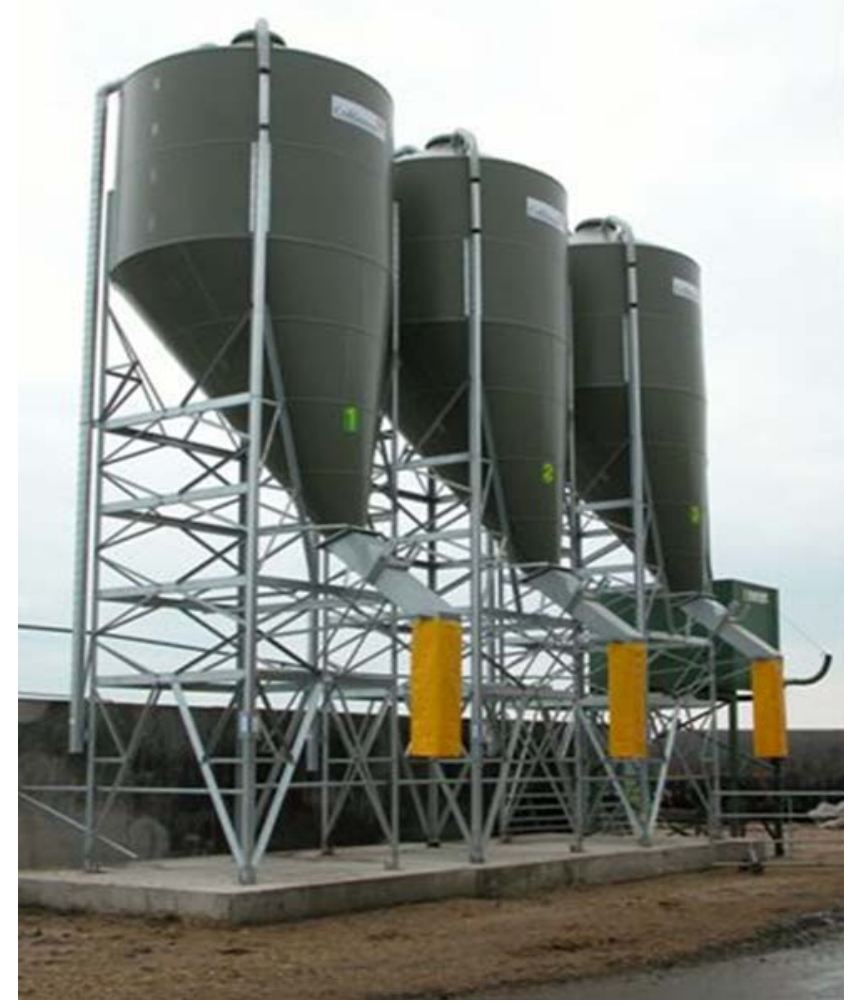

Figura 1.1 - Silos com descarga excêntrica.

A maioria dos acidentes em silos com descarga excêntrica ocorre devido ao surgimento de pressões assimétricas e ocasionam falhas catastróficas. Mesmo para silos com descarga concêntrica pode surgir fluxo excêntrico devido a fatores como segregação, obstruções de fluxo, heterogeneidade do produto e relação altura/lado do silo.

As falhas que ocorrem em silos com fluxo excêntrico geralmente ocorrem devido à perda de estabilidade por compressão axial. Quando isto acontece, observa-se deformação por flambagem, ou seja, a presença de uma onda localizada na altura média do silo ou nas proximidades do seu topo. Essa onda é de pequena altura e normalmente possui largura igual à altura, podendo ocorrer várias ondas adjacentes (ROTTER, 2001). 
A descarga excêntrica pode gerar também ondas de flambagem acima da superfície livre do produto dado que as altas tensões geradas pela compressão axial se estendem acima da superfície do produto, local em que não há a restrição de deslocamento imposto pela presença do produto armazenado (ROTTER, 1985).

Apesar de muitos experimentos internacionais já terem sido conduzidos no assunto tais como os apresentados por Jamielson (1904), Pieper (1969), Ravenet (1974), Nielsen e Kristiansen (1979), Nielsen e Andersen (1981), Hartlen et al. (1984), ainda faltam respostas com relação ao comportamento das pressões em silos com descarga excêntrica, assim como, o estabelecimento de um procedimento de cálculo satisfatório que considere esse tipo de situação.

Além disso, existe a necessidade de elaboração de recomendações que norteiem projetos, execução e utilização das estruturas destinadas à armazenagem de produtos agrícolas principalmente no Brasil, país dotado de vasto território e com a vocação genuinamente agrícola, onde os parâmetros de projeto ainda são baseados em normas estrangeiras como ANSI/ASAE EP433 (2001), AS 3774 Supplement 1 (1997), DIN 1055-6 (2005) EUROCODE 1 (2002), ISO - 11697 (1995).

Várias pesquisas têm sido desenvolvidas no LAMEM-SET-EESC-USP, perfazendo uma gama notável de conhecimentos que muito têm a contribuir para finalmente elaborarmos uma norma que considere as condições reais de armazenagem em nosso país. Dentre elas pode-se destacar Freitas (2001), Palma (2005) e Cheung (2007).

O Brasil, sendo um dos maiores produtores de grãos do mundo e um país que desempenha um papel fundamental na economia mundial, não pode ter sua capacidade de armazenamento prejudicada devido ao desconhecimento das ações atuantes nas estruturas de armazenamento. Neste sentido, este estudo contribuirá também para a elaboração de recomendações normativas a respeito das ações em silos com descarga excêntrica para o desenvolvimento de uma futura norma que considere as condições reais de armazenagem em nosso país. 



\section{FLUXO E PROPRIEDADES FÍSICAS DOS PRODUTOS ARMAZENADOS}

\subsection{Propriedades físicas e sua relação com o fluxo}

O projeto completo de uma unidade de armazenamento inclui o projeto estrutural e o projeto de fluxo. $O$ projeto estrutural tem a função de garantir a segurança e estabilidade da edificação para que ela resista aos esforços solicitantes sem atingir os estados limites último e de serviço. O projeto de fluxo está relacionado com a funcionalidade da unidade, visando a completa descarga do produto sem que apareçam problemas de obstrução de fluxo. Também por questões de economia, é sempre desejável que o silo seja descarregado por gravidade, dado que o emprego de dispositivos que promovam o fluxo onera 0 projeto e requer maior freqüência de manutenção da estrutura.

Conhecer as propriedades físicas do produto é determinante tanto para o projeto de fluxo como para o projeto estrutural porque são elas que definem o tipo de fluxo e a intensidade das pressões que vão ocorrer durante a vida útil do silo. As propriedades físicas do produto também se denominam propriedades de fluxo, que são:

- peso específico $(\gamma)$ do produto, de acordo com o grau de consolidação e umidade;

- granulometria;

- ângulo de atrito interno do produto $\left(\phi_{\mathrm{i}}\right)$;

- ângulo efetivo de atrito interno $\left(\phi_{\mathrm{e}}\right)$;

- ângulo de atrito em repouso $\left(\phi_{r}\right)$;

- ângulo de atrito com a parede $\left(\phi_{\mathrm{w}}\right)$;

- fator fluxo da tremonha (ff); 
- função fluxo instantânea (FF) e função fluxo com o tempo (FFt).

O comportamento do produto armazenado é basicamente uma combinação entre os líquidos e os sólidos. Eles não podem ser considerados como sólidos porque não são capazes de suportar elevadas tensões sem a presença de contenções mas também não podem ser classificados como líquidos porque formam taludes estáveis quando armazenados em repouso sobre uma superfície horizontal e geram atrito nas paredes, o que não ocorre no armazenamento de líquidos.

Segundo Jenike (1964), existem duas diferenças fundamentais entre um produto armazenado e um líquido. A primeira delas é que o produto armazenado transfere esforços de cisalhamento sob condições estáticas, pois possui ângulo de atrito estático maior que zero. A segunda é que o produto armazenado pode adquirir resistência após uma pressão ter sido aplicada sobre ele, mantendo a sua forma sobre pressão.

Geralmente o verbo fluir é utilizado para os líquidos, porém no estudo dos produtos armazenados fluir está relacionado com o surgimento da deformação plástica do produto, dando início ao movimento da massa do produto que é denominada fluxo. No instante em que o fluxo se inicia, existem duas configurações fundamentais que podem ocorrer: o fluxo de massa e o fluxo de funil, este último inclui o fluxo em tubo e o fluxo misto.

O fluxo de massa é caracterizado pelo movimento contínuo de todas as partículas do produto armazenado durante a operação de descarga, conforme a Figura 2.1 (a), enquanto que no fluxo de funil parte do material permanece em repouso formando zonas estáticas do produto próximas à parede do silo, Figura 2.1 de (b) à (d).

O fluxo de funil pode ainda ser classificado em dois grupos: o fluxo em tubo e o fluxo misto. O fluxo em tubo é aquele cujo canal de fluxo se estende até a superfície do produto armazenado como Figura 2.1 (b) e (c) e no fluxo misto, o canal de fluxo intercepta a parede do silo, Figura 2.1 (d). 


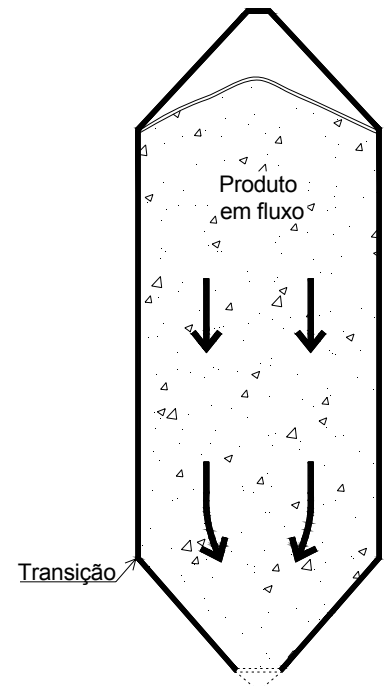

(a) Fluxo de massa

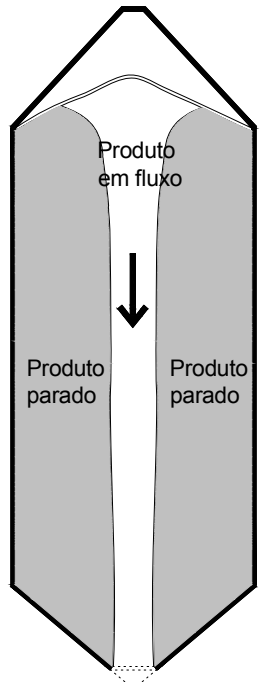

(b) Tubo interno paralelo

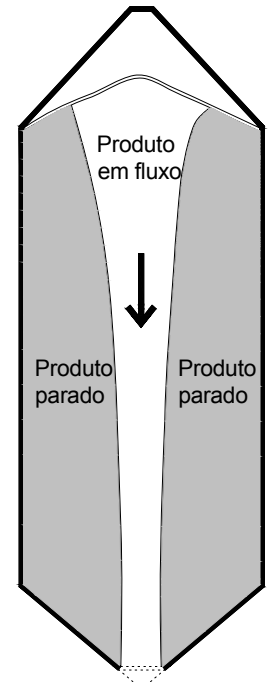

(c) Tubo interno cônico

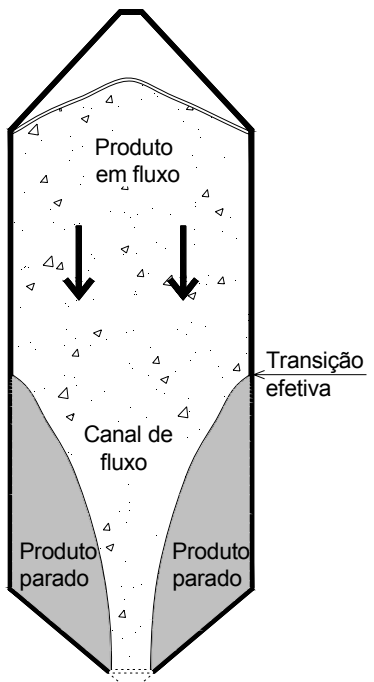

(d) Fluxo misto

FLUXO DE MASSA

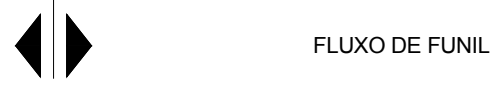

Figura 2.1 - Tipos de fluxo em silos com descarga concêntrica. Fonte: EUROCODE (2002).

O tipo de fluxo depende também das dimensões do silo, da inclinação e rugosidade das paredes da tremonha e da configuração da boca de saída: centrada ou excêntrica. Na figura anterior (Figura 2.1) foram ilustrados os tipos de fluxo para silos que possuem boca de saída concêntrica. No caso de silos excêntricos, os tipos de fluxo são basicamente os mesmos, conforme a Figura 2.2.

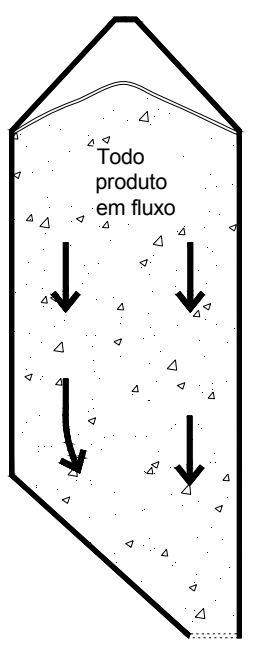

(a) Massa

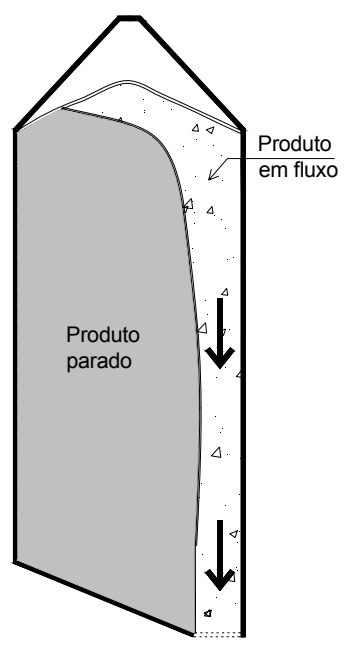

(b) Tubo paralelo

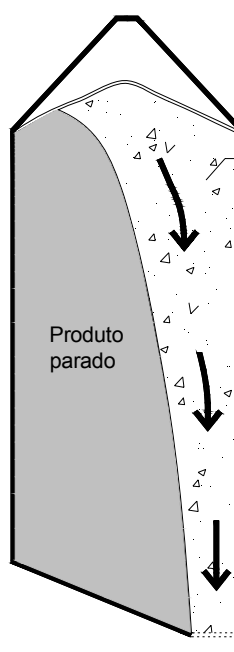

(c) Tubo inclinado

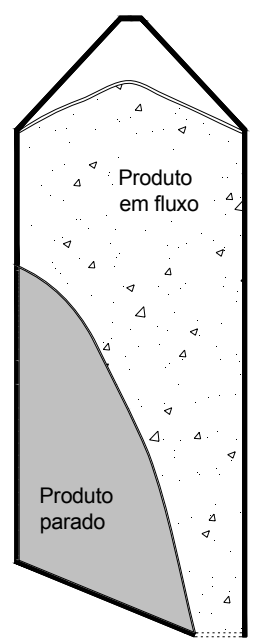

(d) Misto completamente excêntrico

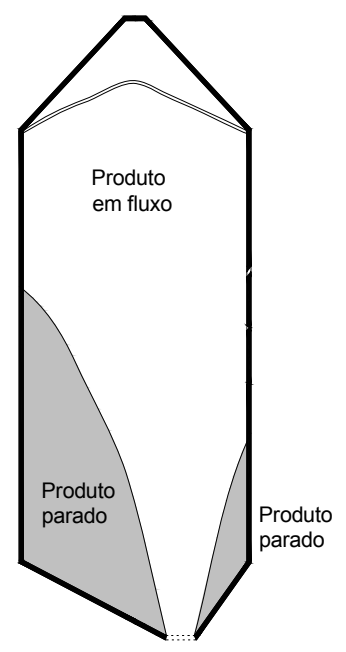

(e) Misto parcialmente excêntrico

Figura 2.2 - Tipos de fluxo em silos com descarga excêntrica. Fonte: EUROCODE (2002). 
De acordo com Schulze (1996), o fluxo excêntrico pode surgir pelas seguintes razões:

- formação de zonas estacionárias assimétricas em silos com fluxo de funil;

- silo com sistema de descarga que retira o produto apenas de uma parte da boca de saída;

- silo com tremonhas assimétricas;

- silo que possui mais de uma boca de saída sendo que uma ou mais delas estão obstruídas ou em desuso.

Segundo Rotter (2001), mesmo silos com saídas concêntricas podem apresentar fluxo excêntrico especialmente nos seguintes casos:

- ocorrência de segregação no produto;

- bloqueio parcial ou falhas funcionais do sitema de descarga;

- diferenças de temperatura e de umidade em diferentes lados do silo, causando o fluxo preferencial em um deles.

Outro caso, considerado pelas normas EUROCODE (2002) e DIN (2005), é o caso de silos com saída concêntrica que desenvolvem fluxo excêntrico devido à sua elevada esbeltez, como na Figura 2.3.

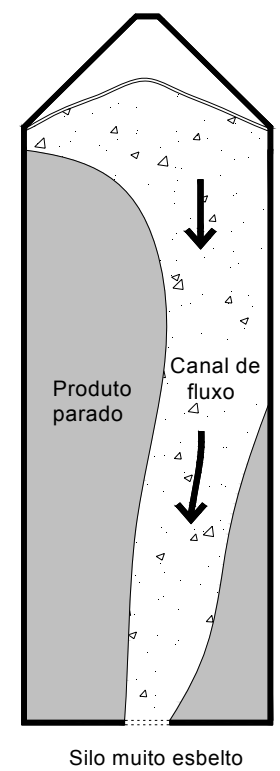

Figura 2.3 - Silo muito esbelto. Fonte: EUROCODE (2002).

Segundo Roberts (1987), as condições necessárias para a ocorrência do fluxo de massa são bem definidas e há muito tempo estabelecidas, sendo mais difícil investigar os critérios que determinam a ocorrência do fluxo de funil, especialmente 
quando o silo possui várias bocas de descarga, carregamento excêntrico ou armazena produtos propícios à segregação. Além disso, Rotter (2001) enfatiza a dificuldade de determinar o tipo de fluxo de funil que pode ser: fluxo misto ou fluxo em tubo interno.

Palma (2005) afirma que o fluxo de massa é o padrão de fluxo ideal e deve ser obtido sempre que possível porque possui muitas vantagens como remoção total do produto, possibilidade de re-mistura na tremonha, maior homogeneização do produto, menor segregação e produz fluxo uniforme que pode ser controlado.

A geometria da tremonha e coeficiente de atrito da parede da tremonha são fundamentais para a garantia do fluxo de massa. Por isso, a maioria das normas internacionais apresenta gráficos (Figuras 2.4 e 2.5) para a determinação do tipo de fluxo em função do ângulo de inclinação, coeficiente de atrito com a parede da tremonha e tipo de tremonha. No caso de silos excêntricos, ou seja, que possuem tremonhas assimétricas cuja inclinação da tremonha varia ao redor da circunferência do silo, adota-se o maior valor de $\beta$ para analisar o tipo de fluxo, que corresponde à pior situação de projeto.
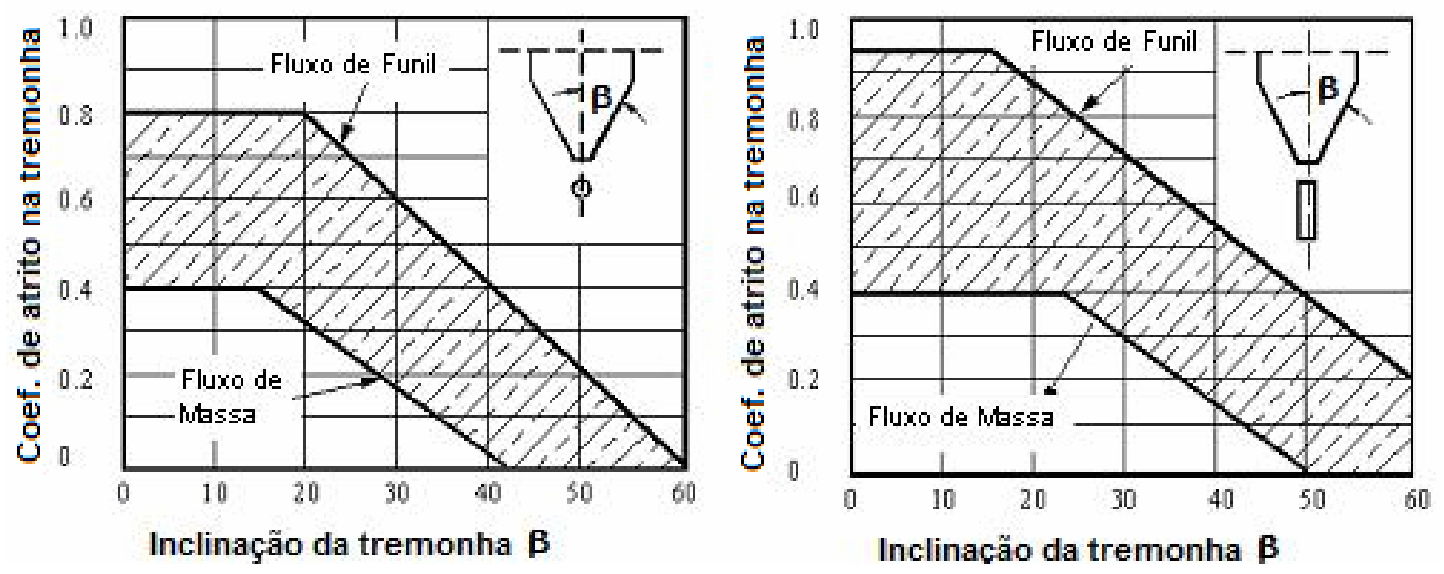

Figura 2.4 - Determinação gráfica do tipo de fluxo. Fonte: AS 3774 (1996).
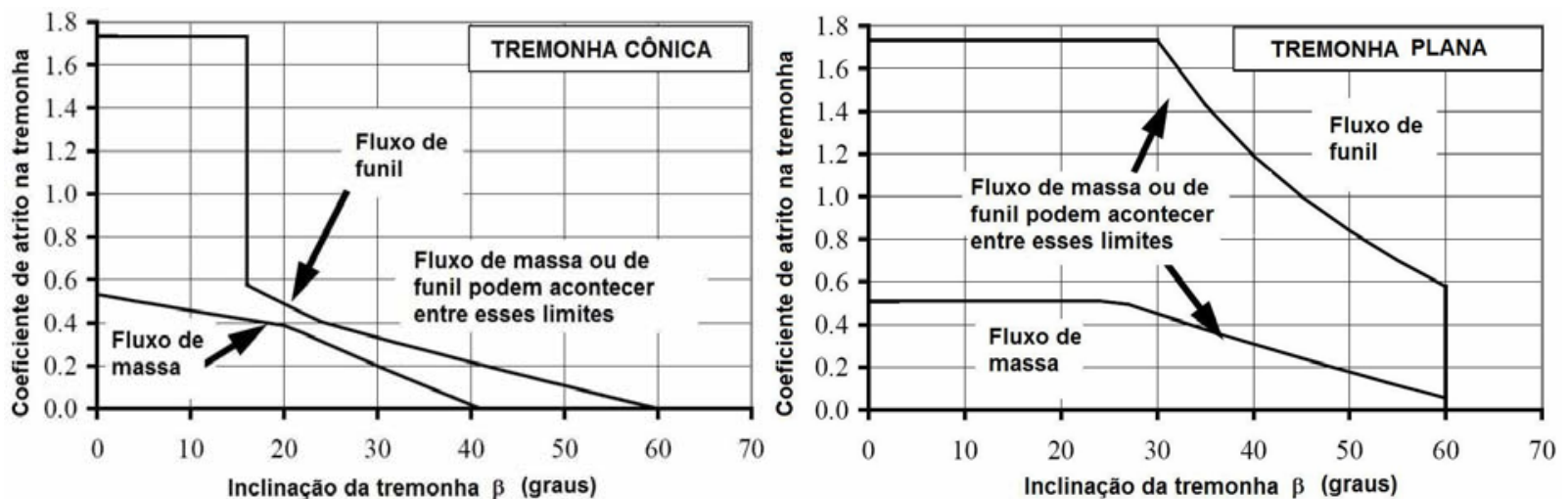

Figura 2.5 - Determinação gráfica do tipo de fluxo. Fonte: DIN 1055-6 (2005), EUROCODE 1 (2002). 
O padrão de fluxo influencia fortemente na intensidade das pressões que ocorrem nas paredes do silo durante a descarga do produto. Portanto, as pressões não serão previstas corretamente a menos que o padrão de fluxo seja conhecido.

Apesar da correlação entre as pressões e o tipo de fluxo, existe uma linha de pesquisa ligada diretamente ao tipo de fluxo. Kim (1959) observou que o movimento do produto era menor nas zonas próximas à parede em comparação com zonas no centro do silo. Este pesquisador realizou experimentos com diversos produtos em silos com paredes transparentes e observou a existência do fluxo de massa e do fluxo de funil, acontecendo esporadicamente um fluxo de comportamento intermediário entre esses dois. Kim (1959) também constatou também que o fluxo de funil acontecia em silos com paredes rugosas e com relação altura lado elevada.

Deutsch e Clyde (1967) propuseram um modelo de quatro zonas de fluxo, conforme a Figura 2.6. Na primeira zona (zona I) o produto armazenado possui um fluxo mássico, com todo o produto em movimento descendente em direção à boca de saída Na superfície livre do produto se forma uma depressão na parte central com inclinação crescente até formar um ângulo igual ao ângulo de atrito interno do produto.

A zona III é caracterizada por apresentar elevada velocidade devido à proximidade da boca de saída. Nesta zona, o produto se desloca rapidamente em direção à boca de saída, formando uma espécie de tubo. A zona II está localizada na transição entre a zona I e a zona III por isso o produto na zona II é o alimentador da zona III. O produto nesta zona sofre um aumento progressivo da velocidade, que se inicia na zona I até atingir a zona III. Finalmente, o produto situado na zona IV está em repouso. Muitos experimentos posteriores publicados em: Kotchanova (1970), Sugita (1972) e McCabe (1974), validaram o modelo de fluxo misto de Deutsch e Clyde (1967). 


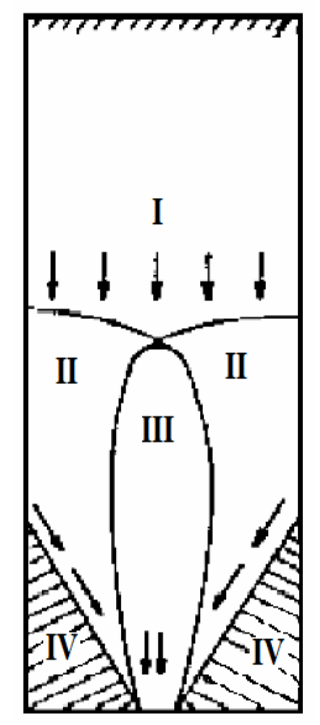

Figura 2.6 - Zonas de fluxo. Fonte: Deutsh e Clyde (1967).

Muitos estudos têm sido conduzidos com o objetivo de prever o formato do canal de fluxo. Giunta (1991) afirma que em silos de saída circular com o diâmetro grande o suficiente para evitar problemas de obstrução de fluxo, o formato do canal de fluxo será um cone que se inicia na boca de saída. Na parte superior do silo o diâmetro do canal de fluxo será máximo. Giunta testou sua hipótese em um silo de fundo plano de $45 \mathrm{~cm}$ de diâmetro com boca de saída centrada. Vários produtos foram testados e os formatos do canal de fluxo encontrado concordaram razoavelmente com aquele previsto pela teoria de Giunta.

Carson e Jenkyn (1993) afirmam que o estudo de Giunta não foi bem sucedido no sentido de identificar uma correlação entre o ângulo do canal e as propriedades de fluxo do produto como ângulo efetivo de atrito interno ou o ângulo de repouso e que claramente, mais trabalhos precisam ser feitos para chegar a uma conclusão definitiva.

Carson e Jenkyn (1993) estudaram o formato do canal de fluxo resultante para silos com boca de saída excêntrica e concluíram que a inclinação do canal de fluxo é a mesma, independente da posição da boca de saída, como mostra a Figura 2.7 . 


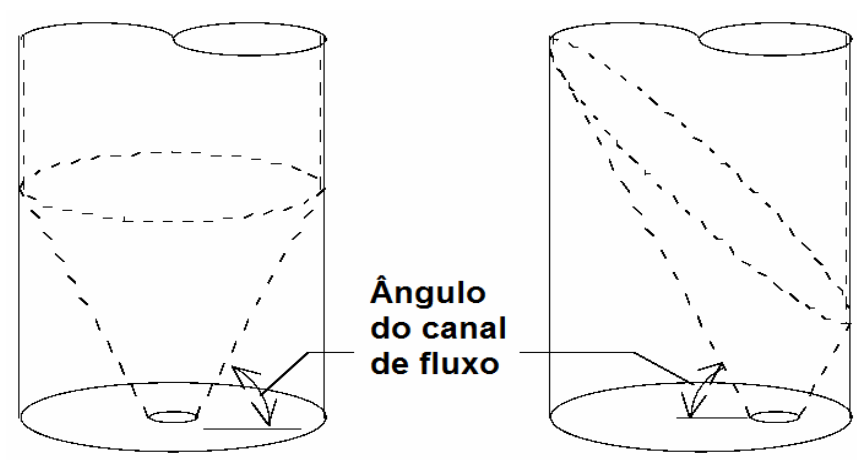

Figura 2.7 - Canal de fluxo em uma tremonha concêntrica e excêntrica em um silo com fluxo de funil. Fonte: Carson e Jenkyn (1993).

Basicamente, o fluxo acontece quando as tensões no produto são maiores que sua própria resistência, dando início à deformação plástica no produto. É fundamental, portanto, conhecer a intensidade das pressões que atuam em cada camada do produto armazenado.

\subsection{O estado de tensão e o fluxo}

Quando o produto se encontra em repouso no interior do silo, a ação atuante é devido ao seu peso próprio, de forma que o peso das camadas superpostas dividido pela área do silo fornece a tensão vertical atuante em cada camada $\left(\sigma_{v}\right)$. Esta tensão aumenta com a profundidade do silo, conforme ilustrado na Figura 2.8.

Também uma tensão horizontal $\left(\sigma_{h}\right)$ atua no produto devido ao confinamento lateral ou restrição de deslocamento imposto pela parede do silo. Existe uma relação entre a pressão horizontal na parede do silo e a pressão vertical no produto que é conhecida internacionalmente como coeficiente $\mathrm{K}$ ou parâmetro $\mathrm{K}$, adotado pela primeira vez por Janssen (1895).

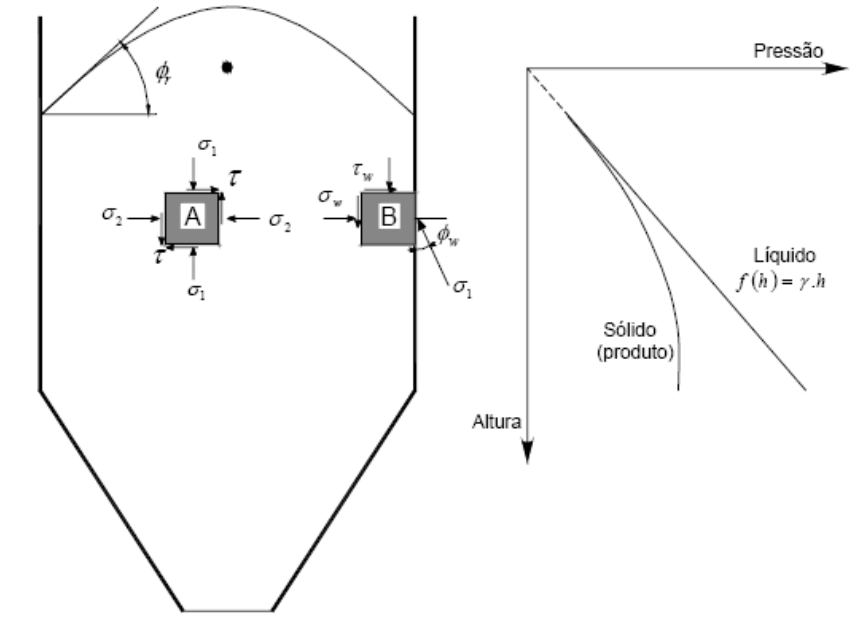

Figura 2.8 - Estado de tensão no silo. Fonte: Cheung e Calil (2005). 
O produto granular dentro do silo está submetido a dois estados principais de tensões: o estado ativo e o estado passivo. O estado ativo ocorre durante 0 carregamento e permanece até o momento anterior ao início da descarga. Ele é caracterizado pelo fato de que a tensão principal máxima, no eixo que passa pelo centro do silo, possui direção vertical, enquanto a tensão mínima é horizontal. $\mathrm{Na}$ mecânica dos sólidos, por convenção, as tensões que atuam em planos principais são representadas por $\sigma_{1}$ e $\sigma_{2}$. Sendo assim, no estado ativo, a maior tensão principal $\left(\sigma_{1}\right)$ é vertical $\left(\sigma_{v}\right)$ enquanto a menor tensão principal $\left(\sigma_{2}\right)$ atua no plano horizontal e é representado por $\sigma_{\mathrm{h}}$.

A partir do momento em que o produto granular começa a fluir em direção à boca de saída, o produto se deforma plasticamente, se expande verticalmente e se comprime horizontalmente. Esta é uma situação típica do estado passivo de tensões, na qual a maior tensão principal $\left(\sigma_{1}\right)$, na linha que passa pelo centro do silo, está agora atuando na direção horizontal. Desta forma, no estado passivo, a maior tensão principal $\left(\sigma_{1}\right)$ é horizontal $\left(\sigma_{h}\right)$ enquanto a menor tensão principal $\left(\sigma_{2}\right)$ é vertical $\left(\sigma_{\mathrm{v}}\right)$.

Para que o produto inicie seu fluxo no instante da abertura da boca de saída, a intensidade das tensões deve ser elevada o suficiente para atingir a superfície de deslizamento do produto. Caso contrário existirão problemas de obstrução do fluxo (Figura 2.9) que podem ser: formação de um arco estável próximo à saída da tremonha também conhecido como efeito arco, formação de um tubo de descarga (efeito tubo) com grande parte do produto estagnado ao redor desde e descarga incompleta do produto.

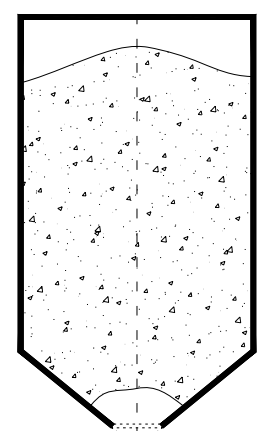

(a) Obstrução em abóbada

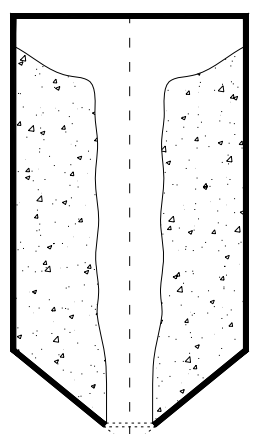

(b) Obstrução em tubo

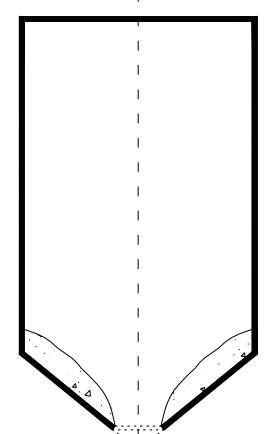

(c) Descarga incompleta

Figura 2.9 -Tipos de obstruções de fluxo. Fonte: Palma (2005). 
Obstruções do fluxo estão relacionados com o ganho de resistência dos produtos e trazem sérios problemas à integridade da unidade de armazenamento. Elas reduzem a capacidade de armazenamento da estrutura e em casos extremos de obstrução de fluxo, a estrutura precisa ser abandonada dado que os procedimentos necessários para a desobstrução podem, muitas vezes, acarretar no colapso do silo (CARSON, 2000). Não é objetivo deste trabalho a abordagem mais completa dos problemas de fluxo. Para maiores informações, consultar Jenike (1964).

Imprescindivel é estar ciente que todos os problemas de fluxo podem ser evitados a partir da execução de um projeto de fluxo fundamentado no estudo prévio das propriedades físicas do produto, incluindo sua variabilidade nas piores condições possíveis de umidade, temperatura e pressão durante a vida útil da estrutura. Daí a importância do estudo da determinação das propriedades físicas do produto armazenado.

\subsection{Propriedades dos produtos armazenados}

Apesar dos inúmeros estudos realizados com os produtos granulares ao longo dos últimos 150 anos, ainda não se conhece perfeitamente seu comportamento e muitas de suas propriedades ainda não são medidas (FREITAS, 2001).

Um produto granular é composto por duas partes principais: a partícula (grãos) e os vazios. Seu comportamento é regido pela interação na superfície de contato entre suas partículas, onde surgem forças de atração devido à presença de moléculas de água adsorvidas aos grãos. A variação da umidade, temperatura, tempo de estocagem, distribuição, formato das partículas e composição química causam o aumento ou redução dessas forças.

A umidade, por exemplo, gera um aumento nas forças adesivas entre os grãos, fator que dificulta o fluxo do produto devido ao ganho de resistência do mesmo. $O$ formato das partículas também interfere na capacidade de fluxo do produto. É natural esperar que partículas irregulares como as do milho possuam maior resistência ao fluxo quando comparadas às partículas esféricas como as da soja. 
Uma outra característica dos produtos armazenados é que sua resistência depende do seu histórico de tensões de tal forma que um mesmo produto pode iniciar seu fluxo sob diferentes níveis de tensão de acordo com a carga a que foi anteriormente submetido.

Schulze (1996) mostra que as propriedades do produto podem ser entendidas a partir de um teste simples que consiste em preencher um cilindro circular vazado com um produto granular. O produto é então submetido a uma tensão vertical $\left(\sigma_{v}\right)$ crescente, denominada tensão de consolidação, conforme ilustra a Figura 2.10 (a). À medida que a tensão aplicada aumenta, o volume da amostra diminui e a densidade do material aumenta. Quanto mais compressível o produto, menor o volume da amostra e consequentemente maior sua densidade.

A Figura 2.10 (b) ilustra o instante em a tensão vertical atinge seu valor máximo igual a $\sigma_{1}$. Neste instante, a amostra se encontra comprimida (pela presença da tensão de compressão) e consolidada (pela presença das paredes do cilindro), com seu valor máximo de tensão de consolidação $\sigma_{1}$. Na seqüência, a tensão de consolidação é aliviada e o cilindro vazado removido, Figura 2.10 (c).

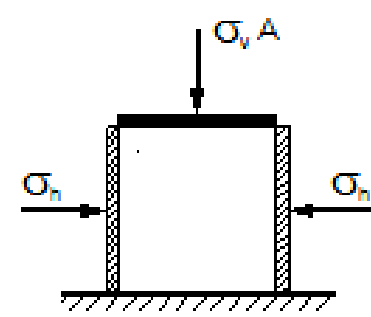

(a)

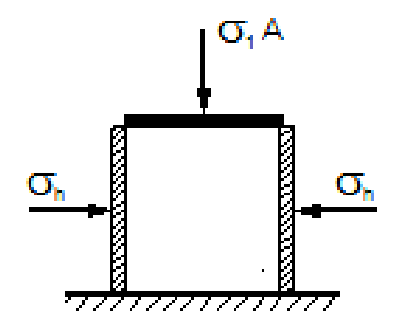

(b)

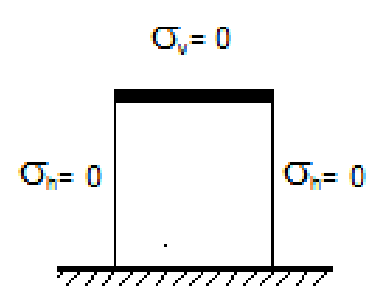

(c)

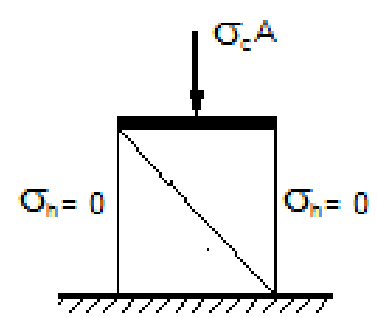

(d)

Figura 2.10 - Amostra de um produto granular submetida à compressão e consolidação. Fonte: Schulze (1996).

Se a coesão entre as partículas não for suficiente para manter sua forma depois de removido o cilindro, a amostra se rompe. Caso exista coesão entre as partículas, a amostra permanecerá com o mesmo formato e, ao submeter novamente a amostra a uma tensão crescente, a ruptura será observada quando o valor da tensão aplicada atingir a resistência à compressão do produto, denominada resistência inconfinada, representada por $\sigma_{c}$, conforme ilustrada a Figura 2.10 (d).

A palavra inconfinada está relacionada com a ausência das paredes do cilindro que anula a tensão horizontal $\left(\sigma_{h}=0\right)$. Em outras palavras, a resistência inconfinada é a magnitude do carregamento necessário para vencer a coesão entre 
as partículas quando a amostra se encontra inconfinada, de forma que o produto comece a fluir. No plano onde se dá a ruptura, o produto se deforma plasticamente e se expande dando início ao fluxo.

Amostras de um mesmo produto quando submetidas a diferentes valores de tensão de consolidação $\left(\sigma_{1}\right)$, apresentarão tensão de ruptura $\left(\sigma_{c}\right)$ distintos porque a resistência do produto depende do seu histórico de tensões. Para a maioria dos produtos quanto maior a tensão de consolidação $\sigma_{1}$, maior o peso específico do produto $\gamma$ e maior também a resistência inconfinada $\sigma_{c}$.

A Figura 2.11 mostra as curvas de variação do peso específico e da resistência inconfinada de quatro produtos: $A, B, C$ e D, obtidas a partir de amostras do mesmo produto ensaiadas com diferentes valores de tensão de consolidação $\sigma_{1}$.

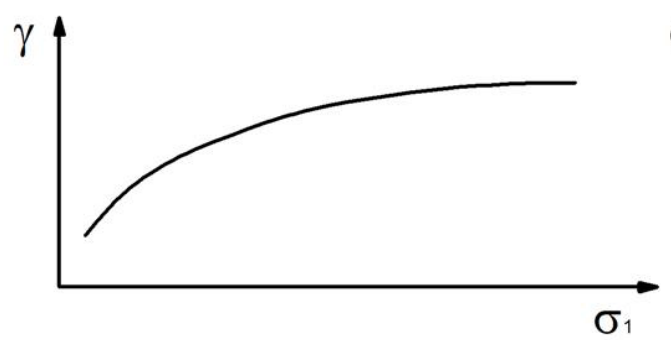

(a)

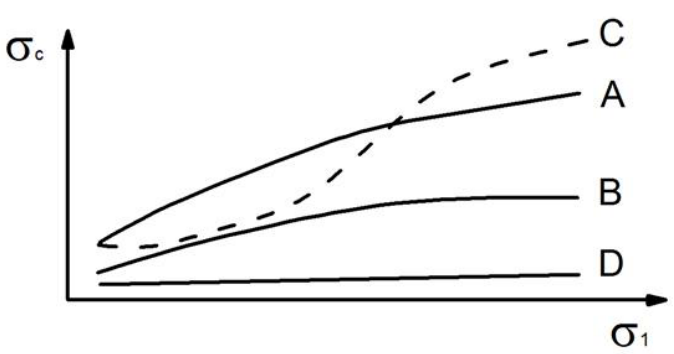

(b)

Figura 2.11 - (a) densidade (b) função fluxo dos materiais A, B e C e D. Fonte: Schulze (1996).

O comportamento do produto A é o mais usual, pois ganha resistência com o aumento da tensão aplicada. O mesmo acontece com o produto $B$, porém com menor intensidade. Existem ainda produtos de comportamento atípico como os representados pela curva $\mathrm{C}$.

A diferença principal entre os produtos coesivos e não coesivos (ou de fluxo livre) é que os produtos coesivos apresentam tensão inconfinada de ruptura $\sigma_{c}$ quando consolidados, enquanto que nos não coesivos o valor de $\sigma_{c}$ é praticamente nulo, mesmo para grandes tensões de consolidação (como o produto D).

As curvas de $\sigma_{\mathrm{c}} \times \sigma_{1}$ definem uma propriedade importante do produto, denominada Função Fluxo (FF), também definida por:

$$
F F=\frac{\sigma_{1}}{\sigma_{c}}
$$

Quanto maior o fator FF, maior a capacidade do produto em fluir. Seguindo esse raciocínio, Jenike (1964) elaborou uma classificação dos produtos de acordo com o valor de FF, que está na Tabela 2.1: 
Tabela 2.1 - Classificação da capacidade de fluxo dos produtos segundo JENIKE (1964).

\begin{tabular}{|c|l|}
\hline FF & Classificação \\
\hline $\mathrm{FF}<2$ & muito coesivos \\
\hline $2<\mathrm{FF}<4$ & coesivos \\
\hline $4<\mathrm{FF}<10$ & flui facilmente \\
\hline $\mathrm{FF}>10$ & fluxo livre \\
\hline
\end{tabular}

O tempo também é um fator que deve ser considerado ao determinar as propriedades físicas dos produtos porque a maioria dos produtos adquire resistência quando estocados por certo período de tempo, mesmo quando se mantém constante seu estado de tensão. Este fenômeno é conhecido como consolidação com o tempo.

Uma forma simplificada de quantificar este efeito é aplicar na amostra da Figura 2.10, a tensão de consolidação $\sigma_{1}$ num período de tempo maior, simulando longas estocagens do produto dentro do silo. Os resultados dos testes serão curvas de variação de $\sigma_{c}$ com $\sigma_{1}$ (Figura 2.12) deslocadas para cima indicando ganho da resistência inconfinada do produto com o tempo de armazenamento. Estas curvas são denominadas Função de Fluxo com o tempo (FFt).

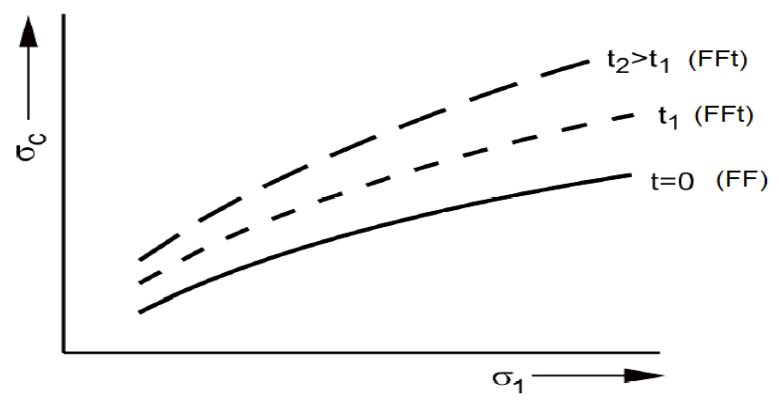

Figura 2.12 - Curvas de função fluxo com o tempo para diferentes períodos de armazenamento.

É possível e conveniente representar o estado de tensão da amostra da Figura 2.10 num diagrama de tensões normais e tensões cisalhantes $(\sigma \mathbf{x} \tau)$, mais conhecido como Círculo de Mohr-Coulomb. Desprezando o peso da tampa, o peso do produto granular e o atrito do produto com as paredes do cilindro, tanto as tensões verticais $\left(\sigma_{v}\right)$ quanto as tensões horizontais $\left(\sigma_{h}\right)$ são considerados constantes na profundidade e na altura da amostra.

Nesta situação, é válido admitir que o estado de tensão seja o mesmo em qualquer ponto dentro da amostra. Além disso, como as tensões de cisalhamento são nulas, os pares de valores $(\sigma x \tau)$ do ensaio de compressão serão pontos localizados no eixo horizontal $\sigma$. 
Nos planos perpendiculares às tensões cisalhantes nulas, atuam as tensões principais $\sigma_{v}$ e $\sigma_{h}$, ou seja, $\sigma_{1}$ e $\sigma_{2}$. A Figura 2.13 ilustra as condições de carregamento e confinamento da amostra com o seu respectivo estado de tensão.

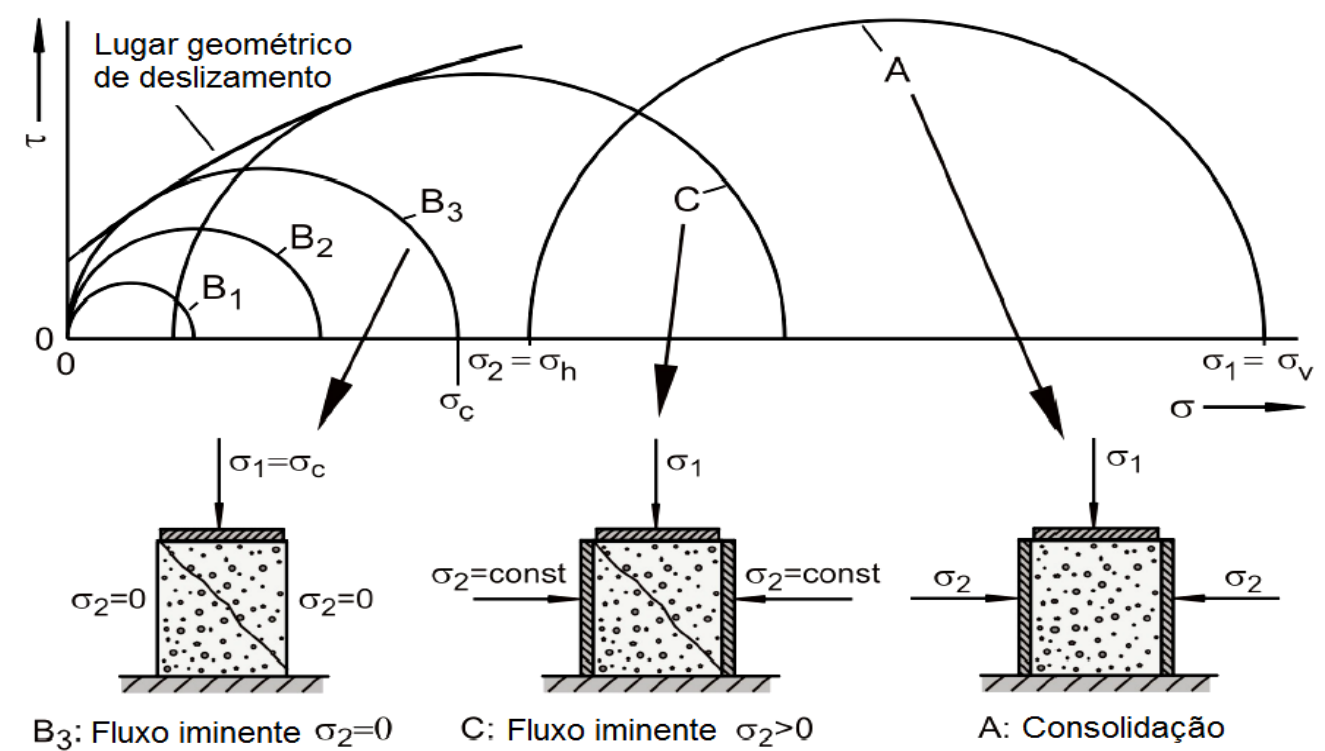

Figura 2.13 - Estado de tensão para várias condições da amostra. Fonte: Schulze (1996).

A superfície de deslizamento ou lugar geométrico de deslizamento da Figura 2.13 indica tensões limites na amostra. Observa-se que os círculos B1 e B2 estão abaixo da superfície de deslizamento. Nesta condição, o produto possui apenas deformação elástica, sem a falha da amostra. Note que os círculos da configuração B passam pela origem do diagrama, pois a tensão na superfície vertical da amostra é nula. No instante que $\sigma_{1}$ alcança o valor de $\sigma_{c}$, ocorre o início do fluxo indicado pelo círculo B3. Um círculo maior que B3 não é possível, pois a amostra se rompe primeiro.

O círculo A mostra o estado de tensão na amostra durante a consolidação, sem que aconteça a ruptura. A amostra, nesta situação se encontra extremamente comprimida e a tensão de cisalhamento não atingiu valor elevado o suficiente para romper o produto. Diferente do que ocorre com o círculo $C$, no qual se observa que mesmo a amostra estando confinada, a tensão vertical é suficientemente para rompê-la.

A junção dos pontos limites dos círculos de Mohr-Coulomb resulta numa curva denominada Yield locus ou lugar geométrico de deslizamento do produto, também conhecido como critério de resistência ou ainda envoltório de MohrCoulomb (Figura 2.13). 
A posição do envoltório depende da tensão de consolidação do produto (maior tensão principal durante o estado de deformação permanente), tempo de consolidação, umidade e temperatura. Usualmente a umidade, temperatura e tempo podem ser considerados constantes para a simplificação na análise das propriedades, porém não devem ser desprezados.

No critério de Mohr-Coulomb, a ruptura do produto é expressa pela relação entre a tensão normal com a tensão de cisalhamento. A expressão matemática que exprime a condição da ruptura é:

$$
f(\sigma)=c+\sigma \tan \left(\phi_{i}\right)
$$

Onde:

$c=$ coesão

$\phi_{i}=$ ângulo de atrito interno

As principais propriedades dos produtos armazenados são determinadas a partir da curva do lugar geométrico de deslizamento, expressa pela equação 2.02, que são: ângulo efetivo de atrito interno; ângulo de atrito interno; coesão e resistência inconfinada.

Apesar das normas internacionais apresentarem tabelas com os valores dessas propriedades, recomenda-se sempre que possível, realizar ensaios de caracterização dado que cada produto possui suas particularidades. Além disso, observa-se grande discrepância entre os valores sugeridos em diferentes normas.

Carson e Jenkyn (1993) enfatizam que os dados fornecidos em tabelas devem ser utilizados com muita cautela, pois não é possível saber as propriedades do produto pelo seu nome genérico. Também afirmam que a prática de interpolação dos dados ou o processo de adotar as propriedades de produtos com semelhanças superficiais deve ser evitada.

A execução de testes é a melhor alternativa para conhecer o comportamento do produto. Vários aparelhos e procedimentos de testes foram elaborados na tentativa de quantificar de forma numérica o comportamento dos produtos armazenados sendo que o aparelho mais utilizado atualmente é o Jenike shear test, desenvolvido por Jenike por volta de 1960. 


\subsubsection{Teste de cisalhamento com o produto}

Jenike investigou como as forças adesivas entre as partículas se relacionam com o comportamento de fluxo examinando as tensões normais e cisalhantes dos produtos. Com base nisto, desenvolveu um aparelho para quantificar a resistência cisalhante de acordo com as pressões normais.

O aparelho de Jenike (Figura 2.14) é composto basicamente por uma base cilíndrica fixa em uma bancada, um anel de cisalhamento, uma tampa e um pendural com pesos para a aplicação de uma força normal de compressão na tampa da célula de cisalhamento, detalhada na Figura 2.15. Fixado à tampa, na sua lateral, existe uma haste para que a parte de superior da célula seja deslocada horizontalmente contra sua base que permanece fixa. No momento do deslocamento, a força de cisalhamento é registrada.
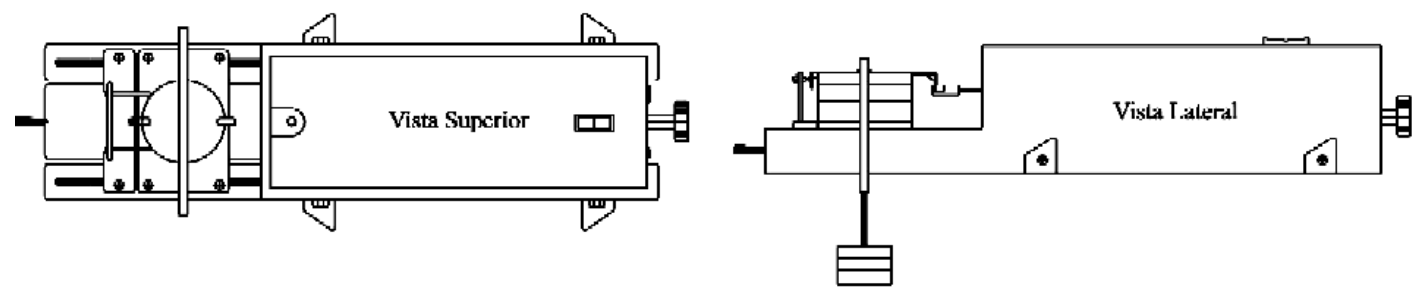

Figura 2.14 - Aparelho de cisalhamento de Jenike, vista superior e vista lateral.

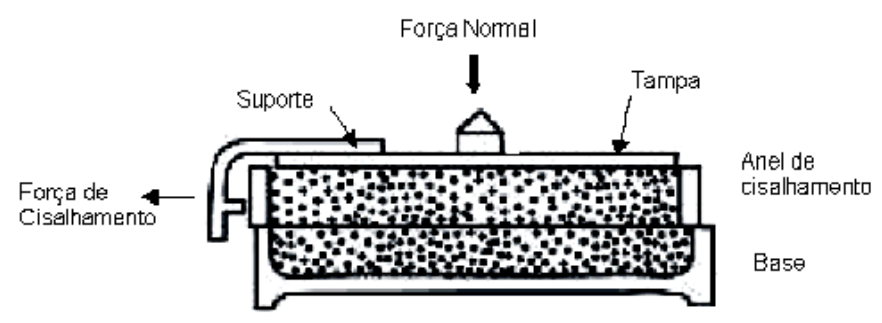

Figura 2.15 - Detalhe da célula de cisalhamento de Jenike.

No teste com o aparelho de Jenike, a amostra deve ser inicialmente homogeneizada e compactada sob uma tensão vertical previamente conhecida $\sigma_{\text {pré }}$. O estado de homogeneização e compactação da amostra se dá por meio de um procedimento denominado twist que consiste em aplicar $\sigma_{\text {pré }}$ na amostra com movimentos iterativos de vai e vem. Antes do cisalhamento propriamente dito, a amostra é pré-cisalhada com o mesmo valor de tensão na qual ela foi homogeneizada, ou seja, $\sigma_{\text {pré }}$.

No início do pré-cisalhamento, a tensão de cisalhamento do produto $(\tau)$ aumenta com o tempo, até o momento em que ela se torna estável (Figura 2.16). Este valor estável, obtido na fase de pré-cisalhamento, é representado por $\tau_{\text {pré }}$. 
Depois de alcançado o valor de $\tau_{\text {pré }}$, a resistência ao cisalhamento e a densidade da amostra permanecem constantes.

A densidade da amostra e a tensão de cisalhamento durante o précisalhamento para um mesmo produto dependem somente da tensão normal aplicada $\sigma_{\text {pré }}$. Isso significa que diferentes amostras de um mesmo produto quando pré-cisalhadas com o mesmo valor de tensão normal $\sigma_{\text {pré }}$, apresentarão o mesmo estado de consolidação. $O$ par de valores $\left(\sigma_{\text {pré }}, \tau_{\text {pré }}\right)$ deve ser plotado no diagrama $\sigma \times \tau$, e é denominado ponto de pré-cisalhamento.

O pré-cisalhamento é importante para a obtenção do estado de fluxo estável da amostra. O estado de fluxo estável é importante porque deixa a amostra sob condições constantes de densidade, tensão normal e tensão de cisalhamento. Quando o estado de fluxo estável é alcançado, diz-se que a amostra está criticamente consolidada. Segundo Milani (1993) a consolidação crítica é um grau de compactação que ocorre quando a força de cisalhamento cresce e, alcançado certo valor, permanece constante durante o resto do cisalhamento. No diagrama $\sigma \times \tau$ da Figura 2.16 (a) pode ser observado o estado de fluxo estável a partir do ponto em que o ensaio de cisalhamento atinge uma força de cisalhamento constante.

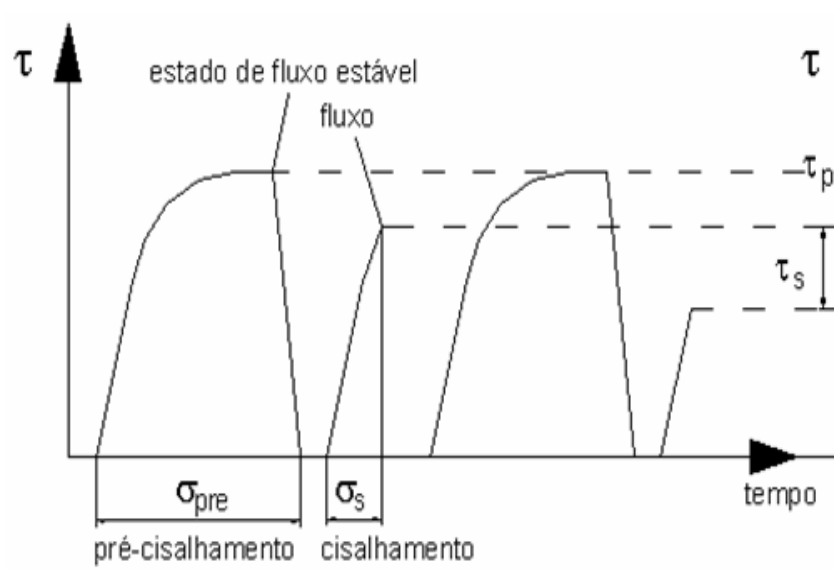

(a)

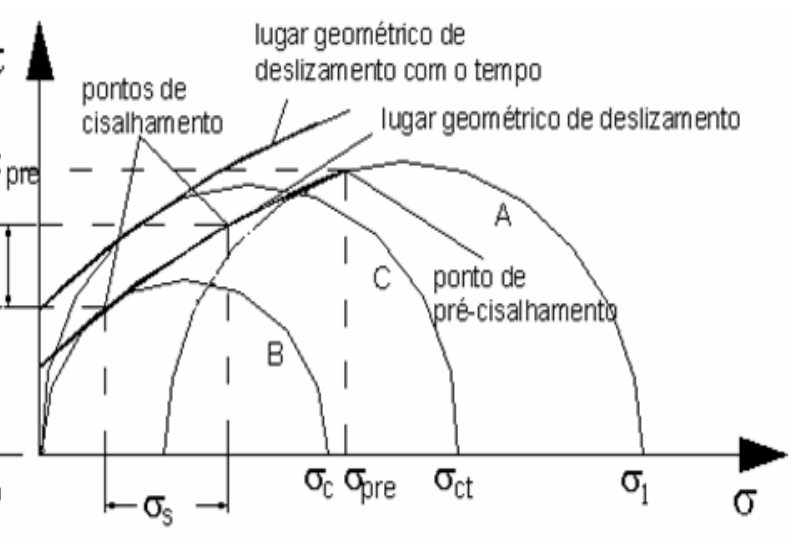

(b)

Figura 2.16 - Etapas do teste de cisalhamento direto para a obtenção do lugar geométrico de deslizamento. Fonte: Palma (2005).

Após o pré-cisalhamento, a tensão normal na amostra é reduzida para um valor pré-determinado $\sigma_{s}$ sempre menor que $\sigma_{\text {pré }}$ e então a amostra será cisalhada até atingir o valor máximo da tensão de cisalhamento resistente $\left(\tau_{s}\right)$, Figura 2.16. Para determinar o lugar geométrico de deslizamento, diversos testes como o 
descrito acima, devem ser realizados variando-se o valor de $\sigma_{s}$ para amostras na mesma condição de consolidação.

A superfície de deslizamento ou yield locus será a curva que tangencia os diversos círculos obtidos no ensaio. A tensão de consolidação $\left(\sigma_{1}\right)$ é igual à maior tensão principal do círculo de Mohr-Coulomb que tangencia o lugar geométrico de deslizamento e intercepta o ponto de estado de fluxo estável $\left(\sigma_{p r e ́}, \tau_{p r e}\right)$. Este círculo representa o estado de tensão da amostra no final do procedimento de consolidação.

A resistência inconfinada $\left(\sigma_{c}\right)$ é obtida traçando-se um círculo de tensão que passa pela origem e é tangente ao yield locus. A linha reta que passa pela origem do diagrama $\sigma \times \tau$, tangente ao maior círculo de Mohr-Coulomb é o efetivo lugar geométrico de deslizamento, definido por Jenike (1964). O ângulo formado pelo efetivo lugar de deslizamento e o eixo das abscissas é denominado ângulo efetivo de atrito interno, representado por $\phi_{e}$.

\subsubsection{Teste de cisalhamento com a parede}

As pressões de um produto em um silo são dependentes do coeficiente de atrito entre o sólido e a parede do silo $(\mu)$. A determinação do ângulo de atrito do produto armazenado com a parede também pode ser obtida com o aparelho de Jenike. Neste caso, a base da célula de cisalhamento é substituída por uma amostra do material da parede que será avaliada.

A tensão de cisalhamento $\left(\tau_{w}\right)$ durante o deslizamento do produto contra $\circ$ material da parede são medidas sob diferentes níveis de tensões normais $\sigma_{w}$. $O$ envoltório de deslizamento com a parede é obtido plotando-se os pares de valores $\left(\sigma_{w}, \tau_{w}\right)$ em um diagrama $\sigma \times \tau$ (Figura 2.17). O ângulo de atrito com a parede $\phi_{w}$ é a inclinação do envoltório de deslizamento com a parede com o eixo $\sigma$, portanto pode ser calculado pela equação:

$$
\phi_{w}=\operatorname{arctg}\left(\tau_{w} / \sigma_{w}\right)
$$

sendo:

$$
\mu=\operatorname{tg} \phi_{w}
$$



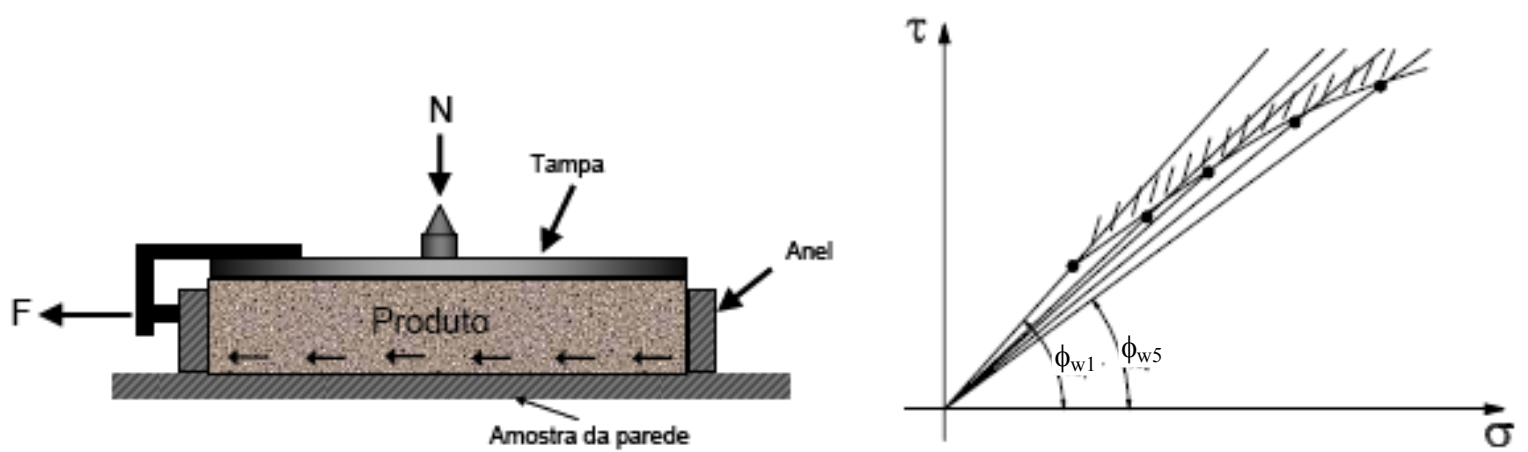

Figura 2.17 - Determinação do atrito com a parede na célula de Jenike. Fonte: Jenike (1964).

Atualmente a maioria dos silos possui paredes formadas por chapas de aço corrugado, no formato de ondas ou em trapézios (Figura 2.18). A vantagem de adotar este tipo de geometria é o ganho de inércia sem um aumento significativo na quantidade de material. No caso de paredes corrugadas, uma parte do atrito ocorre entre produto e a parede e a outra parte entre o próprio produto devido à presença de grãos estacionários nas ondas ou dobras das paredes. $O$ atrito efetivo com a parede deve ser calculado considerando esta particularidade.

De acordo com as normas européia e alemã, EUROCODE (2002) e DIN (2005), o coeficiente de atrito efetivo de paredes de chapa de aço corrugada deve ser calculado por:

$$
\mu_{\text {eff }}=\left(1-a_{w}\right) \tan \phi_{i}+a_{w} \mu_{w}
$$

Sendo:

$$
a_{w}=\frac{b_{w}}{b_{w}+b_{i}}
$$

$b_{w}$ e $b_{i}$ estão indicados na Figura 2.18.
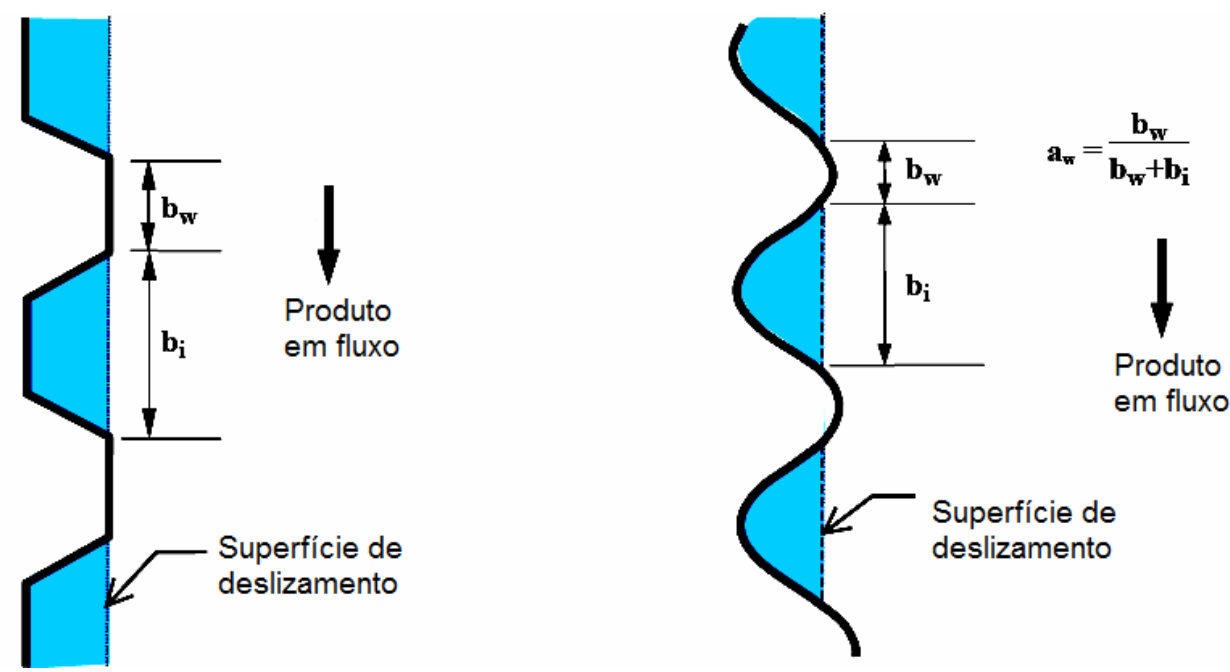

Figura 2.18 - Dimensões das paredes corrugadas. Fonte: EUROCODE (2002) e DIN (2005). 


\subsubsection{Granulometria}

O tamanho das partículas interfere no comportamento de fluxo dos produtos. De acordo com Calil (1984) os produtos podem ser classificados, conforme a dimensão do diâmetro de suas partículas em: produtos granulares, pulverulentos coesivos, pulverulentos coesivos finos e pulverulentos coesivos extra-finos. A Tabela 2.2 apresenta os valores limites do diâmetro das partículas para cada um deles.

Tabela 2.2 - Classificação dos produtos de acordo com a granulometria. Fonte: Calil (1984).

\begin{tabular}{|c|l|}
\hline $\mathbf{D}(\mathbf{m m})$ & Classificação \\
\hline$d_{p}>0,42$ & Granulares \\
\hline $0,42<d_{p}<0,149$ & Pulverulentos coesivos \\
\hline $0,149<d_{p}<0,079$ & Pulverulentos coesivos finos \\
\hline$d_{p}<0,079$ & Pulverulentos coesivos extra-finos \\
\hline
\end{tabular}

\section{$2.4 O$ coeficiente $K$}

A determinação da relação entre o as pressões horizontais e verticais no produto armazenado, o coeficiente $\mathrm{K}$, é um dos maiores problemas no estudo e projeto dos silos. Seu valor influencia significativamente no regime de pressões em um silo. Em vários trabalhos de pesquisa e normas são sugeridas diferentes recomendações para calcular o valor deste parâmetro. Na maioria dos casos, o cálculo de $\mathrm{K}$ é realizado conhecendo-se apenas ângulo de atrito interno do produto, havendo casos em que o ângulo de atrito com a parede também é utilizado.

Segundo Kaminiski e Wirska (1998), além do ângulo de atrito interno do produto e do ângulo de atrito do produto com a parede, experiências mostram que os valores das pressões e do parâmetro K, a elas relacionado, dependem de quase quarenta fatores, agrupados em grupos primários como: propriedades físicoquímicas do produto granular; forma e dimensões do silo; tipo de fluxo do produto durante o descarregamento do silo; efeito do tempo e parâmetros de temperatura e de umidade e interação entre a estrutura do silo e o produto granular.

As primeiras pesquisas sobre o parâmetro $\mathrm{K}$ para produtos armazenados foram baseadas nas teorias clássicas sobre empuxo de terra, formuladas por Coulomb (1773) e por Rankine (1856 apud CALIL, 1997). Rankine (1856 apud CALIL, 1997) associou o coeficiente $K$ de maciços granulares a três estados de tensão: estado ativo, passivo e em repouso.

Koenen (1896 apud GOMES, 2000), baseado no coeficiente de pressão ativa da teoria de Rankine para empuxos de terra, definiu a seguinte expressão para o 
cálculo de $\mathrm{K}$ nos produtos granulares não coesivos no estado de tensão ativo e passivo respectivamente:

$$
\begin{aligned}
& K_{a}=\frac{1-\operatorname{sen} \phi_{i}}{1+\operatorname{sen} \phi_{i}}=\operatorname{tg}^{2}\left(\frac{\pi}{4}-\frac{\phi_{i}}{2}\right) \\
& K_{p}=\frac{1+\operatorname{sen} \phi_{i}}{1-\operatorname{sen} \phi_{i}}=\operatorname{tg}^{2}\left(\frac{\pi}{4}+\frac{\phi_{i}}{2}\right)
\end{aligned}
$$

As expressões 2.07 e 2.08 são derivadas do círculo de Mohr-Coulomb e, portanto, admite-se que as tensões verticais e horizontais no produto armazenado sejam tensões principais. Por isso, elas são válidas apenas em situações em que a parede do silo é perfeitamente lisa, ou seja, não é capaz de absorver tensão por atrito. Isto faz com que essas equações sejam teoricamente incompatíveis com a situação real de armazenamento nos silos.

Jaky (1948) obteve uma relação para o parâmetro K considerando o produto em repouso e parede lisa:

$$
K=\frac{\left(1-\operatorname{sen} \phi_{e}\right)\left(1+\frac{2}{3} \operatorname{sen} \phi_{e}\right)}{1-\operatorname{sen} \phi_{e}}
$$

que foi simplificada para a forma geralmente usada:

$$
K=1-\operatorname{sen} \phi_{e}
$$

Hartmann em 1966 (apud LOHNES,1993), utilizou a teoria elástica para calcular $K_{a}$ para silos com paredes rugosas e obteve a seguinte equação para $o$ parâmetro K:

$$
K=\frac{1-\operatorname{sen}^{2} \phi_{i}}{1+\operatorname{sen}^{2} \phi_{i}}
$$

Walker (1966) usou a geometria do círculo de Mohr-Coulomb para deduzir a equação para o cálculo do parâmetro K, assumindo que o produto ensilado está em ruptura e desliza simultaneamente ao longo de uma parede rugosa com coeficiente de atrito $\mu_{w}$ :

$$
K=\frac{1+\operatorname{sen}^{2} \phi_{i}-2 \sqrt{\operatorname{sen}^{2} \phi_{i}-\mu_{w}{ }^{2} \cos ^{2} \phi_{i}}}{4 \mu_{w}{ }^{2}+\cos ^{2} \phi_{i}}
$$

A equação de Walker (1966) foi citada por vários autores a partir de 1966 de diferentes formas. Observa-se que, nesta equação, se o ângulo de atrito com a parede é zero $\left(\mu_{w}=0\right)$, ela se reduz ao coeficiente de pressão ativa de Rankine, ou 
seja, equação 2.07. Da mesma forma, quando a parede é muito rugosa de forma que o produto desliza sobre ele mesmo no lugar de deslizar com a parede, o valor do coeficiente de pressão lateral fica equivalente à equação 2.11 , que foi obtida primeiramente por Hartman (1966). Para valores intermediários de atrito da parede, a equação de $\mathrm{K}$ fornece valores de transição entre essas duas últimas. Quando o efetivo ângulo de atrito interno do produto é elevado, o coeficiente $\mathrm{K}$ do produto se torna pequeno e consequentemente as pressões horizontais se tornam menores.

Uma outra expressão para K é dada por Frazer que considerou o equilíbrio de forças no contorno na superfície da parede:

$$
K=\frac{1}{\frac{1+\operatorname{sen}^{2} \phi_{e}}{\cos ^{2} \phi_{e}}+\frac{2 \operatorname{sen} \phi_{e}}{\cos ^{2} \phi_{e}} \sqrt{1-\frac{\operatorname{tg}^{2} \phi_{w}}{\operatorname{tg}^{2} \phi_{e}}}}
$$

Calil (1984) determinou o valor do coeficiente $\mathrm{K}$ a partir de dados experimentais de pressões obtidas em silos modelos com paredes lisas carregados com milho, ração e farinha de trigo. Os resultados experimentais foram comparados com os valores teóricos definidos por Rankine, Walker, Frazer e Jaky. O autor concluiu que os resultados de $\mathrm{K}$ obtidos pela fórmula de Frazer foram os que melhor se aproximaram dos resultados experimentais para todos os produtos analisados. Além disso, conclui que o valor de $\mathrm{K}$ varia com a relação altura-lado do silo e que durante a descarga há um acréscimo significativo do valor de $\mathrm{K}$ para produtos granulares e permanece praticamente constante para produtos coesivos.

Rotter (2001) afirma que a medida direta, por meio de testes com o produto, é a ideal, mas em casos onde não há possibilidade de realizar testes, a seguinte estimativa é válida:

$$
K=1,1\left(1-\operatorname{sen} \phi_{i}\right)
$$

A maioria das normas internacionais adota a equação 2.14 para a determinação indireta do coeficiente $\mathrm{K}$. Portanto, apesar da rugosidade e flexibilidade da parede influenciarem no valor de $\mathrm{K}$, ele é considerado constante. Esta simplificação é satisfatória desde que sejam consideradas paredes suficientemente rígidas e lisas. 


\subsection{Considerações sobre o capítulo}

Para o melhor entendimento das pressões nos silos, neste capítulo foram discutidos conceitos a respeito das propriedades físicas do produto, ou seja, o comportamento dos produtos e os fatores que interferem neste comportamento. Também foram explicados os métodos para mensurar as suas propriedades, sendo o teste de cisalhamento direto com o aparelho de Jenike o mais utilizado atualmente.

Apesar da grande aceitação e utilização do teste de cisalhamento direto, ele é limitado no sentido de não mensurar as propriedades do produto na condição dinâmica, que envolve a variação de densidade do produto, características de viscosidades, entre outros.

O conhecimento das propriedades físicas é importante também para estimar o tipo de fluxo do produto, que está relacionado com a intensidade das pressões. Além disso, o tipo de fluxo está ligado à funcionalidade da estrutura de armazenamento, que deve ser dimensionada de forma a propiciar o fluxo do produto no instante da abertura da boca de saída.

Outro ponto importante no estudo das pressões é o coeficiente $K$, que relaciona as pressões horizontais na parede com as pressões verticais no produto. O coeficiente $\mathrm{K}$ normalmente é obtido a partir do ângulo de atrito interno do produto apesar da influência de outros fatores como rugosidade, flexibilidade da parede, geometria do silo, entre outros. 



\section{PRESSÕES EXERCIDAS PELOS PRODUTOS ARMAZENADOS}

\subsection{Considerações iniciais e notações}

O projeto estrutural de um silo necessita do conhecimento da distribuição de pressões e de como esta distribuição varia durante o carregamento, armazenagem e descarga. Durante sua vida útil, um silo sofre uma série de ciclos de enchimento, armazenamento e descarga, com conseqüente variação na distribuição de pressões com o tempo.

De acordo com Calil (1990), a pressão nas paredes é função de três conjuntos de parâmetros: as propriedades do produto armazenado; as propriedades geométricas e estruturais do silo e o modo de operação. Com relação às propriedades do produto armazenado devem ser considerados:

- peso específico;

- ângulo de atrito interno;

- ângulo de atrito com a parede;

- forma, dimensão e distribuição da partícula;

- resistência elástica e cisalhante;

- coesão;

- consolidação;

- umidade;

- temperatura.

Com relação às características do silo deve-se considerar:

- altura de carga;

- seção transversal; 
- geometria de descarga;

- obstruções internas;

- rigidez na parede;

- rugosidade da parede.

Com relação ao modo de operação características do silo tem-se:

- vazão de carga;

- vazão de descarga;

- tipo de fluxo;

- carregamento;

- descarga;

- excentricidade de carregamento;

- excentricidade de descarga.

No cálculo das pressões é sempre desejável prever as piores condições de pressão que o silo estará sujeito durante sua vida útil. As condições do processo de armazenamento não conseguem ser controladas como nos ensaios de laboratório por isso a maioria das normas internacionais utiliza faixas de variação (limites superior e inferior) das propriedades do produto. Considerar os limites superior e inferior do produto é importante para que se possa encontrar as maiores solicitações sobre a estrutura. Para o cálculo da solicitação deve ser utilizado o valor apropriado das propriedades físicas de acordo com a Tabela 3.1.

Tabela 3.1 -Limite superior e inferior das propriedades físicas do produto. Fonte: AS 3774,1996.

\begin{tabular}{|c|c|c|c|}
\hline Objetivo & $\begin{array}{c}\text { Coef. de atrito na } \\
\text { parede }(\mu)\end{array}$ & $\begin{array}{c}\text { Parâmetros } \\
\text { K e K}^{\prime}\end{array}$ & $\begin{array}{c}\text { Ângulo de atrito } \\
\text { interno }\left(\phi_{i}\right)\end{array}$ \\
\hline $\begin{array}{c}\text { Máxima pressão horizontal } \\
\text { na parede vertical }\end{array}$ & Inferior & Superior & Inferior \\
\hline $\begin{array}{c}\text { Máxima pressão de atrito } \\
\text { na parede vertical }\end{array}$ & Superior & Superior & Inferior \\
\hline Máxima pressão vertical & Inferior & Inferior & Superior \\
\hline $\begin{array}{c}\text { Máxima pressão estática } \\
\text { na tremonha }\end{array}$ & $\begin{array}{c}\text { Valor superior para } \\
\text { a tremonha }\end{array}$ & Inferior & Inferior \\
\hline $\begin{array}{c}\text { Máxima pressão dinâmica } \\
\text { na tremonha }\end{array}$ & $\begin{array}{c}\text { Valor inferior para a } \\
\text { tremonha }\end{array}$ & Superior & Superior \\
\hline
\end{tabular}

É importante estabelecer uma nomenclatura única para as pressões que atuam nas paredes do silo, de acordo com sua direção de atuação, fase de 
operação do silo e local da parede em que a pressão atua. A Figura 3.1 ilustra as pressões atuantes e suas respectivas notações.
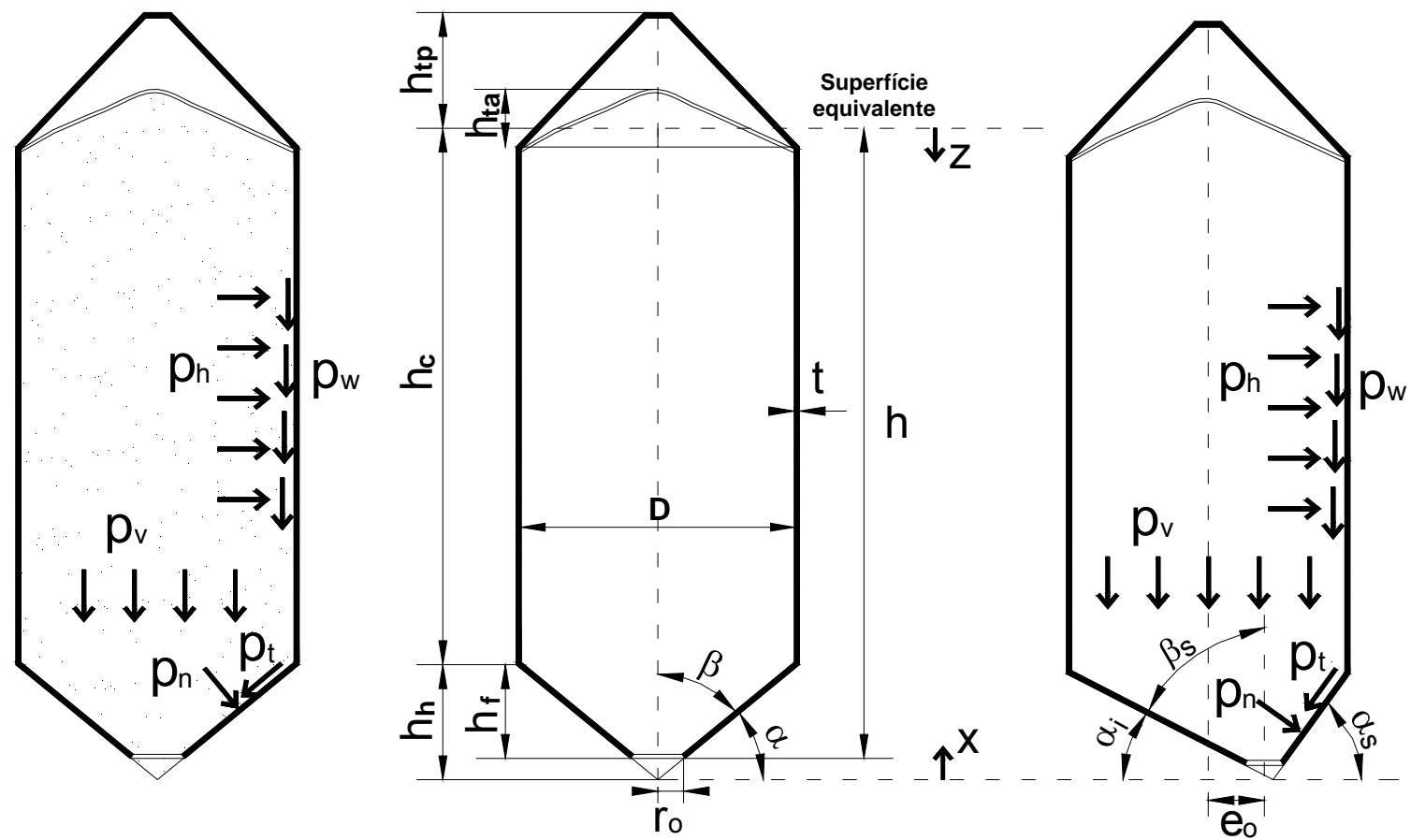

Figura 3.1 - Pressões atuantes e notações adotadas para silo com descarga concêntrica e excêntrica.

Nas paredes verticais, na parte cilíndrica do silo, atuam pressões horizontais que são normais às paredes, representadas por $p_{h}$ e pressões de atrito $p_{w}$ que são paralelas às paredes. $\mathrm{Na}$ tremonha, atuam pressões tangenciais às paredes representadas por $p_{t}$ e pressões normais, $p_{n}$. $\mathrm{Na}$ base ou fundo, atuam pressões verticais, representadas por $p_{v}$, que são provenientes do peso das camadas superpostas do produto armazenado.

A pressão de atrito é distribuída na superfície interna das paredes e equilibra parte do peso do produto, resultando em esforços de compressão na parede do silo. A presença da pressão de atrito faz com que a pressão horizontal nas paredes não aumente linearmente com a profundidade do silo como as pressões hidrostáticas.

As pressões nas paredes do silo durante o armazenamento do produto em repouso recebem as seguintes denominações: estática, inicial, em repouso, de carregamento ou ainda, pressões ativas e apresentam o sub índice "f". A justificativa do emprego da letra "f" é que ela é a inicial da palavra "filling" que significa carregamento em inglês. Portanto, $p_{\mathrm{hf}}, p_{\mathrm{vf}}$ e $\mathrm{p}_{\mathrm{wf}}$ são as pressões horizontais, verticais 
e de atrito, respectivamente, que atuam nas paredes do silo quando este se encontra completamente cheio e com o produto armazenado em repouso.

Quando o produto está armazenado em repouso no interior do silo atua o campo de tensões iniciais que difere significativamente da condição de descarregamento no qual atua o campo de tensões dinâmicas. A diferença no campo de tensão entre a situação de carregamento e descarga, acarreta um aumento considerável nas pressões que atuam nas paredes do silo, podendo aparecer picos de pressões quando a situação de fluxo é obtida.

Tradicionalmente, o aumento das pressões foi atribuído à mudança do estado de equilíbrio do produto armazenado, que se encontra no estado ativo de equilíbrio durante o armazenamento em repouso e passa para o estado passivo quando os produtos iniciam seu movimento (Jenike \& Johanson, 1968).

O aparecimento das sobrepressões também está relacionado ao tipo de fluxo que o produto desenvolve durante a descarga. Jenike \& Johanson (1968) demonstraram que em silos com fluxo de massa o pico de pressões aparece na transição entre a parede cilíndrica e a tremonha, enquanto que em silos com fluxo de funil o pico se localiza no local onde o fluxo intercepta a parede, sem variação de pressões abaixo deste ponto dado que uma parte do produto permanece em repouso.

Mais recentemente, esta sobrepressão tem sido atribuída ao fenômeno da dilatância dado que os grãos não se deslocam paralelos à linha de ruptura, ocorrendo uma dilatação volumétrica do produto e consequentemente um aumento das pressões laterais (Zhang et al.,1994).

As pressões nas paredes do silo durante o descarregamento (condição dinâmica) do produto recebem o sub índice "e", proveniente de "empyting" cuja tradução é descarregamento.

Dado as diferentes direções de atuação das pressões, as diferentes fases de operação do silo (carregamento ou descarga) e a geometria do silo, existem várias formas de considerar as pressões na estrutura do silo:

- pressões estáticas na parede cilíndrica ou corpo do silo ( $p_{h f}, p_{v f}$ e $\left.p_{w f}\right)$;

- pressões dinâmicas na parede cilíndrica ou corpo do silo ( $p_{h e}, p_{v e}$ e $\left.p_{w e}\right)$;

- pressões verticais estáticas na transição ( $\left.p_{\text {vft }}\right)$;

- pressões estáticas na tremonha $\left(p_{n f}\right.$ e $\left.p_{t f}\right)$; 
- pressões dinâmicas na tremonha $\left(p_{n e}, p_{t e}\right)$.

Os estudos e teorias desenvolvidos no intuito de quantificar estas pressões serão expostos no decorrer deste capítulo.

\subsection{Histórico}

Por volta de 1870 e 1880, os calculistas acreditavam que os produtos armazenados se comportavam como líquidos, projetando as estruturas para pressões equivalentes aos líquidos. Roberts (1884) observou que as pressões nas paredes não aumentavam linearmente com a profundidade a partir de ensaios em silos de escala reduzida munidos de uma balança em suas bases. As medidas indicadas na balança mostraram que as pressões na base paravam de aumentar à medida que a altura do material armazenado excedia duas vezes a largura do silo. Roberts concluiu que uma parcela do peso do produto era transferida para as paredes por atrito e estabeleceu uma teoria simplificada para quantificar este fenômeno.

Janssen (1895) propôs uma teoria para o cálculo das pressões a partir do equilíbrio de forças atuantes em uma camada elementar da massa ensilada de espessura infinitesimal. Sua teoria mudou o conceito de cálculo de pressões em silos, sendo até hoje utilizada pelas principais normas internacionais para o cálculo das pressões de carregamento, quando o silo se encontra com o produto armazenado em repouso dado que na época em que Janssen formulou sua teoria, não era de conhecimento dos pesquisadores que as pressões durante a descarga eram diferentes da condição estática.

Em 1904, Jamielson no Canadá realizou ensaios em silos reais de madeira e seus resultados concordaram com a teoria de Janssen para as pressões horizontais. Jamielson não obteve sobrepressões nas paredes durante a descarga, pois o dispositivo utilizado pelo pesquisador para medir a pressão na parede do silo estava localizado em um local onde o produto permanecia estacionado, decorrente do desencadeamento de fluxo de funil. Jamielson também realizou experimentos em silos com descarga excêntrica e encontrou sobrepressões na parede oposta à boca de saída e depressões na parede próxima à saída.

A teoria de Janssen serviu de base para muitos projetos de silos até a década de 1930. A partir deste período, constatou-se um grande número de falhas em silos 
projetados de acordo com a teoria de Janssen, colocando em dúvida a validade da mesma. Foi então que pesquisadores de vários países começaram novos estudos em modelos reduzidos e em silos em escala real, obtendo pressões de descarga de 2 a 3 vezes superiores às previstas pela teoria de Janssen.

Com a descoberta de que as pressões durante o fluxo diferem das pressões estáticas, vários estudos experimentais foram feitos com o intuito de mensurar em que proporção as pressões de descarga excediam as pressões iniciais. Na década de 50 o investigador russo Petrov (1958) utilizou silos industriais em operação com fundo plano construídos em concreto armado para o armazenamento de cimento. Um deles com diâmetro interior de 8,1 m, altura de 16,9 m e espessura da parede de $18 \mathrm{~cm}$. O segundo com diâmetro interior de $10 \mathrm{~m}$, altura de $25 \mathrm{~m}$ e espessura da parede de $20 \mathrm{~cm}$. As medições foram feitas por meio de extensômetros localizados em diferentes alturas ao longo da parede do silo. Petrov observou que na zona de maior profundidade dos silos, as pressões estáticas eram superiores às previstas pela teoria de Janssen, com uma variação entre 1,4 e 1,6. Durante a descarga, as pressões registradas eram ainda maiores, variando entre 1,5 a 2,2 vezes as pressões obtidas com o método de Janssen.

No mesmo ano, Petrov e Kovtum (1959, apud GALLEGO, 2006) apresentaram um extenso trabalho onde foram ensaiados três silos cilíndricos de concreto com fundo plano cujas dimensões estão especificadas na Tabela 3.2 empregados para o armazenamento de trigo.

Tabela 3.2 - Características dos silos de concreto ensaiados por Petrov e Kovtum (1959).

\begin{tabular}{|c|c|c|c|}
\hline Silo & Diâmetro $(\mathbf{m})$ & Altura $(\mathbf{m})$ & Parede \\
\hline 1 & 3,7 & 22 & Lisa \\
\hline 2 & 5 & 17,5 & Lisa \\
\hline 3 & 6 & 40 & Corrugada \\
\hline
\end{tabular}

Na Figura 3.2 observa-se que as pressões obtidas para o carregamento eram próximas das deduzidas pela equação de Janssen enquanto que na descarga apareceram sobrepressões em todos os silos ensaiados. 


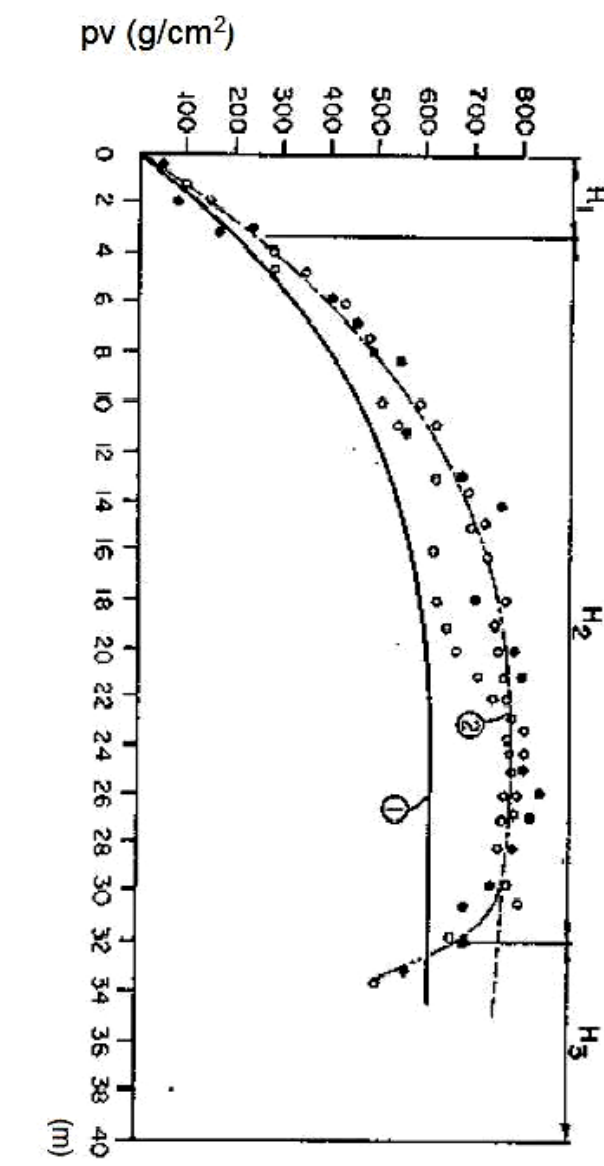

ph $\left(\mathrm{g} / \mathrm{cm}^{2}\right)$

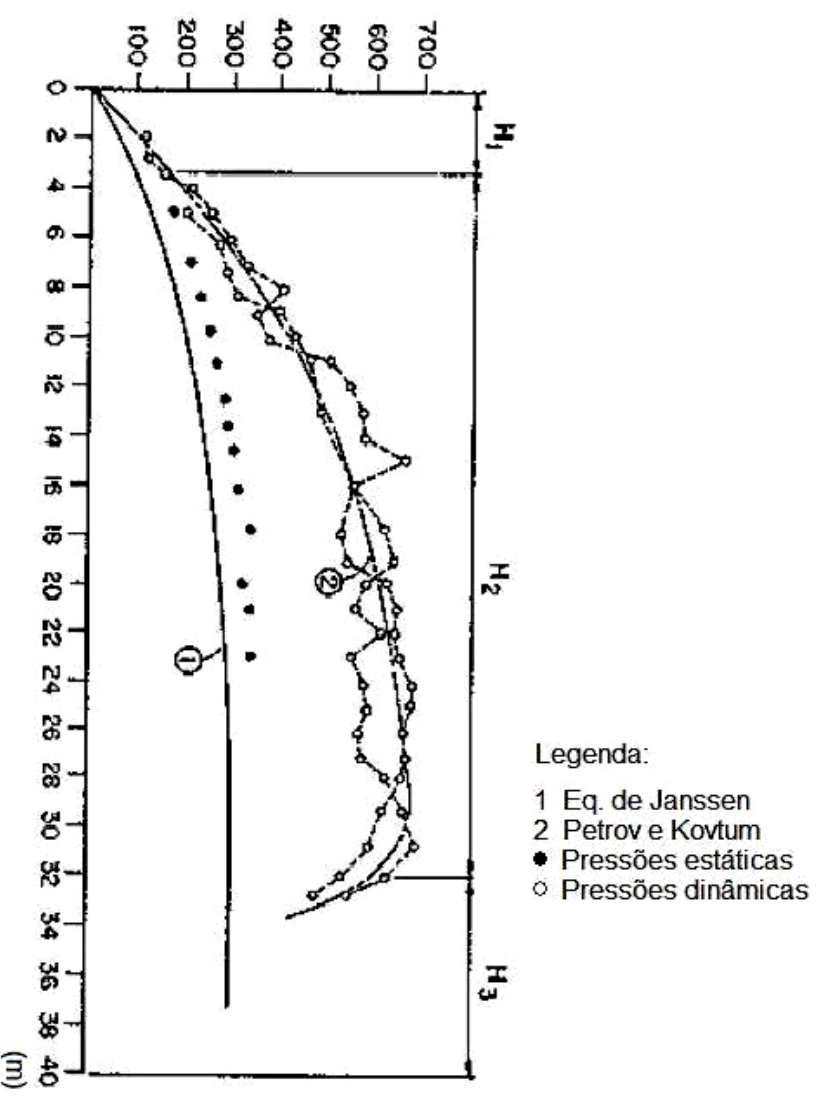

Figura 3.2 - Pressões verticais e horizontais registradas no silo 2 por Petrov e Kovtum (1959). Fonte: Gallego (2006).

Paralelamente ao estudo das pressões, na década de 50 também aconteceu um grande avanço da pesquisa na área de armazenamento de produtos em silos com os pesquisadores Jenike e Johanson, que em conjunto publicaram três boletins técnicos, considerados como fundamento da teoria moderna de produtos armazenados e fluxo. Segundo Roberts (1998), os resultados mais importantes obtidos por Jenike e Johanson foram:

- estabelecimento dos dois tipos principais de fluxo (fluxo de massa e fluxo de funil);

- teoria das pressões radiais descritas para silos com tremonhas com fluxo de massa e definição do limite para o fluxo de massa;

- critério de fluxo e não fluxo;

- desenvolvimento da célula de cisalhamento direto para a determinação das propriedades dos produtos armazenados.

A descarga excêntrica foi estudada pelos pesquisadores: Pieper e Wagner (1969), Ravenet (1977) e Rong (1994) que confirmaram que a distribuição e 
magnitude das pressões sofrem alterações significativas quando o silo possui descarga excêntrica. Pieper e Wagner (1969) realizaram uma série de ensaios em silos com diferentes excentricidades de saída com areia, trigo e arroz. Para o trigo e a areia, pressões laterais máximas apareciam na parede próxima à saída excêntrica e não na parede oposta (Figura 3.3) ao contrário do que acontecia com o arroz (Figura 3.4). Anos mais tarde se comprovou que as pressões laterais máximas ocorrem na parede oposta à saída excêntrica, concordando com as curvas de pressões obtidas por eles com o arroz.
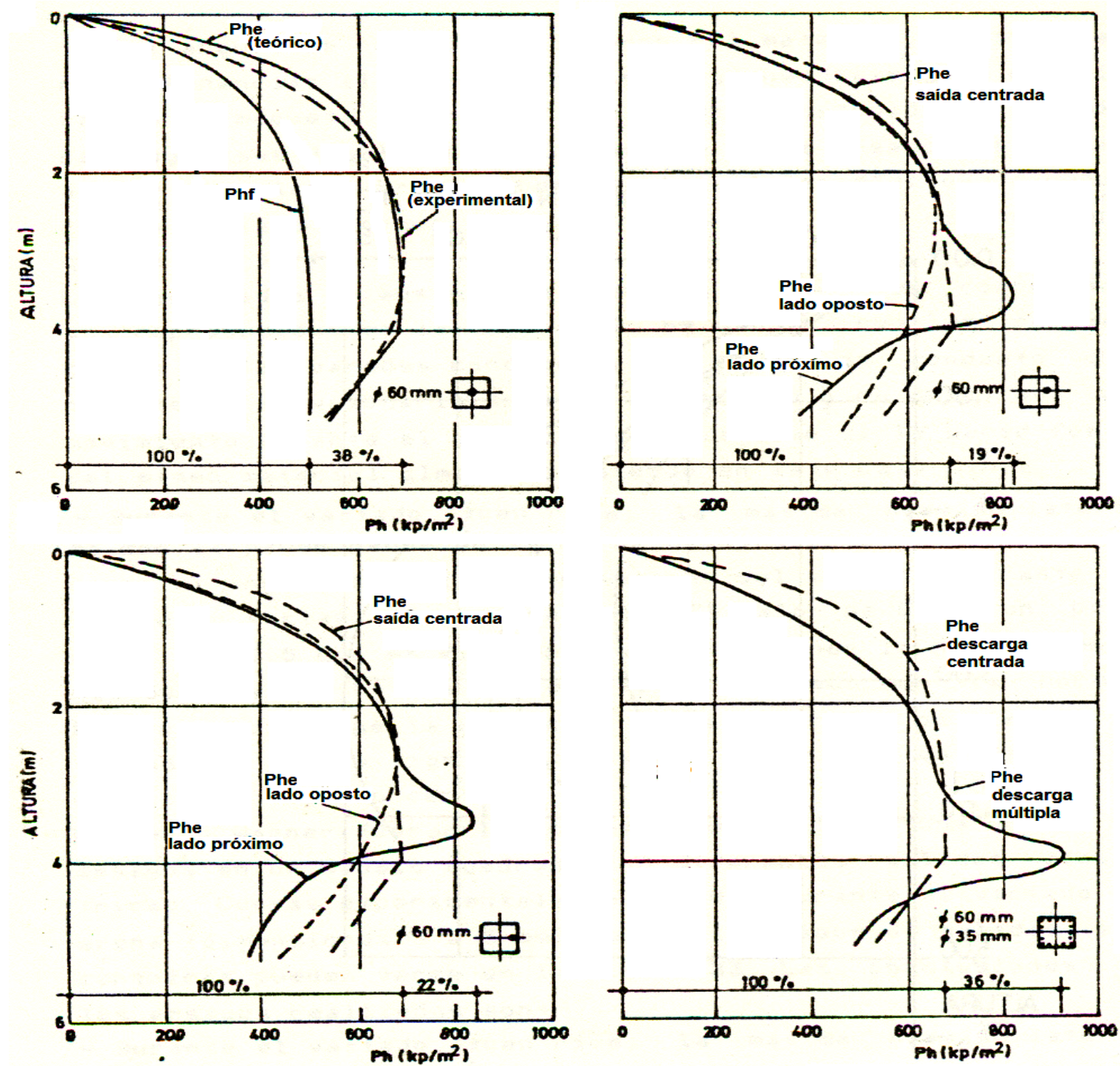

Figura 3.3 - Resultados dos ensaios com descarga excêntrica feitos por Pieper e Wagner para a areia. Fonte: Calil (1984). 

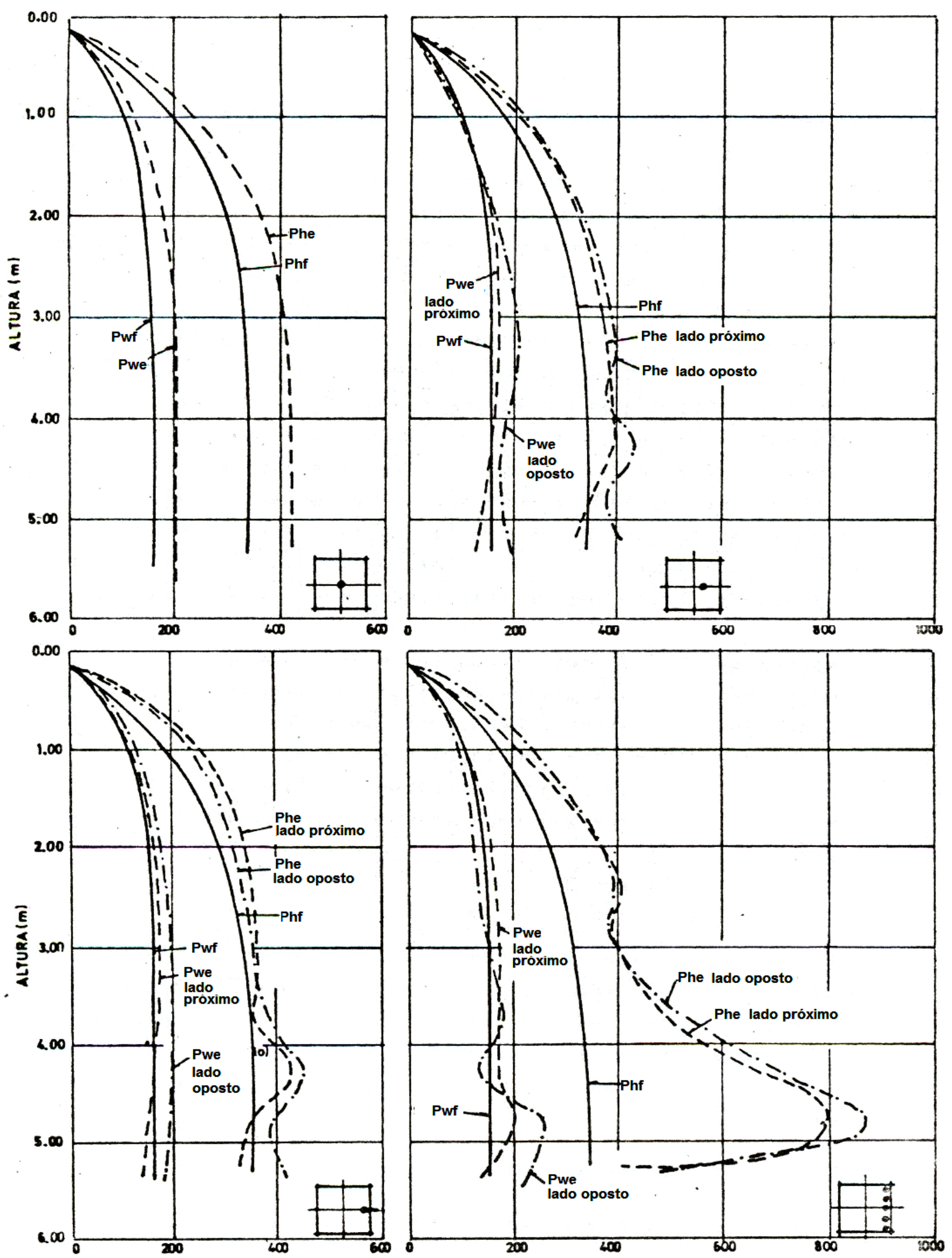

Figura 3.4 - Resultados dos ensaios com descarga excêntrica feitos por Pieper e Wagner para o arroz. Fonte: Calil (1984). 
Baseado nos experimentos de Pieper e Wagner, Safarian (1969) propôs uma metodologia de cálculo das pressões em silos com descarga excêntrica. Sua teoria será detalhada mais adiante.

$\mathrm{Na}$ década de setenta, importantes investigações em modelos reduzidos foram feitas por Ravenet (1974), Ravenet (1977) e Nielsen (1977). Na década de 80, muitos experimentos importantes foram realizados com silos reais por MunchAndersen e Nielsen (1986), Enstad (1983); Rotter et al. (1989).

Kmita (1985, apud GALLEGO, 2006) realizou ensaios em um silo modelo retangular e propôs a teoria de que as sobrepressões produzidas durante a descarga do silo eram decorrentes da formação de um sistema de vibração autoinduzido pelo próprio material em movimento. Na tremonha este fenômeno é ainda mais acentuado devido ao atrito do material com a parede.

Zhang et al. (1993), baseando-se na idéia de Smith e Lohnes (1983), relatou que o ângulo de dilatância do produto durante o seu deslocamento vertical é o principal fator que gera o aparecimento de sobrepressões e desenvolveu uma teoria completa sobre este assunto.

Durante os anos 90 , os testes experimentais foram conduzidos no intuito de comparar os valores experimentais das pressões com aqueles obtidos pela aplicação dos métodos numéricos, linha de pesquisa que evoluiu rapidamente graças ao desenvolvimento da computação e elaboração de programas comerciais com o emprego do método dos elementos finitos (MEF).

Vários autores desenvolveram métodos teóricos para o cálculo das pressões baseando-se nos resultados experimentais obtidos ao longo dos anos. A seguir serão apresentadas as principais teorias desenvolvidas.

\subsection{Teoria de Janssen (1895)}

A teoria de Janssen foi proposta em 1895 e é a mais utilizada atualmente para o cálculo das pressões no corpo dos silos. Janssen desenvolveu sua teoria considerando o equilíbrio de forças de uma camada elementar do produto em repouso, conforme a Figura 3.5. Algumas simplificações e hipóteses da teoria de Janssen são:

- equilíbrio estático vertical;

- pressões horizontais e verticais constantes no plano horizontal, ou seja, K 
constante;

- ângulo de atrito do produto com a parede constante ao longo da seção transversal e da altura do silo;

- peso específico do produto uniforme;

- paredes do silo totalmente rígidas.

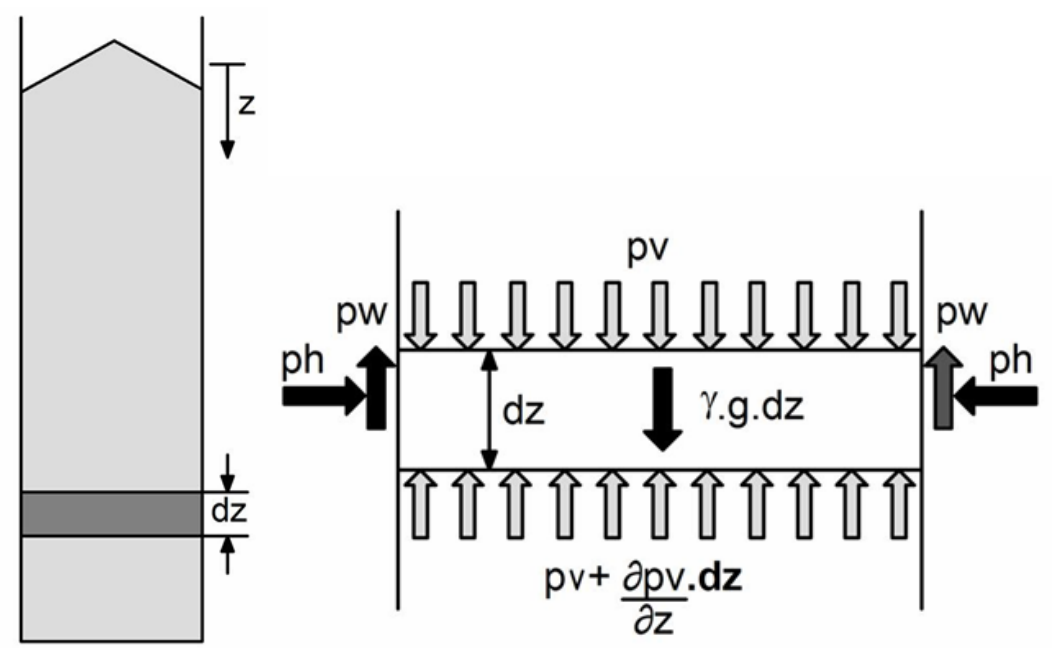

Figura 3.5 - Forças na camada elementar de altura dz adotada por Janssen (1895).

O equilíbrio das forças verticais atuantes na camada elementar da Figura 3.5, de altura $\mathrm{dz}$ e peso específico $\gamma$ resulta em:

$$
p_{h f} \cdot \mu_{w} \cdot d z \cdot U+\left(p_{v f}+p d_{v f}-p_{v f}\right) \cdot A-\gamma \cdot A \cdot d z=0
$$

A partir da substituição de $\mathrm{K} . \mathrm{dp}_{\mathrm{vf}}=\mathrm{dp} \mathrm{p}_{\mathrm{hf}}$, do rearranjo dos termos e da aplicação da condição de contorno $p_{v f}(0)=0$, obtêm-se:

$$
p_{h f}(z)=\frac{\gamma}{\mu_{w}} \cdot \frac{A}{U} \cdot\left(1-e^{-z \cdot K \cdot \mu_{w} \cdot \frac{U}{A}}\right)
$$

A equação 3.02 é conhecida como equação de Janssen. Ela fornece o valor da pressão horizontal estática após o enchimento do silo. Como $K \cdot \mathrm{dp}_{\mathrm{vf}}=\mathrm{dp}_{\mathrm{hf}}$, a pressão vertical estática após o enchimento do silo pode ser obtida por meio de 3.02, com a seguinte equação:

$$
p_{v f}(z)=\frac{\gamma}{K \cdot \mu_{w}} \cdot \frac{A}{U} \cdot\left(1-e^{-z \cdot K \cdot \mu_{w} \cdot \frac{U}{A}}\right)
$$

como a pressão de atrito nas paredes obedece a relação:

$$
p_{w f}(z)=\mu_{w} \cdot p_{h f}(z)
$$

tem-se: 


$$
p_{w f}(z)=\gamma \cdot \frac{A}{U} \cdot\left(1-e^{-z \cdot K \cdot \mu_{w} \cdot \frac{U}{A}}\right)
$$

A pressão de atrito na parede ( $p_{\mathrm{wf}}$ ) causa esforço de compressão na parede que é distribuída na superfície interior das paredes e equilibra parte do peso do produto. A existência do atrito faz com que as pressões horizontais que o produto exerce nas paredes não aumentem linearmente com a altura como as pressões hidrostáticas, mas apresentem um crescimento que tende a um valor máximo exponencial.

A força de compressão resultante sobre a parede $p_{w f}(z)$ por unidade de perímetro é obtida pela integração de $\mathrm{p}_{\mathrm{wf}}(\mathrm{z})$ ao longo da altura do silo:

$$
P_{w f}(z)=\mu_{w} \cdot \int_{0}^{h} p_{w f}(z) \cdot d z=\frac{A}{U} \cdot\left(\gamma \cdot z-p_{v f}\right)
$$

Uma das principais dificuldades do método proposto por Janssen foi a escolha de um valor apropriado para a relação entre as tensões horizontais e verticais, ou seja, o valor do parâmetro K. Janssen adotou a formulação proposta por Koenen (1895), a equação 2.07.

De acordo com Rotter (2001), os valores das pressões após o enchimento do silo são muito próximos dos valores obtidos pela teoria de Janssen, desde que considerados os parâmetros apropriados dos produtos.

A maioria das normas internacionais utiliza a teoria de Janssen também para a predição das pressões de descarregamento do silo, multiplicando as pressões estáticas por coeficientes de sobrepressão.

\subsection{Teoria de Jenike et al. (1973)}

Jenike e Johanson realizaram numerosos trabalhos na década de 1960: Jenike (1964), Jenike e Johanson (1968) e Jenike e Johanson (1969). Jenike e Johanson foram os primeiros pesquisadores que apresentaram uma teoria para explicar o efeito das sobrepressões que surgem no instante da descarga do silo baseando-se na teoria do balanço de energia. Os autores explicam que quando o silo está sendo carregado, o produto se comprime verticalmente sem deformação horizontal, desenvolvendo um campo ativo de tensões, com a maior tensão principal 
$\left(\sigma_{1}\right)$ atuando na direção vertical ao longo do eixo do silo, aproximando-se da horizontal próximo das paredes, como ilustra a Figura 3.6 (a).

Durante o armazenamento, observa-se que as pressões no corpo do silo aumentam com a profundidade de acordo com as expresssões de Janssen, apresentando uma descontinuidade na transição entre o corpo e a tremonha. As pressões na tremonha dependem principalmente da sua inclinação.

A abertura da boca de saída provoca uma mudança no estado de equilíbrio do produto, inicialmente na tremonha, dando início ao estado passivo de tensões caracterizado pelo alívio das pressões verticais no fundo do silo. Caso o produto se descarregue em fluxo de massa, toda a massa do produto se encontra em movimento descendente e durante este movimento o produto é comprimido lateralmente ao passar pelas paredes convergentes da tremonha enquanto as tensões verticais são reduzidas devido ao fluxo do produto. Isto caracteriza o estado passivo.

A Figura 3.6 (b) ilustra a direção das tensões principais no início da descarga, com o estado passivo atuando somente na parte inferior da tremonha, enquanto que na Figura 3.6 (c) pode ser observado o momento em que o estado passivo passa a atuar em toda a tremonha. Na parte vertical cilíndrica do silo o estado de tensão continua inalterado (estado ativo). Caso a descarga seja interrompida, o estado passivo permanece.

Em silos com fluxo de massa, a transição do estado ativo para o estado passivo ocorre na altura da transição, gerando um pico de pressões neste local, denominado "switch". Em silos com fluxo de funil, o produto flui formando um canal no interior do silo, com zonas do produto estático adjacente à parede da tremonha. No local onde o canal de fluxo intercepta a parede, ocorrerá um pico de pressões (switch), conforme a Figura 3.6 (d). A posição deste pico não pode ser prevista com exatidão pois depende das propriedades físicas dos produtos. Portanto, toda a parede vertical deve ser dimensionada para resistir este pico. 


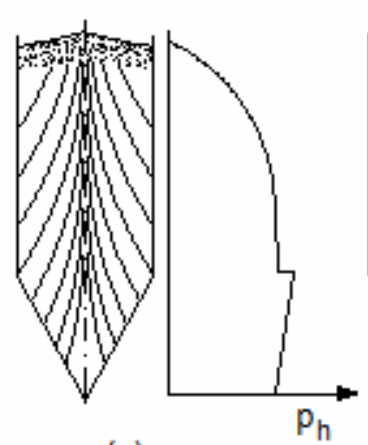

(a)

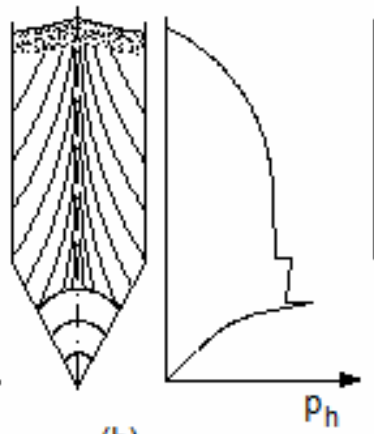

(b)

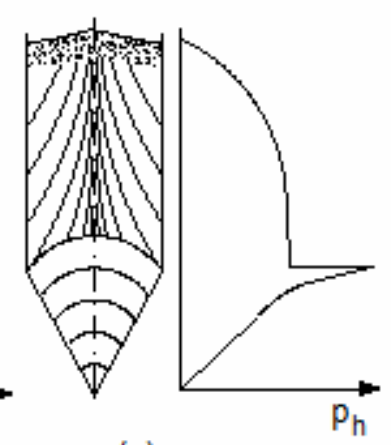

(c)

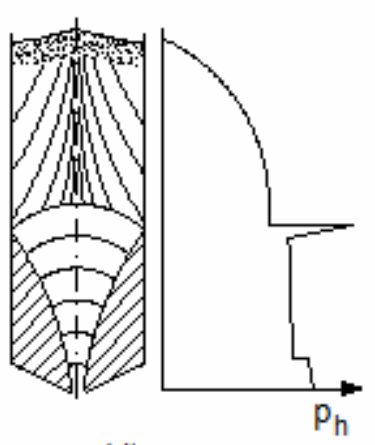

(d)

Figura 3.6 - Evolução das pressões horizontais de acordo com o estado de tensão atuante no silo.

A Figura 3.7 (a) mostra a intensidade da pressão vertical no produto durante o estado ativo e a Figura 3.7 (b) durante o estado passivo em um silo com fluxo de massa. A Figura 3.7 (a) corresponde à Figura 3.6 (a) e a Figura 3.7 (b) corresponde à Figura 3.6 (c). No corpo do silo, a pressão vertical e a pressão horizontal evoluem de forma equivalente, enquanto que na tremonha as pressões dependem da tensão vertical na transição, das características do produto armazenado e da inclinação das paredes da tremonha. Portanto a curva ilustrada na Figura 3.7 (a) pode ser uma possível trajetória para as pressões verticais.

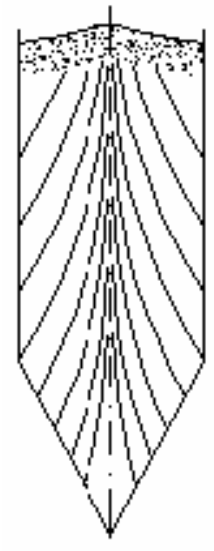

(a)

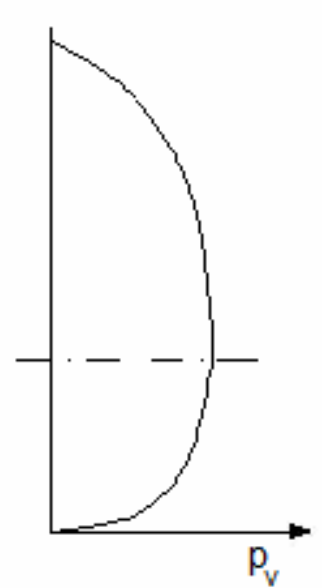

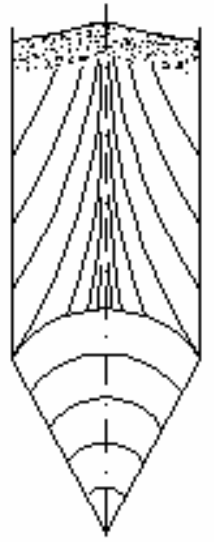

(b)

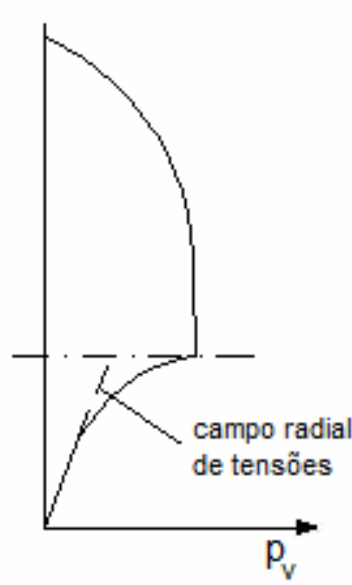
(a) e na descarga (b) para silo com fluxo de massa.

Durante o descarregamento do silo, Jenike e Johanson (1968) mostraram que as pressões verticais na tremonha no estado passivo diminuem bruscamente no início da descarga, principalmente na parte inferior da tremonha, numa razão linear e cai para zero. Esta redução é proporcional ao raio local da tremonha e por isso a 
distribuição de pressões na tremonha recebe o nome de distribuição radial de pressões, conforme pode ser observado na Figura 3.7 (b)

A localização do pico de pressão na mudança do estado ativo para o estado passivo é de difícil determinação. Ele pode ocorrer na parede vertical, mesmo em silos com fluxo de massa, devido a pequenas imperfeições na parede. Segundo Jenike (1973) o canal de fluxo em silos com relação H/D inferior a dois e com fundo plano, raramente intercepta a parede e caso interceptasse, ele seria insignificante. Portanto, nesse caso específico, a estrutura do silo pode ser projetada considerando o silo com fluxo de massa, com a teoria de Janssen para a predição das pressões.

\subsubsection{Silos com fluxo de massa}

\subsubsection{Pressões estáticas}

No caso estático, Jenike et al. (1973) mostraram por meio de experimentos, que a formulação proposta por Janssen fornece bons resultados para as pressões no corpo do silo quando comparados aos resultados da teoria do balanço de energia. Portanto, recomendam que no caso estático as pressões no corpo do silo sejam determinadas pela teoria de Janssen com K=0,4. Na tremonha Jenike (1977) recomenda as expressões de Walker (1966) para a determinação das pressões estáticas.

\subsubsection{Pressões dinâmicas}

No caso dinâmico, Jenike et al. (1973) recomendam que as pressões sejam calculadas considerando a segunda lei da termodinâmica, baseada no princípio de que a energia interna de um sistema tende a ser minimizada. Dado a complexidade de obtenção das pressões a partir deste método, em Jenike et al. (1973) são apresentados gráficos para a determinação das envoltórias da pressão horizontal sob condições de fluxo. Porém, de acordo com Palma (2005) este procedimento proposto causa dificuldades para os projetistas na maioria das situações práticas porque os gráficos não cobrem algumas formas geométricas.

Partindo do princípio da energia de deformação, a pressão horizontal dinâmica em silos com fluxo de massa é dada por:

$$
p_{h e}(z)=\left(\frac{\gamma \cdot R}{\mu_{\text {eff }}}\right) \cdot\left(1-(\partial-\omega) \cdot \frac{\mu_{\text {eff }}}{M^{m_{c}}}\right)
$$


Onde $\partial$ e $\omega$ são dados por:

$$
\begin{aligned}
& \partial=\frac{-\left(K \cdot M^{m_{c}}-1\right) \cdot\left(S_{0}-N\right) \cdot e^{-j}+M^{m_{c}} \cdot\left(\mu_{e f f}^{-1}-K \cdot N\right)}{\left(K_{h} \cdot M^{m_{c}}+1\right) \cdot e^{j}-\left(K_{h} \cdot M^{m_{c}}-1\right) \cdot e^{-j}} \\
& \omega=S_{0}-N-\partial
\end{aligned}
$$

Sendo $j$ e $S_{0}$ :

$$
\begin{gathered}
j=\frac{\mu_{\text {eff }}}{M^{m_{c}} \cdot R}(H-z) \\
S_{0}=\frac{1}{\mu_{e f f} \cdot K} \cdot\left(1-e^{-\frac{\mu_{\text {eff }} \cdot K \cdot z}{R}}\right)
\end{gathered}
$$

M e N são constantes dadas por:

$$
\begin{aligned}
& M=\sqrt{2 .(1-v)} \\
& N=\frac{2 \cdot v}{\mu_{\text {eff }} \cdot M^{2 .\left(1-m_{c}\right)}}
\end{aligned}
$$

Com

$m_{c}=0$ para fluxo axissimétrico

$m_{c}=1$ para fluxo plano

\subsubsection{Silos com fluxo de funil}

\subsubsection{Pressões estáticas}

Assim como no cálculo dos silos com fluxo de massa, as pressões estáticas no corpo do silo são calculadas teoria de Janssen e na tremonha com as expressões de Walker (1966).

\subsubsection{Pressões dinâmicas}

De acordo com a teoria de Jenike et al. (1973) o ângulo que o canal de fluxo forma com o eixo vertical, ilustrado na Figura 3.8, influencia na intensidade do pico das pressões. 


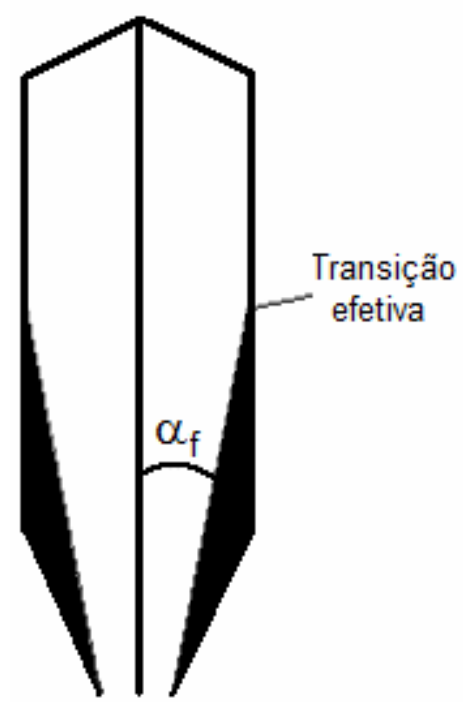

Figura 3.8 - Indicação do ângulo formado entre o canal de fluxo com a vertical, num silo com fluxo de funil

O dimensionamento dos silos com fluxo de funil, de acordo com a teoria de Jenike et al. (1973), consiste em calcular os picos de pressões para vários valores de z com a finalidade de construir uma envoltória de pressões. A intensidade dos picos de pressão é dada por:

$$
p_{h e}(z)=\lambda \cdot p_{v e}(z)
$$

Sendo:

$\mathrm{p}_{\mathrm{ve}}(\mathrm{z})=$ pressão vertical dinâmica calculada com a teoria de Janssen com $K=0,4$;

$\lambda$ para tremonhas de eixo simétrico dado por:

$$
\lambda=\frac{\left(24 \cdot \operatorname{tg}\left(\alpha_{f}\right)+\frac{\pi}{q}\right) \cdot\left(1-\operatorname{sen} \phi_{e} \cdot \operatorname{tg}\left(\alpha_{f}\right)\right)}{16 \cdot\left(\operatorname{sen} \phi_{e}+\operatorname{tg}\left(\alpha_{f}\right)\right)}
$$

Com:

$$
\begin{aligned}
& q=\frac{\pi}{24 \cdot \operatorname{sen}\left(\alpha_{f}\right)}\left[\frac{2 \cdot Y}{(X-1) \cdot \operatorname{sen}\left(\alpha_{f}\right)}\left(\operatorname{tg}\left(\alpha_{f}\right)+\operatorname{sen} \phi_{e}\right)-1\right] \\
& X=\frac{2^{m} \operatorname{sen} \phi_{e}}{1-\operatorname{sen} \phi_{e}} \cdot\left[\frac{\operatorname{sen}\left(2 \beta+\alpha_{f}\right)}{\operatorname{sen}\left(\alpha_{f}\right)}+1\right] \\
& Y=\frac{\left(2-2 \cos \left(\beta+\alpha_{f}\right)\right)^{m}\left(\beta+\alpha_{f}\right)^{1-m} \operatorname{sen}\left(\alpha_{f}\right)+\operatorname{sen}(\beta) \cdot \operatorname{sen}^{1+m}\left(\beta+\alpha_{f}\right)}{\left(1-\operatorname{sen} \phi_{e}\right) \cdot \operatorname{sen}^{2+m}\left(\beta+\alpha_{f}\right)}
\end{aligned}
$$




$$
\beta=\frac{1}{2} \cdot\left[\phi_{w}+\operatorname{sen}^{-1}\left(\frac{\operatorname{sen} \phi_{w}}{\operatorname{sen} \phi_{e}}\right)\right]
$$

Jenike (1973) considera que em silos com fluxo de funil, o campo de pressões no corpo do silo se estende até a tremonha, portanto:

$$
\begin{aligned}
& p_{n e}(z)=p_{h e}\left(h_{c}\right) \cdot\left[\left(\frac{\operatorname{sen}^{2}(\alpha)}{K}+\cos ^{2}(\alpha)\right)+\left(\frac{2 r}{D} \mu_{w} \cdot \operatorname{sen}(\alpha) \cdot \cos (\alpha)\right)\right] \\
& p_{t e}=p_{h e .}\left(h_{c}\right) \cdot\left[\left(\frac{1}{K}-1\right) \cdot \operatorname{sen}(\alpha) \cdot \cos (\alpha)+\frac{2 r}{D} \cdot \mu_{w} \cdot\left(\cos ^{2}(\alpha)-\frac{\operatorname{sen}^{2}(\alpha)}{K}\right)\right]
\end{aligned}
$$

Onde:

$r=$ coordenada radial;

$\mathrm{p}_{\mathrm{he}}=$ pressão horizontal dinâmica de Janssen para $\mathrm{z}=\mathrm{h}_{\mathrm{c}}$.

\subsection{Teoria de Walker (1966)}

A maior contribuição de Walker foi desenvolver uma teoria para a predição de pressões na tremonha durante o fluxo, indicando também fatores críticos para garantir um fluxo por gravidade contínuo. Segundo Gomes (2000), a teoria de Walker (1966) é bastante precisa para os cálculos no estado estático e dinâmico nas paredes da tremonha.

Considerando o equilíbrio de forças verticais numa camada horizontal de produto a uma distância x acima do vértice (ápice) da tremonha (Figura 3.9) e assumindo que a pressão vertical seja uniformemente distribuída, Walker estabeleceu a seguinte equação para o cálculo das pressões verticais de descarga na tremonha:

$$
\begin{aligned}
& p_{v}=\left(\frac{h_{h}}{n-1}\right)\left\{\left(\frac{x}{h_{h}}\right)-\left(\frac{x}{h_{h}}\right)^{n}\right\}+p_{v f t}\left(\frac{x}{h_{h}}\right)^{n} \\
& p_{v f t}=\text { pressão vertical na transição } \\
& n=S .\left(F \cdot \mu_{h e f f} \cdot \cot (\beta)+F-1\right) \\
& \mathrm{S}=1 \text { para tremonhas em cunha; } \\
& \mathrm{S}=2 \text { para tremonhas cônicas ou piramidais; }
\end{aligned}
$$


$\mathrm{F}=$ razão entre a pressão normal na parede da tremonha e a tensão vertical principal no produto dentro da tremonha.

As pressões estáticas são obtidas a partir da equação 3.22, por:

$$
\begin{aligned}
& p_{n f}=F_{f} \cdot p_{v} \\
& p_{t f}=\mu_{h e f f} \cdot p_{n f}
\end{aligned}
$$

substituindo $F$ na equação 3.22 por $F_{f}$, sendo:

$$
F_{f}=\frac{\operatorname{tg}(\beta)}{\operatorname{tg}(\beta)+\mu_{\text {heff }}}
$$

No estado dinâmico esta teoria se baseia nas seguintes hipóteses:

- as direções das tensões principais maior e menor estão no plano vertical próximo à seção da parede e estas definem o escorregamento do produto, independente da terceira tensão principal, perpendicular a este plano;

- o produto deve escorregar e ser capaz de deslocar independentemente das variações transversais da tremonha;

- o produto é de fluxo livre e, para fins de projeto, o silo é dimensionado para fluxo de massa;

- supõe-se que as pressões verticais sobre o mesmo plano horizontal são constantes.

As pressões dinâmicas são obtidas a partir da equação 3.22 por:

$$
\begin{aligned}
& p_{n e}=F_{e} \cdot p_{v} \\
& p_{t e}=\mu_{\text {heff }} \cdot p_{n e}
\end{aligned}
$$

substituindo $F$ na equação 3.22 por $F_{e}$, sendo:

$$
F_{e}=\frac{1+\operatorname{sen} \phi_{e} \cdot \cos \left(2 \cdot \varepsilon_{2}\right)}{1-\operatorname{sen} \phi_{e} \cdot \cos \left(2 \cdot\left(\beta+\varepsilon_{2}\right)\right)}
$$

Com

$$
\varepsilon_{2}=\frac{1}{2}\left(\phi_{w}+\operatorname{sen}^{-1}\left(\frac{\operatorname{sen} \phi_{w}}{\operatorname{sen} \phi_{e}}\right)\right)
$$




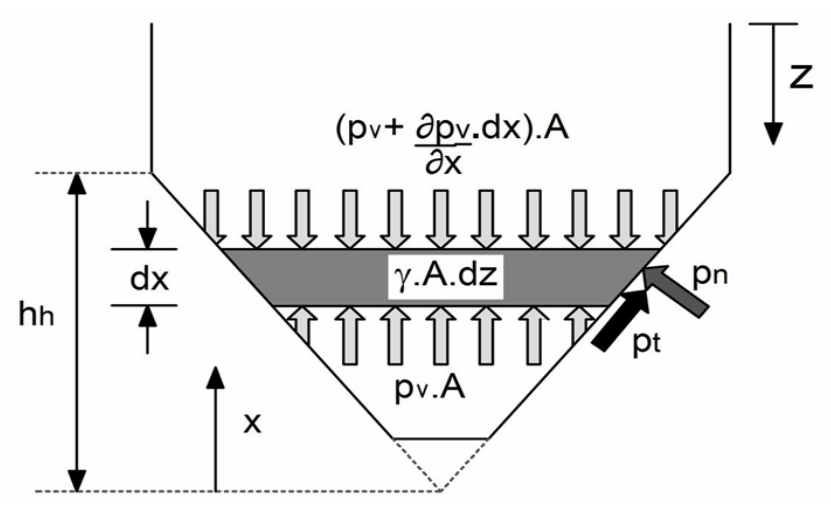

Figura 3.9 - Forças numa faixa elementar da tremonha (Walker, 1966).

\subsection{Teoria de Safarian (1969)}

Safarian (1969) se baseou nos resultados experimentais de Pieper e Wagner (1969) para propor um método de cálculo das pressões em silos com descarga excêntrica. Para silos circulares, Safarian propõe que as pressões de descarga sejam calculadas inicialmente com fórmula de Janssen (equação 3.6) multiplicada por um coeficiente de sobrepressão. O resultado obtido é, então, majorado no lado oposto à excentricidade e reduzido no lado próximo (Figura 3.10).

$\mathrm{O}$ aumento ou redução depende das pressões horizontais considerando um raio imaginário da seção transversal $\left(r_{i}\right)$ cujo centro coincide com o centro da boca de saída. A sobrepressão devida à descarga excêntrica é considerada constante na parede da tremonha e decresce linearmente até zero desde a transição até a parte superior do silo.

Figura 3.10 - Distribuição das pressões dinâmicas na descarga excêntrica adotada por Safarian. Fonte: Calil (1984). 
O valor da pressão a ser adicionada no lado oposto e reduzida no lado adjacente à saída, varia linearmente na altura do silo na razão de $z / h_{c}$ e depende do valor da pressão $p_{h i}$ que é a pressão de Janssen calculada utilizando o valor do raio imaginário $\left(r_{i}\right)$ :

$$
p_{p e}(z)=\frac{Z}{h_{c}}\left(p_{h i}-p_{h e}\right)
$$

Que atua segundo uma distribuição variável ao redor na circunferência de acordo com a equação:

$$
p_{p e s}(\theta)=p_{p e} \cos \theta
$$

\subsection{Teoria de Rotter (1986)}

Rotter (1986) estudou a descarga excêntrica para silos de fundo plano e sugeriu procedimentos para o cálculo das pressões neste tipo de silo, que foram incluídos nas normas EUROCODE (2002) e DIN (2005).

Rotter (2001) afirma que sua teoria fornece bons resultados para o projeto estrutural de silos e foi validada com sucesso em várias investigações de acidentes em silos. Também foi avaliada por muitos experimentos, contidos em Rotter et al. (1995).

A principal diferença entre a teoria de Rotter (1986) com outros métodos de cálculo, é que ela satisfaz as equações de equilíbrio estáticas em qualquer seção transversal do silo. Porém possui as seguintes limitações, ou hipóteses de validade, que são:

- fluxo paralelo à parede do silo;

- valor de K constante tanto na zona de fluxo quanto nas zonas estáticas;

- pressão de atrito na parede é mobilizada integralmente pelo coeficiente de atrito da parede $\left(\mu_{w}\right)$;

- coeficiente de atrito no contato entre o sólido estático e o sólido fluindo $\left(\mu_{s c}\right)$ igual à tangente do ângulo de atrito interno $\left(\theta_{i}\right)$ no sólido, ou seja: $\mu_{s c}=\tan \theta_{i}$;

- distribuição das pressões conforme Figura 3.11 (b). 


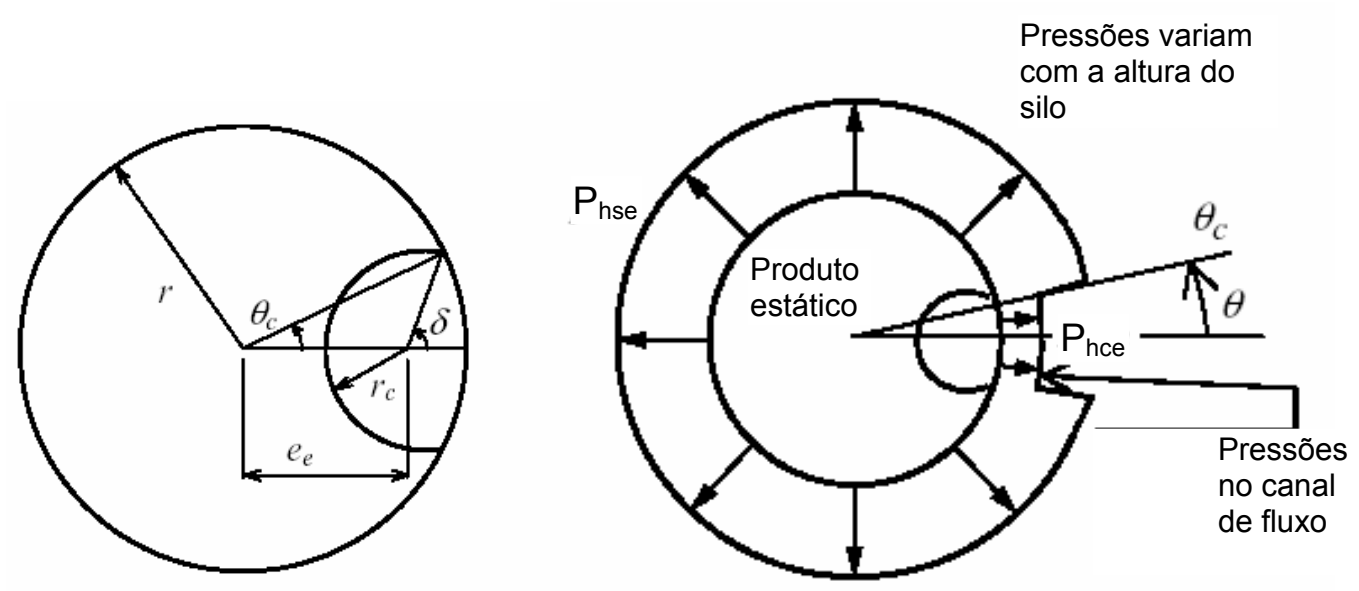

Figura 3.11 - (a) Parâmetros geométricos na seção transversal (b) distribuição de pressões. Fonte: Rotter (1986).

Antes de considerar o equilíbrio, é importante quantificar os parâmetros geométricos da seção transversal, Figura 3.11 (a) que são: área transversal do canal de fluxo $\left(A_{c}\right)$ e área do sólido estático $\left(A_{s}\right)$, calculadas respectivamente por:

$$
\begin{aligned}
& A_{c}=(\pi-\delta) \cdot r_{c}^{2}+\theta_{c} \cdot r^{2}-r \cdot r_{c} \cdot \operatorname{sen} \cdot\left(\delta-\theta_{c}\right) \\
& A_{s}=\pi \cdot r^{2}-A_{c}
\end{aligned}
$$

O ângulo $\delta$ está relacionado com o raio do silo e o raio do canal da seguinte forma:

$$
\operatorname{sen} \delta=\frac{r}{r_{c}} \cdot \operatorname{sen} \theta_{c}
$$

E a excentricidade do centro do canal de fluxo $\left(e_{c}\right)$ é igual a:

$$
e_{c}=r \cdot \cos \delta-r_{c} \cdot \cos \theta_{c}
$$

Sendo $\theta_{c}$ o ângulo formado pela reta horizontal que passa pelo centro do silo e pelo centro do canal de fluxo e a reta que cruza o ponto de encontro do fluxo com a parede do silo, calculado por:

$$
\cos \theta_{c}=\frac{r^{2}+e_{c}{ }^{2}-r_{c}{ }^{2}}{2 . r . e_{c}}
$$

O comprimento do perímetro de contato entre o canal de fluxo e a parede $\left(U_{w c}\right)$, entre o sólido estático e a parede $\left(U_{w s}\right)$ e entre o canal de fluxo com o sólido estático $\left(U_{s_{c}}\right)$ são calculados elas equações:

$$
U_{w_{c}}=2 \cdot \theta_{c} \cdot r
$$




$$
\begin{aligned}
& U_{w s}=2 \cdot\left(\pi-\theta_{c}\right) \cdot r \\
& U_{s c}=2 \cdot r_{c} \cdot(\pi-\delta)
\end{aligned}
$$

Definidas todas as constantes geométricas da seção transversal, o equilíbrio das forças verticais que atuam em uma camada elementar dentro do canal de fluxo fornece:

$$
A_{c} \cdot \frac{d q_{c}}{d z}+q_{c} \cdot\left(\mu_{w} \cdot K \cdot U_{w c}+\mu_{s c} \cdot K \cdot U_{s c}\right)=\gamma \cdot A_{c}
$$

Sendo $q_{c}$ a pressão vertical no canal de fluxo na altura z, abaixo da superfície equivalente. Resolvendo a equação de equilíbrio 3.41 e aplicando-se a condição de contorno de pressão nula na superfície equivalente $(z=0)$ obtém-se a pressão horizontal no canal de fluxo $p_{\text {hce }}$ (Figura $3.11 \mathrm{~b}$ ):

$$
p_{h c e}=\gamma \cdot\left(\frac{A_{c}}{U_{w c} \cdot \mu_{w}+U_{s c} \cdot \mu_{s c}}\right)\left(1-\exp \left\{-z \cdot K \frac{U_{w c} \cdot \mu_{w}+U_{s c} \cdot \mu_{s c}}{A_{c}}\right\}\right)
$$

Dada a relação:

$$
p_{\text {wce }}=\mu_{w} \cdot p_{\text {hce }}
$$

O valor da pressão de atrito no canal de fluxo é:

$$
p_{w c e}=\mu_{w} \cdot \gamma \cdot\left(\frac{A_{c}}{U_{w c} \cdot \mu_{w}+U_{s c} \cdot \mu_{s c}}\right)\left(1-\exp \left\{-z \cdot K \cdot \frac{U_{w c} \cdot \mu_{w}+U_{s c} \cdot \mu_{s c}}{A_{c}}\right\}\right)
$$

O canal de fluxo, na teoria de Rotter, apresentará uma geometria de forma a maximizar o peso de cada camada elementar, enquanto minimiza a força de atrito nos lados do canal. Isso pode ser explicado pelo fato de que o canal de fluxo vai se formar quando houver alguma perturbação local onde a condição de equilíbrio não é satisfeita. Nestas condições, o peso da camada elementar do sólido e a força de atrito na sua superfície lateral vão exceder a resistência ao fluxo, iniciando o fluxo para satisfazer o equilíbrio. Nesta condição a relação $A_{c} /\left(U_{w c} \mu_{w}+U_{s c} \mu_{s c}\right)$ é máxima. Fixando-se o raio do canal, temos:

$$
\begin{aligned}
& {\left[(\pi-\delta) \cdot\left(\frac{r_{c}}{r}\right)^{2}+\theta_{c}-\frac{r_{c}}{r} \cdot \operatorname{sen}\left(\delta-\theta_{c}\right)\right]\left(1-\frac{\cos \theta_{c}}{\cos \delta} \frac{\mu_{s c}}{\mu_{w}}\right)=} \\
& {\left[\theta_{c}+(\pi-\delta) \cdot \frac{r_{c}}{r} \cdot \frac{\mu_{s c}}{\mu_{w}}\right]\left[1-\frac{\cos \left(\delta-\theta_{c}\right) \cdot \cos \theta_{c}}{\cos \delta}+\frac{r_{c}}{r} \cdot\left(\cos \left(\delta-\theta_{c}\right)-\frac{\cos \theta_{c}}{\cos \delta}\right)\right]}
\end{aligned}
$$


Os parâmetros $e_{c}, \delta$ e $\theta_{c}$ podem ser encontrados pela resolução da equação 3.45, considerando a máxima relação $A_{c} /\left(U_{w c} \mu_{w}+U_{s c} \mu_{s c}\right)$. Porém a resolução desta equação é trabalhosa, uma solução aproximada que pode ser utilizada com uma boa precisão, segundo Rotter (2001b) é:

$$
r_{c}=r\left\{1-\frac{e_{o}}{r}\left[\frac{e_{o}}{r}+\frac{\mu_{w}}{\mu_{s c}}\left(1-\frac{e_{o}}{r}\right)\right]\right\}
$$

A pressão horizontal na interface entre o sólido estático e o sólido fluindo dentro do canal de fluxo deve ser igual à $p_{\text {hce }}$, enquanto que no contato com a parede devem existir pressões maiores para permitir o equilíbrio estático da massa sólida (uma baixa tensão horizontal causaria baixa pressão de atrito na parede ocasionando altas tensões verticais no sólido estático que passaria a fluir).

A tensão vertical no sólido estático não pode ser considerada constante como no sólido fluindo, dado que o produto é deformável. Porém as superfícies do canal de fluxo se dilatam de tal forma que as pressões horizontais e de atrito são iguais para ambos os lados. Então, a força de atrito mobilizada no sólido estático pelo sólido fluindo não depende do coeficiente $\mathrm{K}$, sendo somente necessário conhecer o valor da tensão vertical principal no sólido $\left(q_{s}\right)$.

A equação de equilíbrio das forças verticais de uma camada elementar no sólido estático é:

$$
\begin{aligned}
& A_{s} \cdot \frac{d q_{s}}{d z}+q_{s} \cdot \mu_{w} \cdot K \cdot U_{w c}= \\
& \gamma \cdot A_{c}+\mu_{s c} \cdot U_{s c} \cdot \gamma \cdot\left(\frac{A_{c}}{U_{w c} \mu_{w}+U_{s c} \cdot \mu_{s c}}\right)\left(1-\exp \left\{-z \cdot K \cdot \frac{U_{w c} \cdot \mu_{w}+U_{s c} \cdot \mu_{s c}}{A_{c}}\right\}\right)
\end{aligned}
$$

Resolvendo a equação 3.47 e incluindo a condição de contorno em $z=0$, encontra-se a pressão horizontal estática na parede $\left(p_{\text {hse }}\right)$ distante do canal de fluxo:

$$
p_{h s e}=\gamma \cdot \frac{A_{s}}{U_{w s} \cdot \mu}\left[1+w+\text { w.u.e } e^{\frac{-z \cdot K \cdot U_{w s} \cdot \mu}{A_{s}}}-(1+w+w \cdot u) \exp \left\{\frac{-z \cdot K \cdot U_{w s} \cdot \mu}{A_{s}}\right\}\right]
$$

Valendo a relação:

$$
p_{\text {wse }}=\mu \cdot p_{\text {hse }}
$$

Tem-se: 


$$
p_{\text {wse }}=\mu \cdot \gamma \cdot \frac{A_{s}}{U_{w s} \cdot \mu}\left[1+w+w \cdot u \cdot e^{\frac{-z \cdot K \cdot U_{w s} \cdot \mu}{A_{s}}}-(1+w+w \cdot u) \exp \left\{\frac{-z \cdot K \cdot U_{w s} \cdot \mu}{A_{s}}\right\}\right]
$$

Onde:

$$
\begin{aligned}
& w=\left(\frac{A_{c}}{A_{s}}\right) \cdot\left(\frac{U_{s c} \cdot \operatorname{sen} \theta_{i}}{U_{w c} \cdot \mu+U_{s c} \cdot \tan \theta_{i}}\right) \\
& u=\frac{\frac{A_{c}}{U_{w c} \cdot \mu_{w}+U_{s c} \cdot \mu_{s c}}}{\left(\frac{A_{c}}{U_{w c} \cdot \mu_{w}+U_{w c} \cdot \mu_{s c}}\right)+\left(\frac{A_{s}}{U_{w s} \cdot \mu}\right)}
\end{aligned}
$$

\subsection{Recomendações de Ravenet (1974)}

Ravenet estudou as sobrepressões de descarga nas paredes de silos em modelos reduzidos com várias relações altura-lado, com descarga centrada e descarga excêntrica com o produto milho. Os modelos com saída excêntrica utilizados por Ravenet eram quadrados com $30 \mathrm{~cm}$ de lado, fundo plano e relações altura-lado de 7 e 1,5. Ravenet concluiu que as sobrepressões que aparecem durante a descarga do silo dependem da sua relação altura-lado e, portanto os coeficientes de sobrepressão devem ser diferentes conforme essa relação. Com relação à descarga excêntrica, Ravenet recomenda que as pressões sejam calculadas pelo método de Janssen, utilizando os seguintes coeficientes de sobrepressão $\left(\mathrm{C}_{\mathrm{he}}\right)$ :

- descarga excêntrica e relação altura-lado igual a 7 para o lado oposto à boca de saída $C_{h e}=1,95$, para o lado adjacente, $C_{h e}=0,66$;

- descarga excêntrica e relação altura-lado igual a 1,5 para o lado oposto à boca de saída $C_{h e}=1,48$, para o lado adjacente, $C_{h e}=0,74$.

O autor recomenda dar atenção especial para silos cilíndricos metálicos com descarga excêntrica porque as fortes sobrepressões e depressões durante a descarga podem produzir deformações na parede. 


\subsection{Considerações finais sobre o capítulo}

As pressões exercidas pelos produtos armazenados dependem de muitos fatores como as propriedades físicas do produto, o tipo de fluxo, o método de operação do silo, a geometria do silo, entre outros. O desconhecimento do comportamento das pressões nos silos incentivou vários pesquisadores a realizar estudos experimentais e desenvolver teorias baseadas nos resultados destes estudos. As principais teorias desenvolvidas para o cálculo das pressões em silos esbeltos foram apresentadas neste capítulo. A maioria dessas teorias constitui a base de cálculo das pressões nas normas vigentes que abordam ações em silos.

É de consenso no meio científico que teoria de Janssen é a que melhor prevê as pressões no corpo do silo para o caso de silos esbeltos na condição estática. Entretanto, esta teoria é baseada em hipóteses simplificadoras e por isso não é válida para estimar pressões na condição da descarga do silo nem pode ser aplicada para o caso de silos excêntricos.

Portanto, ainda existem muitas incertezas em relação às pressões em silos, especialmente quando se trata de silos excêntricos ou quando envolve o descarregamento do silo. As teorias que abordam a descarga excêntrica são a de Safarian e a teoria de Rotter, sendo que nenhuma delas pode ser aplicada para a predição das pressões em tremonhas excêntricas.

Considerando as limitações dos métodos analíticos, pode ser visto claramente que métodos mais precisos são urgentemente necessários para uma melhor compreensão das ações devido ao produto armazenado. Neste contexto, a simulação numérica parece ser o método mais apropriado e oferece muitas vantagens quando comparados aos estudos experimentais que consomem um tempo considerável, possuem custos elevados, são difíceis de serem conduzidos e apenas a reações nas paredes são mensuradas e não o comportamento do produto armazenado dentro do silo. 


\section{MÉTODOS NUMÉRICOS NO ESTUDO DOS SILOS}

A dificuldade de obter teorias clássicas satisfatórias para prever com precisão as pressões exercidas pelo produto armazenado nas paredes do silo, aliado ao avanço extraordinário da computação nos últimos anos, incentivaram a utilização dos métodos numéricos como uma nova forma de abordagem do estudo das pressões em silos.

Os métodos numéricos trazem vantagens como permitir análise das pressões em silos com geometrias particulares, como a descarga excêntrica ou silos com fundo inclinado (tremonhas), assim como a possibilidade de escolha de uma teoria de comportamento mais coerente com a realidade para o produto armazenado, incluindo comportamento plástico e não linear.

Outras vantagens como a rapidez na obtenção dos resultados e a facilidade de acesso por meio de programas prontos, disseminaram a utilização dos métodos numéricos no estudo dos silos. Porém, estes aspectos podem se tornar um ponto negativo caso o usuário não possua um conhecimento estrutural sólido para interpretar e analisar devidamente os resultados gerados pelos softwares prontos.

Os métodos numéricos mais utilizados no estudo dos silos são: o método dos elementos finitos (MEF) e o método dos elementos discretos (MED). O MED consiste em simular individualmente as partículas que integram o meio a partir do emprego de modelos de choque e da segunda lei de Newton. Estas considerações permitem a obtenção do movimento e velocidade individual de cada grão, incluindo a influência de choques e atritos existentes entre as próprias partículas e entre estas e a parede. O cálculo das tensões resultantes será obtido mediante integração dos resultados individuais. O MED é o tipo de análise ideal para o estudo das pressões principalmente no momento da descarga do produto. 
Apesar do grande potencial do MED, sua aplicação não é viável atualmente porque a simulação de todas as partículas armazenadas no silo exigiria necessidades computacionais extraordinariamente elevadas (Rotter et al. 1998; Gallego 2006). Portanto, o método mais empregado atualmente é o MEF.

No MEF, a hipótese fundamental na confecção do modelo matemático é a continuidade do meio, dado que este método é baseado na Mecânica do Contínuo. A Mecânica do Contínuo é um ramo da mecânica que trata a matéria como sendo um meio contínuo, sem vazios interiores de forma que qualquer porção de volume, por menor que seja, é totalmente preenchida por certa quantidade de massa. Além disso, o meio inicialmente contínuo deve permanecer contínuo depois de aplicado o carregamento externo.

O conceito "continuum" permite a definição do ponto geométrico (de volume igual a zero), por um limite matemático tal como na definição de derivadas no cálculo infinitesimal. Assim, na Mecânica do Contínuo os princípios da física são escritos sob a forma de equações diferenciais. Os efeitos da constituição interna dos materiais são levados em conta de forma macroscópica através das equações constitutivas do material.

O meio contínuo será dividido ou discretizado em pequenos elementos, denominados elementos finitos. Esses elementos são definidos por barras, nós e funções de interpolação. $O$ conjunto de barras e nós define a malha do modelo. As equações que governam o comportamento estrutural de cada elemento são escritas em matrizes individuais e transferidas para uma matriz global. Os carregamentos na estrutura e restrições de deslocamento são aplicados e a solução é então determinada a partir do equilíbrio entre forças aplicadas e esforços internos, compatibilização dos deslocamentos e condições de contorno da estrutura.

Por meio do MEF é possível adotar comportamentos estruturais distintos para cada elemento do modelo. Portanto, cada elemento do modelo possui uma matriz de rigidez que, em conjunto, forma a matriz de rigidez global da estrutura, de forma análoga ao método utilizado na análise matricial de estruturas. Nos pontos de união entre os elementos, ou seja, nos nós, se determinam as condições para calcular o equilíbrio da estrutura.

O processo de modelagem pelo MEF no estudo dos silos teve um avanço importante ao longo dos últimos 30 anos. Três equipes de investigação se destacam neste processo: a equipe de Rotter utilizando o programa ABAQUS, a equipe de Eibl 
com o programa computacional SILO e a equipe de Ayuga utilizando o programa ANSYS.

\subsection{Evolução dos modelos numéricos no estudo dos silos}

Os primeiros modelos utilizados no estudo das pressões nos silos foram bidimensionais axissimétricos de silos com fundo plano. Para representar comportamento do produto utilizava-se o modelo mais simplificado, o elástico-linear. Uma das características desses primeiros modelos foi a ausência de paredes, pois se partiu do princípio de que as tensões nas paredes são desprezíveis, dado sua elevada rigidez em comparação com o produto armazenado. O atrito na superfície do produto era, portanto, simulado aplicando-se forças verticais no contorno externo do produto. Este modelo foi utilizado nos estudos de Mahmoud (1975) e Jofriet (1977).

Anos mais tarde, Jofriet e Czajkowski (1980) utilizaram um modelo bidimensional com carregamento progressivo que permitia a atualização do peso específico e do módulo de elasticidade do produto em cada camada durante o carregamento do silo.

No trabalho de Mahmoud e Abdel-Sayed (1981) foi estudada a influência da flexibilidade das paredes na distribuição das pressões a partir de modelos bidimensionais incluindo o carregamento progressivo e adotando um modelo de comportamento elástico não linear para representar o produto.

Ooi e Rotter (1990) utilizou modelos axissimétricos bidimensionais de silos com com corpo vertical e tremonha adotando comportamento elástico-linear para o produto armazenado e simulando a interação entre o produto e a parede por meio de elementos intermediários, denominados elementos de contato (Figura 4.1).

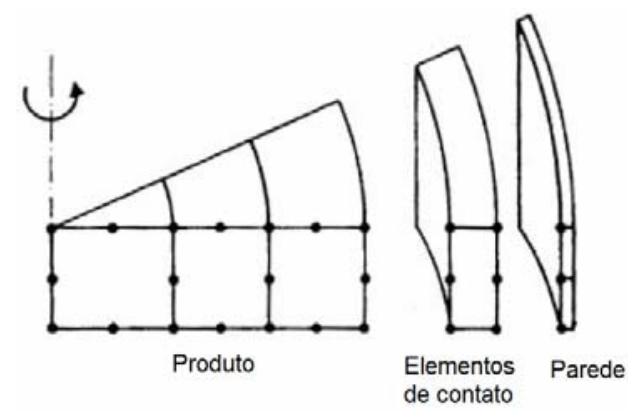

Figura 4.1 - Simulação do contato por meio de elementos intermediários: elementos de contato. 
Em 1982 uma equipe de pesquisadores liderada por Eibl, deu início ao desenvolvimento um programa específico para silos que utiliza o MEF, denominado SILO. As primeiras análises conduzidas com o programa SILO objetivaram a determinação das pressões estáticas e podem ser vistas em Eibl et al. (1982).

Mais tarde, Häußer e Eibl (1984) apresentam a análise das pressões dinâmicas com o programa SILO. O modelo utilizado foi um silo axissimétrico bidimensional com tremonha. O comportamento do produto foi considerado elastoplástico incluindo propriedades viscosas na análise dinâmica, propriedade análoga à dos fluidos. Segundo Häußer e Eibl (1984), a viscosidade do produto é o parâmetro principal que determina a intensidade das pressões durante 0 descarregamento do silo.

Considerando a dificuldade de medir a viscosidade dos produtos granulares devido à inexistência de aparelhos e procedimentos de testes, Häußler e Eibl (1984) realizaram experimentos nos quais mediram a velocidade do produto durante o fluxo que foi comparada com as velocidades obtidas numericamente, simuladas para vários valores de viscosidade. O valor considerado ideal foi aquele que produziu resultados numéricos de velocidade similares aos resultados experimentais.

A partir do programa SILO, Rombach (1991), orientado por Eibl, apresenta os primeiros modelos de descarga em silos tridimensionais com fundo plano concêntricos. A descarga excêntrica em silos tridimensionais de fundo plano é estudada no trabalho de Rombach e Eibl (1995). A Figura 4.2 ilustra o resultado das pressões horizontais nas paredes do silo no instante $t=0$ segundo e $t=1$ segundo. Nestes modelos, a interação produto-parede foi representada por elementos de contato.
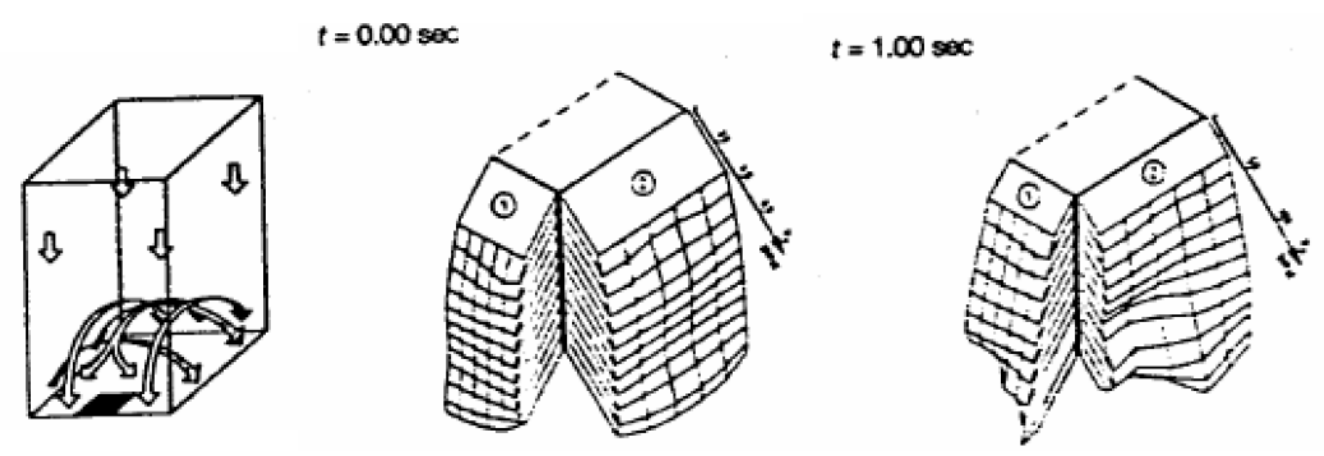

Figura 4.2 - Distribuição de pressões horizontais estáticas ( $t=0$ segundos) e dinâmicas ( $t=1$ segundo) para um silo de fundo plano e descarga excêntrica. Fonte: Rombach e Eibl (1995). 
Rombach e Neumann (2004) apresentam os valores das pressões em um silo quadrado a partir do modelo tridimensional em diferentes instantes de tempo (Figura 4.3) e posteriormente comparam os valores obtidos com os recomendados pelas normas ACI e EUROCODE, Figura 4.4.
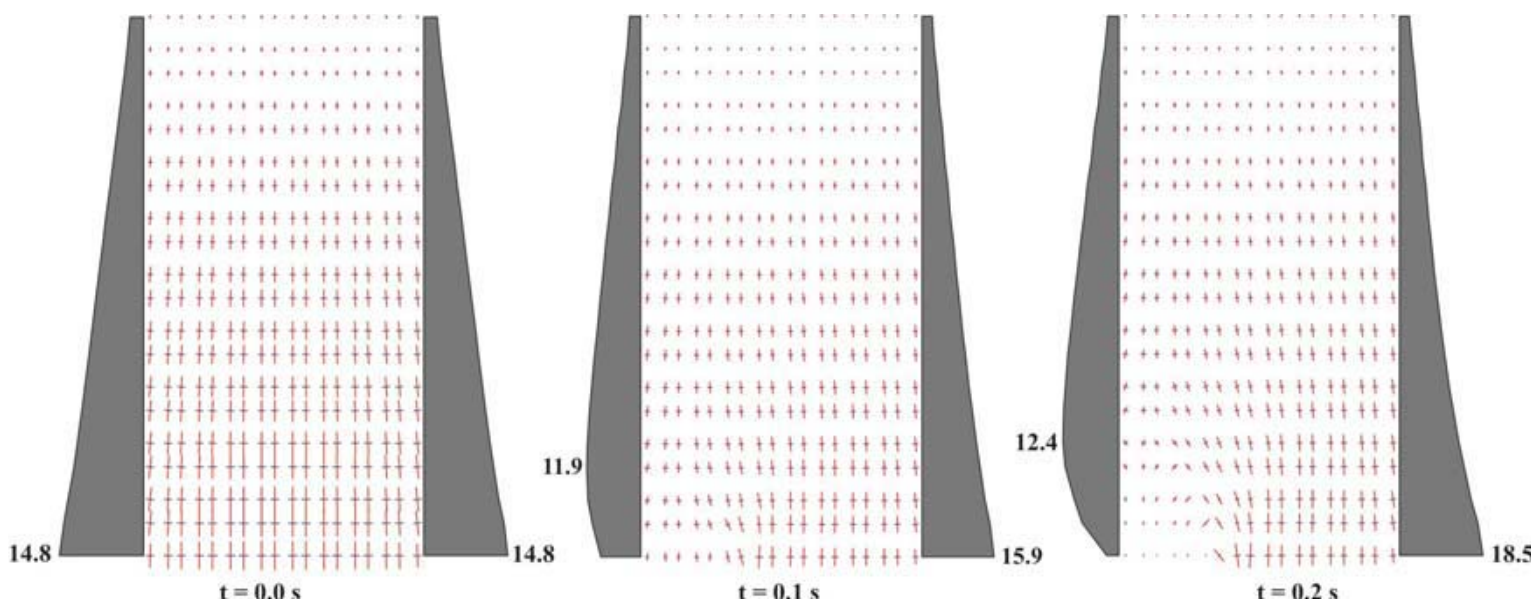

Figura 4.3 - Pressões horizontais para $t=0$ segundo, $t=0,1$ segundo e $t=0,2$ segundo em um silo de fundo plano e descarga excêntrica. Fonte: Rombach e Neumann (2004).

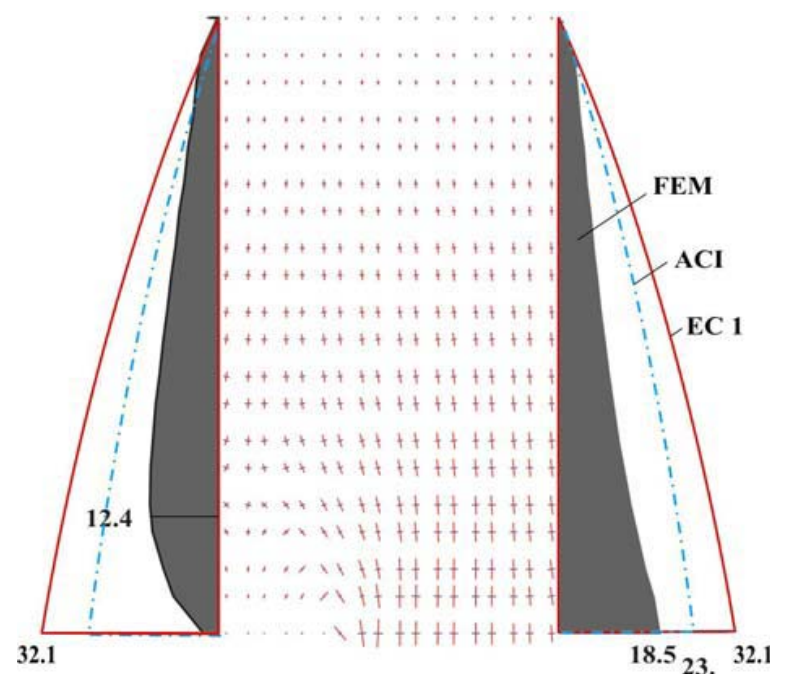

Figura 4.4 - Comparação com as normas de pressões horizontais dinâmicas em um silo de fundo plano e descarga excêntrica. Fonte: Rombach e Neumann (2004).

Jofriet retorna o estudo das pressões em silos e no ano de 1994, um de seus pesquisadores apresenta um trabalho inovador por utilizar o MED. Trata-se do trabalho exposto em Rong (1994) no qual são determinadas as pressões estáticas a partir de um modelo bidimensional de silo com fundo plano. E em Rong et al. (1995) os resultados de pressões dinâmicas são apresentados considerando um comportamento visco elástico para o produto. 
Meng et al. (1997), também da equipe de Jofriet, gerou um modelo em 2D com a hipótese de deformação plana para o estudo das pressões dinâmicas. $O$ modelo de comportamento empregado foi o elastoplástico com o critério de plastificação de Drucker-Prager (DRUCKER \& PRAGER,1952).

A partir dos modelos desenvolvidos por Rong et al. (1995) e Meng et al. (1997), Lu et al. (1997) desenvolvam um modelo híbrido em MEF e MED. Trata-se de um modelo axissimétrico formado por corpo vertical e tremonha onde em locais específicos como na transição corpo-tremonha e na boca de saída foi utilizado o MED, conforme ilustra a Figura 4.5.

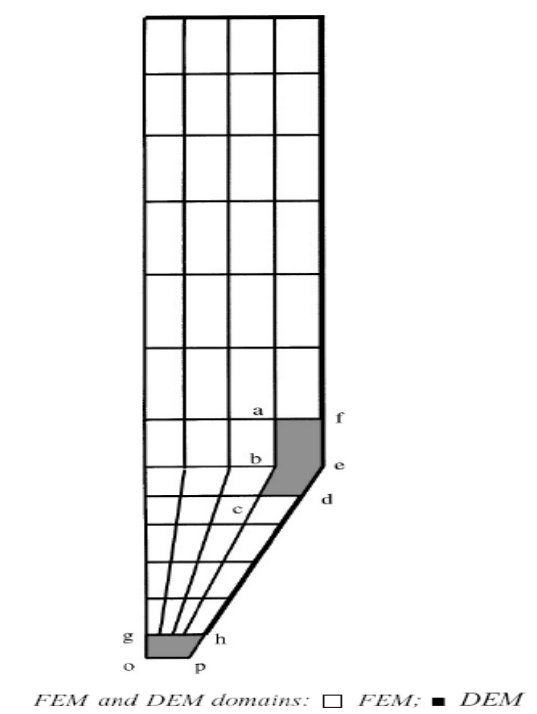

Figura 4.5 - Modelo numérico híbrido com MEF e MED. Fonte: Lu et al. (1997).

O grupo de investigação espanhol dirigido pelo professor Ayuga, utilizando o programa ANSYS, apresenta seu primeiro trabalho em Guaita (1995) onde as pressões estáticas foram determinadas a partir de um modelo bidimensional considerando leis de comportamento do material elásticas e elastoplásticas. Este último com o critério de plastificação de Drucker-Prager.

O trabalho de Couto (2000) aborda pela primeira vez o estudo das pressões estáticas em silos tridimensionais com tremonha excêntrica. Os resultados deste trabalho foram publicados em Ayuga et al. (2001ª) e Guaita et al. (2003).

Em Ayuga et al. $\left(2001^{b}\right)$ é apresentado um novo modelo numérico para simular o descarregamento do produto forçando o grão a se movimentar para baixo (Figura 4.6), em direção à boca de saída do silo, com um pequeno deslocamento, simulando a descarga do silo. 


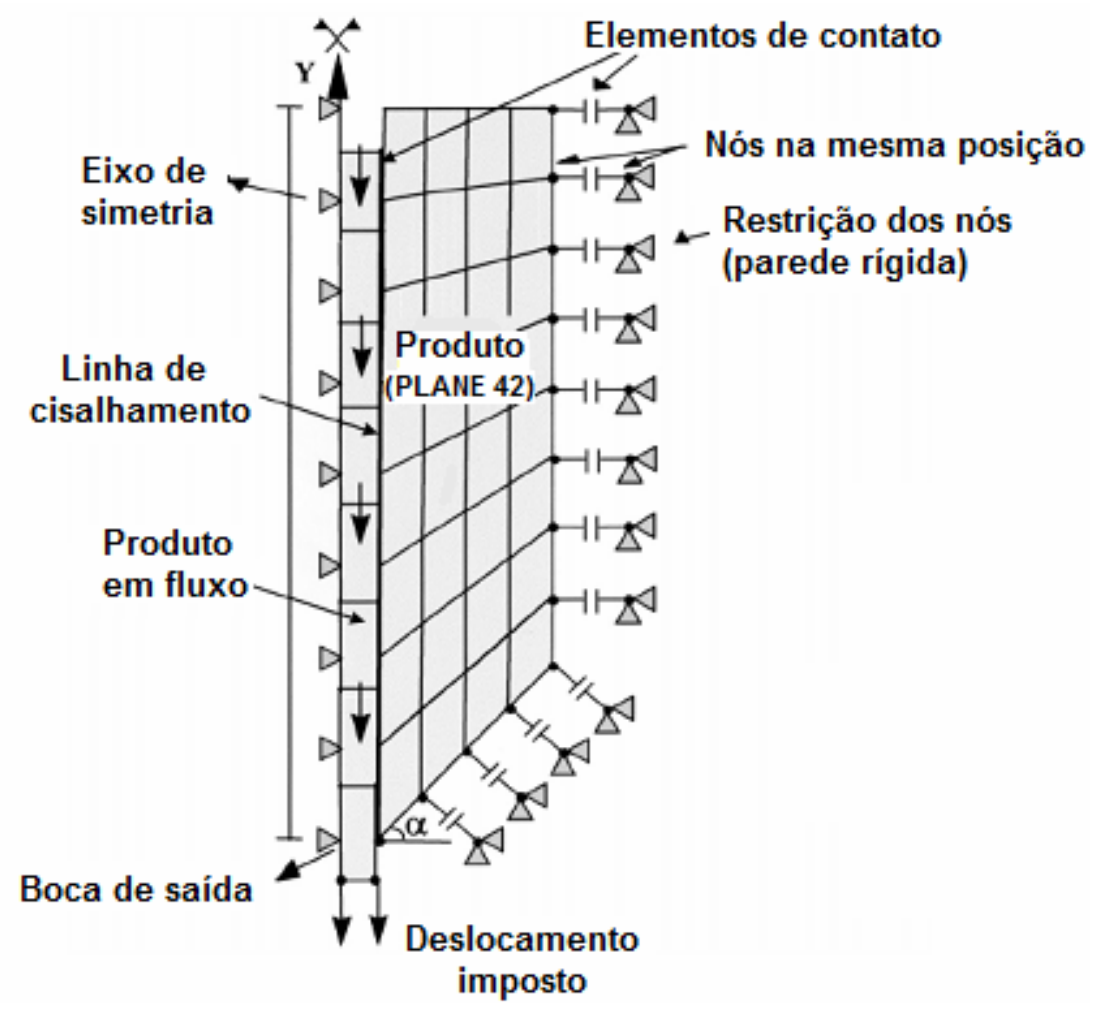

Figura 4.6 - Modelo de descarga para fluxo de massa utilizado por Ayuga (2001).

Neste modelo utilizado por Ayuga et al. $\left(2001^{\mathrm{b}}\right)$ foi necessário introduzir elementos de contato também no interior do produto, em linhas específicas, permitindo o deslizamento no produto de forma a simular o seu fluxo. Na Figura 4.6 pode ser observada a linha de deslizamento (linha mais espessa) formadas por elementos de contato.

Para a análise dinâmica das pressões, a questão mais delicada, do ponto de vista de modelagem, é a simulação do contato entre superfícies. Na condição dinâmica, o contato é de difícil solução, pois envolve a determinação de diversos parâmetros, como rigidez da superfície de contato, penetração e atrito entre os corpos. Além disso, como é um problema que está relacionado com alterações nas restrições e vinculação da estrutura, apresenta forte não-linearidade.

Vidal (2003) ampliou o estudo da descarga para silos tridimensionais, considerando também a influência da excentricidade da tremonha utilizando o modelo de contato entre a superfície e o sólido desenvolvido por Cescotto \& Charlier (1992), que apresentaram um método no qual a tensão de contato e os deslocamentos no contorno de um sólido são discretizados independentemente, através do princípio variacional. Sendo assim, a descarga do silo em Vidal (2003) foi simulada utilizando uma análise dinâmica transitória, cuja principal característica é 
fornecer a resposta dinâmica da estrutura sob um carregamento que varia com o tempo com a aplicação do método de Newton-Raphson, expresso na seguinte equação:

$M \ddot{u}+K u=F(t)$

Onde

$M$ = matriz de massa;

$K=$ matriz de rigidez;

$\ddot{u}=$ vetor de aceleração nodal;

$u=$ vetor nodal de deslocamento;

$F(t)=$ vetor de forças aplicadas

A análise transiente é importante no sentido de analisar a resposta das pressões com o tempo e por isso permite avaliar o tempo crítico a partir do qual as pressões decrescem. Meng et al. (1997) encontraram um tempo crítico de $1 \mathrm{~s}$ para silos de paredes metálicas. Vidal; Guaita e Ayuga (2005) encontrarm um tempo crítico de 1,7s, enfatizando que o tempo crítico não é o mesmo para todos os pontos do silo, sendo necessário mostrar o resultado por meio de envoltórias das maiores pressões. A não linearidade causada pelo contato, pelo produto e pelos altos deslocamentos deve ser incorporada na análise tridimensional dinâmica tansitória que considera as pressões estáticas do produto.

Também foram desenvolvidos estudos para comparar os resultados obtidos com programas distintos, como em Rombach et al. (2005), trabalho que compara as pressões estáticas e dinâmicas obtidas pelos programas ANSYS e o programa SILO, elaborado especificamente para análises não lineares estáticas e dinâmicas de silos através do MEF. Os resultados mostraram uma boa correlação entre os programas. Esta mesma conclusão foi obtida por Gallego et al. (2004) quando comparou os valores das pressões estáticas com os programas ANSYS e ABAQUS, enfatizando que a qualidade dos resultados depende da adoção de parâmetros apropriados para o modelo adotado.

A simulação do descarregamento do silo é uma das linhas de estudo que se destaca atualmente, assim como trabalhos experimentais para a validação dos resultados numéricos. Ayuga et al. (2006), compararam os resultados numéricos das pressões estáticas obtidas com o MEF, com os valores propostos pelo EUROCODE (2002) e com resultados experimentais de um silo em escala real (Figura 4.7). As 
dimensões do silo real utilizado foram: $h_{c}=5 m ; D=2 m, h_{t}=1,54 m$, paredes de aço liso com $2 \mathrm{~mm}$ de espessura e três tipos de saída: centrada, parcialmente excêntrica e totalmente excêntrica. O produto analisado foi o trigo. Os resultados obtidos pelos autores, são mostrados na Figura 4.8.
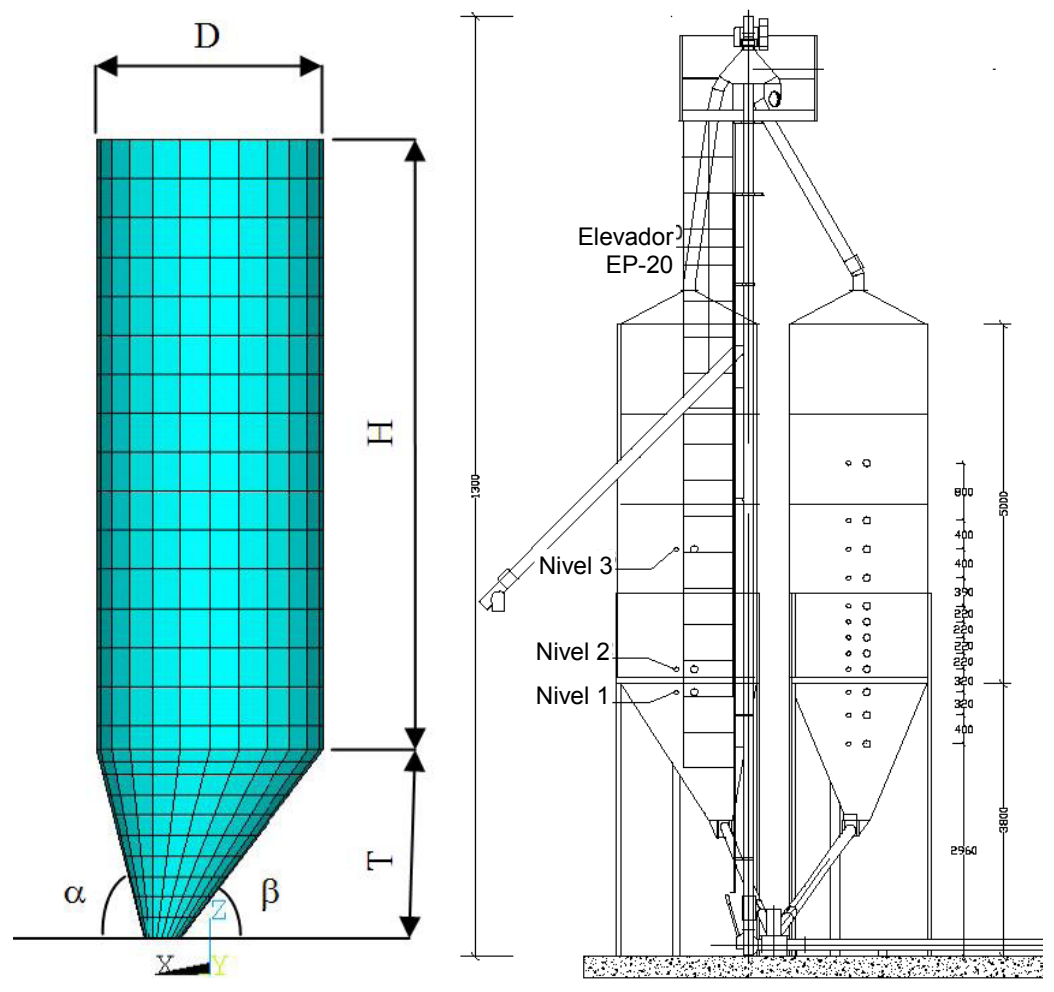

Figura 4.7 - Modelo numério e modelo real. Fonte: Ayuga et al. (2006).

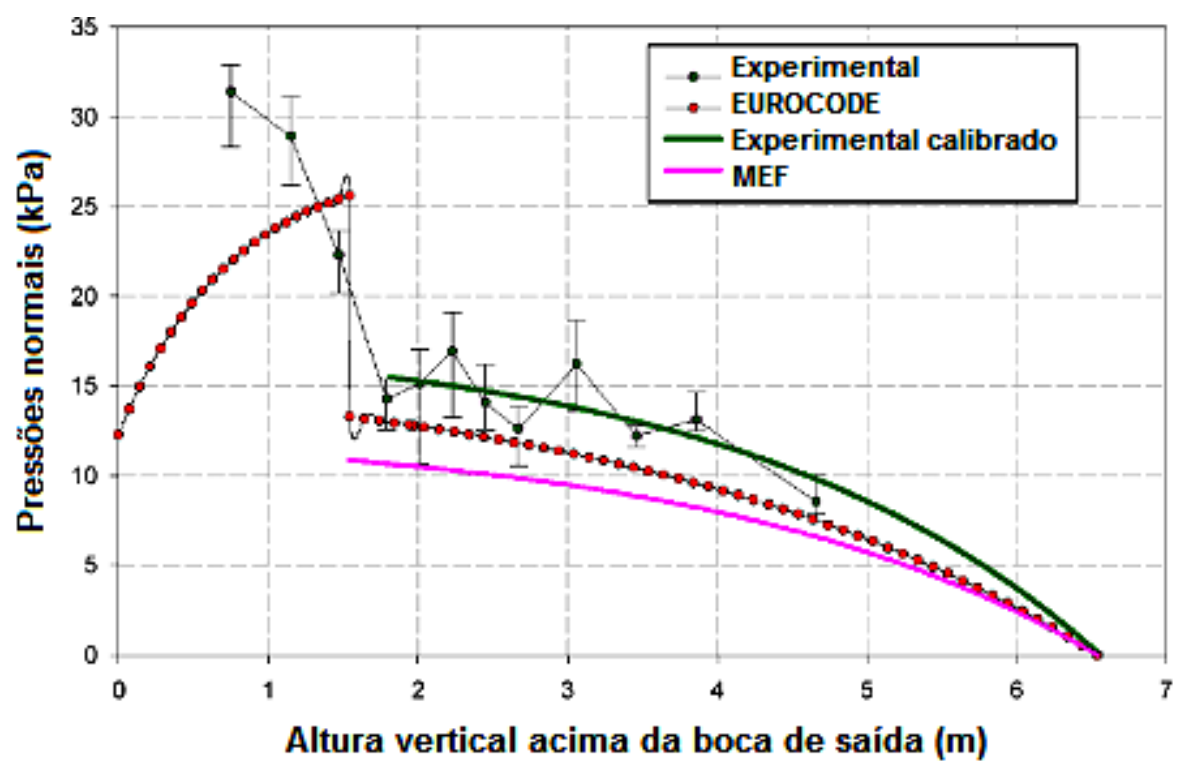

Figura 4.8 - Compração dos resultados das pressões horizontais estáticas na parede silo. FONTE: Ayuga (2006). 
Os resultados de Ayuga et al. (2006), mostram que as pressões laterais no corpo do silo, obtidas experimentalmente são muito próximas das pressões obtidas pela teoria de de Janssen. Diferentemente do corpo do silo, as pressões na tremonha apresentam um comportamento atípico e, portanto, de acordo com os autores, as pressões nas tremonhas devem ser melhor analisadas.

Observa-se também que os resultados numéricos pelo MEF fornecem pressões laterais menores do que as experimentais. Ramirez et al. (2006) explicam que esta diferença pode ter acontecido devido aos valores das propriedades físicas do produto ou devido à problemas nos sensores tais como: falta de rigidez da membrana e imperfeições na parede na área em que foram instalados os medidores de pressão.

\subsection{Considerações finais sobre o capítulo}

A utilização do MEF para predição das pressões devido ao produto armazenado nas paredes dos silos sofreu grande avanço nas últimas décadas e permitiu que o problema fosse modelado de forma mais realista. Entretanto, ainda existem muitas lacunas principalmente com relação à simulação do descarregamento do silo cujas hipóteses simplificadoras distanciam muito do problema real analisado. 


\section{RECOMENDAÇÕES DAS NORMAS INTERNACIONAIS ANALISADAS}

\subsection{EUROCODE ENV 1991-4 (2002) e DIN 1055-6 (2005)}

A norma européia EUROCODE 1 e a norma alemã DIN são as normas que possuem as versões mais recentes, publicadas respectivamente em 2002 e 2005. Estão sendo abordadas em conjunto neste item do trabalho, pois são extremamente semelhantes na maioria das recomendações.

\subsubsection{Propriedades físicas dos produtos armazenados}

As propriedades físicas para alguns produtos armazenados são tabeladas pelas normas, mas devem ser utilizadas em último caso, quando não existir a possibilidade de realizar ensaios para sua determinação. Os procedimentos de ensaio também são normalizados seguindo os princípios explicados no capítulo 2 . A equação para a obtenção do coeficiente $\mathrm{K}$ adotado por essas normas é o mesmo recomendado por Rotter (2001), ou seja, equação 2.14.

\subsubsection{Classificação dos silos}

Quanto à excentricidade, os silos podem ser classificados em silos de pequena excentricidade $\left(e_{0} \leq 0,25 D\right)$ e silos de grande excentricidade $\left(e_{0}>0,25 D\right)$. É importante destacar que atualmente as normas EUROCODE e a DIN não restringem o valor da excentricidade de descarga em 25\% do diâmetro como acontecia nas suas versões anteriores. Essa limitação foi eliminada após a adoção da teoria de Rotter (1986).

As normas EUROCODE e DIN consideram diferentes critérios para o projeto estrutural dos silos e por isso separam os silos em classes de confiabilidade, seguindo os parâmetros indicados na Tabela 5.1 . 
Tabela 5.1 - Classificação dos silos em classes de confiabilidade.

\begin{tabular}{|c|l|}
\hline Confiabilidade & \multicolumn{1}{c|}{ Descrição } \\
\hline Classe 1 & Silos com capacidade abaixo de 100 toneladas \\
\hline Classe 2 & Todos os silos que não pertencem às classes 1 e 3 \\
\hline & $\begin{array}{l}\text { Silos com capacidade acima de 10000 toneladas } \\
\text { Silos com capacidade acima de 1000 toneladas em que ocorre pelo } \\
\text { menos uma das seguintes situações: }\end{array}$ \\
& $\begin{array}{l}\text { (a) descarga excêntrica com } e_{o} / d_{c}>0,25 \\
\text { Classe 3 silos quadrados com excentricidade de carregamento } e_{t} / d_{c}>0,25\end{array}$ \\
\hline
\end{tabular}

O procedimento de separar as estruturas de acordo com a classe de confiabilidade tem a finalidade de reduzir o risco de falha para diferentes estruturas. Quanto maior a classe de confiabilidade do silo, mais rigoroso o método de cálculo recomendado para o seu projeto. Nos silos de classe 3, por exemplo, não é permitido utilizar valores tabelados das propriedades dos produtos, sendo necessário a execução de testes experimentais para a sua determinação.

Também existe diferença no método de cálculo das pressões de acordo com a excentricidade do silo. O carregamento nas paredes verticais de silos com pequenas excentricidades é considerado por uma distribuição simétrica de pressões e uma pressão horizontal adicional que atua num determinado trecho na parede do silo. Nos silos de grande excentricidade, o carregamento é representado por uma distribuição assimétrica de pressões, que deve ser considerada como um caso separado de carregamento.

A metodologia de cálculo das pressões estáticas e dinâmicas nas paredes do silo também varia de acordo com sua esbeltez, ou seja, segundo a relação $h_{c} / D$. Os valores limites da relação $h_{d} / D$ para cada classe de esbeltez são dados na Tabela 5.2. Neste trabalho só serão estudadas as recomendações para o cálculo das pressões em silos esbeltos, com relação $h_{c} / D$ superior a 2 .

Tabela 5.2 - Classificação dos silos de acordo com a esbeltez.

\begin{tabular}{|c|c|}
\hline Classificação & Limites da Relação $\mathbf{h}_{\mathrm{c}} / \mathbf{D}$ \\
\hline Silo esbelto & $\mathrm{h}_{\mathrm{d}} / \mathrm{D} \geq 2$ \\
\hline Silo medianamente esbelto & $1 \geq \mathrm{h}_{\mathrm{c}} / \mathrm{D} \geq 2$ \\
\hline Silo baixo & $0,4 \geq \mathrm{h}_{\mathrm{c}} / \mathrm{D} \geq 1$ \\
\hline Silo horizontal & $\mathrm{h}_{\mathrm{d}} / \mathrm{D} \leq 0,4$ \\
\hline
\end{tabular}




\subsubsection{Pressões estáticas nas paredes verticais de silos esbeltos}

O carregamento que representa a condição do silo completamente cheio com o produto em repouso é composto pela combinação pressões estáticas simétricas e pressões estáticas adicionais.

As pressões estáticas simétricas adotadas pela EUROCODE e DIN são obtidas pela formulação de Janssen, com as equações 3.02, 3.03, 3.05 e 3.06, utilizando os valores apropriados $\gamma, \mu, K$. No caso de silos que se enquadram na primeira classe de confiabilidade, por exemplo, adotam-se os valores médios de $\mu \mathrm{e}$ $K$, enquanto que em silos das classes 2 e 3 , devem ser utilizados os valores inferiores e superiores de $\gamma, \mu, K$, conforme a Tabela 3.1.

Além da distribuição de pressão calculada por Janssen, deve ser adotada uma pressão adicional $\left(p_{p f}\right)$ com o objetivo de considerar incertezas provenientes de excentricidades acidentais durante o processo de enchimento do silo e imperfeições geométricas da parede. Nos silos com classe 1 de confiabilidade a pressão estática adicional pode ser desprezada.

A magnitude da pressão adicional estática ou de carregamento ( $\left.p_{p f}\right)$ é:

$$
p_{p f}=C_{p f} \cdot p_{h f}
$$

Sendo $p_{h f}$ a pressão inicial de Janssen calculada na altura $(z)$ igual à altura de aplicação da pressão adicional e $C_{p f}$ o coeficiente de pressão adicional estática $\left(C_{p f} \geq 0\right)$ dado por:

$$
C_{p f}=0,24 \cdot C_{o p} \cdot\left[1+2 \cdot\left(\frac{2 \cdot e_{f}}{D}\right)^{2}\right]\left(1-e^{-1,5 \cdot\left[\left(\frac{h_{c}}{D}\right)-1\right]}\right)
$$

e $C_{o p}$ é o coeficiente do produto armazenado, variando em função do tipo de produto. Para a soja $C_{o p}$ é igual a 0,5 e 0,9 para o milho.

Esta pressão adicional deve atuar em uma área quadrada de lado "s" calculado por:

$$
s=\frac{\pi \cdot D}{16}
$$

Em silos cilíndricos de paredes rígidas, a pressão adicional é constante e atua em áreas posicionadas em lados opostos do silo enquanto que para os silos circulares de paredes finas, sua intensidade varia de um valor máximo $\left(p_{p f}\right)$ até um 
valor mínimo $\left(-p_{p f}\right)$, conforme a Figura 5.1. Esta variação de intensidade é expressa em termos de uma distribuição de pressões assimétrica $\left(p_{p f s}\right)$ regida pela equação 5.04 :

$$
p_{p f s}=p_{p f} \cdot \cos \theta
$$

A altura que define a localização vertical da pressão adicional $\left(z_{p}\right)$ é o menor valor entre $z_{0}$ e $0,5 h_{c}$ e deve ser considerada a partir da superfície equivalente conforme a Figura 5.1. Sendo:

$$
z_{0}=\frac{1}{K \cdot \mu} \cdot \frac{A}{U}
$$
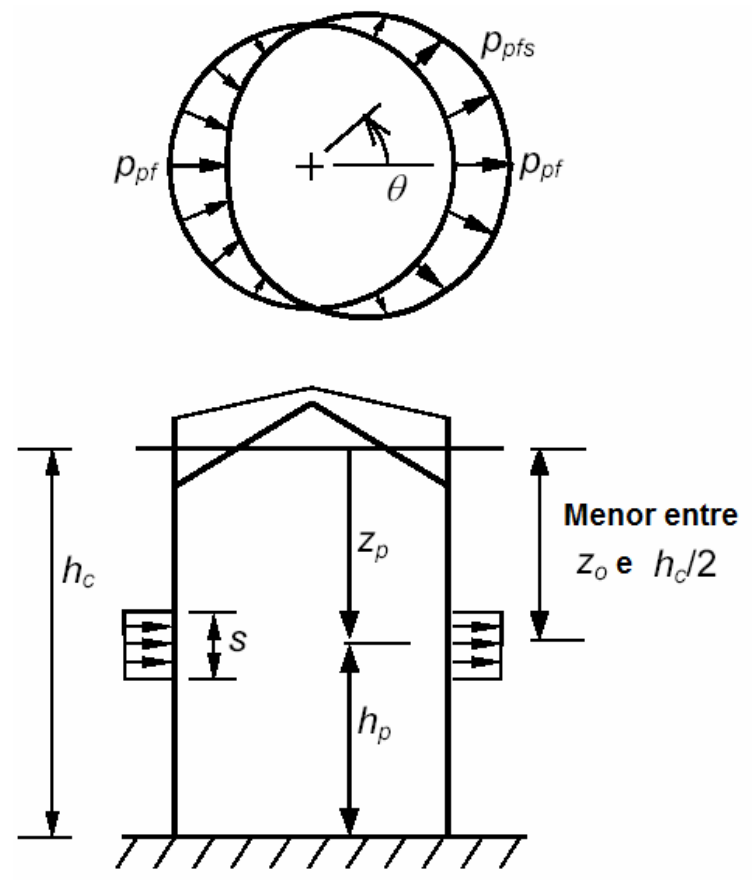

Figura 5.1 - Distribuição da pressão adicional para silos cilíndricos de paredes finas.

\subsubsection{Pressões dinâmicas nas paredes verticais de silos esbeltos}

Da mesma forma que no caso estático, o carregamento nas paredes verticais no caso dinâmico é composto por pressões simétricas de descarga e pressões adicionais de descarga.

As pressões simétricas de descarga são calculadas a partir das pressões estáticas multiplicadas por coeficientes de sobrepressão, representados pela letra C, com o sub índice apropriado. Seguindo este raciocínio, a pressão horizontal dinâmica $\left(p_{h e}\right)$ e a pressão de atrito dinâmica $\left(p_{\text {we }}\right)$, são dadas por:

$$
p_{h e}=C_{h} \cdot p_{h f}
$$




$$
p_{w e}=C_{w} \cdot p_{w f}
$$

Sendo $C_{h}=1,15$ e $C_{w}=1,10$ para silos das classes 2 e 3 de confiabilidade. Nos silos da classe 1 de confiabilidade, cujos valores médios de $\mu$ e $K$ foram utilizados no cálculo das pressões, os coeficientes de descarga devem ser calculados conforme as equações:

$$
\begin{aligned}
& C_{h}=1,5 \cdot\left(1+0,4 \cdot e_{o} / D\right) \cdot C_{o p} \\
& C_{w}=1,4 \cdot\left(1+0,4 \cdot e_{o} / D\right)
\end{aligned}
$$

A pressão adicional de descarga $\left(p_{p e}\right)$ tem a finalidade de representar pressões assimétricas durante a descarga, assim como excentricidades de esvaziamento. Ela não precisa ser considerada para silos da classe 1 de confiabilidade. Sua magnitude é dada por:

$$
p_{p e}=C_{p e} \cdot p_{h e}
$$

Sendo $p_{h e}$ a pressão dinâmica na altura (z) igual à altura de aplicação da pressão adicional e $C_{p e}$ é o coeficiente de pressão adicional dinâmica $\left(C_{p f} \geq 0\right)$ dado por:

$$
C_{p e}=0,42 \cdot C_{p o}\left[1+2 \cdot\left(\frac{2 \cdot e_{o}}{D}\right)^{2}\right] \cdot\left(1-e^{-1,5 \cdot\left[\frac{h_{c}}{D}-1\right]}\right) \quad \text { (segundo a DIN) }
$$

Uma das poucas diferenças existentes entre o EUROCODE e a DIN é no cálculo de $C_{p e}$. Segundo o EUROCODE, a constante 0,48 deve ser substituída no lugar da constante 0,42 na equação 5.11 .

Esta pressão adicional $\left(p_{p e}\right)$ é aplicada num comprimento do perímetro de lado "s" (equação 5.03) e sua intensidade varia, para o caso de silos circulares esbeltos de paredes finas, conforme a seguinte distribuição de pressões:

$$
p_{p e s}=p_{p e} \cos \theta
$$

e deve ser aplicada na mesma altura $z_{p}$ a partir da superfície equivalente (figura 5.1), sendo $z_{p}$ o menor dentre $z_{0}$ e $0,5 h_{c}$.

\subsubsection{Pressões de descarga excêntrica}

Em silos com descarga excêntrica cuja excentricidade de descarga $e_{o}$ excede o valor crítico $\left(e_{o, c r}\right)$, fixado em de $25 \%$ de $\mathrm{D}$, um novo caso de carregamento deve 
ser considerado e também para silos concêntricos muito esbeltos $\left(h_{c} / D \geq 4\right)$ pois valores extremos de esbeltez podem acarretar a formação de canal de fluxo em tubo excêntrico (Figura 2.3).

As pressões assimétricas variam ao redor da circunferência do silo como ilustra a Figura 5.2 e sua intensidade varia de acordo com a classe de confiabilidade do silo.
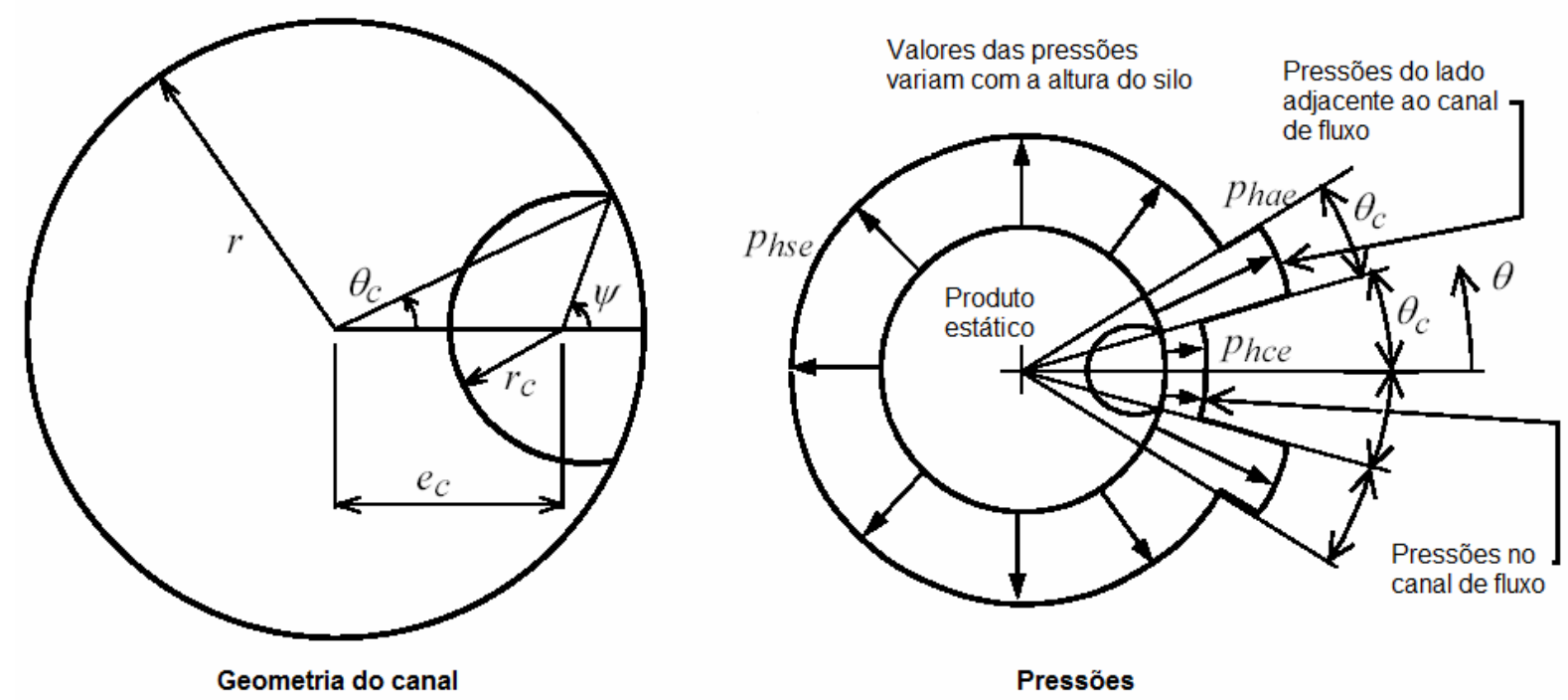

Figura 5.2 - Distribuição de pressões para silos com fluxo excêntrico. Fonte: EUROCODE (2002).

Silos da classe 2, as pressões assimétricas são obtidas por um método simplificado que consiste em desprezar a pressão horizontal na parede em contato com o canal de fluxo ( $\left.p_{\text {hce }}\right)$, ou seja:

$$
p_{\text {hce }}=0
$$

As pressões horizontais, onde o produto permanece estático, na parede oposta à excentricidade $\left(p_{\text {hse }}\right)$ e na parede próxima $\left(p_{\text {hae }}\right)$ são calculadas, respectivamente por:

$$
\begin{aligned}
& p_{\text {hse }}=p_{h f} \\
& p_{\text {hae }}=2 \cdot p_{h f}
\end{aligned}
$$

Da mesma forma, o procedimento simplificado estabelece que as pressões de atrito na parede na parede oposta à saída $\left(p_{\text {wse }}\right)$ e na parede próxima $\left(p_{\text {wae }}\right)$, sejam calculadas conforme as equações:

$$
\begin{aligned}
& p_{\text {wse }}=p_{w f} \\
& p_{\text {wae }}=2 \cdot p_{w f}
\end{aligned}
$$


As pressões nos silos da classe 3 são obtidas por meio das equações propostas pela teoria de Rotter. O EUROCODE sugere que o cálculo das pressões seja realizado para pelo menos três valores do raio do canal de fluxo $\left(r_{c}\right)$ a saber:

$$
\begin{aligned}
& r_{c}=0,1 \cdot D \\
& r_{c}=0,175 \cdot D \\
& r_{c}=0,25 \cdot D
\end{aligned}
$$

A norma alemã (DIN) é um pouco mais conservadora, recomendando que sejam adotados os seguintes valores raio do canal de fluxo $\left(r_{c}\right)$ :

$$
\begin{aligned}
& r_{c}=0,25 \cdot D \\
& r_{c}=0,375 \cdot D \\
& r_{c}=0,45 \cdot D
\end{aligned}
$$

A excentricidade do canal de fluxo $\left(e_{c}\right)$ é dada por:

$$
e_{c}=0,5 . D \cdot\left\{\frac{\mu_{m}}{\tan \phi_{i m}}\left(1-2 \cdot \frac{r_{c}}{D}\right)+\left(1-\frac{\mu_{m}}{\tan \phi_{i m}}\right) \sqrt{1-2 \cdot \frac{r_{c}}{D}}\right\}
$$

A pressão horizontal na parede em contado com a zona de fluxo ( $\left.p_{\text {hce }}\right)$, é calculada de forma idêntica à teoria de Rotter, utilizando a equação 3.42 e os parâmetros das equações 3.33 a 3.41, expostos na teoria de Rotter, no capítulo 3 .

Diferente da teoria de ROTTER, o EUROCODE considera o valor da pressão na parede vertical distante do canal de fluxo, onde o sólido permanece estável ( $p_{\text {hse }}$ ) igual à pressão horizontal estática após o enchimento do silo $\left(p_{h f}\right)$, ou seja:

$$
p_{\text {hse }}=p_{\text {hf }}
$$

A pressão de atrito na parede vertical distante do canal de fluxo, onde o sólido permanece estável ( $p_{\text {wse }}$ ), deve ser tomada como sendo a pressão de atrito após o enchimento do silo $\left(p_{w f}\right)$ :

$$
p_{w s e}=p_{w f}
$$

Além disso, uma nova distribuição de pressão é adotada para o lado da parede adjacente ao canal de fluxo $\left(p_{\text {hae }}\right)$ calculada como segue:

$$
p_{\text {hae }}=2 . p_{\text {hf }}-p_{\text {hce }}
$$

E a pressão de atrito na parede adjacente ao canal de fluxo ( $\left.p_{\text {hae }}\right)$ é dada por:

$$
p_{\text {wae }}=\mu \cdot p_{\text {hae }}
$$




\subsubsection{Pressões na tremonha}

As pressões nas paredes de tremonhas concêntricas são calculadas pela teoria de Walker (1966), explicada no capítulo 3. As normas EUROCODE e DIN não apresentam um método de cálculo para o caso de tremonhas excêntricas.

Um método alternativo de cálculo para prever as pressões em tremonhas concêntricas consiste em admitir que a pressão na tremonha seja a soma das componentes ilustradas na Figura 5.3:

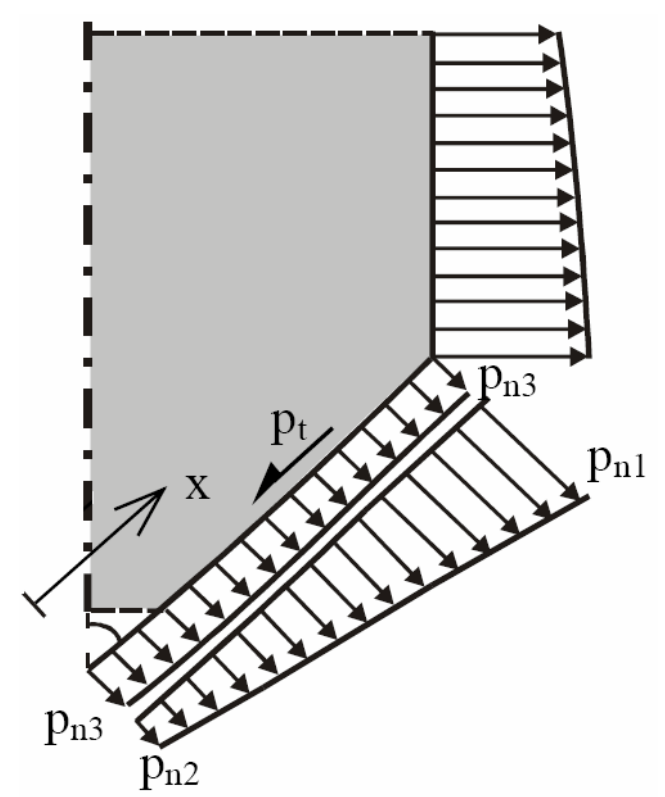

Figura 5.3 - Distribuição de pressões nas tremonhas pelo método alternativo. Fonte: EUROCODE (2002).

Ou seja, a pressão normal de carregamento $p_{n f}$ na tremonha é dada por:

$$
p_{n f}=p_{n 3}+p_{n 2}+\left(p_{n 1}-p_{n 2}\right) \cdot \frac{x}{l_{h}}
$$

Sendo:

$$
\begin{aligned}
& p_{n 1}=p_{v f t} \cdot\left(C_{b} \cdot \operatorname{sen}^{2} \beta+\cos ^{2} \beta\right) \\
& p_{n 2}=p_{v f t} \cdot C_{b} \cdot \operatorname{sen}^{2} \beta \\
& p_{n 3}=3 \cdot \frac{A}{U} \cdot \frac{\gamma \cdot K_{s}}{\sqrt{\mu_{h}}} \cdot \cos ^{2} \beta
\end{aligned}
$$

Com $l_{h}$ sendo o comprimento da parede da tremonha. A pressão estática de atrito na tremonha é calculada por:

$$
p_{t f}=p_{n f} \cdot \mu_{h}
$$




\subsection{Norma australiana AS 3774 (1996)}

\subsubsection{Propriedades dos produtos armazenados}

As propriedades físicas da maioria dos produtos armazenados também são tabeladas pela AS 3774, mas devem ser utilizadas em último caso, quando não existir a possibilidade de realizar ensaios com os produtos. Os procedimentos de ensaio são normalizados e análogos àqueles apresentados no capítulo 2.

A norma australiana também utiliza valores representativos (limites inferiores e superiores) para cada parâmetro do produto como mostrado na Tabela 3.1. 0 valor do coeficiente $\mathrm{K}$ deve ser calculado de acordo com a teoria de Walker (1966), ou seja, de acordo com a equação 2.12 , limitando $K \geq 0,35$ para garantir que o ângulo de atrito não esteja superestimado.

O ângulo de atrito com a parede não pode exceder o ângulo de atrito interno do produto, caso contrário, o produto vai deslizar sobre ele mesmo próximo à parede. Observações experimentais indicam que o ângulo de atrito interno dinâmico do produto é, usualmente, menor do que o ângulo de atrito interno estático. Então, uma vez que o sólido inicia seu fluxo, o plano de ruptura é frequentemente o principal e o valor do ângulo efetivo é levemente diminuído.

\subsubsection{Classificação dos silos}

A norma Australiana possui uma classificação mais completa das unidades de armazenamento, sendo sua classificação de acordo com a Tabela 5.3: 
Tabela 5.3 - Classificação dos silos conforme AS 3774.

\begin{tabular}{|c|c|}
\hline Critério & Classificação \\
\hline \multirow{3}{*}{ Esbeltez $\left(h_{c} / D\right)$} & Baixos $(h / D<1)$ \\
\hline & Medianamente esbeltos $(1 \leq h / D \leq 3)$ \\
\hline & Esbeltos $(h / D>3)$ \\
\hline \multirow{5}{*}{$\begin{array}{l}\text { Tipo de fluxo durante a } \\
\text { descarga }\end{array}$} & Fluxo de massa \\
\hline & Fluxo de funil \\
\hline & Fluxo em tubo \\
\hline & Fluxo expandido \\
\hline & Fluxo excêntrico \\
\hline \multirow{4}{*}{ Geometria do fluxo } & $\begin{array}{l}\text { Fluxo simétrico (centro de gravidade do canal de fluxo } \\
\text { coincide com o eixo vertical do silo) }\end{array}$ \\
\hline & Fluxo plano simétrico (tremonha retangular) \\
\hline & Fluxo assimétrico \\
\hline & Fluxo de superfície livre em silos baixos \\
\hline \multirow{4}{*}{$\begin{array}{l}\text { Rugosidade das paredes } \\
\text { internas }\end{array}$} & Muito lisa \\
\hline & Lisa \\
\hline & Rugosa \\
\hline & Corrugada \\
\hline \multirow{3}{*}{ Flexibilidade das paredes } & Paredes rígidas $(\mathrm{D} / \mathrm{t}<100)$ \\
\hline & Paredes semi-rígidas $(100<\mathrm{D} / \mathrm{t}<500)$ \\
\hline & Paredes finas $(D / t>500)$ \\
\hline \multirow{2}{*}{$\begin{array}{l}\text { Continuidade das paredes } \\
\text { na direção vertical }\end{array}$} & $\begin{array}{l}\text { Paredes contínuas como silos de aço completamente } \\
\text { soldados ou silos de concreto protendido }\end{array}$ \\
\hline & Paredes descontínuas, como as de aço corrugado \\
\hline \multirow{7}{*}{$\begin{array}{l}\text { Formato da seção } \\
\text { transversal }\end{array}$} & Circular \\
\hline & Quadrada \\
\hline & Retangular \\
\hline & Estrela \\
\hline & Poligonal \\
\hline & Anelar \\
\hline & Irregular \\
\hline \multirow{4}{*}{$\begin{array}{l}\text { Posição da abertura de } \\
\text { descarga }\end{array}$} & $\begin{array}{l}\text { Boca de saída circular ou quadrada localizada no centro da } \\
\text { seção transversal projetada para o fluxo uniforme }\end{array}$ \\
\hline & $\begin{array}{l}\text { Boca de saída retangular localizada no centro da seção } \\
\text { transversal }\end{array}$ \\
\hline & $\begin{array}{l}\text { Boca de saída circular ou quadrada excêntrica isolada ou } \\
\text { múltiplas saídas ao redor de uma circunferência }\end{array}$ \\
\hline & Abertura de descarga situada na parede do silo \\
\hline \multirow{5}{*}{$\begin{array}{l}\text { Meios de promoção do } \\
\text { fluxo }\end{array}$} & Fluxo gravitacional \\
\hline & Vibração mecânica \\
\hline & Introdução de ar sobre toda a superfície do fundo do silo \\
\hline & Equipamentos dinâmicos de impacto \\
\hline & Promoção combinada de fluxo \\
\hline
\end{tabular}

O procedimento de diferenciar os silos em classes de confiabilidade não é adotado pela norma australiana. 


\subsubsection{Pressões estáticas nas paredes verticais de silos esbeltos}

A pressão estática horizontal $\left(p_{h f}\right)$, assim como a pressão estática vertical no produto $\left(p_{v f}\right)$ e a pressão de atrito $\left(p_{w f}\right)$ são calculadas de acordo com a teoria de Janssen, portanto, equações, 3.02, 3.03 e 3.05, sendo o parâmetro $\mathrm{K}$ calculado segundo teoria de Walker (1966), equação 2.12.

Esta norma prevê aumentos na pressão estática normal à parede, quando qualquer uma das seguintes situações ocorrer: rápido carregamento, expansão do produto armazenado devido à absorção de umidade, carregamento excêntrico, sucção devido a mudanças térmicas adiabáticas, entre outras.

\subsubsection{Pressões dinâmicas nas paredes verticais de silos esbeltos}

As pressões de descarga ou pressões dinâmicas para a norma australiana são calculadas a partir das pressões estáticas multiplicadas por coeficientes de sobrepressão (C), como no EUROCODE e DIN (equação 5.05 e 5.06).

Somente a forma de determinação deste coeficiente que é diferente entre as normas. O coeficiente de sobrepressão aplicado à pressão horizontal $\left(C_{h}\right)$ deve ser o maior valor entre:

$$
\begin{aligned}
& C_{h}=7,6\left(\frac{h}{D}\right)^{0,06}-6,4 \\
& \text { e } \\
& C_{h}=1,2 c_{c}
\end{aligned}
$$

Sendo:

$h=$ altura equivalente do silo (Figura 3.1) e

$c_{c}=$ coeficiente de geometria do fluxo.

Em silos com fluxo de funil, o coeficiente de descarga $C_{h}$ pode ser reduzido a partir da altura da transição efetiva $\left(h_{t r}\right)$ :

$$
h_{t r}=0,4 D \tan \phi_{i}
$$

admitindo, a partir dessa altura, uma interpolação linear para obter o coeficiente multiplicador entre o valor de $p_{v f}\left(z=h_{t}\right)$ e 1,2. O coeficiente de descarga majorador da pressão de atrito $\left(C_{w}\right)$ é igual a 1,2 para silos de fluxo axissimétrico. 


\subsubsection{Pressões na tremonha}

A pressão vertical nas paredes da tremonha é calculada pela expressão proposta por Walker (1966), não incluindo o caso de tremonhas excêntricas.

\subsubsection{Considerações sobre descarga excêntrica}

Em unidades de armazenamento projetadas com abertura excêntrica, devem ser adotadas pressões assimétricas a partir da adição ou subtração das pressões simétricas definidas nos itens 5.2.2 e 5.2.3, conforme ilustra a Figura 5.4.

Excentricidades menores que $10 \%$ de D são desprezadas, executando 0 cálculo como se o silo fosse de saída concêntrica. Para maiores excentricidades, no lado oposto, a pressão de descarga sofre um acréscimo que varia de zero a um valor máximo $\left(p_{h s e}\right)$, igual a:

$$
p_{\text {hse } \max }=p_{\text {he }} \cdot\left(\frac{e_{o}}{D}-0,1\right) \geq 0
$$

Que deve ser aplicada numa altura $h_{D}$ (Figura 5.4) de:

$$
h_{D}=\left(0,5 \cdot D+e_{o}\right) \cdot \tan \phi_{i}
$$

A distribuição de pressões varia em função do ângulo $\theta$ :

$$
\begin{array}{ll}
p_{\text {hse }}=p_{\text {hse, } \max } \cdot(-\cos \theta) & \text { para } 90^{\circ} \leq \theta \leq 270^{\circ} \\
p_{\text {hse }}=0 & \text { para }-90^{\circ} \leq \theta \leq 90^{\circ}
\end{array}
$$

No lado próximo à excentricidade atua uma pressão de descarga de intensidade $p_{h c e, r e d}$ que deve ser reduzida, sendo:

$$
p_{\text {hce }, \text { red }}=1,5 \cdot p_{h e} \cdot\left(\frac{e_{o}}{D}-0,1\right)
$$

que deve ser aplicada, no caso de silos cilíndricos, numa altura igual ao diâmetro do silo e num comprimento variando de $-d_{e}$ à $+d_{e}$ do perímetro do silo:

$$
d_{e}=1,83 \cdot\left(1-0,43 \cdot e_{o} / D\right)
$$

que pode também ser definida em função do comprimento angular $\beta_{e}$, dado por:

$$
\beta_{e}=105-105 \cdot \frac{e_{o}}{D}
$$




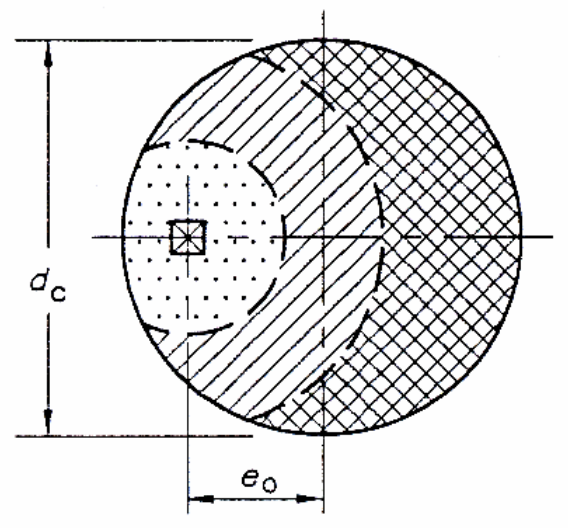

Seção A-A

Zonas de fluxo

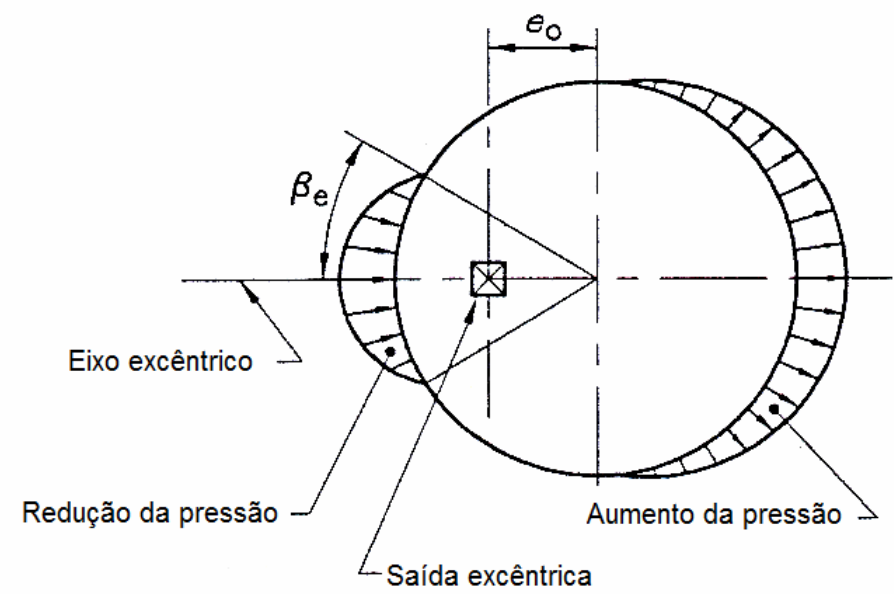

Variação circunferencial da pressão na parede

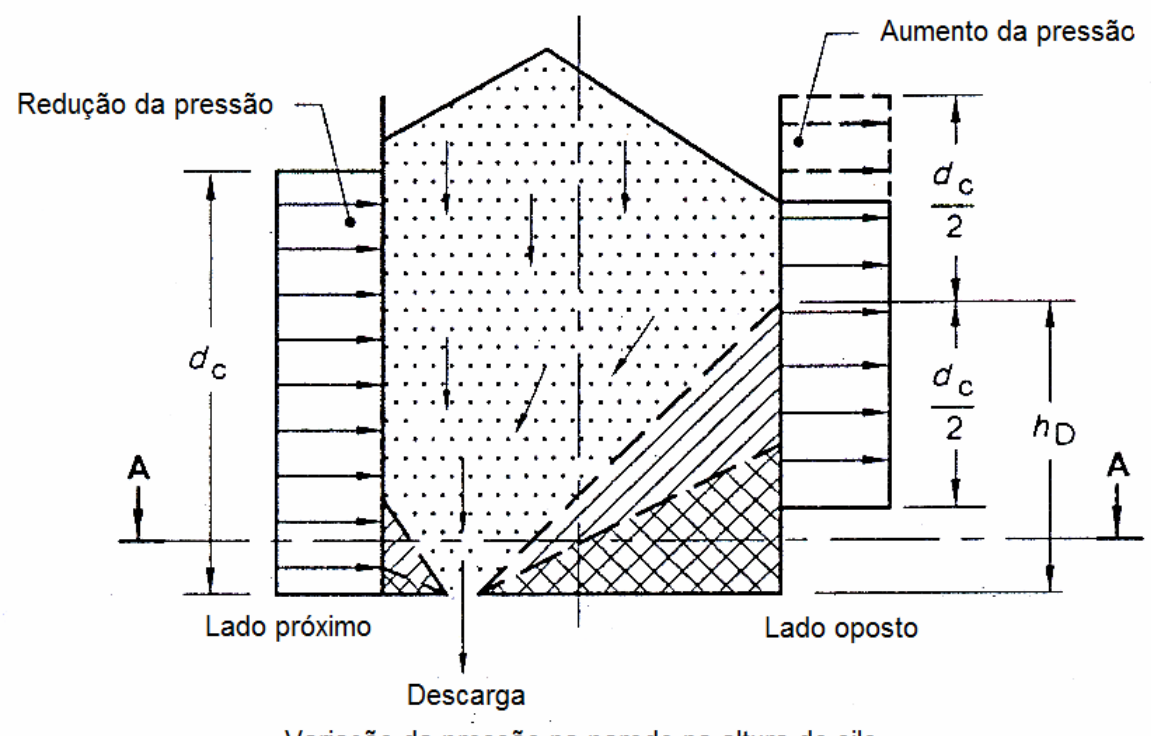

Variação da pressão na parede na altura do silo

LEGENDA:

$\because \because \because$ Zona de fluxo principal Zona

Figura 5.4 - Distribuição de pressões para fluxo excêntrico. Fonte: AS 3774 (1996).

\subsection{International Standard ISO 11697 (1995)}

\subsubsection{Considerações iniciais}

O cálculo da distribuição de pressões nas paredes do silo proposto pela norma ISO está sujeito às seguintes limitações:

- contínuo processo de enchimento do silo, com efeitos de inércia desprezíveis e pressões de impacto irrelevantes; 
- diâmetro máximo da partícula estocada menor do que $10 \%$ da relação $(\mathrm{A} / \mathrm{U})$;

- fluxo contínuo e centrado nas situações onde são utilizados dispositivos de descarga;

- em silos com fundo plano o produto é de fluxo livre e possui baixa coesão;

- excentricidade de carregamento e de descarga em relação à linha de centro da unidade menor que $0,25 \mathrm{D}$ para silos cilíndricos;

- relação altura diâmetro menor do que 10; altura menor que $100 \mathrm{~m}$ e diâmetro menor que $50 \mathrm{~m}$.

\subsubsection{Classificação}

De acordo com a esbeltez, os silos podem ser classificados em silos esbeltos, medianamente esbeltos e baixos, conforme mostra a Tabela $5.4 \mathrm{em}$ :

Tabela 5.4 - Classificação dos silos de acordo com a esbeltez segundo a norma ISO 11697 (1995).

\begin{tabular}{|l|l|}
\hline Classificação & Limites da Relação hc/D \\
\hline Silo esbelto & $\mathrm{h} / \mathrm{D} \geq 1,5$ \\
\hline Silo medianamente esbelto & $1 \geq \mathrm{h} / \mathrm{D} \geq 1,5$ \\
\hline Silo baixo & $\mathrm{h} / \mathrm{D} \leq 1$ \\
\hline
\end{tabular}

\subsubsection{Pressões estáticas nas paredes verticais de silos esbeltos}

O cálculo das pressões estáticas recomendadas pela ISO 11697 (1995) é feito aplicando-se a formulação de Janssen (equações 3.02, 3.03, 3.05 e 3.06), com o valor do parâmetro $K$ da equação 2.14.

\subsubsection{Pressões dinâmicas nas paredes verticais de silos esbeltos}

O cálculo das pressões dinâmicas segue a mesma metodologia das demais normas, utilizando coeficientes de sobrepressão para majorar as pressões estáticas. O coeficiente de sobrepressão é dado por:

$$
C_{h}=1,35+0,02\left(\phi_{i}-30^{\circ}\right)<1,35
$$

Também é prevista uma pressão adicional de magnitude:

$$
p_{p e}=0,2 p_{\text {he }}
$$

atuando numa área quadrada de comprimento $\mathrm{s}$, em qualquer altura do silo, calculado por: 


$$
s=0,8 \frac{A}{U}
$$

\subsubsection{Pressões na tremonha}

As pressões na tremonha são calculadas pelo método alternativo utilizado pelas normas EUROCODE e DIN, não incluindo caso de tremonhas excêntricas.

\subsubsection{Considerações sobre descarga excêntrica}

A norma ISO 11697 (1995) não inclui o cálculo das pressões em silos cuja excentricidade de descarga $\left(\mathrm{e}_{\mathrm{o}}\right)$ excede $25 \%$ de do diâmetro $\mathrm{D}$ do silo. Para silos com $e_{o}<0,25 D$, a pressão adicional deve ser aumentada por um fator $B_{e}$ dado na seguinte equação:

$$
B_{e}=1+4 \cdot \frac{e_{o}}{D}
$$

\subsection{Considerações finais sobre o capítulo}

A determinação das pressões estáticas no corpo do silo, em todas as normas estudadas, se baseia na teoria de Janssen (1895). Também em todas elas, as pressões dinâmicas são obtidas multiplicando-se as pressões estáticas por coeficientes de sobrepressão. A determinação destes coeficientes difere muito entre as normas sendo que algumas delas fornecem valores fixos enquanto outras recomendam a utilização de equações empíricas. Nenhum destes procedimentos leva em conta os efeitos da dilatância do produto, a mudança do estado de tensão, variação da sobrepressão ao longo da altura do silo, entre outros.

Qualquer excentricidade indesejada durante 0 carregamento ou descarregamento e outras incertezas de projeto são consideradas por meio de pressões adicionais. Ou seja, até mesmo em silos concêntricos devem atuar as pressões adicionais, que são pressões assimétricas aplicadas no corpo do silo. Não existe um consenso entres as normas em relação à altura de aplicação desta pressão e nem sobre sua variação ao longo da seção transversal do silo. A norma ISO, por exemplo, afirma que ela pode ser aplicada em qualquer altura do silo em paredes opostas enquanto o EUROCODE e DIN fornecem uma expressão para o cálculo da altura e adotam uma variação senoidal da intensidade da pressão ao longo de toda a circunferência do silo. 
A diferença entre silos concêntricos e excêntricos, nos quais a excentricidade não excede $25 \%$ de $\mathrm{D}$, é a intensidade das pressões adicionais, que aumenta caso a boca de saída seja excêntrica.

Quando se trata de silos com grande excentricidade (e/D $>25 \%$ ), as normas EUROCODE, DIN e AS adotam um novo método que considera pressões assimétricas ao redor da circunferência, enquanto que a norma ISO não admite este tipo de situação. As normas EUROCODE e DIN adotaram recentemente a teoria desenvolvida por Rotter para cobrir este tipo de excentricidade e a norma australiana também adota um novo caso de carregamento mais simplificado e empírico.

Na tremonha, a teoria de Walker é adotada para a maioria das normas, sendo que nenhuma delas propõe um método de cálculo das pressões em tremonhas excêntricas. 


\section{ANÁLISE NUMÉRICA}

A simulação numérica foi feita com a utilização do programa ANSYS que é um programa de análise estrutural baseado no método dos elementos finitos. Escolhidas as geometrias para o estudo, a análise numérica consistiu em:

- determinar experimentalmente as propriedades físicas dos produtos analisados, que são o farelo de milho e a soja;

- a partir dos ensaios experimentais com os produtos, escolher o modelo de comportamento e seus parâmetros para a análise numérica;

- definir tipos de elementos a serem utilizados na análise numérica;

- determinar a densidade da malha do modelo;

- parametrizar o contato entre o produto e a parede.

Obtidos os resultados numericamente, foi possível compará-los com as pressões previstas pelas normas estudadas.

\subsection{Geometrias dos silos estudados}

Os silos analisados possuem paredes verticais cilíndricas compostas por chapas de aço corrugado, cujas dimensões são ilustradas na Figura 6.1. As tremonhas foram consideradas como sendo de paredes lisas.

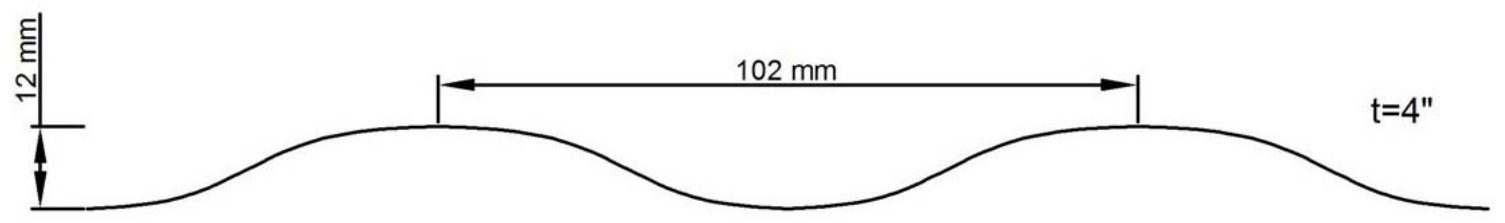

Figura 6.1 - Dimensões, em milímetros, da parede adotada.

Para fins de análise, foram adotadas três geometrias: silo de fundo plano, silo com tremonha concêntrica e silo com tremonha excêntrica. $O$ silo de fundo plano possui boca de saída de grande excentricidade, ou seja, a relação $e_{0} / D$ superior a 25\%. A escolha desta geometria permite o estudo da teoria de Rotter (1986), 
exposta no item 3.7 que foi incluída nas normas mais recentes de pressões em silos pelos códigos normativos EUROCODE (2002) e DIN (2005).

A segunda geometria corresponde a um silo com tremonha concêntrica porque nesta situação é possível aplicar as metodologias de cálculo propostas pelas normas analisadas e ainda permite a utilização de modelos numéricos bidimensionais axissimétricos, que reduzem consideravelmente 0 custo computacional da análise. A terceira geometria é um silo com tremonha excêntrica, escolhida para o estudo efetivo da descarga excêntrica em silos com tremonha.

Os três silos estudados são classificados como esbeltos de acordo com as quatro normas analisadas. O que apresenta fundo plano é de grande excentricidade com relação $e_{o} / D$ igual a $30 \%$. A Tabela 6.1 contém as dimensões do silo de fundo plano, cujo desenho esquemático é ilustrado na Figura 6.2.

Tabela 6.1 - Características e dimensões do silo de fundo plano (silo 1).

\begin{tabular}{|l|c|c|c|c|c|c|c|}
\hline Produto & $\begin{array}{c}\mathbf{D} \\
(\mathbf{m})\end{array}$ & $\begin{array}{c}\mathbf{H} \\
(\mathbf{m})\end{array}$ & $\begin{array}{c}\mathbf{r}_{\mathrm{o}} \\
(\mathbf{m})\end{array}$ & $\begin{array}{c}\mathbf{e}_{\mathrm{o}} \\
(\mathbf{m})\end{array}$ & $\begin{array}{c}\mathbf{h}_{\mathbf{c}} \\
(\mathbf{m})\end{array}$ & $\begin{array}{c}\mathbf{h}_{\text {tp }} \\
(\mathbf{m})\end{array}$ & $\begin{array}{c}\mathbf{h}_{\text {ta }} \\
(\mathbf{m})\end{array}$ \\
\hline F. milho & 3,0 & 11,0 & 0,3 & 0,9 & 10,4 & 0,6 & 0,9 \\
\hline Soja & 3,0 & 11,0 & 0,3 & 0,9 & 10,5 & 0,5 & 0,7 \\
\hline
\end{tabular}

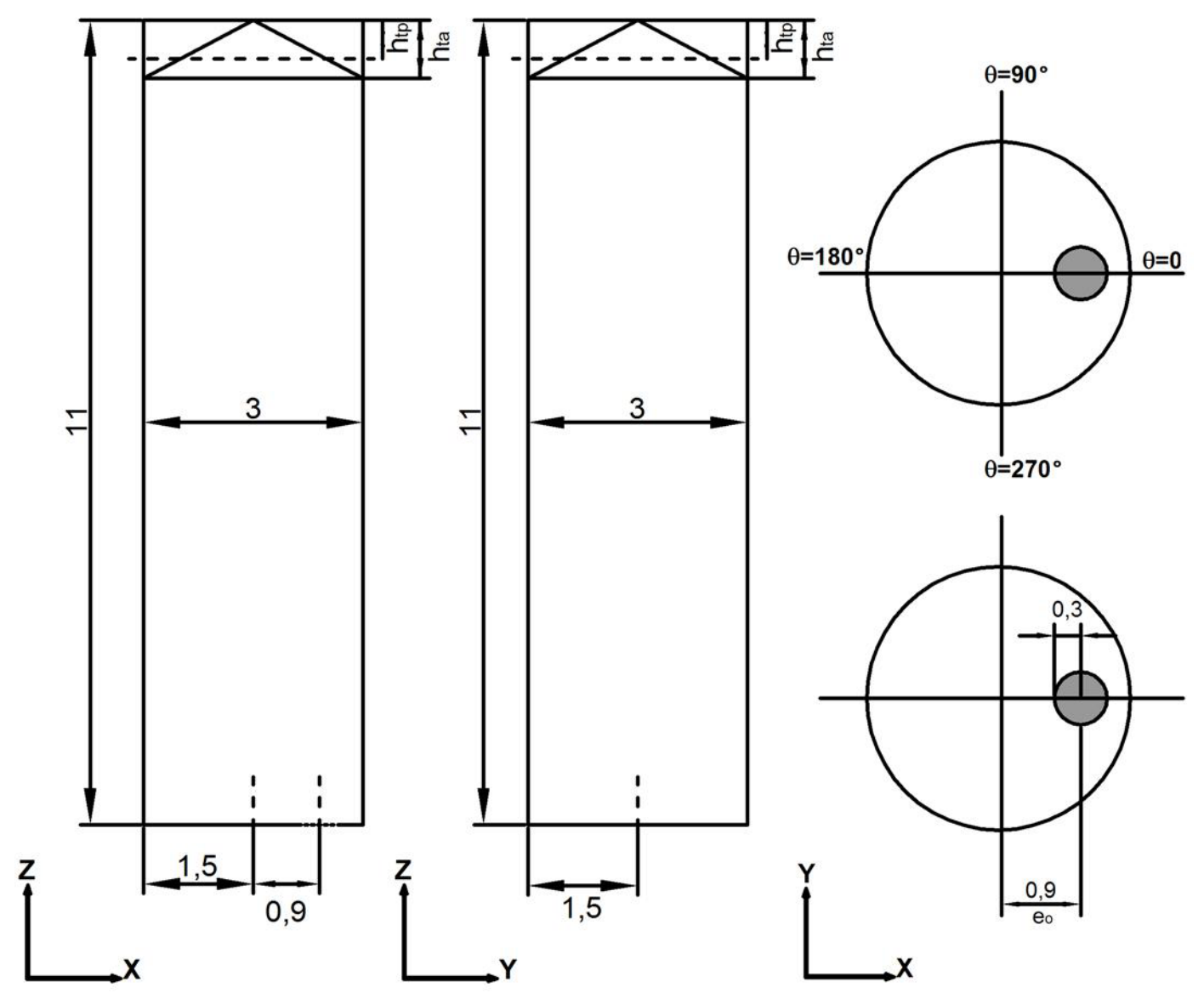

Figura 6.2- Desenho esquemático e dimensões, em metros, do silo de fundo plano. 
A Tabela 6.2 contém as dimensões do silo com tremonha concêntrica, cujo desenho esquemático é ilustrado na Figura 6.3.

Tabela 6.2 - Características e dimensões do silo com tremonha (silo 2).

\begin{tabular}{|l|c|c|c|c|c|c|c|c|c|c|c|c|c|}
\hline Produto & $\begin{array}{c}\mathbf{D} \\
(\mathbf{m})\end{array}$ & $\begin{array}{c}\mathbf{H} \\
(\mathbf{m})\end{array}$ & $\begin{array}{c}\mathbf{h}_{\mathbf{f}} \\
(\mathbf{m})\end{array}$ & $\begin{array}{c}\mathbf{h}_{\mathbf{h}} \\
(\mathbf{m})\end{array}$ & $\begin{array}{c}\mathbf{e}_{\mathbf{o}} \\
(\mathbf{m})\end{array}$ & $\begin{array}{c}\mathbf{r}_{\mathrm{o}} \\
(\mathbf{m})\end{array}$ & $\begin{array}{c}\boldsymbol{\beta}_{\mathrm{i}} \\
\left.\mathbf{(}^{\circ}\right)\end{array}$ & $\begin{array}{c}\boldsymbol{\beta}_{\mathbf{s}} \\
\left.\mathbf{(}^{(}\right)\end{array}$ & $\begin{array}{c}\boldsymbol{\alpha}_{\mathrm{i}} \\
\left.\mathbf{(}^{\circ}\right)\end{array}$ & $\begin{array}{c}\boldsymbol{\alpha}_{\mathbf{s}} \\
\left.\mathbf{(}^{\circ}\right)\end{array}$ & $\begin{array}{c}\mathbf{h}_{\text {tp }} \\
(\mathbf{m})\end{array}$ & $\begin{array}{c}\mathbf{h}_{\text {ta }} \\
(\mathbf{m})\end{array}$ & $\begin{array}{c}\mathbf{h}_{\mathbf{c}} \\
(\mathbf{m})\end{array}$ \\
\hline F. milho & 3,0 & 13,8 & 2,8 & 3,5 & 0 & 0,3 & 23,2 & 23,2 & 66,8 & 66,8 & 0,6 & 0,9 & 10,4 \\
\hline Soja & 3,0 & 13,8 & 2,8 & 3,5 & 0 & 0,3 & 23,2 & 23,2 & 66,8 & 66,8 & 0,5 & 0,7 & 10,5 \\
\hline
\end{tabular}
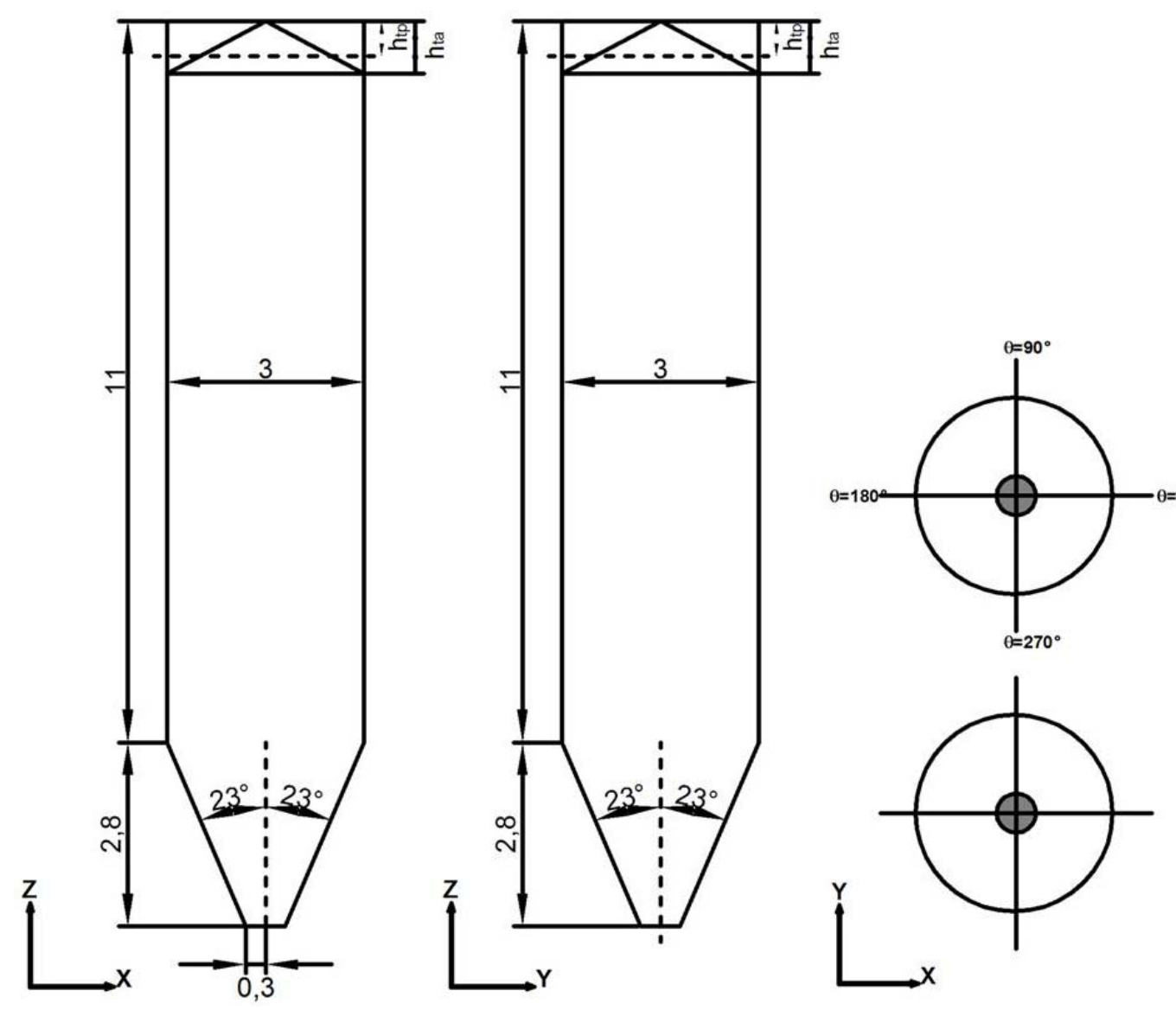

Figura 6.3- Desenho esquemático e dimensões, em metros, do silo com tremonha concêntrica.

O ângulo entre a parede da tremonha com a direção vertical foi calculado para que houvesse fluxo de massa nos silos com tremonha. O silo com tremonha excêntrica possui relação $e_{0} / D$ igual à $25 \%$, valor limite segundo as normas EUROCODE, DIN e AS. A Tabela 6.3 contém as dimensões do silo com tremonha excêntrica, cujo desenho esquemático é ilustrado na Figura 6.4.

Tabela 6.3 - Características e dimensões do silo com tremonha (silo 2).

\begin{tabular}{|l|c|c|c|c|c|c|c|c|c|c|c|c|c|}
\hline Produto & $\begin{array}{c}\mathbf{D} \\
(\mathbf{m})\end{array}$ & $\begin{array}{c}\mathbf{H} \\
(\mathbf{m})\end{array}$ & $\begin{array}{c}\mathbf{h}_{\mathbf{f}} \\
(\mathbf{m})\end{array}$ & $\begin{array}{c}\mathbf{h}_{\mathbf{h}} \\
(\mathbf{m})\end{array}$ & $\begin{array}{c}\mathbf{e}_{\mathrm{o}} \\
(\mathbf{m})\end{array}$ & $\begin{array}{c}\mathbf{r}_{\mathrm{o}} \\
(\mathbf{m})\end{array}$ & $\begin{array}{c}\boldsymbol{\beta}_{\mathrm{i}} \\
\left.\mathbf{(}^{\circ}\right)\end{array}$ & $\begin{array}{c}\boldsymbol{\beta}_{\mathbf{s}} \\
\left.\mathbf{(}^{\circ}\right)\end{array}$ & $\begin{array}{c}\boldsymbol{\alpha}_{\mathrm{i}} \\
\left.\mathbf{(}^{\circ}\right)\end{array}$ & $\begin{array}{c}\boldsymbol{\alpha}_{\mathbf{s}} \\
\left.\mathbf{(}^{\circ}\right)\end{array}$ & $\begin{array}{c}\mathbf{h}_{\mathbf{t p}} \\
(\mathbf{m})\end{array}$ & $\begin{array}{c}\mathbf{h}_{\mathbf{t a}} \\
(\mathbf{m})\end{array}$ & $\begin{array}{c}\mathbf{h}_{\mathbf{c}} \\
(\mathbf{m})\end{array}$ \\
\hline F. milho & 3,0 & 13,8 & 2,8 & 3,5 & 0,6 & 0,3 & 9,1 & 34,9 & 55,1 & 80,9 & 0,6 & 0,9 & 10,4 \\
\hline Soja & 3,0 & 13,8 & 2,8 & 3,5 & 0,6 & 0,3 & 9,1 & 34,9 & 55,1 & 80,9 & 0,5 & 0,7 & 10,5 \\
\hline
\end{tabular}




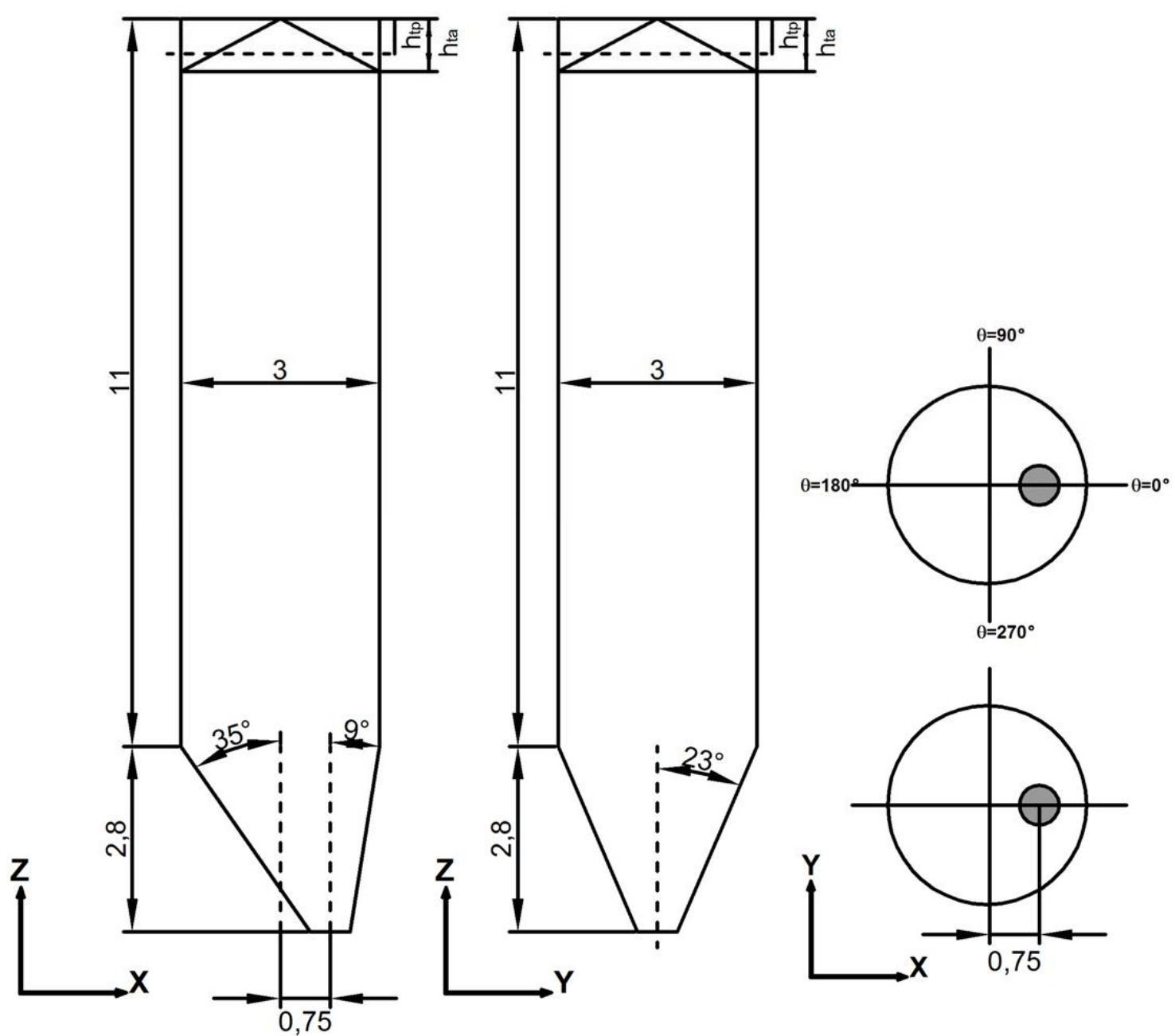

Figura 6.4- Desenho esquemático e dimensões, em metros, do silo com tremonha excêntrica.

Segundo McLean (1986), o maior ângulo entre a parede da tremonha com a direção vertical para que o fluxo seja de massa, é dado por:

$$
\begin{aligned}
& \beta_{\text {crit }}=0,5\left[180-\cos ^{-1}\left(\frac{\left(1-\operatorname{sen} \phi_{e}\right.}{2 \operatorname{sen} \phi_{e}}\right)-\left(\phi_{w}+\operatorname{sen}^{-1}\left(\frac{\operatorname{sen} \phi_{w}}{\operatorname{sen} \phi_{e}}\right)\right)\right] \\
& \beta_{\text {crit }}=0,5\left[180-\cos ^{-1}\left(\frac{(1-\operatorname{sen} 38,3}{2 \operatorname{sen} 38,3}\right)-\left(\phi_{w}+\operatorname{sen}^{-1}\left(\frac{\operatorname{sen} 13,65}{\operatorname{sen} 38,3}\right)\right)\right] \\
& \beta_{\text {crit }}=35,92^{\circ}
\end{aligned}
$$

Ou seja, para garantir o fluxo de massa, o ângulo entre a parede da tremonha com a direção vertical deve ser menor que $35,9^{\circ}$. Foi adotado, para o silo concêntrico, o valor de $\beta=35^{\circ}$. 


\subsection{Determinação das propriedades físicas dos produtos}

Os produtos analisados foram: (a) farelo de milho e (b) soja, devido a sua grande produção nacional e por ser um produto granular de fluxo livre. Os resultados das propriedades físicas dos produtos foram importantes para o cálculo das pressões segundo as normas internacionais analisadas e também para definir os parâmetros utilizados durante a modelagem numérica.

Os testes realizados para obter as propriedades físicas foram: determinação da umidade e temperatura; teste de granulometria, teste de cisalhamento direto com o produto e teste de cisalhamento direto com a parede.

\subsubsection{Ensaio de umidade e temperatura dos produtos}

Sabendo-se que as condições de temperatura e umidade dos produtos interferem no seu comportamento, foi medido o teor de umidade e temperatura dos produtos com o aparelho medidor de umidade digital modelo G800 (Figura 6.5).
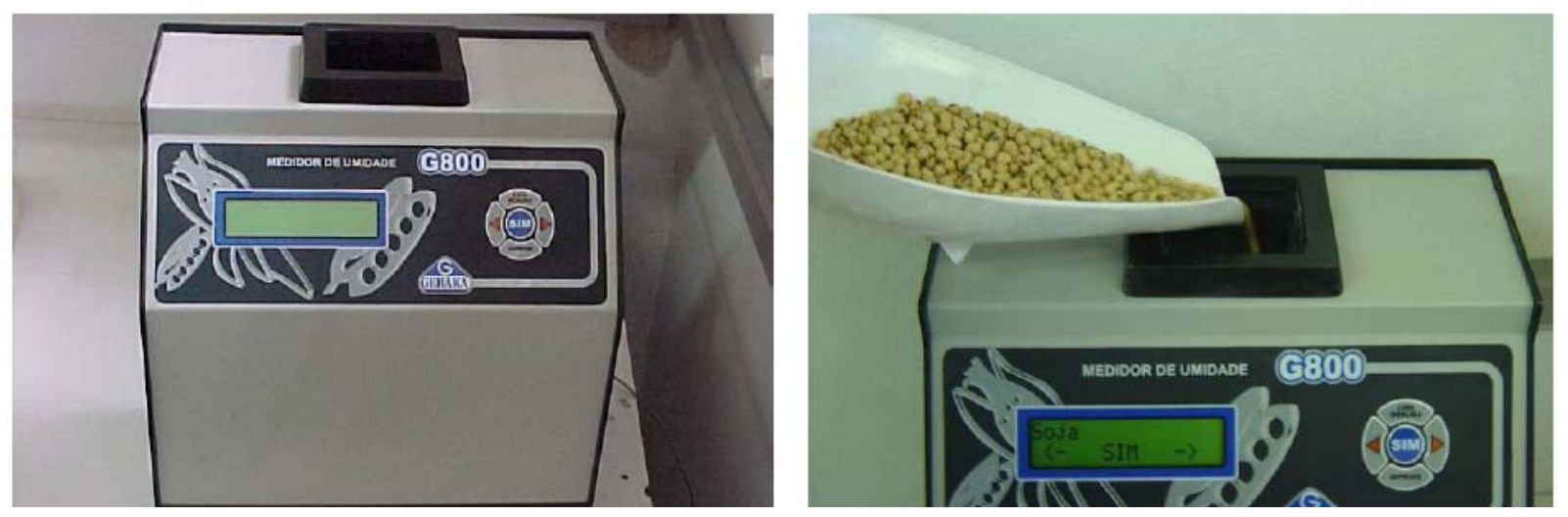

Figura 6.5 - Aparelho para medidas de umidade, temperatura e peso específico.

A umidade obtida para o farelo de milho foi de $12,4 \%$ e temperatura de $25,7^{\circ} \mathrm{C}$. Para a soja a umidade foi de $10,7 \%$ e temperatura de $24,7^{\circ} \mathrm{C}$. Portanto, estas são as condições de umidade e temperatura para os quais os resultados dos demais testes são válidos.

\subsubsection{Ensaio de granulometria}

O teste de granulometria é importante para indicar a quantidade de partículas finas do produto. Este teste foi realizado a partir do peneirador automático da Solotest da Figura 6.6 durante o tempo de 15 minutos. 


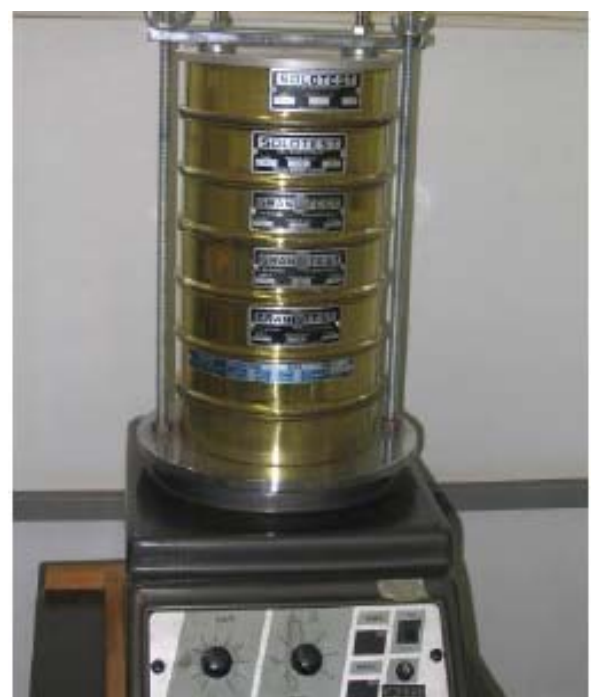

Figura 6.6- Aparelho utilizado no ensaio granulométrico.

Os resultados obtidos no teste de granulometria com o farelo de milho encontram-se na Tabela 6.4 .

Tabela 6.4 - Resultados do teste de granulometria com o farelo de milho.

\begin{tabular}{|c|c|c|c|c|c|c|c|c|}
\hline Produto & Peneira & $\begin{array}{c}\text { Malha \# } \\
(\mathbf{m m})\end{array}$ & $\begin{array}{c}\text { Peneira } \\
(\mathbf{g})\end{array}$ & $\begin{array}{c}\text { Retido + } \\
\text { peneira } \mathbf{( g )}\end{array}$ & $\begin{array}{c}\text { Retido } \\
\mathbf{( g )}\end{array}$ & $\begin{array}{c}\text { Ret/acum. } \\
\mathbf{( g )}\end{array}$ & $\begin{array}{c}\text { \% } \\
\text { Ret. }\end{array}$ & $\begin{array}{c}\text { \% } \\
\text { Ret/acum }\end{array}$ \\
\hline \multirow{4}{*}{$\begin{array}{c}\text { Farelo } \\
\text { de } \\
\text { milho }\end{array}$} & ABNT 6 & 3,36 & 615,0 & 617,7 & 2,7 & 2,7 & 0,5 & 0,5 \\
\cline { 2 - 9 } & ASTM 8 & 2,38 & 454,0 & 471,0 & 17,0 & 19,7 & 3,4 & 3,9 \\
\cline { 2 - 9 } & ASTM 16 & 2,0 & 429,9 & 493,9 & 64,0 & 83,7 & 12,8 & 16,7 \\
\cline { 2 - 9 } & ASTM 16 & 1,18 & 449,9 & 698,5 & 248,6 & 332,3 & 49,7 & 66,5 \\
\cline { 2 - 9 } & ASTM 40 & 0,425 & 415,0 & 576,8 & 161,8 & 494,1 & 32,4 & 98,8 \\
\cline { 2 - 9 } & ASTM 100 & 0,149 & 382,4 & 388,2 & 5,8 & 499,9 & 1,2 & 100,0 \\
\cline { 2 - 9 }
\end{tabular}

Graficamente, na escala logarítimica, tem-se (Figura 6.7):

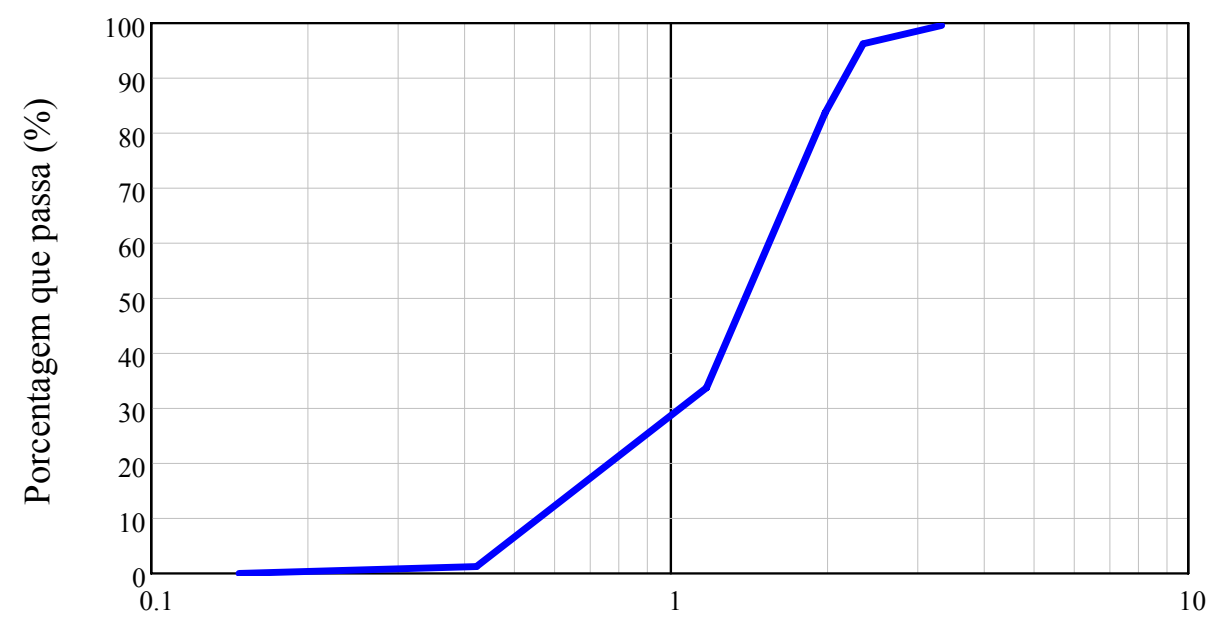

Diâmetro das partículas ( $\mathrm{mm})$

Figura 6.7 - Curva granulométrica do farelo de milho. 
Constata-se que quase a metade $(49 \%)$ do peso total do farelo de milho ficou retido na peneira de $1,18 \mathrm{~mm}$. Somente $1 \%$ do produto em peso é composto por partículas menores que $0,425 \mathrm{~mm}$. Segundo a classificação proposta por Calil (1984), exposta na Tabela 2.2, o farelo de milho é um produto granular.

Não foi necessário realizar o teste de granulometria com a soja porque o produto foi comprado pelo tamanho do grão, com partículas em sua maioria, maiores que 0,425 mm. Portanto, segundo a classificação proposta por Calil (1984), a soja é, assim como o farelo de milho, é um produto granular.

\subsubsection{Ensaio de cisalhamento direto com o produto}

As propriedades físicas dos produtos analisados foram obtidas a partir do ensaio de cisalhamento direto, utilizando o equipamento TSG 70-140 conhecido internacionalmente como Jenike Shear Tester (Figura 6.8). Os procedimentos de ensaios foram os recomendados no manual Standart Shear Testing Technique for Particulate Solids Using the Jenike Shear Cell (1989), elaborado pela Federação Européia de Engenharia Química.
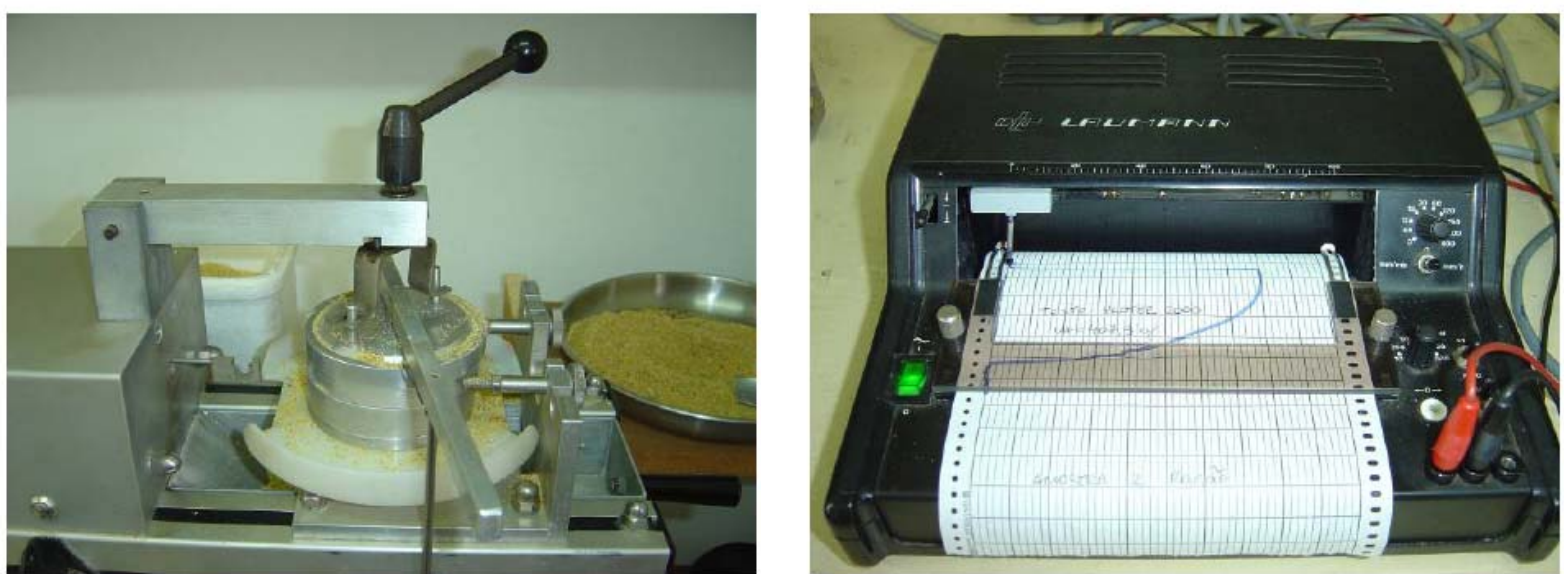

Figura 6.8- Equipamento de Jenike modelo TSG 70-140 e o ploter a ele conectado.

As amostras foram pré-cisalhadas com forças normais de pré-cisalhamento $\left(\mathrm{W}_{\mathrm{p}}\right)$ de $100 \mathrm{~N}, 70 \mathrm{~N}$ e $50 \mathrm{~N}$. Para cada uma delas, executaram-se três ensaios de cisalhamento com diferentes valores de forças normais de cisalhamento $\left(W_{s}\right)$. A Tabela 6.5 apresenta os níveis de carregamento de pré-cisalhamento e cisalhamento em Newton. 
Tabela 6.5 - Níveis de carregamentos utilizados nos ensaios com o produto armazenado.

\begin{tabular}{|c|c|c|c|c|c|}
\hline \multicolumn{2}{|c|}{ YL1 } & \multicolumn{2}{c|}{ YL2 } & \multicolumn{2}{c|}{ YL3 } \\
\hline $\mathbf{W}_{\mathbf{p}} \mathbf{( N )}$ & $\mathbf{W}_{\mathbf{s}}(\mathbf{N})$ & $\mathbf{W}_{\mathbf{p}} \mathbf{( N )}$ & $\mathbf{W}_{\mathbf{s}}(\mathbf{N})$ & $\mathbf{W}_{\mathbf{p}}(\mathbf{N})$ & $\mathbf{W}_{\mathbf{s}}(\mathbf{N})$ \\
\hline 100 & 70 & 70 & 50 & 50 & 35 \\
\hline 100 & 50 & 70 & 35 & 50 & 20 \\
\hline 100 & 35 & 70 & 20 & 50 & 10 \\
\hline
\end{tabular}

Os resultados médios obtidos no ensaio com os produtos estão reproduzidos na Tabela 6.6.

Tabela 6.6 - Resultados experimentais do teste de cisalhamento direto com o farelo de milho $\left(\mathrm{U}=12,4 \%\right.$ e $\left.\mathrm{T}=25,7^{\circ} \mathrm{C}\right)$ e com a soja $\left(\mathrm{U}=10,7 \%\right.$ e $\left.\mathrm{T}=24,7^{\circ} \mathrm{C}\right)$.

\begin{tabular}{|c|c|c|c|c|c|c|c|c|c|c|}
\hline \multirow{2}{*}{$\begin{array}{l}\text { Produto } \\
\text { Ensaio }\end{array}$} & \multicolumn{5}{|c|}{ Farelo de milho } & \multicolumn{5}{|c|}{ Soja } \\
\hline & $\begin{array}{l}\text { Wp } \\
\text { (N) }\end{array}$ & $\begin{array}{l}\text { Ws } \\
\text { (N) }\end{array}$ & $\begin{array}{l}\text { Wt } \\
\text { (g) }\end{array}$ & $\begin{array}{l}\text { Sp } \\
\text { (N) }\end{array}$ & $\begin{array}{l}\text { Ss } \\
\text { (N) }\end{array}$ & $\begin{array}{l}\text { Wp } \\
\text { (N) }\end{array}$ & $\begin{array}{l}\text { Ws } \\
\text { (N) }\end{array}$ & $\begin{array}{l}\text { Wt } \\
\text { (g) }\end{array}$ & $\begin{array}{l}\text { Sp } \\
\text { (N) }\end{array}$ & $\begin{array}{l}\text { Ss } \\
\text { (N) }\end{array}$ \\
\hline \multirow{4}{*}{ YL1 } & 100,0 & 100,0 & 376,80 & 70,0 & - & 100,0 & 100,0 & 392,1 & 76,0 & - \\
\hline & 100,0 & 70,0 & 376,50 & 70,0 & 59,0 & 100,0 & 70,0 & 386,1 & 68,0 & 53,0 \\
\hline & 100,0 & 50,0 & 376,00 & 70,0 & 46,0 & 100,0 & 50,0 & 389,5 & 74,0 & 42,0 \\
\hline & 100,0 & 35,0 & 376,50 & 70,0 & 35,0 & 100,0 & 35,0 & 392,1 & 68,0 & 28,2 \\
\hline \multirow{4}{*}{ YL2 } & 70,0 & 70,0 & 377,80 & 50,0 & - & 70,0 & 70,0 & 396,9 & 50,0 & - \\
\hline & 70,0 & 50,0 & 378,70 & 51,0 & 45,0 & 70,0 & 50,0 & 387,8 & 54,0 & 42,5 \\
\hline & 70,0 & 35,0 & 378,40 & 52,0 & 35,5 & 70,0 & 35,0 & 286,0 & 52,0 & 31,1 \\
\hline & 70,0 & 20,0 & 377,70 & 54,0 & 24,0 & 70,0 & 20,0 & 395,0 & 52,5 & 21,5 \\
\hline \multirow{4}{*}{ YL3 } & 50,0 & 50,0 & 378,40 & 38,0 & - & 50,0 & 50,0 & 387,3 & 41,1 & - \\
\hline & 50,0 & 35,0 & 377,80 & 37,2 & 32,5 & 50,0 & 35,0 & 389,0 & 39,9 & 30,5 \\
\hline & 50,0 & 20,0 & 377,80 & 38,9 & 22,4 & 50,0 & 20,0 & 390,4 & 40,0 & 22,3 \\
\hline & 50,0 & 10,0 & 376,80 & 38,6 & 14,2 & 50,0 & 10,0 & 397,9 & 42,2 & 14,1 \\
\hline
\end{tabular}

\subsubsection{Ensaio de cisalhamento com a parede}

O teste de cisalhamento com a parede foi realizado com o aparelho de Jenike mediante substituição da base da amostra por duas placas (Figura 6.9), uma o aço liso e outra de aço rugoso. As forças normais $\left(W_{w}\right)$ aplicadas durante o ensaio para a obtenção do lugar geométrico instantâneo de deslizamento com a parede foram $50 \mathrm{~N}, 40 \mathrm{~N}, 30 \mathrm{~N}, 20 \mathrm{~N}$ e $10 \mathrm{~N}$.

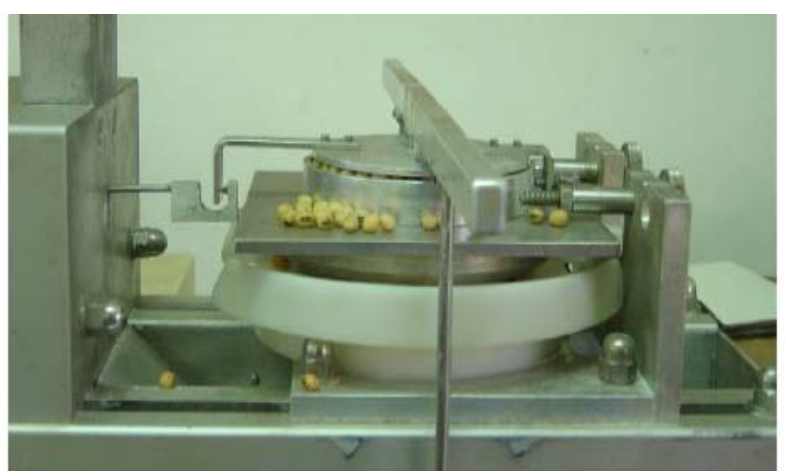

Figura 6.9 - Ensaio de cisalhamento direto com a parede com o aparelho de Jenike modelo TSG 70-140. 
Os valores experimentais médios obtidos no teste de cisalhamento com a parede, com a simulação do aço liso e do aço rugoso, são mostrados na Tabela 6.7.

Tabela 6.7 - Resultados experimentais do teste de cisalhamento com a parede do farelo de milho $\left(\mathrm{U}=12,4 \%\right.$ e $\left.\mathrm{T}=25,7^{\circ} \mathrm{C}\right)$ e da soja $\left(\mathrm{U}=10,7 \%\right.$ e $\left.\mathrm{T}=24,7^{\circ} \mathrm{C}\right)$.

\begin{tabular}{|c|c|c|c|c|c|c|}
\hline \multirow[b]{2}{*}{$\begin{array}{c}\text { Material } \\
\text { da parede }\end{array}$} & \multicolumn{3}{|c|}{ Farelo de milho } & \multicolumn{3}{|c|}{ Soja } \\
\hline & $\begin{array}{l}\text { Ww } \\
\text { (N) }\end{array}$ & $\begin{array}{l}\text { Wwt } \\
\text { (N) }\end{array}$ & $\begin{array}{l}\text { Sw } \\
(\mathrm{N})\end{array}$ & $\begin{array}{l}\text { Ww } \\
\text { (N) }\end{array}$ & $\begin{array}{l}\text { Wwt } \\
\text { (N) }\end{array}$ & $\begin{array}{l}\text { Sw } \\
\text { (N) }\end{array}$ \\
\hline \multirow{5}{*}{$\begin{array}{c}\text { Aço } \\
\text { Rugoso }\end{array}$} & 100 & 105,9 & 27,0 & 100 & 105,9 & 23,2 \\
\hline & 80 & 85,9 & 22,5 & 80 & 85,9 & 19,2 \\
\hline & 60 & 65,9 & 18,5 & 60 & 65,9 & 14,8 \\
\hline & 40 & 45,9 & 14,0 & 40 & 45,9 & 10,3 \\
\hline & 20 & 25,9 & 8,7 & 20 & 25,9 & 4,9 \\
\hline \multirow{5}{*}{$\begin{array}{l}\text { Aço } \\
\text { Liso }\end{array}$} & 100 & 105,9 & 21,5 & 100 & 105,9 & 20,3 \\
\hline & 80 & 85,9 & 17,5 & 80 & 85,9 & 15,9 \\
\hline & 60 & 65,9 & 14,0 & 60 & 65,9 & 12,6 \\
\hline & 40 & 45,9 & 10,2 & 40 & 45,9 & 9,2 \\
\hline & 20 & 25,9 & 6,5 & 20 & 25,9 & 4,9 \\
\hline
\end{tabular}

Os dados obtidos experimentalmente foram analisados e os resultados finais das propriedades físicas do produto a partir do teste de cisalhamento direto com 0 produto e com a parede são mostrados na Tabela 6.8 e na Tabela 6.9.

Tabela 6.8 - Resultados médios das propriedades físicas do farelo de milho $\left(\mathrm{U}=12,4 \%\right.$ e $\left.\mathrm{T}=25,7^{\circ} \mathrm{C}\right)$ e da soja $\left(\mathrm{U}=10,7 \%\right.$ e $\left.\mathrm{T}=24,7^{\circ} \mathrm{C}\right)$.

\begin{tabular}{|c|c|c|c|c|c|c|c|c|c|}
\hline Produto & YL & $\begin{array}{l}W p \\
(N)\end{array}$ & $\begin{array}{c}\gamma \\
\left(\mathrm{kN} / \mathrm{m}^{3}\right)\end{array}$ & $\begin{array}{c}c \\
\left(\mathrm{~N} / \mathrm{m}^{2}\right)\end{array}$ & $\phi_{\mathrm{i}}\left({ }^{\circ}\right)$ & $\phi_{\mathrm{e}}\left(^{\circ}\right)$ & $\begin{array}{c}\sigma_{\mathrm{c}} \\
\left(\mathrm{N} / \mathrm{m}^{2}\right)\end{array}$ & $\begin{array}{c}\sigma_{1} \\
\left(\mathrm{~N} / \mathrm{m}^{2}\right) \\
\end{array}$ & $\sigma_{1} / \sigma_{c}$ \\
\hline \multirow{3}{*}{$\begin{array}{c}\text { Farelo } \\
\text { de } \\
\text { milho }\end{array}$} & YL 1 & 100 & 6,36 & 820,8 & 34,4 & 37,1 & 3111,2 & 27573,9 & 8,86 \\
\hline & $\mathrm{YL} 2$ & 70 & 6,45 & 272,8 & 37,1 & 38,3 & 1095,6 & 20019,4 & 18,27 \\
\hline & $\mathrm{YL} 3$ & 50 & 6,42 & 0,0 & 37,6 & 37,6 & 0,0 & 14934,2 & - \\
\hline \multirow{3}{*}{ Soja } & $\mathrm{YL} 1$ & 100 & 7,11 & 227,0 & 34,7 & 32,3 & 867,2 & 17501,0 & 20,2 \\
\hline & $\mathrm{YL} 2$ & 70 & 7,13 & 373,8 & 33,3 & 34,6 & 1386,4 & 22313,8 & 16,1 \\
\hline & YL 3 & 50 & 7,05 & 0,0 & 36,8 & 36,8 & 0,0 & 28573,6 & - \\
\hline
\end{tabular}

Tabela 6.9 - Resultados médios do ensaio de cisalhamento com a parede com o farelo de milho $\left(\mathrm{U}=12,4 \%\right.$ e $\left.\mathrm{T}=25,7^{\circ} \mathrm{C}\right)$ e com a soja $\left(\mathrm{U}=10,7 \%\right.$ e $\left.\mathrm{T}=24,7^{\circ} \mathrm{C}\right)$.

\begin{tabular}{|c|c|c|}
\hline Produto & $\begin{array}{c}\text { Farelo de } \\
\text { milho }\end{array}$ & Soja \\
\hline Material da parede & $\phi_{\mathrm{w}}\left({ }^{\circ}\right)$ & $\phi_{\mathrm{w}}\left({ }^{\circ}\right)$ \\
\hline Aço liso & 10,98 & 10,24 \\
\hline Aço rugoso & 13,65 & 12,28 \\
\hline
\end{tabular}


Segundo a classificação da capacidade de fluxo proposta por Jenike (Tabela 2.1), a soja é um produto de fluxo livre dado que para os três níveis de tensão ensaiados, a Função Fluxo da soja é superior a 10. O farelo de milho é de fluxo livre até um dado nível de tensão, a partir do qual passa a ser classificado como produto de fluxo fácil.

Os resultados das propriedades físicas estão de acordo com os valores tabelados pelas normas internacionais. Para levar em conta a variabilidade dessas propriedades, todas as normas sugerem que sejam adotados valores superiores e inferiores.

Os valores inferiores e superiores das propriedades físicas utilizados na determinação das pressões estão resumidos na Tabela 6.10. Cabe salientar que o coeficiente $\mathrm{K}$ foi determinado de forma indireta, levando em consideração a formulação proposta para cada uma das normas analisadas.

Tabela 6.10 - Valores inferiores, médios e superiores das propriedades físicas.

\begin{tabular}{|c|c|c|c|}
\hline \multicolumn{2}{|c|}{ Produto } & $\begin{array}{c}\text { Farelo } \\
\text { milho }\end{array}$ & Soja \\
\hline \multirow{3}{*}{$\begin{array}{c}\text { Peso } \\
\text { específico }\end{array}$} & $\gamma_{i}\left(k N / m^{3}\right)$ & 6,36 & 7,05 \\
\hline & $\gamma_{\mathrm{m}}\left(\mathrm{kN} / \mathrm{m}^{3}\right)$ & 6,42 & 7,11 \\
\hline & $\gamma_{\mathrm{s}}\left(\mathrm{kN} / \mathrm{m}^{3}\right)$ & 6,45 & 7,13 \\
\hline \multirow{3}{*}{$\begin{array}{l}\text { Ângulo de } \\
\text { atrito interno }\end{array}$} & $\phi_{\mathrm{iii}}\left({ }^{\circ}\right)$ & 34,4 & 33,3 \\
\hline & $\phi_{\text {im }}\left({ }^{\circ}\right)$ & 37,1 & 34,7 \\
\hline & $\phi_{\text {is }}\left({ }^{\circ}\right)$ & 37,6 & 36,8 \\
\hline \multirow{3}{*}{$\begin{array}{l}\text { Ef. Atrito } \\
\text { interno }\end{array}$} & $\phi_{\mathrm{ei}}\left({ }^{\circ}\right)$ & 37,1 & 32,3 \\
\hline & $\phi_{\mathrm{em}}\left(^{\circ}\right)$ & 37,6 & 34,6 \\
\hline & $\phi_{\mathrm{es}}\left({ }^{\circ}\right)$ & 38,3 & 36,8 \\
\hline \multirow{3}{*}{$\begin{array}{l}\text { Coef. de atrito } \\
\text { efetivo parede }\end{array}$} & $\mu_{\text {effi }}$ & 0,44 & 0,38 \\
\hline & $\mu_{\text {effm }}$ & 0,46 & 0,40 \\
\hline & Unffs & 0,48 & 0,42 \\
\hline
\end{tabular}

\begin{tabular}{|c|c|c|c|}
\hline \multicolumn{2}{|c|}{ Produto } & $\begin{array}{c}\text { Farelo } \\
\text { milho }\end{array}$ & Soja \\
\hline \multirow{3}{*}{$\begin{array}{l}\text { Coef. de } \\
\text { atrito com a } \\
\text { tremonha }\end{array}$} & $\mu_{\mathrm{hi}}$ & 0,19 & 0,18 \\
\hline & $\mu_{\mathrm{hm}}$ & 0,22 & 0,20 \\
\hline & $\mu_{\mathrm{hs}}$ & 0,24 & 0,22 \\
\hline \multirow{3}{*}{$\begin{array}{c}\mathrm{K} \\
\text { (EUROCODE } \\
\text { DIN e ISO) }\end{array}$} & $\mathrm{K}_{\mathrm{i}}$ & 0,41 & 0,45 \\
\hline & $\mathrm{K}_{\mathrm{m}}$ & 0,43 & 0,47 \\
\hline & $\mathrm{K}_{\mathrm{s}}$ & 0,45 & 0,50 \\
\hline \multirow{3}{*}{$K(A S)$} & $\mathrm{K}_{\mathrm{i}}$ & 0,42 & 0,44 \\
\hline & $\mathrm{K}_{\mathrm{m}}$ & 0,44 & 0,46 \\
\hline & $\mathrm{K}_{\mathrm{s}}$ & 0,46 & 0,48 \\
\hline \multirow{3}{*}{ c } & $\mathrm{c}_{\mathrm{i}}(\mathrm{KPa})$ & 0,00 & 0,00 \\
\hline & $c_{m}(\mathrm{KPa})$ & 0,27 & 0,23 \\
\hline & $c_{s}(K P a)$ & 0,82 & 0,37 \\
\hline
\end{tabular}

O coeficiente de atrito efetivo com a parede corrugada foi calculado com base nas equações 2.05 e 2.06 enquanto que o coeficiente de atrito com a tremonha foi considerado igual ao coeficiente de atrito obtido no ensaio de cisalhamento direto do produto com o aço liso.

Algumas comparações podem ser feitas com os dois produtos pela análise da Tabela 6.10. Verifica-se que o farelo de milho é menos denso, possui maior ângulo de atrito interno, maior ângulo de atrito efetivo e maior ângulo de atrito com a parede. Dado que o farelo de milho possui maiores ângulos de atrito, maior será a 
parcela do peso deste do produto que será transmitida por atrito na parede, ou seja, o coeficiente de atrito com a parede para o farelo de milho é superior ao da soja.

O farelo de milho também é o produto que apresenta alguma coesão, apesar de que o valor da coesão ser desprezível para os dois produtos. O teste para determinar o ângulo de repouso não foi realizado. Tomando como base os valores recomendados pelas normas internacionais adotou-se para o farelo de milho $\phi_{r}=30^{\circ}$ e para a soja $\phi_{r}=25^{\circ}$.

Considerando as geometrias adotadas e os resultados das propriedades dos produtos, é esperado que o fluxo seja de massa nos silos que possuem tremonha devido principalmente à característica granular e não coesiva dos produtos estudados. Porém o silo com fundo plano, no instante da abertura da boca de saída, pode apresentar fluxo de funil excêntrico com o canal de fluxo interceptando a parede vertical do silo. Isto representa a pior situação de cálculo da estrutura e deve, portanto, ser considerada.

\subsection{Modelos e parâmetros numéricos}

\subsubsection{Produtos armazenados}

Para a simulação numérica é necessário adotar um modelo que represente o comportamento real do produto armazenado. O produto armazenado possui um comportamento complexo porque durante o armazenamento, ele está sujeito a altas tensões e baixas deformações de modo que se comporta aproximadamente como um sólido. Por outro lado, durante o fluxo, atuam baixas tensões e altas deformações, com o produto se comportando aproximadamente como um fluido.

A definição de um modelo de comportamento entre tensões e deformações apresentadas pelo produto é complexa e deve considerar algumas características, como:

- deformação permanente: o produto não recupera sua configuração depois de cessada a aplicação de carregamentos;

- dependência do processo de carga-descarga: não existe uma relação única entre tensões e deformações, ou seja, dado um valor da deformação em um dado instante, só é possível determinar o estado de tensão correspondente conhecendo-se a evolução do processo carga-descarga;

- dependência da taxa de aplicação da carga: o produto pode adquirir 
resistência com o aumento da taxa de aplicação da carga;

- não linearidade elástica: relação não linear entre tensões e deformações;

- comportamento plástico: o produto plastifica a partir de um dado estado de tensão, ou seja, com baixos incrementos de tensão o produto se deforma excessivamente;

- assimetria de comportamento tração-compressão: as forças de coesão interna conferem baixa resistência à tração nos produtos granulares que muitas vezes pode ser considerada desprezível;

A relação entre tensões e deformações dos materiais estruturais é representada por meio de modelos, destacando-se duas teorias: teoria da elasticidade e a teoria da plasticidade. Um material elástico é aquele que recupera sua configuração depois de cessada a aplicação do carregamento e o material plástico não recupera.

Estes dois comportamentos são idealizados e não apresentam satisfatoriamente o comportamento real da maioria dos materiais existentes na natureza, que normalmente podem ser representados pela combinação destes dois. Os produtos granulares, por exemplo, podem ser considerados elásticos até certo valor de tensão a partir do qual se tornam perfeitamente plásticos. Na Figura 6.10 é ilustrada a relação tensão-deformação de um material elastoplástico perfeito.

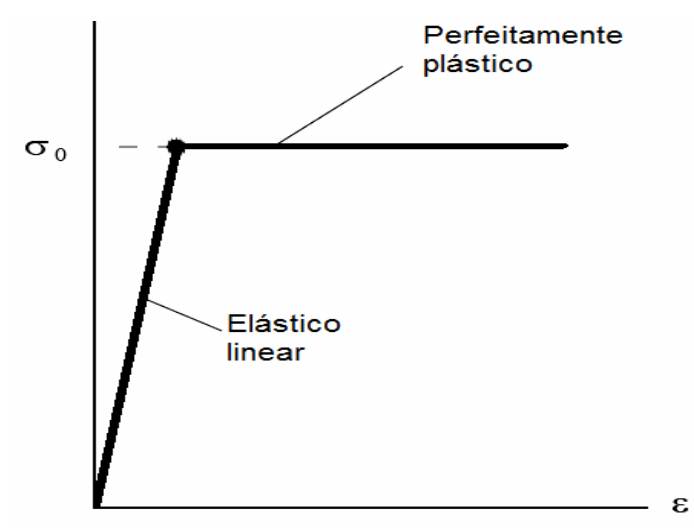

Figura 6.10 - Modelo de comportamento elastoplástico perfeito.

Pode ser observado na Figura 6.10 que o material elastoplástico, depois de alcançado certo valor de tensão $\left(\sigma_{0}\right)$ apresenta excessiva deformação sem o ganho de resistência, ou seja, se plastifica. A plastificação depois de alcançada a superfície de fluência é uma característica dos produtos granulares. Portanto, dentre os 
modelos de comportamento contidos na biblioteca do ANSYS, o modelo elastoplástico é um dos que melhor representa os produtos granulares.

Neste trabalho foram adotados dois modelos de comportamento do produto: elástico (sigla EL) e elastoplástico (sigla ELP), este último com o critério de plastificação de Drucker-Prager que já vem incluído na biblioteca do programa ANSYS. A parte elástica é definida pelos parâmetros: módulo de elasticidade (E) e coeficiente de Poisson do produto $(v)$, sendo este coeficiente um dos parâmetros mais importantes para a determinação das pressões nos silos. Segundo Ayuga, Guaita e Aguado (2001'a), uma variação no coeficiente de Poisson entre 0,2 e 0,4 produz até $90 \%$ de mudança nas pressões estáticas.

Não foi possível determinar experimentalmente o coeficiente de Poisson, por isso este parâmetro foi determinado indiretamente baseando-se em estudos experimentais de Rotter (2001) que mostram que este coeficiente está relacionado com o coeficiente $\mathrm{K}$ no interior do produto no estado estático $\left(\mathrm{K}_{0}\right)$, ou seja, sem deformações, segundo a equação:

$$
v=\frac{K_{0}}{1+K_{0}}
$$

O coeficiente de Poisson tem um notável efeito na forma em que o produto se comporta. Quanto maior o valor do coeficiente $v$ mais dificilmente o produto armazenado vai atingir um estado de tensão que alcance a superfície de deslizamento e consequentemente, seu comportamento será elástico. Portanto, para elevados valores de $v$, a utilização do comportamento elastoplástico não é necessário.

O limite de tensões a partir do qual o produto se plastifica é representado pelo critério de deslizamento, critério de plastificação ou ainda superfície de fluência. $O$ critério de plastificação de Mohr-Coulomb é um dos mais utilizados para os produtos armazenados porque eles possuem ângulo de atrito interno e resistência à tração diferente da resistência à compressão. Além disso, as propriedades dos produtos armazenados segundo o critério de plastificação de Mohr-Coulomb podem ser determinadas a partir do ensaio de cisalhamento direto com o produto.

Entretanto, o critério de Mohr-Coulomb apresenta problemas de implementação nos códigos de elementos finitos porque sua superfície de fluência, ilustrada na Figura 6.11, é formada por arestas na união entre faces adjacentes de 
forma que a direção da reta normal à superfície de fluência nas arestas não é única, gerando problemas para o código de elementos finitos determinar a direção da deformação plástica do produto.

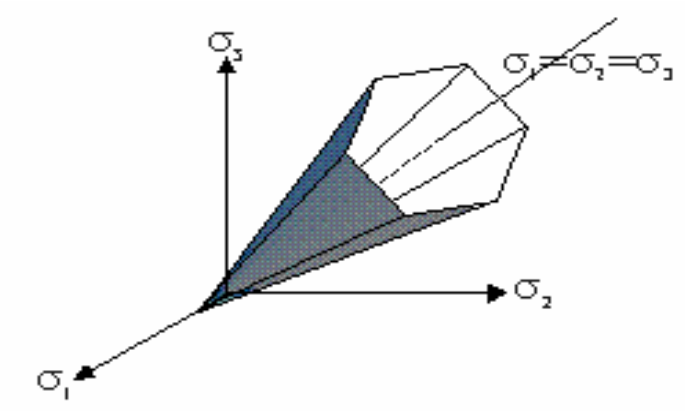

Figura 6.11 - Representação espacial do critério de ruptura de Mohr-Coulomb.

Para contornar este inconveniente, utiliza-se o critério de Drucker-Prager, que é análogo ao modelo de Mohr-Coulomb com a diferença de possuir a superfície de deslizamento arredondada (Figura 6.12), e, portanto, o problema de predição das deformações plásticas não existe. Apesar de existirem modelos mais complexos, o modelo de Drucker-Prager é satisfatório e fácil de ser usado no estudo dos silos com os modelos numéricos (MARTíNEZ et al., 2002). Segundo Guaita et al. (2003) este critério vem sendo utilizado pois permite uma modelagem do produto mais próxima da realidade em comparação com o comportamento meramente elástico.

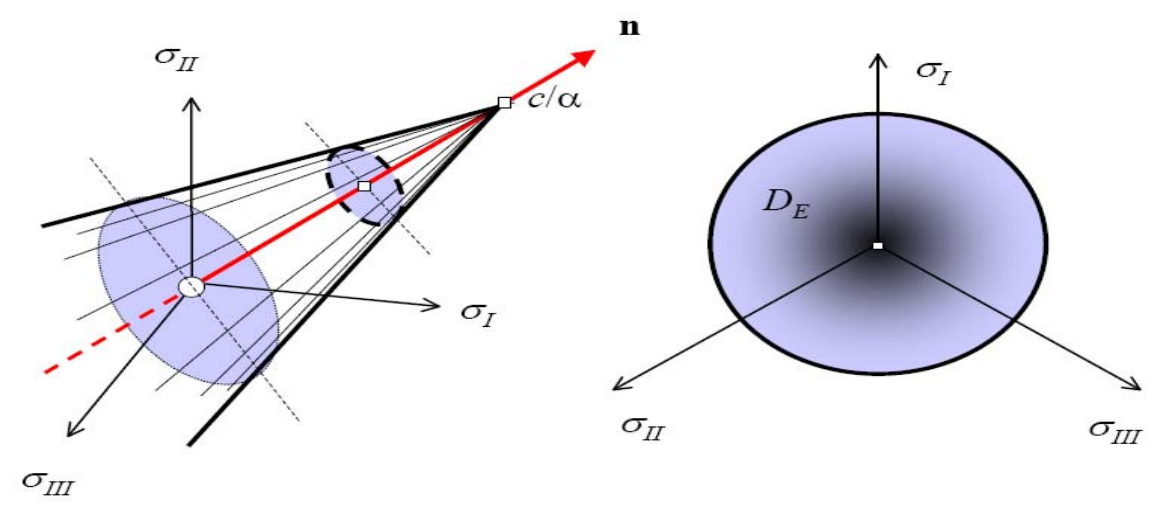

Figura 6.12 - Representação espacial do critério de ruptura de Drucker-Prager.

Para o emprego do modelo de Druck-Prager, três parâmetros dos produtos armazenados são necessários: coesão, ângulo de atrito interno e ângulo de dilatância. Tanto o farelo de milho quanto o soja são produtos de pequena coesão, que pode ser desprezada.

O ângulo de atrito interno do produto $\left(\phi_{\mathrm{i}}\right)$ define a inclinação da superfície de fluência. Baixos valores de $\phi_{\mathrm{i}}$ facilitam a plastificação do produto e, portanto produzem um acréscimo nas tensões horizontais. 
O ângulo de dilatância $(\psi)$ corresponde ao ângulo formado entre a linha de deslizamento da amostra e a direção real do deslizamento (Figura 6.13). Ele está relacionado com a dilatação volumétrica do produto quando ele é submetido ao cisalhamento. Vários autores acreditam que esta dilatação volumétrica é um dos fatores que causam o aumento das pressões na condição de descarga do silo.
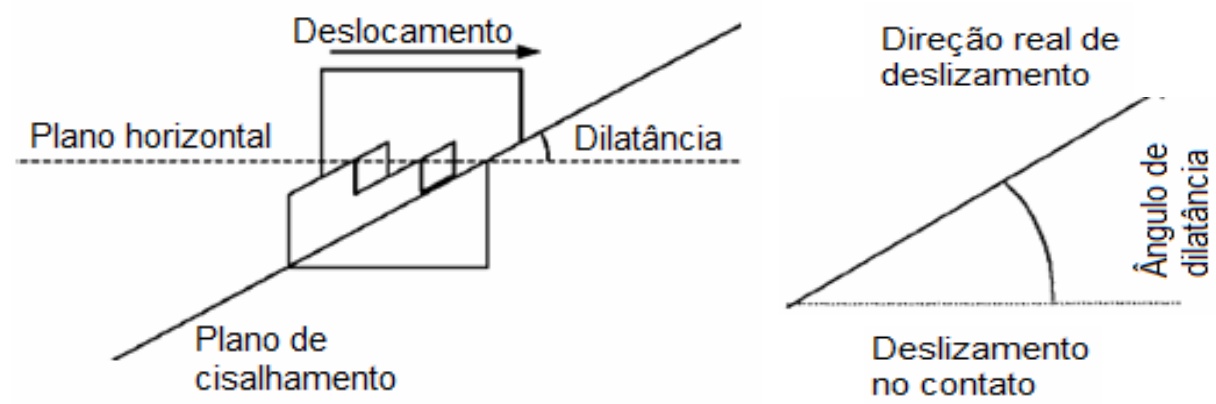

Figura 6.13 - Efeito da dilatância do produto nas linhas de deslizamento.

Numericamente, o ângulo de dilatância determina a direção da deformação plástica. Se o ângulo de dilatância é igual ao ângulo de atrito interno, o início do fluxo é marcado por uma deformação plástica normal à superfície de deslizamento e acontece uma expansão volumétrica do produto com deformação plástica. Se o ângulo de dilatância é menor do que o ângulo de atrito interno haverá menor expansão volumétrica. Seu valor pode variar entre $0^{\circ}$ e o ângulo de atrito interno do produto apesar de que nas pesquisas com produtos granulares realizadas por Hardin et al. (1990) e Zang et al. (1994), o valor do ângulo de dilatância ( $\psi$ ) nunca excedeu $20^{\circ}$.

Os valores dos parâmetros adotados nas simulações numéricas com o programa ANSYS foram baseados nos testes experimentais e são mostrados na Tabela 6.11.

Tabela 6.11 - Propriedades físicas dos produtos utilizados na simulação numérica.

\begin{tabular}{|l|c|c|c|}
\hline \multicolumn{2}{|c|}{ Produto } & $\begin{array}{c}\text { Farelo de } \\
\text { milho }\end{array}$ & Soja \\
\hline Peso especifico & $\gamma_{\mathbf{s}}\left(\mathbf{k N} / \mathbf{m}^{3}\right)$ & 6,45 & 7,13 \\
\hline Módulo de elasticidade & $\mathbf{E}_{\mathbf{s}}\left(\mathbf{k N} / \mathbf{m}^{2}\right)$ & 1647 & 1542 \\
\hline Coeficiente de Poisson & $v$ & 0,30 & 0,32 \\
\hline Ângulo de atrito interno & $\left.\phi_{\mathrm{m}} \mathbf{(}^{\mathbf{}}\right)$ & 37,6 & 34,8 \\
\hline Coesão & $\mathbf{c}(\mathbf{k P a})$ & 0,5 & 0,2 \\
\hline Ângulo de dilatância & $\left.\phi_{\mathrm{d}} \mathbf{(}^{\mathbf{(}}\right)$ & 10 & 14 \\
\hline Atrito com parede corrugada & $\mu_{\mathrm{eff}, \mathbf{m}}$ & 0,46 & 0,40 \\
\hline Atrito com a tremonha & $\mu_{\mathrm{h}, \mathbf{m}}$ & 0,22 & 0,20 \\
\hline Atrito produto-canal de fluxo & $\mu_{\mathrm{sc}, \mathbf{m}}$ & 0,77 & 0,68 \\
\hline
\end{tabular}


O peso específico adotado corresponde ao valor superior encontrado nos ensaios experimentais de forma que os resultados numéricos incluem a variabilidade das pressões devido a incertezas com relação ao peso específico do produto.

O coeficiente de Poisson foi calculado com base na equação 6.05 proposta por Rotter (2001), considerando o valor médio de K. O módulo de elasticidade do produto foi adotado um valor constante com base na equação 6.06 , recomendada pela norma européia EUROCODE (2002). Foi adotado um valor constante para o módulo de elasticidade apesar dele depender da tensão que atua sobre o produto.

$$
E=3 \gamma^{\frac{3}{2}} p_{v f t}
$$

O ângulo de atrito interno foi adotado com base nos valores médios obtidos experimentalmente, que correspondem ao critério de ruptura de Mohr-Coulomb, dado que o programa ANSYS converte automaticamente estes valores para o critério de ruptura de Drucker-Prager.

O elemento utilizado para representar o produto nas análises bidimensionais no programa ANSYS foi o PLANE42 que consiste num elemento plano com quatro nós e dois graus de liberdade cada nó: translações nos eixos x e y (Figura 6.14). $O$ PLANE 42 é um elemento que admite diferentes modelos de plasticidade e permite que sejam adotadas diversas leis de comportamento do produto armazenado, com a inclusão de parâmetros como critério de deslizamento ou ruptura considerando a dilatância do produto e alta capacidade de deformação.

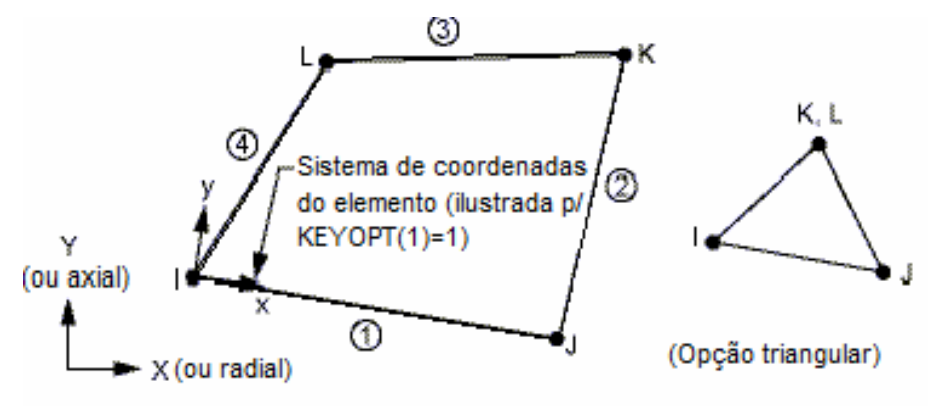

Figura 6.14 - Características elemento finito PLANE42.

$\mathrm{Na}$ análise tridimensional foi utilizado o elemento SOLID45 que é um elemento cúbico definido por oito nós com três graus de liberdade cada um: translações nos eixos x, y e z (Figura 6.15). Também admite diferentes modelos de plasticidade. 


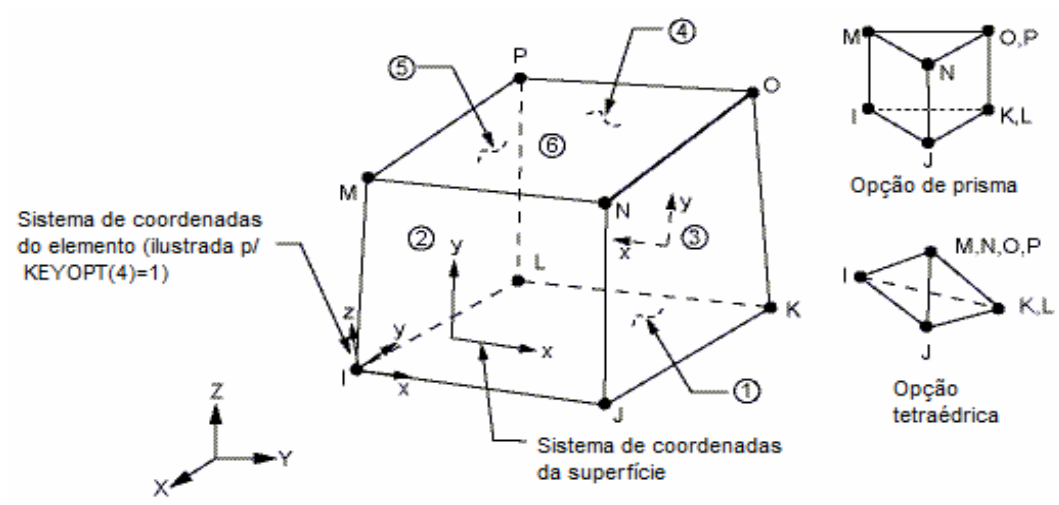

Figura 6.15 - Características do elemento finito SOLID45.

\subsubsection{Parede}

O material da parede do silo é de aço com o modelo de comportamento elástico-linear com as seguintes características (Tabela 6.12):

Tabela 6.12 - Propriedades físicas do aço da parede utilizados na simulação numérica.

\begin{tabular}{|l|c|c|}
\hline \multicolumn{4}{|c|}{ Propriedades do material da parede } \\
\hline Módulo de elasticidade & $\mathrm{E}_{\mathrm{w}}(\mathrm{MPa})$ & 210000 \\
\hline Coeficiente de Poisson & $v_{\mathrm{w}}$ & 0,30 \\
\hline
\end{tabular}

O elemento utilizado para a parede nas análises bidimensionais foi o BEAM3, ilustrado na Figura 6.16. O BEAM3 é um elemento uniaxial que admite tração, compressão e momentos fletores. Ele é formado por dois nós com três graus de liberdade cada nó: translações nas direções x e y e rotação em torno do eixo z.

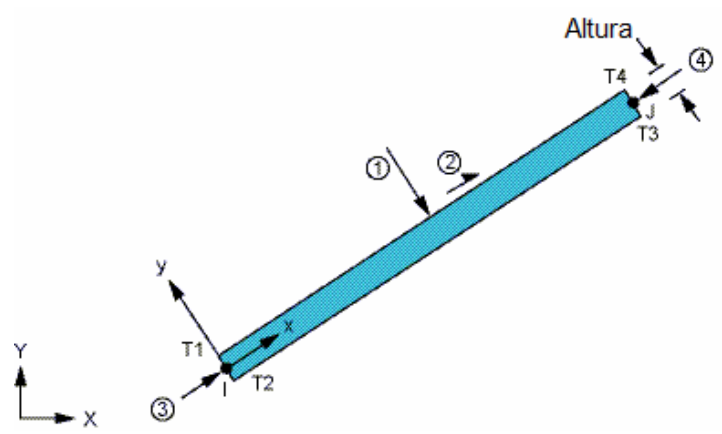

Figura 6.16 - Características do elemento finito BEAM3.

Para as análises tridimensionais foi utilizado o elemento SHELL63, ilustrado na Figura 6.17. Este elemento possui quatro nós com seis graus de liberdade cada um: translações nos eixos $x, y$ e $z$ e rotações em torno dos eixos $x, y$ e $z$. 0 SHELL63 admite esforços de membrana e de flexão, assim como largas deformações. 


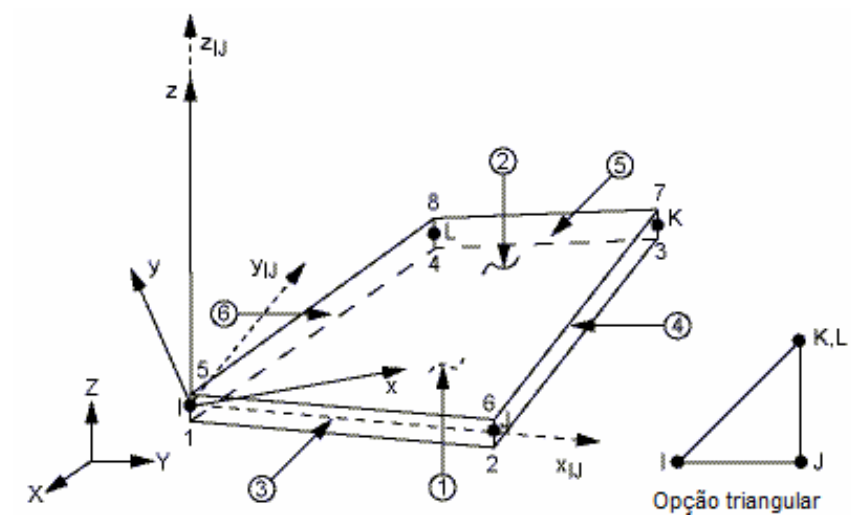

Figura 6.17 - Características do elemento finito SHELL63.

Como pode ser observado, as paredes dos silos estudados foram modeladas no ANSYS como lisas. O efeito da corrugação da parede é considerado de forma simplificada a partir da adoção do coeficiente de atrito efetivo do produto com a parede, conforme mostrado na Tabela 6.11.

\subsubsection{Dimensões dos modelos simulados}

A Tabela 6.13 mostra as dimensões e hipótese de cálculo dos modelos simulados. Nas análises bidimensionais foi admitida a hipótese de axissimetria.

Tabela 6.13 - Geometrias analisadas e seus respectivos modelos em M.E.F.

\begin{tabular}{|c|c|c|c|}
\hline Geometria & $\begin{array}{c}\text { Dimensão } \\
\text { do modelo }\end{array}$ & $\begin{array}{c}\text { Hipótese } \\
\text { de cálculo }\end{array}$ & Sigla \\
\hline Fundo Plano & $2 \mathrm{D}$ & Axissimetria & M2D \\
\cline { 2 - 4 } & $3 \mathrm{D}$ & - & M3D \\
\hline $\begin{array}{c}\text { Tremonha } \\
\text { concêntrica }\end{array}$ & $3 \mathrm{D}$ & - & M3D \\
\hline $\begin{array}{c}\text { Tremonha } \\
\text { excêntrica }\end{array}$ & $3 \mathrm{D}$ & - & M3D \\
\hline
\end{tabular}

\subsection{Densidade das malhas adotadas}

O princípio de utilização do MEF é dividir ou discretizar a estrutura em pequenas regiões conhecidas como elementos finitos. Quanto maior o número de elementos, mais refinada a malha utilizada e, em geral, melhores os resultados obtidos.

Para definir a densidade das malhas é preciso realizar testes de convergência, que consistem em comparar os resultados obtidos com diferentes densidades até que a diferença entre eles seja aceitável, de acordo com o critério adotado. 
Nos modelos bidimensionais, malhas de até $50 \mathrm{~cm}$ produziram resultados próximos quando comparados aos de malhas de $5 \mathrm{~cm}, 10 \mathrm{~cm}$ e $25 \mathrm{~cm}$. A malha de $10 \mathrm{~cm}$ foi escolhida no caso bidimensional pois o custo computacional do modelo bidimensional é baixo. Com base nos resultados bidimensionais, foram escolhidas as seguintes malhas (Figuras 6.18 e 6.19 ) para os modelos tridimensionais:
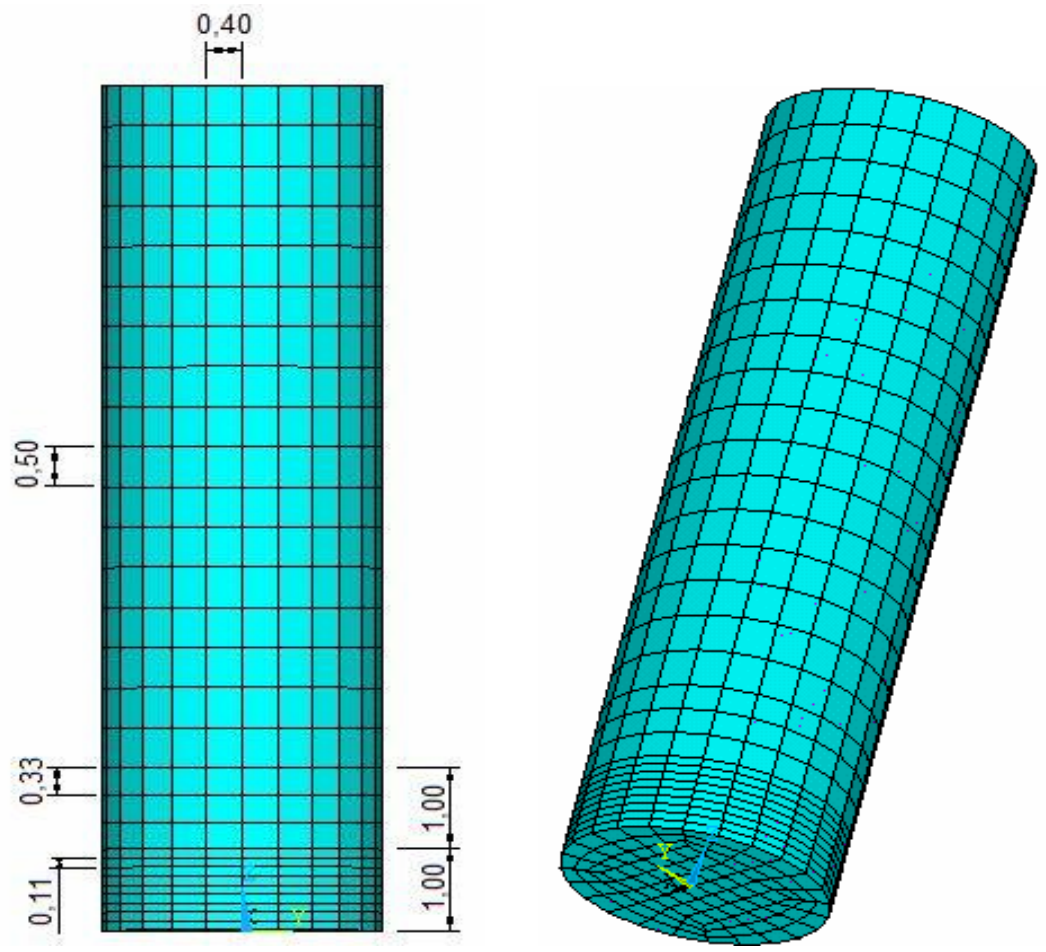

Figura 6.18 - Variação da densidade da malha do silo com fundo plano. 

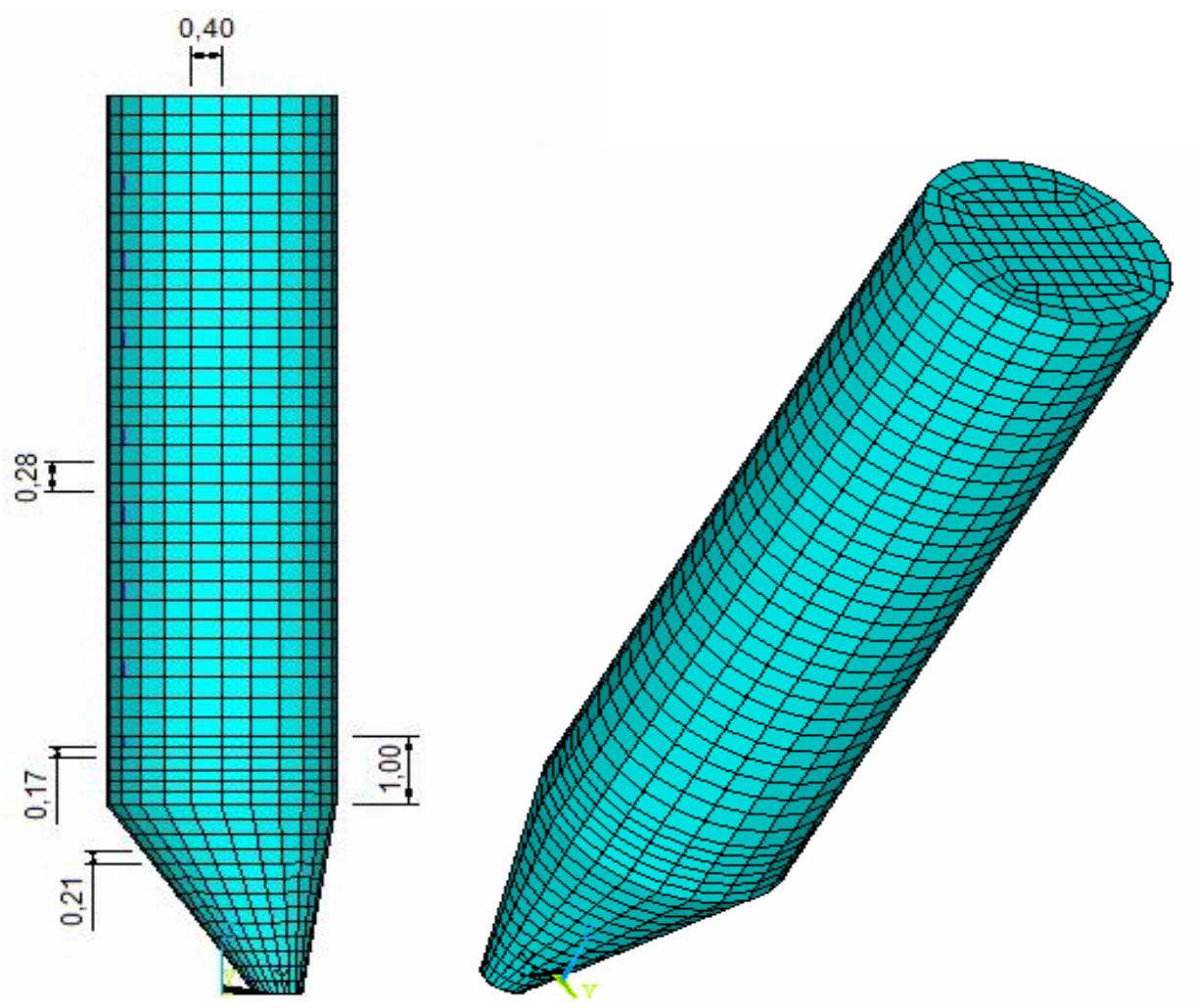

Figura 6.19 - Variação da densidade da malha do silo com tremonha.

Observa-se nas Figuras 6.18 e 6.19 que em locais específicos como na proximidade com o fundo e na transição entre o corpo cilíndrico e a tremonha, utilizou-se uma malha mais densa para conhecer com maior precisão os valores das pressões neste locais.

\subsection{Simulação do contato produto-parede}

Rombach e Neumann (2004) afirmam que as pressões do produto armazenado dependem significativamente da interação entre o produto armazenado e as paredes. Segundo Couto et al. (2000), esta interação é o ponto mais importante da modelagem dos silos. Ela é caracterizada por elementos de contato que permitem estimar a pressão normal e a pressão de atrito na parede.

\subsubsection{Modelagem do contato}

O modelo de atrito utilizado no ANSYS para simular o contato neste trabalho foi o modelo de Mohr-Coulomb, baseado na equação:

$$
\tau=c+\mu . \sigma
$$


O valor da coesão foi considerado nulo e o coeficiente de atrito utilizado no modelo numérico foi o coeficiente de atrito efetivo (valor médio), calculado a partir dos resultados dos ensaios experimentais de cisalhamento com a parede, conforme a Tabela 6.11.

O método dos elementos finitos reconhece possíveis pares de contato através da presença de elementos de contato específicos, localizadas entre as partes do modelo que estão sendo analisadas para a interação. A análise do contato no ANSYS pode ser feita através de três formas: nó-nó, nó-superfície e superfíciesuperfície. Se uma das partes de interação é um ponto, a componente correspondente do modelo é um nó. O contado do produto com a parede no estudo dos silos é considerado como um problema de superfície-superfície.

O contato do tipo superfície-superfície se baseia na definição de duas superfícies: a superfície alvo (target surface) e a superfície de contato (contact surface). O conceito de par contato-alvo é amplamente utilizado na simulação por elementos finitos. A detecção dos pontos de contato é feita por meio da localização dos pontos nodais, ou pontos de Gauss. Os elementos da superfície de contato são restringidos contra a penetração na superfície alvo.

Para que o contato se comporte de forma adequada, a escolha do tipo de superfície deve seguir os critérios recomendados no manual do programa ANSYS. Quando existir o contato entre duas superfícies de diferentes ridigezes, a recomendação do manual é que a superfície alvo represente o material mais rígido enquanto que a superfície de contato deve representar o material mais deformável. Seguindo este raciocínio, no estudo dos silos a superfície da parede é a superfície alvo (target surface) e o contorno do produto em contato com a parede é a superfície de contato (contact surface).

\subsubsection{Rigidez do contato e algoritmo de solução empregado}

Os programas comerciais possuem muitos parâmetros para simular o contato entre dois materiais. No programa ANSYS, existem vários parâmetros, denominados real constants parameters, que estão relacionados com o contato. Gallego et al. (2004) afirma que o fator de rigidez do contato (FKN) é o mais importante deles. A rigidez equivalente do contato $(k)$ é uma fração da rigidez do produto armazenado $(\mathrm{FKN})$ : 
$k=F K N \cdot\left[\frac{f_{s} \cdot \text { Area } \cdot B M}{\text { volume }}\right]$

onde:

$\mathrm{f}_{\mathrm{s}}=$ fator de penalização

Área= área do elemento de contato

volume $=$ volume para segmentos nos elementos sólidos

$\mathrm{BM}=$ módulo granular do elemento que sofreu o contato

Quanto maior o valor de FKN, menor a penetração permitida no contato. Ou seja, o valor do FKN define a rigidez do contato e a quantidade da penetração do contato na parede. De acordo com Guaita (1995) a simulação de paredes rígidas é feita com o maior valor possível de FKN para impedir qualquer tipo de penetração da superfície de contato na superfície alvo. O problema de adotar altos valores de FKN é que quanto maior o FKN, maior é a dificuldade para obter a matriz de rigidez global e, portanto, mais dificilmente o problema vai convergir.

O valor 1 de FKN é adotado como padrão pelo ANSYS, ele fornece um balanço aceitável entre o tempo de convergência e a precisão da solução e pode ser modificado de acordo com o modelo estudado. Segundo Vidal et al. (2005 ${ }^{\mathrm{b}}$ ) este valor pode não ser apropriado para o estudo das pressões nos silos. Neste trabalho foi realizado um estudo paramétrico para determinar o fator de rigidez normal que melhor descreve o comportamento das pressões na parede do silo.

Para determinar se o contato existe entre duas superfícies, o ANSYS utiliza métodos iterativos com fatores de penalização. O contato é detectado se o nó na superfície de contato está na mesma posição do nó da superfície rígida. Algumas condições restritivas são utilizadas para calcular a existência da penetração que são controladas por meio de métodos algorítmicos. Três diferentes algoritmos podem ser usados para o contato: o multiplicador de Lagrange puro (PLM), o método de penalização (PM) ou o método Lagrangeano aumentado (ALM). Neste trabalho foi utilizado o método Lagrangeano aumentado que foi o que apresentou melhores resultados em comparação com os restantes.

\subsubsection{Tipos de elementos utilizados no contato}

A interação produto-parede na análise bidimensional foi realizada com os elementos CONTA171 e TARGE169, Figura 6.20. Estes elementos possuem as 
mesmas características geométricas do elemento com o qual estão conectados. Os elementos de contato revestem os elementos sólidos descrevendo o contorno do corpo deformável e estão potencialmente em contato com a superfície alvo (rígida). A superfície alvo é discretizada por uma série de elementos target, formando par com a superfície de contato conforme ilustra a Figura 6.20.

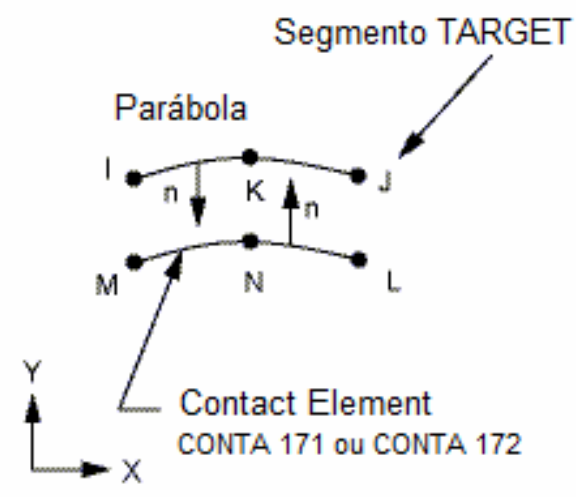

Figura 6.20 - Características dos elementos finitos CONTA171 e TARGE169.

Para a análise tridimensional foi utilizado o par CONTA173 e TARGE170, ilustrados na figura Figura 6.21.

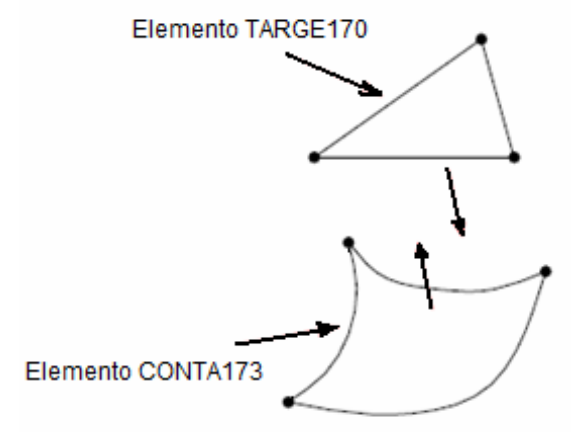

Figura 6.21 - Interação entre os elementos finitos CONTACT 173 e TARGET 170.

O elemento CONTA173 é utilizado para representar o contato e o deslizamento entre a superfície que receberá a pressão, ou seja, a superfície alvo (TARGE170). Este elemento possui três graus de liberdade em cada nó: translações nos eixos $x, y$ e $z$ e está localizado entre a superfície do sólido tridimensional e a superfície de casca e possui as mesmas características geométricas do sólido ou elemento de casca com o qual ele está conectado. O contato ocorre quando o elemento de contato penetra em um dos elementos alvo (TARGE170) da superfície 
alvo. As direções dos vetores normais às superfícies dos elementos CONTAC173 e TARGE170 devem estar em sentido contrário, conforme a Figura 6.21.

\subsubsection{Comportamento da superfície de contato}

No ANSYS existem 7 tipos diferentes de modelos de comportamento para a superfície de contato que são:

- contato padrão: permite separação entre as superfícies target e contact sendo que a pressão normal é nula quando a separação ocorrer;

- contato perfeitamente rugoso: permite a separação entre as superfícies target e contact mas quando existe o contato, o cisalhamento entre elas não existe, ou seja, coeficiente de atrito é considerado infinito;

- contato sem separação: permite a separação inicial entre as superfícies target e contact porém após estabelecido o contato, as superfícies target e contact se unem, sendo permitido o cisalhamento entre elas;

- contato grudado: permite a separação inicial mas quando o contato é estabelecido, as superfícies target e contact permanecem grudadas em todas as direções não sendo permitido o cisalhamento entre elas;

- contato sempre sem separação: elimina a separação inicial que pode ocorrer entre as superfícies target e contact de forma que elas permanecem sempre unidas sendo permitido o cisalhamento entre elas;

- contato sempre grudado: elimina a separação inicial que pode ocorrer entre as superfícies target e contact que permanecem grudadas sempre e em todas as direções não sendo permitido o cisalhamento entre elas;

- contato grudado com contato inicial: admite que as superfícies nas quais existe um contato inicial permanecerão grudadas enquanto que as que não estão inicialmente em contato permanecem sem haver contato.

Neste trabalho foi utilizado o modelo de contato sem separação porque é o que melhor descreve o comportamento do contato entre o produto e a parede e foi a opção que apresentou os melhores resultados. 


\subsection{Modelo de descarregamento para obtenção das pressões dinâmicas}

Vários estudos experimentais, tanto em modelos reduzidos como em silos em escala real, apontam que o principal problema estrutural dos silos é o aumento das pressões horizontais quando a descarga se inicia, porém a magnitude dessas sobrepressões ainda não é totalmente conhecida. Existem muitas lacunas em relação à modelagem numérica do descarregamento do silo. Ela é complexa devido a vários fatores como:

- os efeitos da aceleração e de velocidade das partículas não desprezíveis;

- limitação dos métodos numéricos empregados, normalmente fundamentados na Mecânica do Contínuo;

- dificuldade de obter um modelo constitutivo macroscópico que expresse de forma realista o comportamento do produto durante a descarga;

- inexistência de testes experimentais para mensurar as propriedades dos produtos durante o seu fluxo;

- dificuldade de obter um modelo numérico de comportamento do produto durante o fluxo que considere redução de densidade e características de viscosidade.

O descarregamento do silo é uma condição dinâmica que envolve tempo, velocidade e aceleração como variáveis do problema e requer a consideração do deslocamento de partículas individuais. Sendo o método dos elementos finitos fundamentado na hipótese de meio contínuo, a modelagem do fluxo se torna mais complexa.

Neste trabalho o modelo de descarga foi simplificado e resolvido de duas formas diferentes, conforme a geometria do silo. A simulação da descarga no silo de fundo plano foi realizada a partir da aplicação de um deslocamento prescrito no fundo do silo, numa área igual à área do canal de fluxo determinada segundo a teoria de Rotter.

Desta forma, a simulação da descarga no silo de fundo plano consistiu em dois passos de carga. No primeiro passo de carga, o fundo do silo foi restrito integralmente sendo a gravidade a única força atuando no silo. No segundo passo 
de carga um deslocamento de $50 \mathrm{~cm}$ foi aplicado no fundo do silo numa área correspondente ao canal de fluxo, conforme pode ser observado na Figura 6.22.
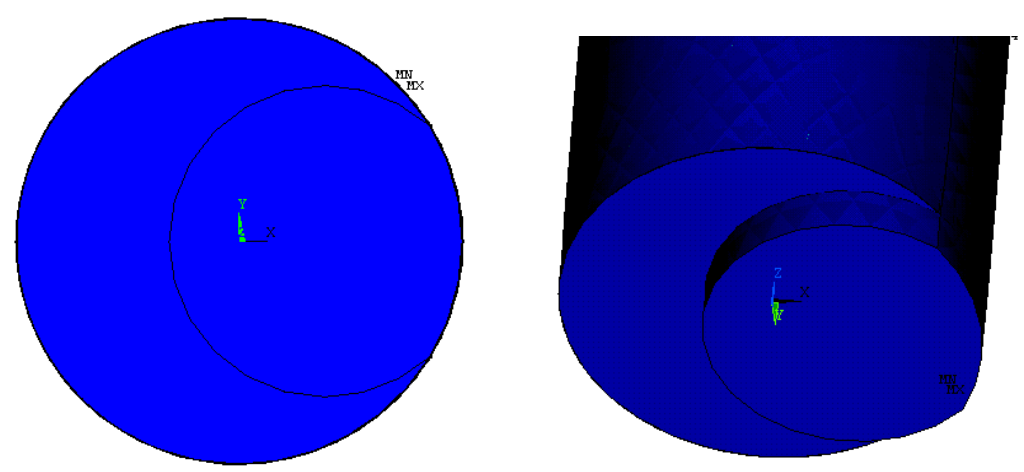

Figura 6.22 - Deslocamento imposto na área canal de fluxo.

A simulação ilustrada na Figura 6.22 não é uma análise dinâmica propriamente dita dado que ela não considera o tempo como variável do problema. Portanto, trata-se de uma análise estática que simula simplificadamente o processo dinâmico que ocorre na descarga real do silo.

No silo com fundo de tremonha a simulação da descarga, foi realizada com base na teoria de Jenike que afirma que, no início da descarga, ocorre a mudança do estado ativo para o estado passivo de tensões gerando durante este processo um aumento significativo no valor do parâmetro $\mathrm{K}$ e consequentemente um aumento no coeficiente de Poisson. Então, a descarga do silo foi simulada a partir de um modelo estático com o coeficiente de Poisson igual a 0,48, que representa um aumento de $50 \%$ no valor de $\mathrm{K}$. 


\section{RESULTADOS E ANÁLISE DOS RESULTADOS}

\subsection{Aspectos da modelagem numérica}

\subsubsection{Influência do fator de rigidez normal do contato (FKN) e do modelo de comportamento do produto}

Na Figura 7.1 e na Figura 7.2 pode ser observada a influência do fator de rigidez normal do contato (FKN) e do modelo de comportamento do produto na distribuição das pressões para o silo com fundo plano.

(a)

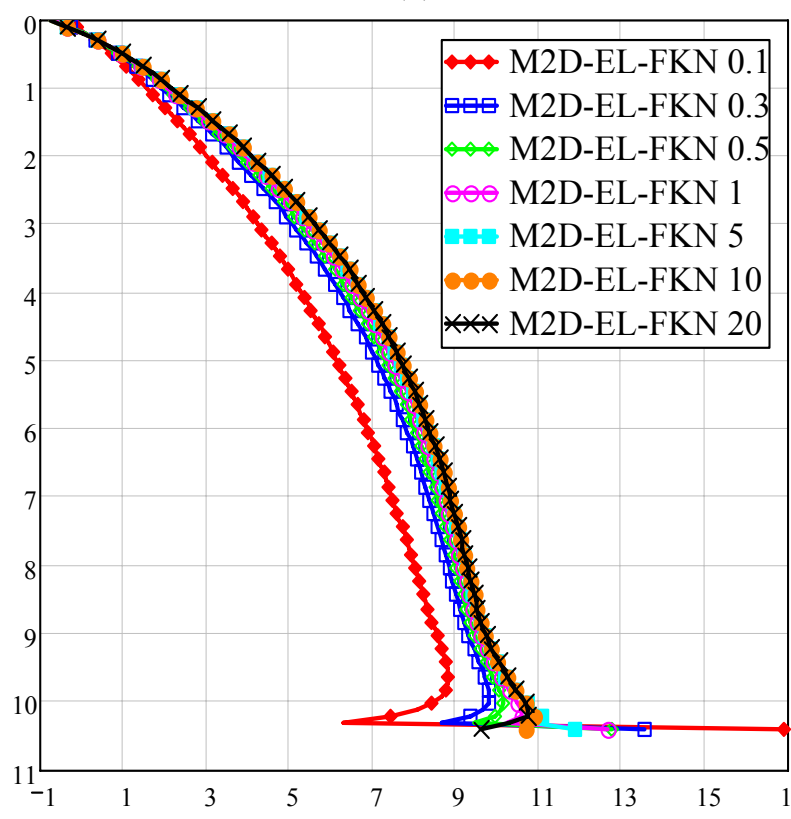

Pressão estática normal à parede em $\mathrm{kPa}$ (b)

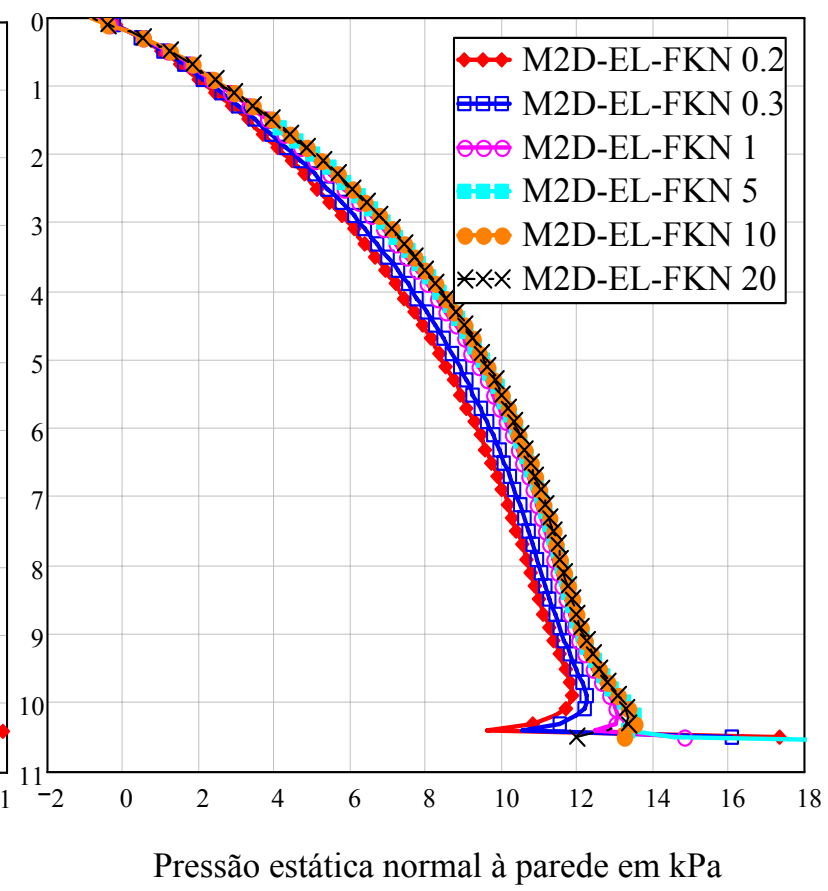

Figura 7.1 - Influência do FKN no estudo das pressões estáticas normais às paredes do silo com fundo plano considerando comportamento elástico para o farelo de milho (a) e a soja (b). 
(a)

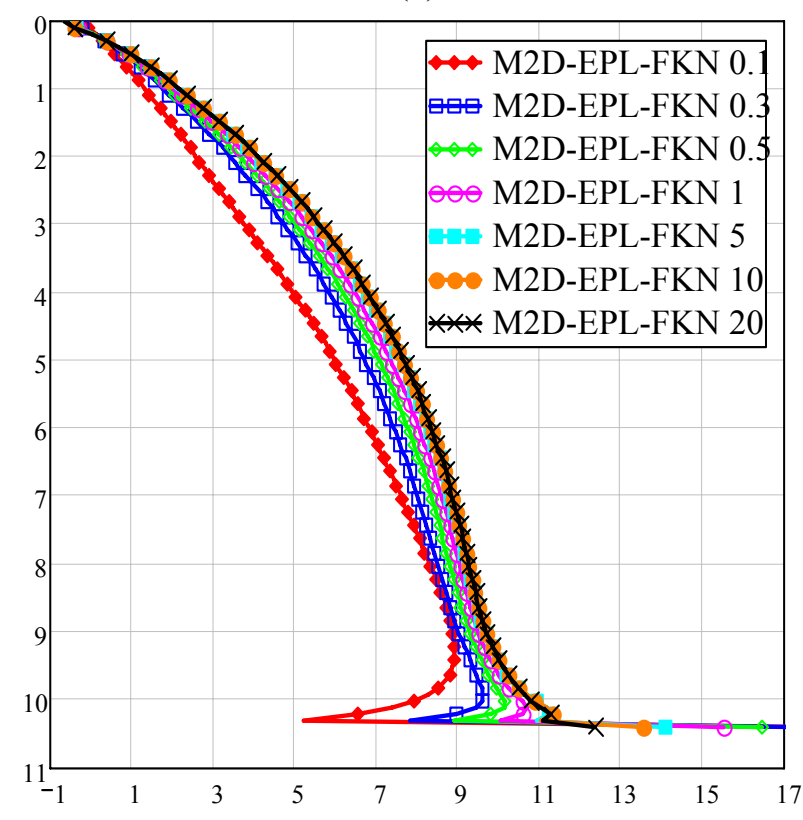

Pressão estática normal à parede em $\mathrm{kPa}$ (b)

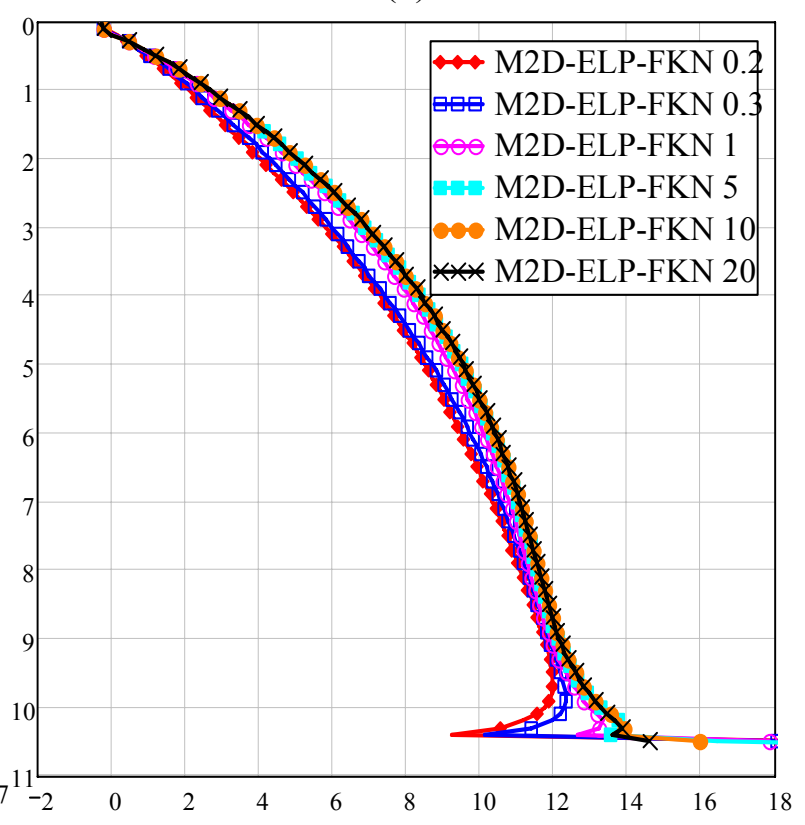

Pressão estática normal à parede em $\mathrm{kPa}$

Figura 7.2 - Influência do FKN no estudo das pressões estáticas normais às paredes do silo com fundo plano considerando comportamento elastoplástico para o farelo de milho (a) e a soja (b).

Comparando as figuras acima, percebe-se que a consideração de produto elástico ou elastoplástico não interfere significativamente no estudo das pressões estáticas. A maior diferença acontece quando o fator de rigidez é baixo de forma que valores de FKN maiores ou igual a 1 produzem resultados das pressões com 0 produto elastoplástico semelhantes aos do elástico. Na realidade, enquanto o produto se encontra armazenado em repouso no interior do silo a consideração de material elástico é adequada.

Com relação ao fator de rigidez normal do contato $(F K N)$, pode-se perceber que quanto maior FKN, maiores as pressões exercidas pelo produto sobre a parede. Valores superiores a 1 estabilizam as pressões. Nos modelos simulados com valores baixos de FKN, situados entre 0,1 e 1, ocorre um alívio de tensões, representando paredes flexíveis. Ou seja, quanto maior a rigidez da parede, maior a pressão e quanto mais flexível (maior deformação) menores as pressões na parede do silo.

A diferença dos valores das pressões para diferentes FKN é explicada pelo valor da penetração no contato que simula o deslocamento horizontal da parede. A penetração da superfície contact na superfície target ao longo da altura do silo pode ser observada na Figura 7.3 (produto elástico) e na Figura 7.4 (produto elastoplástico). 
(a)

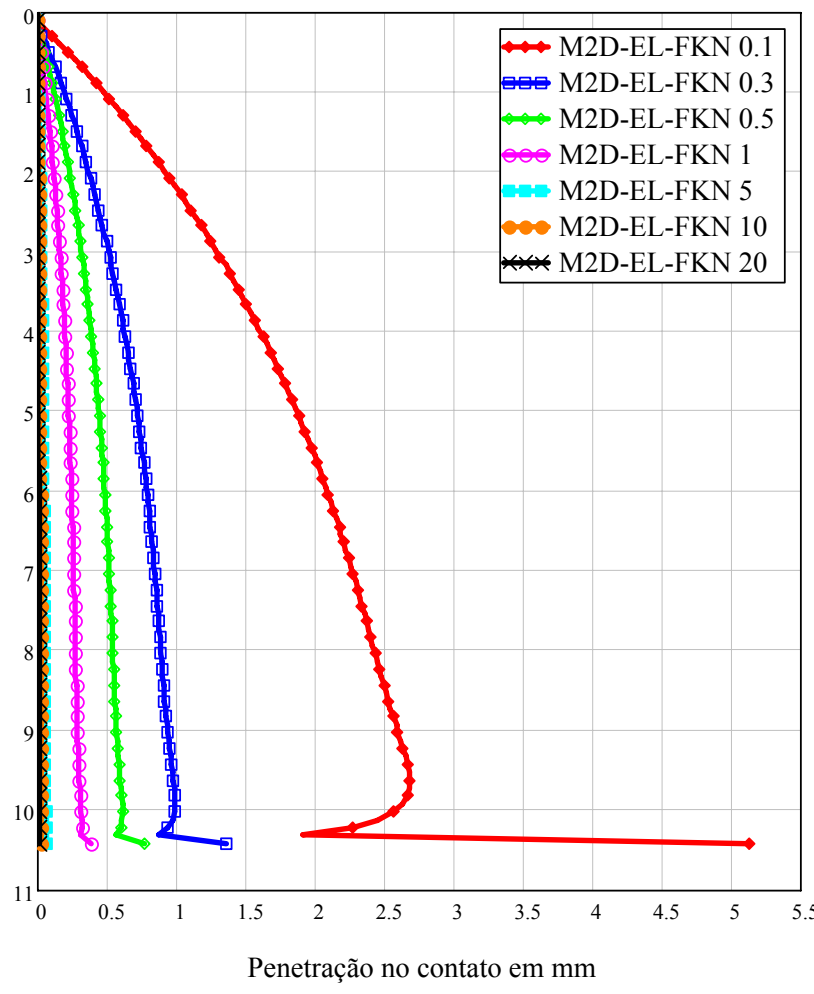

(b)

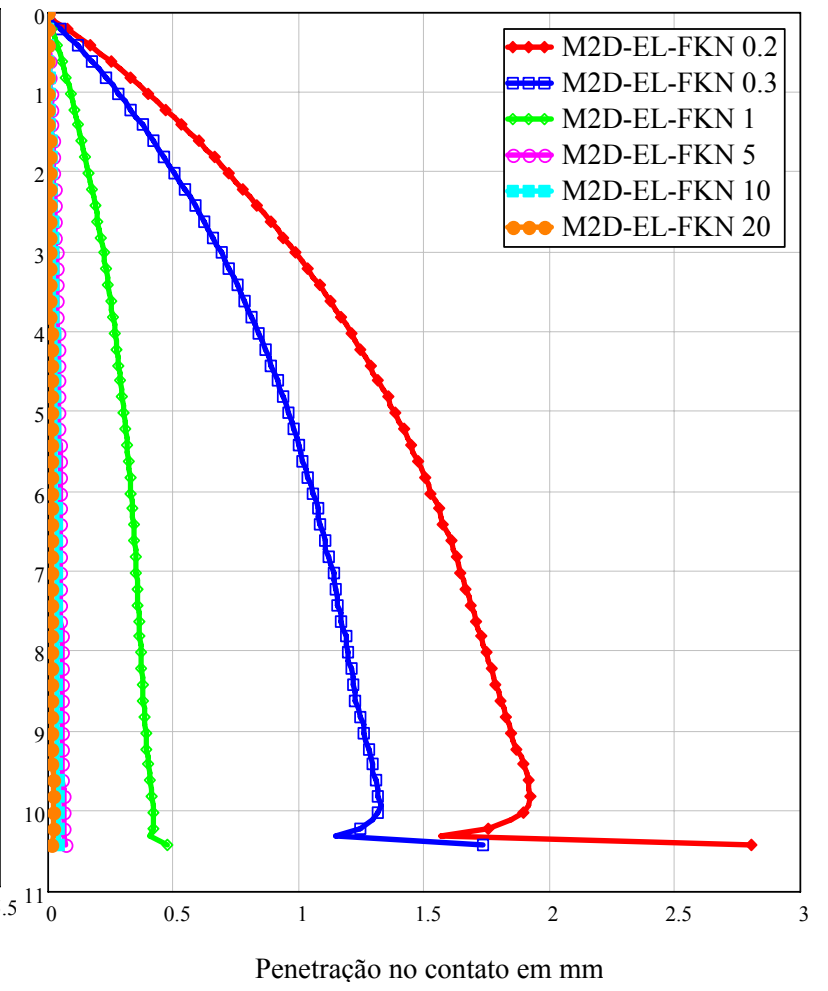

Figura 7.3 - Penetração no contato segundo FKN, considerando comportamento elástico para o farelo de milho (a) e a soja (b).

(a)

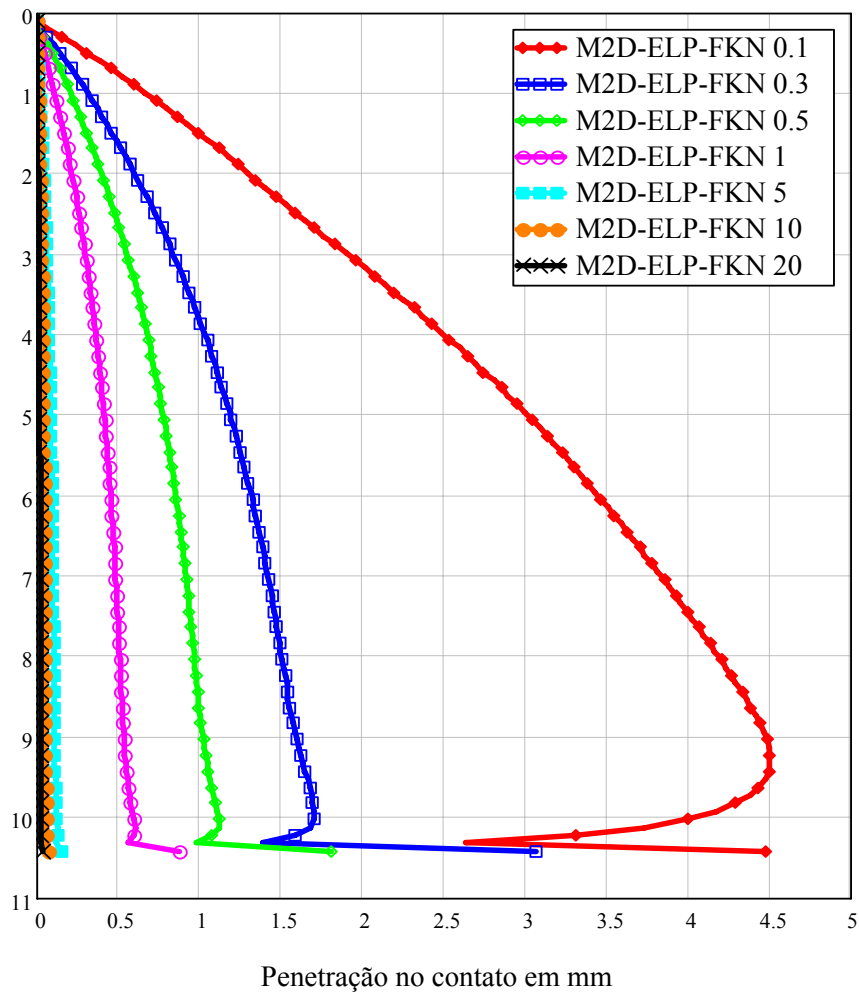

(b)

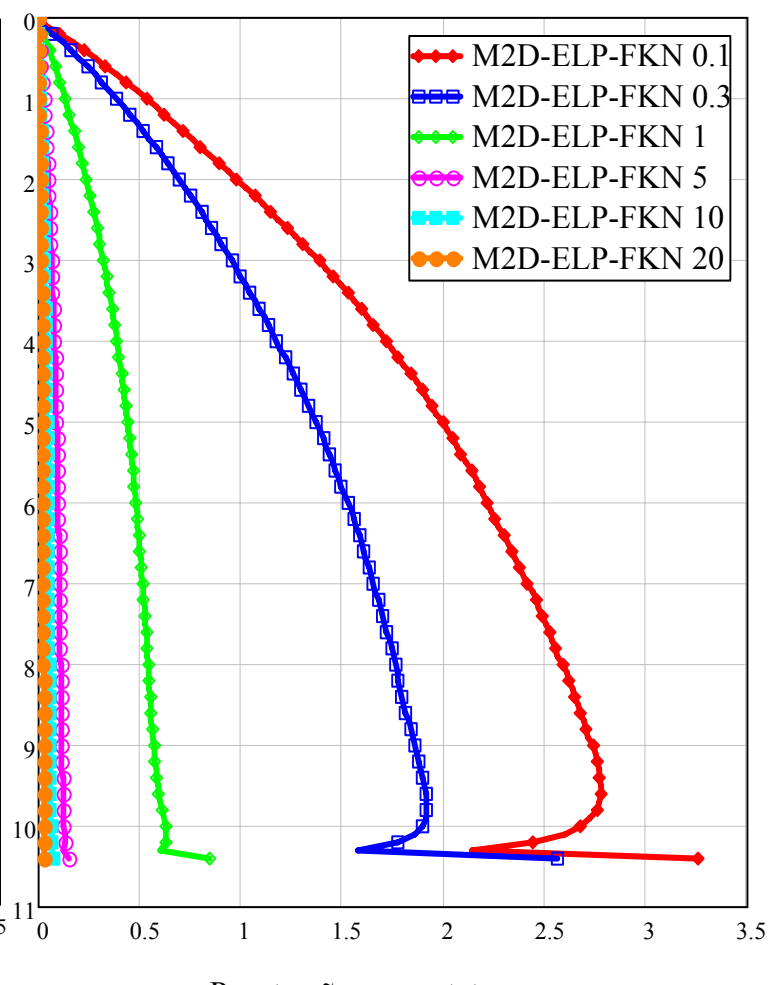

Penetração no contato em mm

Figura 7.4 - Penetração no contato segundo FKN, considerando comportamento elastoplástico para o farelo de milho (a) e a soja (b). 
Conforme explicado, o FKN controla a quantidade de penetração da superfície contact na superfície target e por isso ele é capaz de simular o efeito da flexibilidade das paredes. Nos modelos com FKN abaixo de 1 observa-se maior deformação na parede o que representa paredes flexíveis enquanto valores maiores do que 1 , os deslocamentos na parede são baixos e simulam paredes rígidas. Isto explica o motivo pelo qual os modelos com menor FKN apresentam um alívio de tensões.

Quando FKN é baixo, a penetração no contato obtida com o comportamento elastoplástico são maiores do que com o produto elástico porque baixos valores de FKN permitem a plastificação do produto.

A variação da pressão no fundo do silo de acordo com o fator FKN é ilustrada na Figura 7.5.

(a)

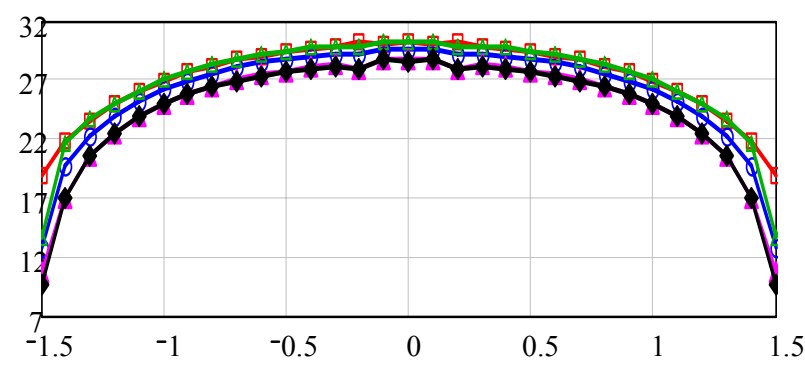

Pressão vertical na base em $\mathrm{kPa}$

M2D-EL-FKN 0.3

M2D-EL-FKN 0.5

$\leftrightarrow \mathrm{M} 2 \mathrm{D}-\mathrm{EL}-\mathrm{FKN} 1$

$\leftrightarrow$ M2D-EL-FKN 10

$\leftrightarrow$ M2D-EL-FKN 20 (b)

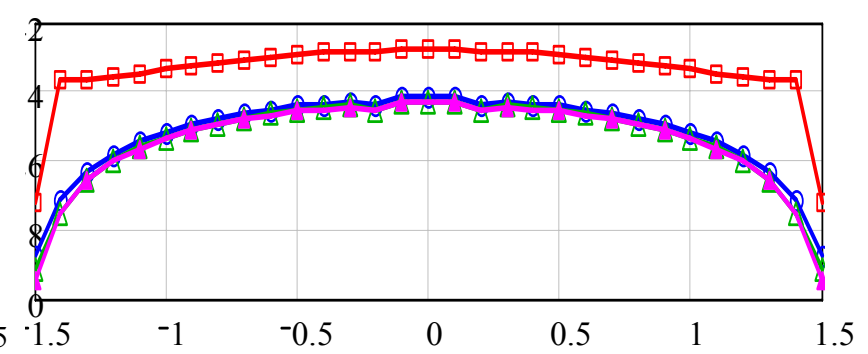

Pressão vertical na base em $\mathrm{kPa}$ M2D-EL-FKN 0.1

M2D-EL-FKN 1

$\Delta \triangle \mathrm{M} 2 \mathrm{D}-\mathrm{EL}-\mathrm{FKN} 10$

M2D-EL-FKN 20

Figura 7.5 - Influência do FKN nas pressões estáticas verticais no fundo do silo com fundo plano considerando comportamento elástico para o farelo de milho (a) e a soja (b).

No fundo do silo, o efeito do fator de rigidez do contato é inverso, ou seja, quanto maior o FKN, menores as pressões no fundo do silo. Esta redução de pressões ocorre pelo fato de que a parcela das forças verticais transmitidas por atrito às paredes verticais do silo aumenta com o aumento do FKN.

Em silos que possuem fundo com tremonhas, o efeito do FKN é mais acentuado, principalmente na tremonha. Na Figura 7.6 pode ser observada influência do fator de rigidez do contato no silo com tremonha concêntrica, considerando o modelo de comportamento elástico para o produto. 
(a)

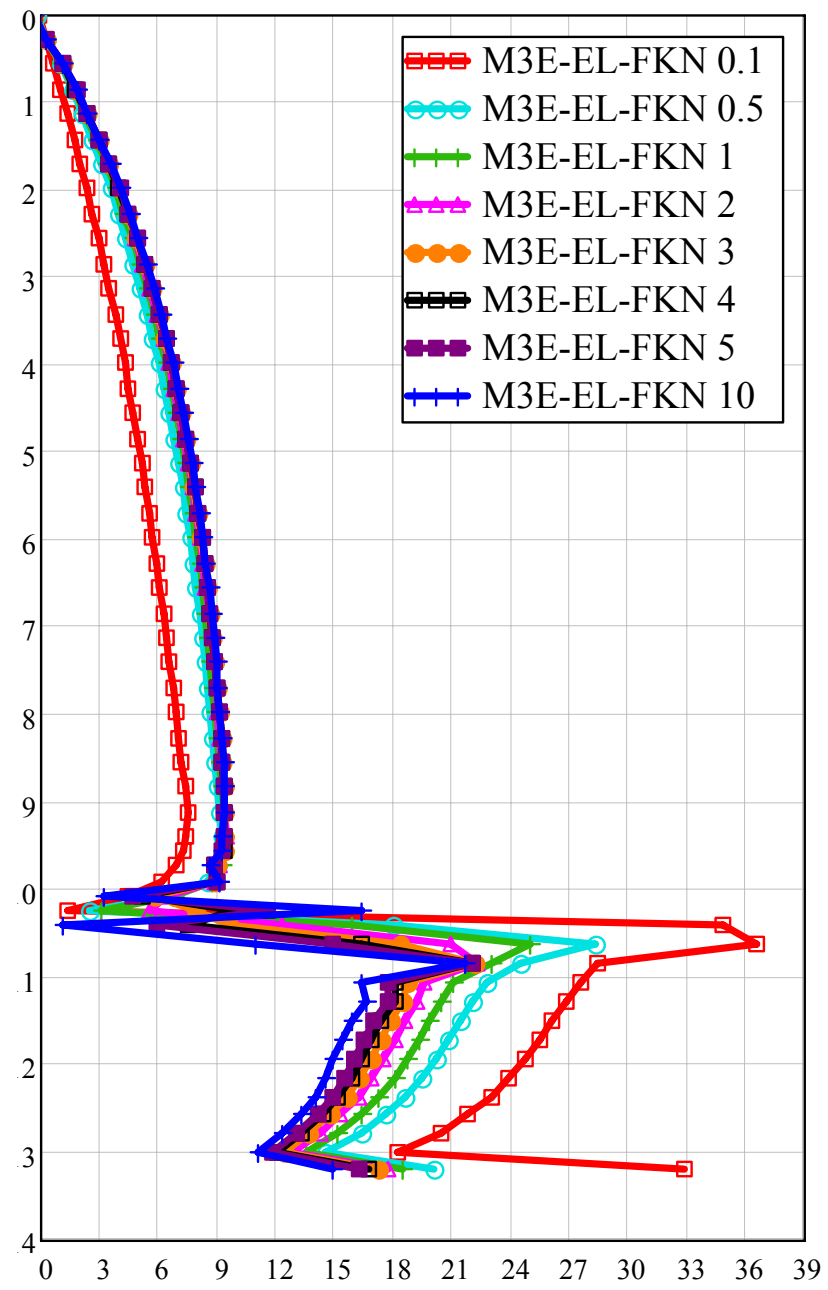

Pressão estática normal à parede em $\mathrm{kPa}$ (b)

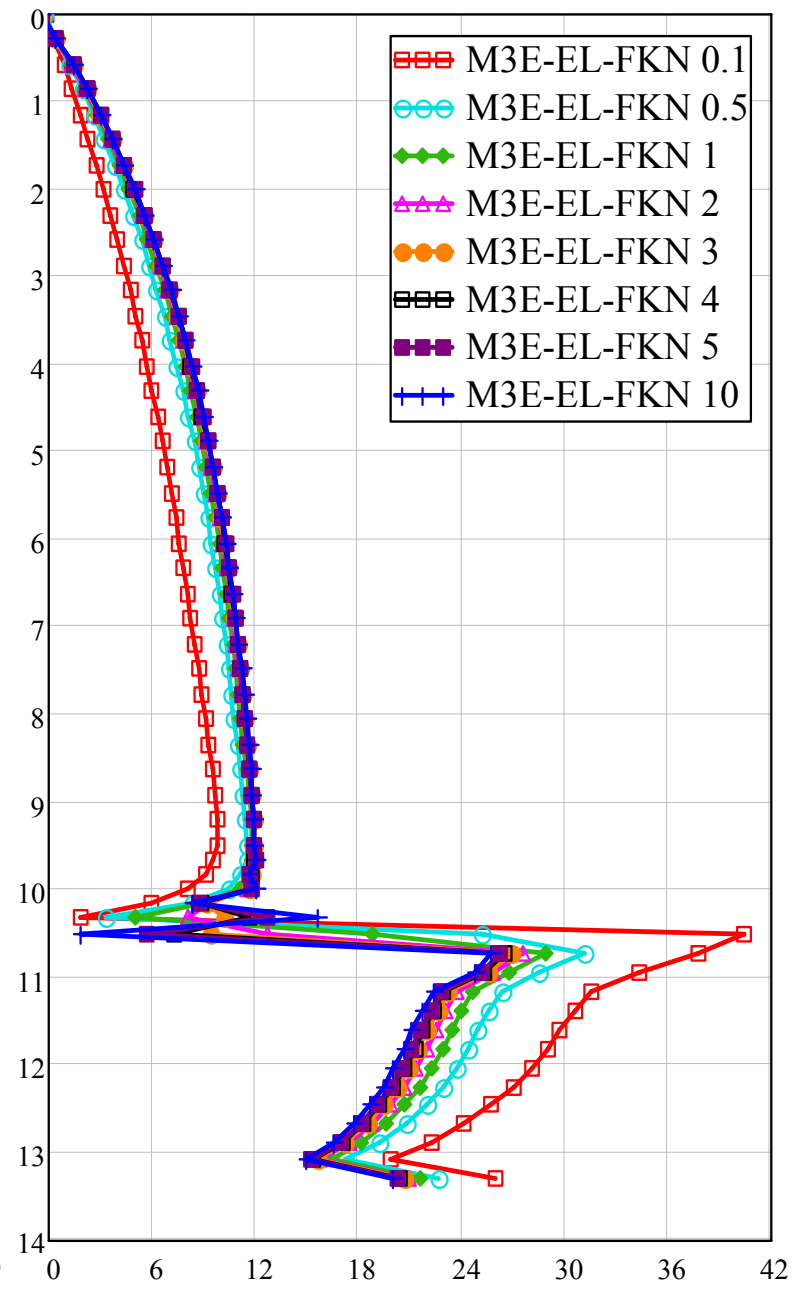

Pressão estática normal à parede em $\mathrm{kPa}$

Figura 7.6 - Influência do FKN nas pressões estáticas normais às paredes (silo com tremonha concêntrica), considerando comportamento elástico para o farelo de milho (a) e a soja (b).

Pode ser visto que o valor de FKN altera significativamente a intensidade das pressões na tremonha de forma que quanto maior FKN, menor a pressão na tremonha. Quando FKN é maior do que 5, ocorre flutuação no valor da pressão na altura da transição entre o corpo cilíndrico e a tremonha (curvas azuis da Figura 7.6). A Figura 7.7 ilustra o efeito do FKN considerando o modelo de comportamento elastoplástico para o produto. 
(a)

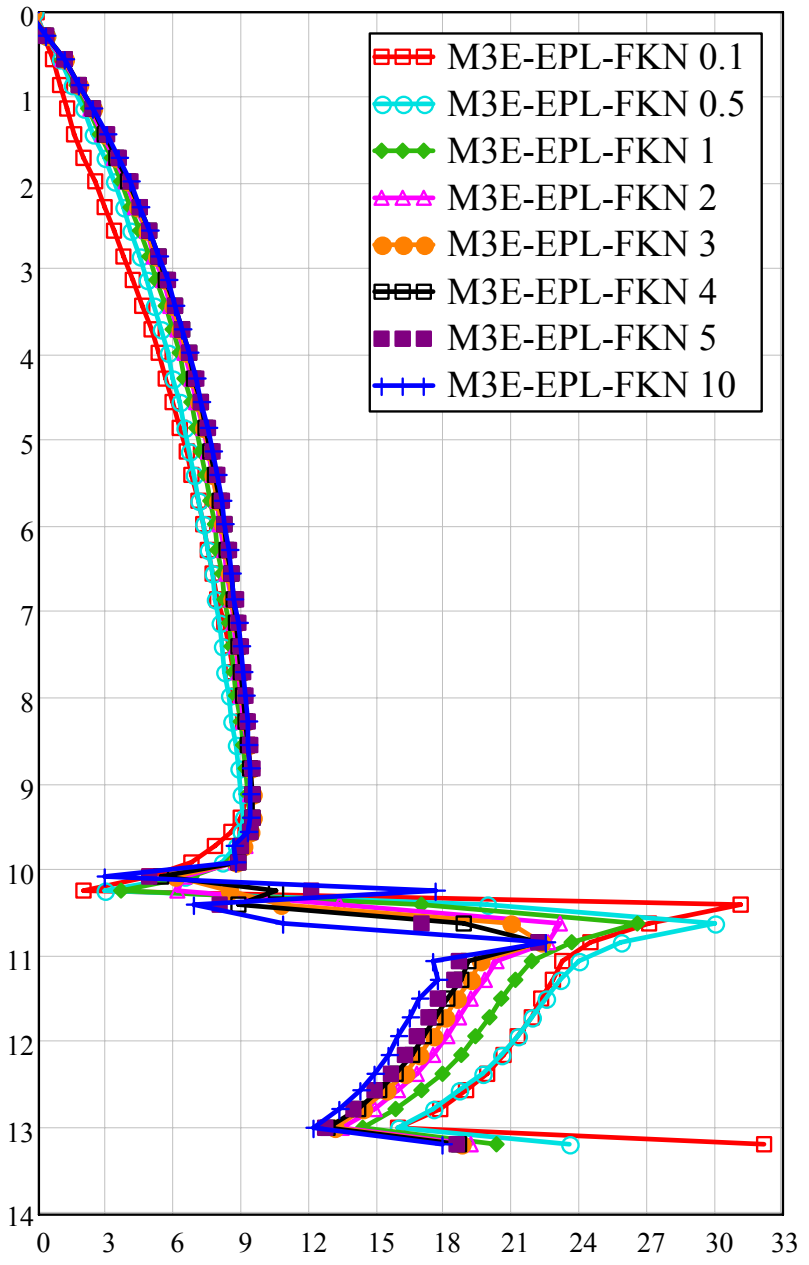

Pressão estática normal à parede em $\mathrm{kPa}$ (b)

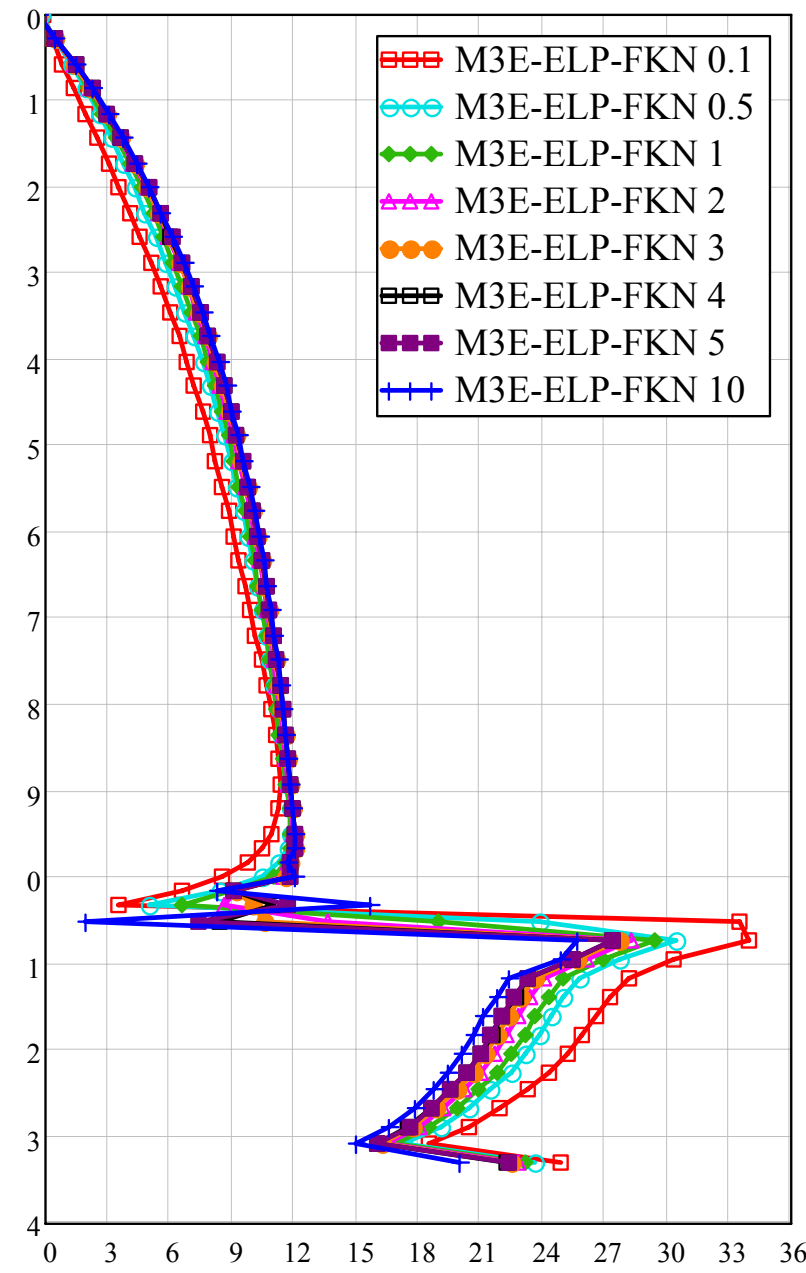

Pressão estática normal à parede em $\mathrm{kPa}$

Figura 7.7 - Influência do FKN nas pressões estáticas normais às paredes do silo com tremonha concêntrica considerando comportamento elastoplástico para o farelo de milho (a) e a soja (b).

A variação das pressões na tremonha de acordo com $F K N$, obtidas considerando o produto elastoplástico é similar quando comparado aos resultados com o produto elástico. A Figura 7.8 ilustra a quantidade de penetração obtida a partir da simulação com FKN igual a 0.1 e considerando o produto elástico. 


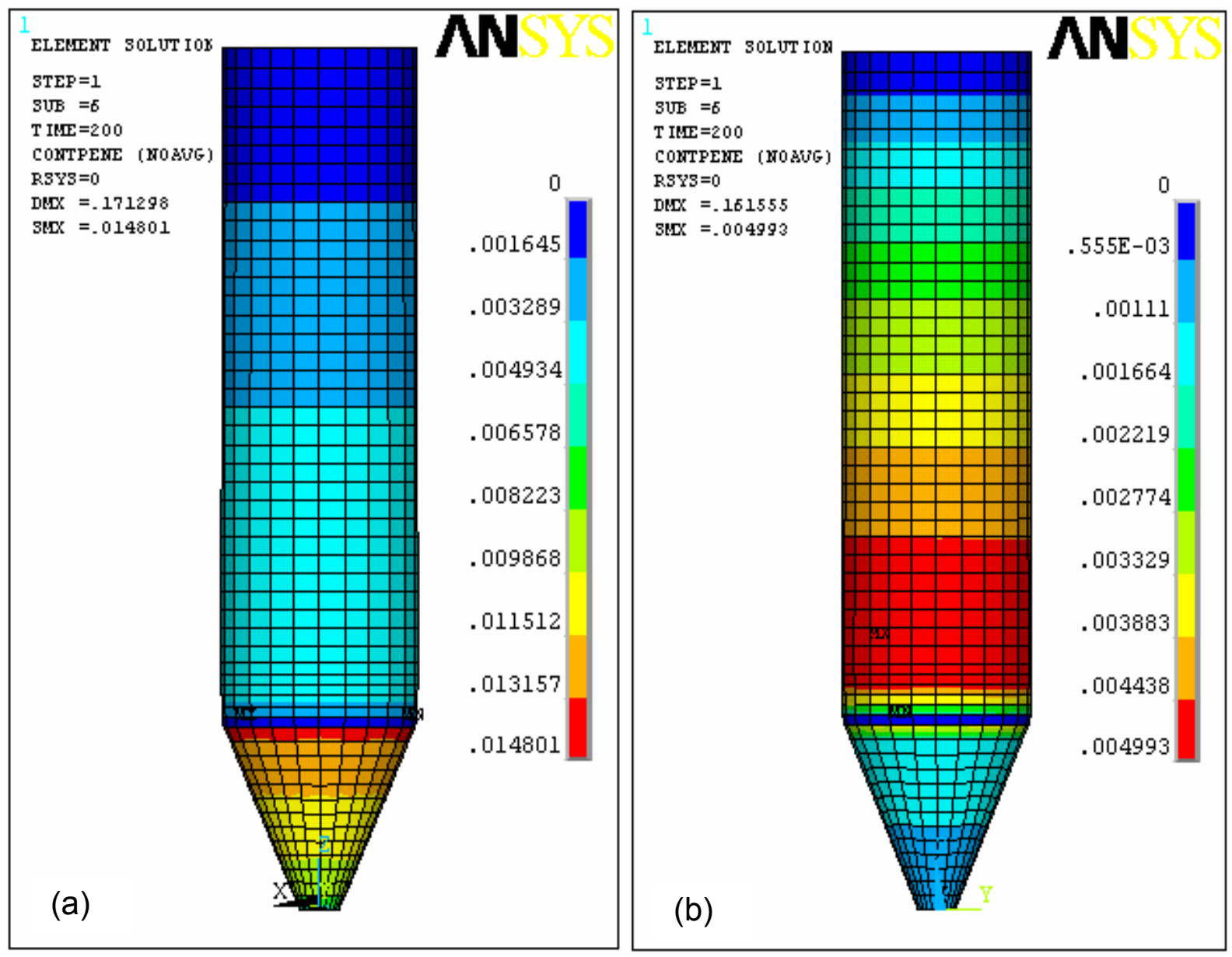

Figura 7.8 - Quantidade de penetração no contato considerando o produto com comportamento elástico para o farelo de milho (a) e a soja (b).

\subsubsection{Influência do coeficiente de Poisson (v)}

O coeficiente de Poisson é um parâmetro importante para a determinação das pressões porque ele está relacionado à dilatação volumétrica do produto que se encontra confinado quando armazenado em repouso dentro do silo. Nos modelos analíticos para o cálculo das pressões, o parâmetro $K$ tem a mesma função de $v$. Portanto, no modelo numérico o parâmetro $K$ é substituído pelo coeficiente de Poisson dado que existe uma relação entre eles.

As normas analisadas consideram a variabilidade das propriedades físicas do produto gerando três valores distintos de $\mathrm{K}$, que são: $\mathrm{K}_{\mathrm{i}}, \mathrm{K}_{\mathrm{m}}$ e $\mathrm{K}_{\mathrm{s}}$. Para cada valor de $\mathrm{K}$, temos os correspondentes valores do coeficiente de Poisson (Tabela 7.1): 
Tabela 7.1 - Variação do coeficiente de Poisson ( $v$ ) com o coeficiente K.

\begin{tabular}{|c|c|c|}
\hline $\begin{array}{c}\text { Coeficiente } \\
\mathbf{K}\end{array}$ & $\begin{array}{c}\text { Farelo } \\
\text { milho }\end{array}$ & Soja \\
\hline $\mathbf{K}_{\mathbf{i}}$ & 0,41 & 0,45 \\
\hline $\mathbf{K}_{\mathbf{m}}$ & 0,43 & 0,47 \\
\hline $\mathbf{K}_{\mathbf{s}}$ & 0,45 & 0,50 \\
\hline
\end{tabular}

\begin{tabular}{|c|c|c|}
\hline $\begin{array}{c}\text { Poisson } \\
(v)\end{array}$ & $\begin{array}{c}\text { Farelo } \\
\text { milho }\end{array}$ & Soja \\
\hline$v_{\mathbf{i}}$ & 0,29 & 0,31 \\
\hline$v_{\mathbf{m}}$ & 0,30 & 0,32 \\
\hline$v_{\mathbf{s}}$ & 0,31 & 0,33 \\
\hline
\end{tabular}

As curvas de pressões correspondentes aos valores de $v$ da Tabela 7.1, são ilustradas na Figura 7.9.

(a)

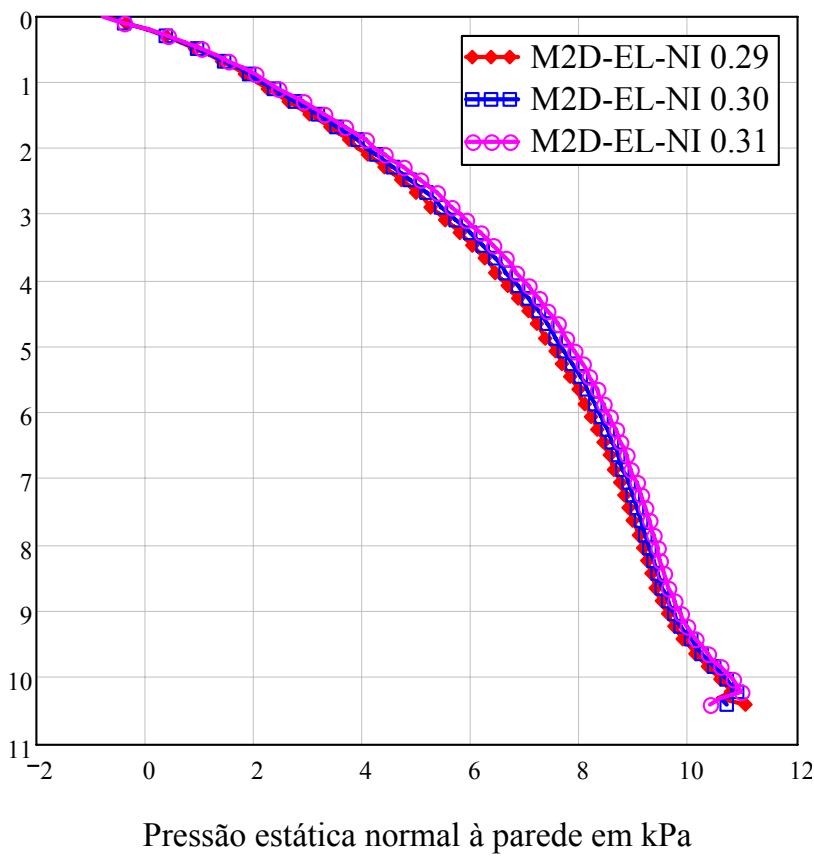

(b)

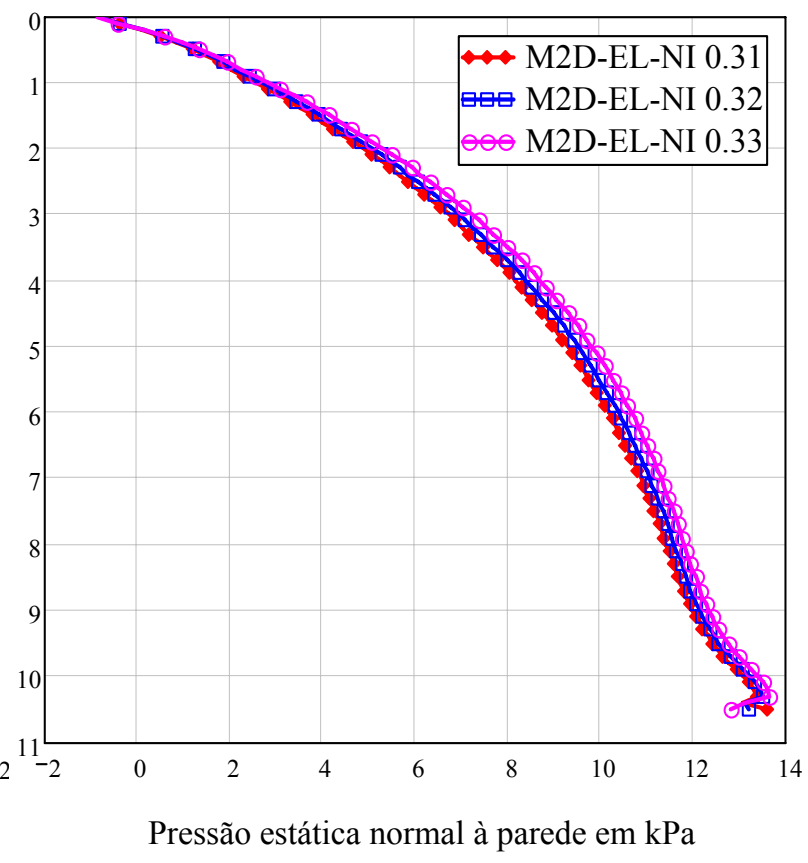

Figura 7.9 - Influência do coeficiente de Poisson (v) na distribuição das pressões estáticas normais às paredes do silo com fundo plano para o farelo de milho (a) e a soja (b).

Constata-se que quanto maior o coeficiente de Poisson, maior a pressão horizontal na parede do silo. Para o farelo de milho, aumentando-se o coeficiente de Poisson de 0,29 para 0,31 ocorre um acréscimo médio de $5 \%$ nos valores das pressões.

O aumento das pressões com o aumento do coeficiente de Poisson acontece devido ao efeito do confinamento do produto. Quanto maior o coeficiente de Poisson, maior a dilatação volumétrica do mesmo quando submetido à compressão. A presença de paredes rígidas no modelo impede que o produto se deforme, o que gera maiores pressões. Este fenômeno também está relacionado com o ângulo de atrito do produto também relacionado com o coeficiente K. Quanto maior o atrito 
interno do produto (consequentemente menor o coeficiente $\mathrm{K}$ ) menores as pressões horizontais.

\subsection{Análise das pressões no silo com fundo plano}

\subsubsection{Pressão estática vertical no produto}

A pressão estática vertical de acordo com cada norma analisada e com o MEF é ilustrada na Figura 7.10.

(a)

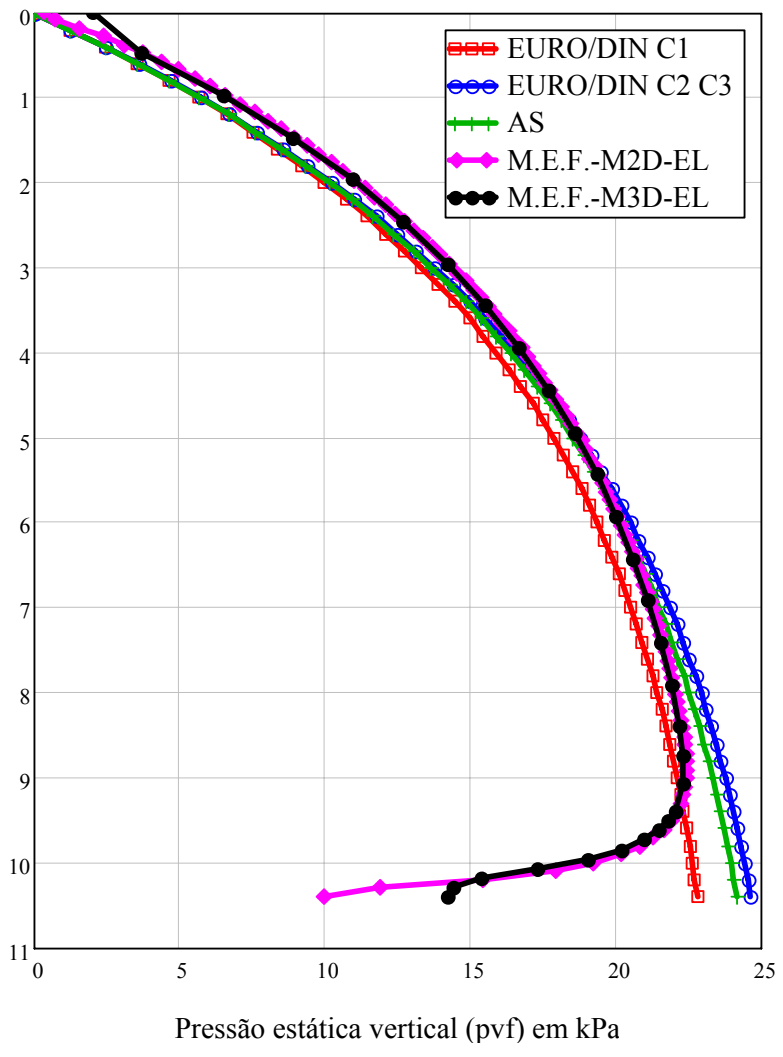

(b)

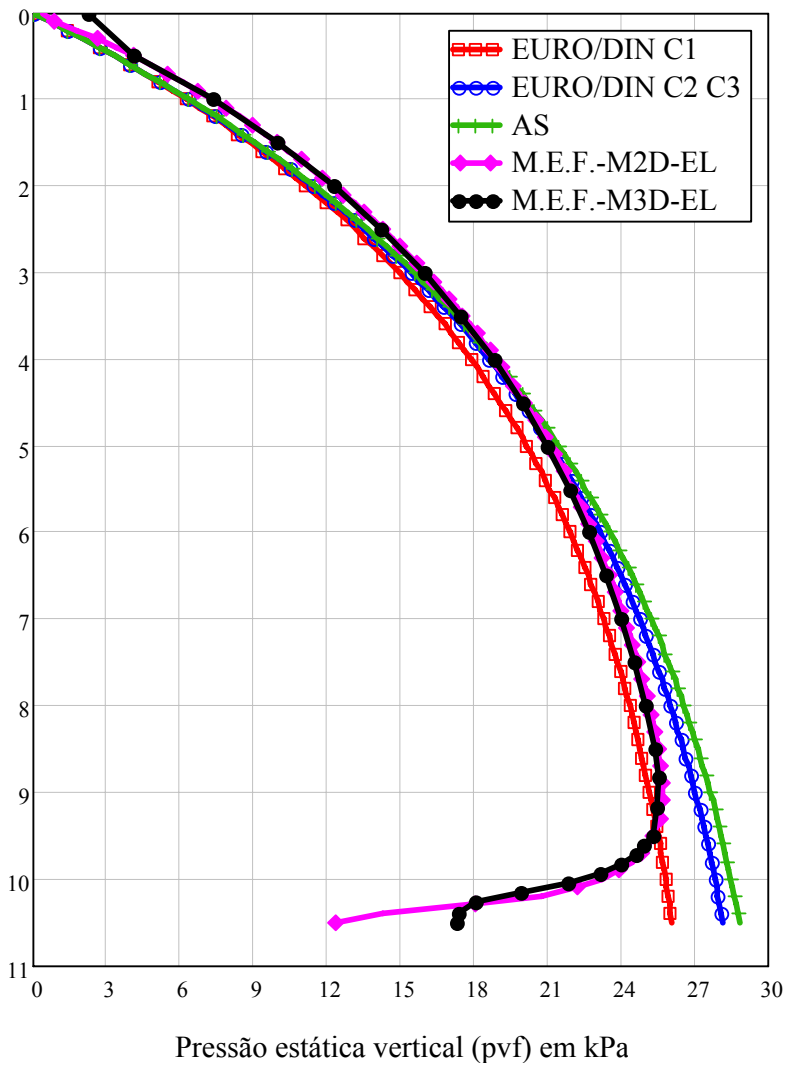

Figura 7.10 - Pressão estática vertical no produto para o farelo de milho (a) e a soja (b) simulados com FKN 10.

A soja possui maior peso específico e, portanto, apresenta os maiores valores para a pressão vertical no produto atingindo o valor médio de $28 \mathrm{kPa}$ na parte mais baixa do silo (segundo as normas) enquanto que para o farelo de milho as pressões estão abaixo de $25 \mathrm{kPa}$. As pressões em silos da classe 1 são menores porque consideram os valores médios de algumas propriedades dos produtos.

Observa-se que a curva de distribuição de pressões obtidas pelo MEF é ligeiramente superior na parte mais alta do silo e sofre um decréscimo apreciável próximo à base do silo. Isto se deve à consideração de base engastada no modelo 
numérico enquanto que a predição de pressões pelas normas é feita utilizando-se a teoria de Janssen, cuja hipótese de cálculo é fundamentada na consideração de um cilindro infinito.

Outro fator que explica a queda brusca da pressão próximo à base do silo é que o MEF é um método baseado na mecânica do contínuo. Portanto, em locais em que ocorre descontinuidade do modelo ocorre concentração de tensões. Isto pode ser observado na Figura 7.11, que ilustra o resultado das pressões verticais em ambos os produtos, em $\mathrm{kPa}$, nos modelos bidimensionais com axissimetria.
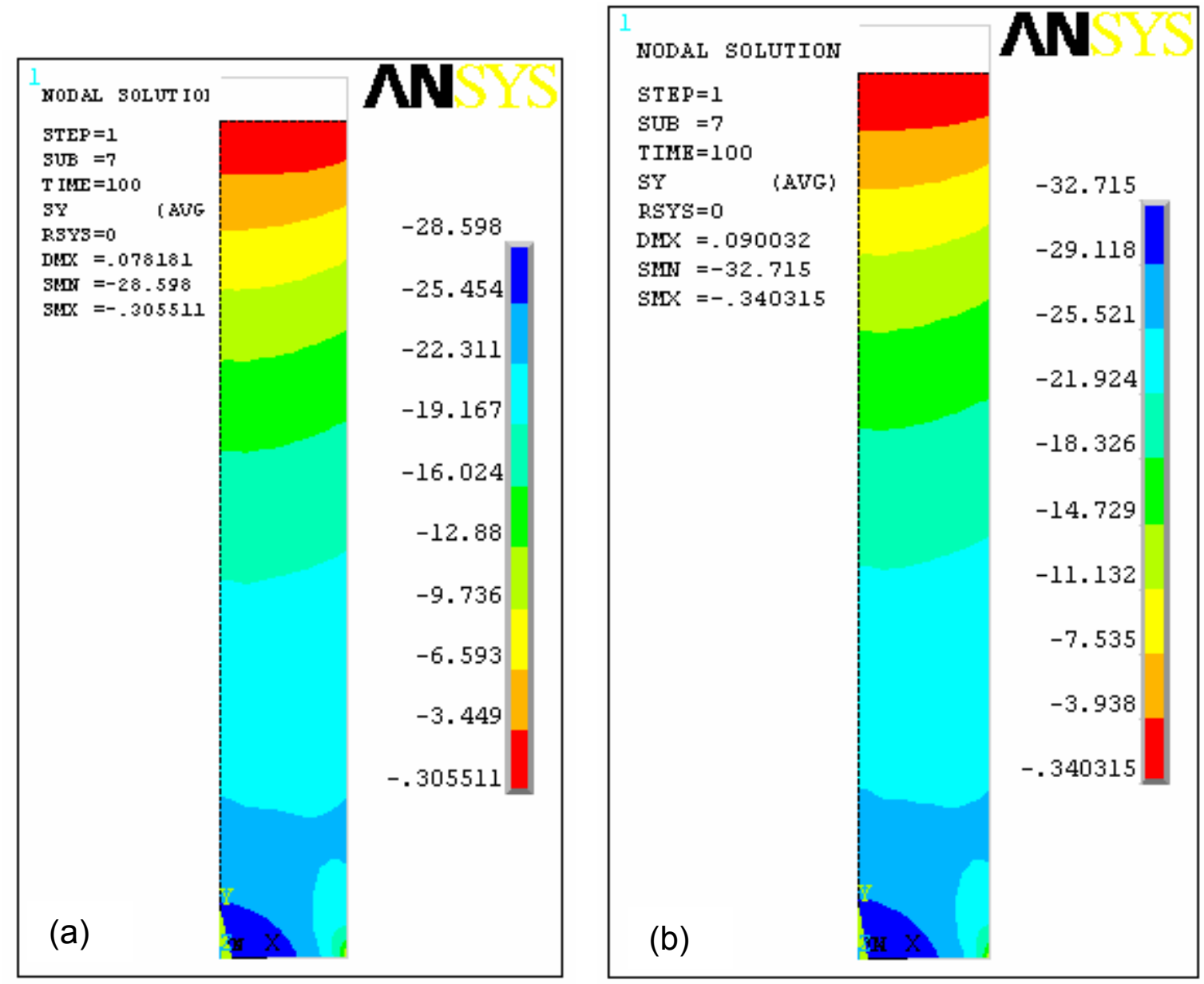

Figura 7.11 - Pressão estática vertical no produto em kPa para o farelo de milho (a) e a soja (b) com o modelo bidimensional axissimétrico FKN 10.

As pressões verticais na interface entre o produto e a parede e em uma linha de corte dentro do produto obtidas com o modelo tridimensional com o farelo de milho são ilustradas na Figura 7.12. 


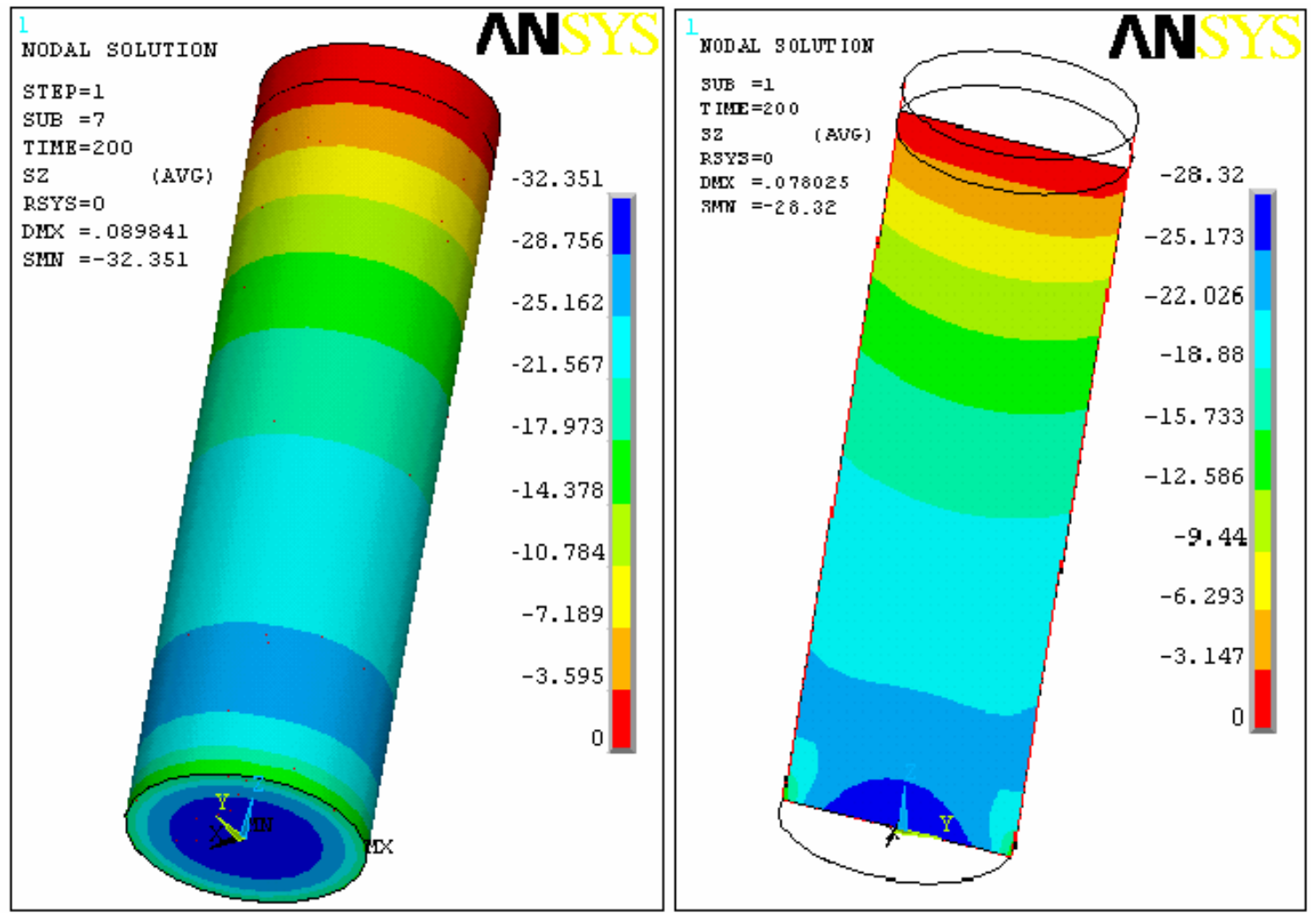

Figura 7.12 - Pressão estática vertical no produto em kPa para o farelo de milho com o modelo tridimensional.

Outra hipótese de validade da teoria de Janssen é a consideração de que as pressões verticais independem da coordenada horizontal, ou seja, a distribuição das pressões verticais varia somente ao longo da altura do silo. Pode ser observado na Figura 7.12 e na Figura 7.13 que a pressão vertical é maior no eixo central do silo e diminui conforme se aproxima da parede, com excessão das proximidades do fundo do silo, mostrando que a hipótese de tensões verticais constantes ao longo do raio não é coerente.

A distribuição de pressões obtida numericamente concorda com a teoria de Jenike, que afirma que a direção principal é vertical no eixo e muda sua direção se tornando mais próxima da horizontal conforme se proxima da parede.

\subsubsection{Pressão estática vertical no fundo do silo}

A comparação dos valores da pressão vertical no fundo do silo prescritos pelas normas e os obtidos pelo MEF é ilustrada na Figura 7.13. 
(a)

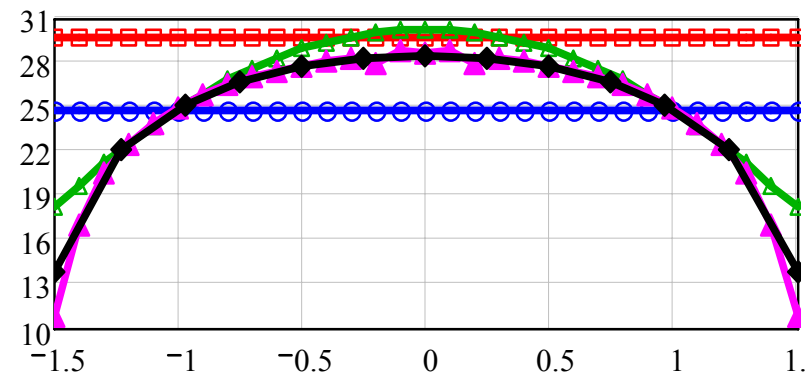

Pressão estática vertical (pvf) em kPa

$\mathrm{EURO} / \mathrm{DIN} \mathrm{Cl}$

EURO/DIN C2 C3

$\because \mathrm{AS}$

\pm M.E.F.-M2D-EL

$\leftrightarrow$ M.E.F.-M3D-EL (b)

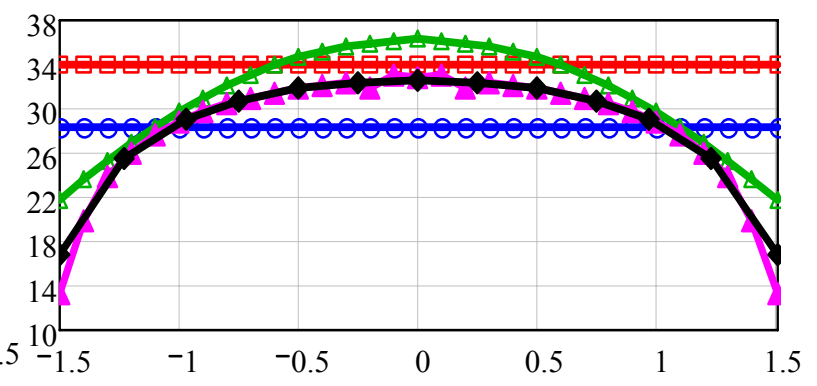

Pressão estática vertical (pvf) em $\mathrm{kPa}$

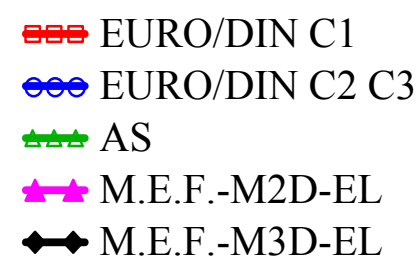

Figura 7.13 - Pressão estática vertical no fundo do silo para o farelo de milho (a) e a soja (b).

No caso de silos esbeltos das classes 2 e 3, a pressão estática vertical no fundo de acordo com as normas EUROCODE e DIN é constante ao longo do raio e igual ao valor da pressão vertical calculada com a teoria de Janssen para a altura z igual à $h_{c}$. Se o silo se enquadrar na classe 1 , cujos valores médios de $K, \mu$ e $\phi$ foram utilizados no cálculo das pressões, um coeficiente majorador de 1,3 deve ser aplicado. Isto explica o maior valor da pressão no fundo para o silo da classe 1.

A norma australiana é mais conservadora e por isso não faz distinção entre silos baixos e esbeltos no cálculo da pressão estática vertical no fundo e considera uma variação da pressão vertical em função da coordenada radial no fundo.

$\mathrm{Na}$ verdade, os valores da pressão no fundo dos silos das classes 2 e 3 seriam muito próximos ou até mesmo maiores que os da classe 1 caso fosse considerada uma maior variabilidade nos valores das propriedades físicas dos produtos. Portanto não se pode a partir dos resultados da Figura 7.13, afirmar que as normas estão subestimando os valores da pressão no centro da base devido à baixa variabilidade de $\mathrm{K}, \mu$ e $\phi$ adotados neste trabalho.

\subsubsection{Pressão estática normal à parede}

Segundo as normas EUROCODE e DIN, em silos das classes de confiabilidade 2 e 3 devem ser adotadas pressões adicionais atuando em conjunto com as pressões normais simétricas. Essas pressões adicionais são assimétricas e 
têm como objetivo cobrir incertezas provenientes de excentricidades acidentais durante o enchimento do silo, imperfeições geométricas na parede, entre outros. A combinação da pressão simétrica com a pressão adicional (assimétrica) pode ser observada na Figura 7.14 que ilustra a variação da pressão em função da altura do silo e do ângulo ao redor da circunferência do silo $(\theta)$ para os dois produtos.
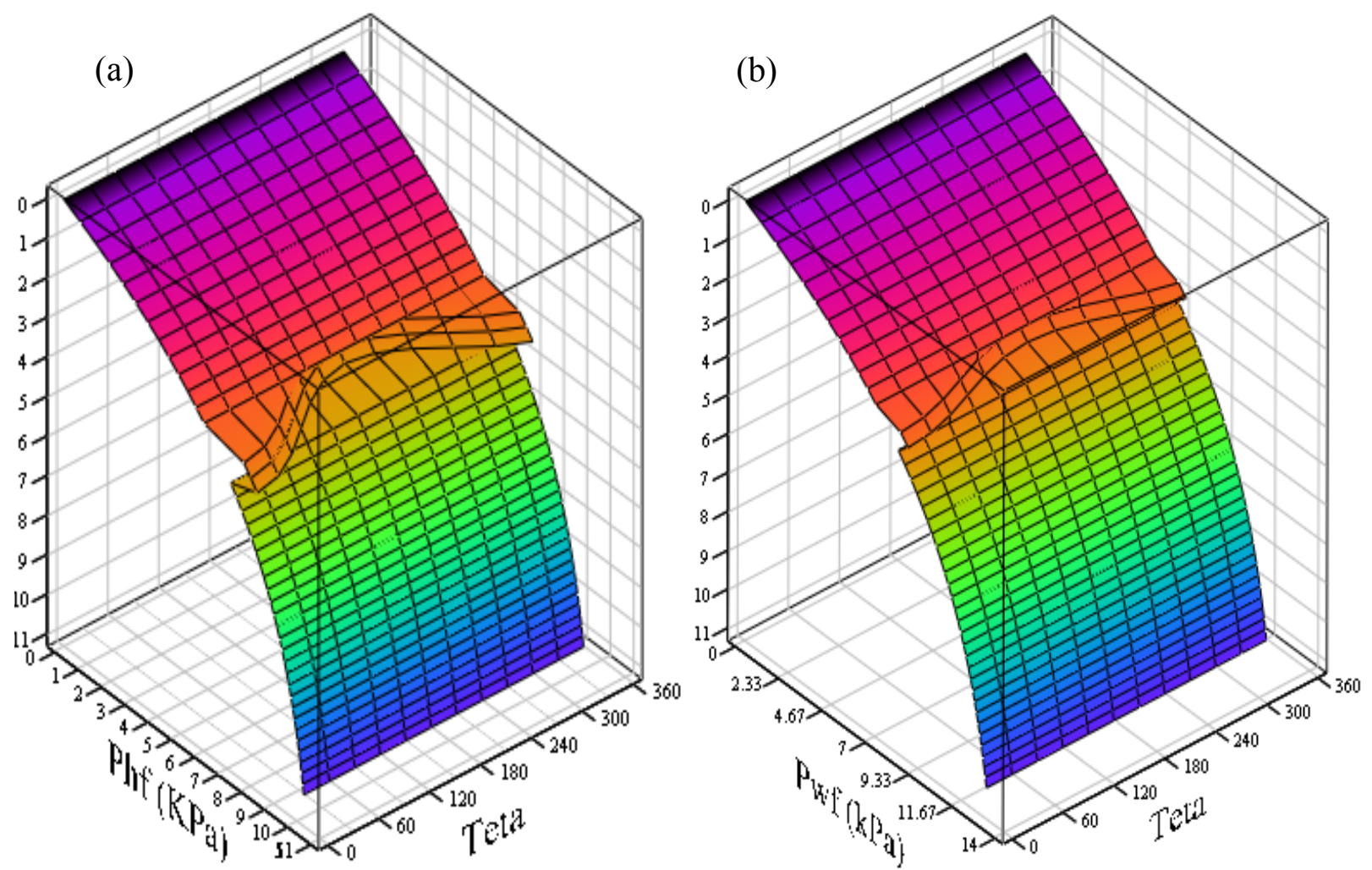

Figura 7.14 - Pressão estática normal simétrica mais pressão estática adicional segundo as normas EUROCODE e DIN para silos de classes 2 e 3 para farelo de milho (a) e a soja (b).

A pressão estática adicional está aplicada em uma altura $z$ entre $3,2 \mathrm{~m} \mathrm{e} \mathrm{3,8}$ $\mathrm{m}$ e varia de zero a 1,4 kPa para o farelo de milho e de zero a 0,9 $\mathrm{kPa}$ para a soja, com distribuição cossenoidal no perímetro do silo. Com o objetivo de comparar os resultados das normas com os resultados numéricos com o MEF, são apresentadas na Figura 7.15 as pressões horizontais para o valor do ângulo $\theta$ igual a zero. 
(a)

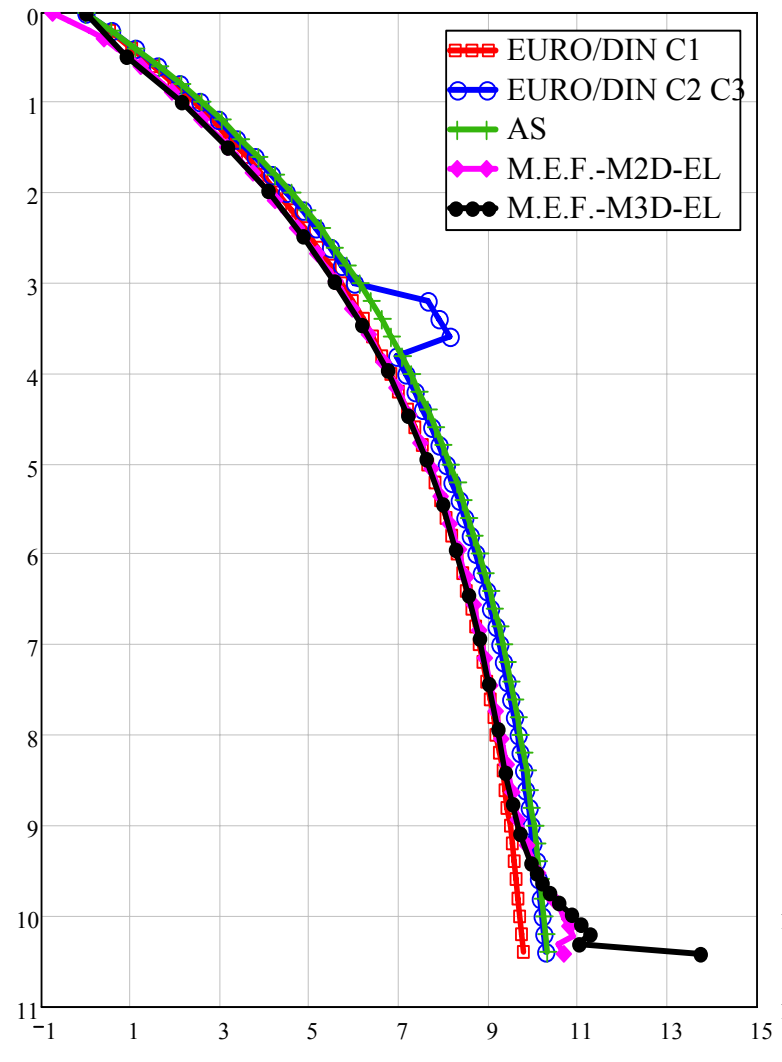

Pressão estática normal à parede em $\mathrm{kPa}$ (b)

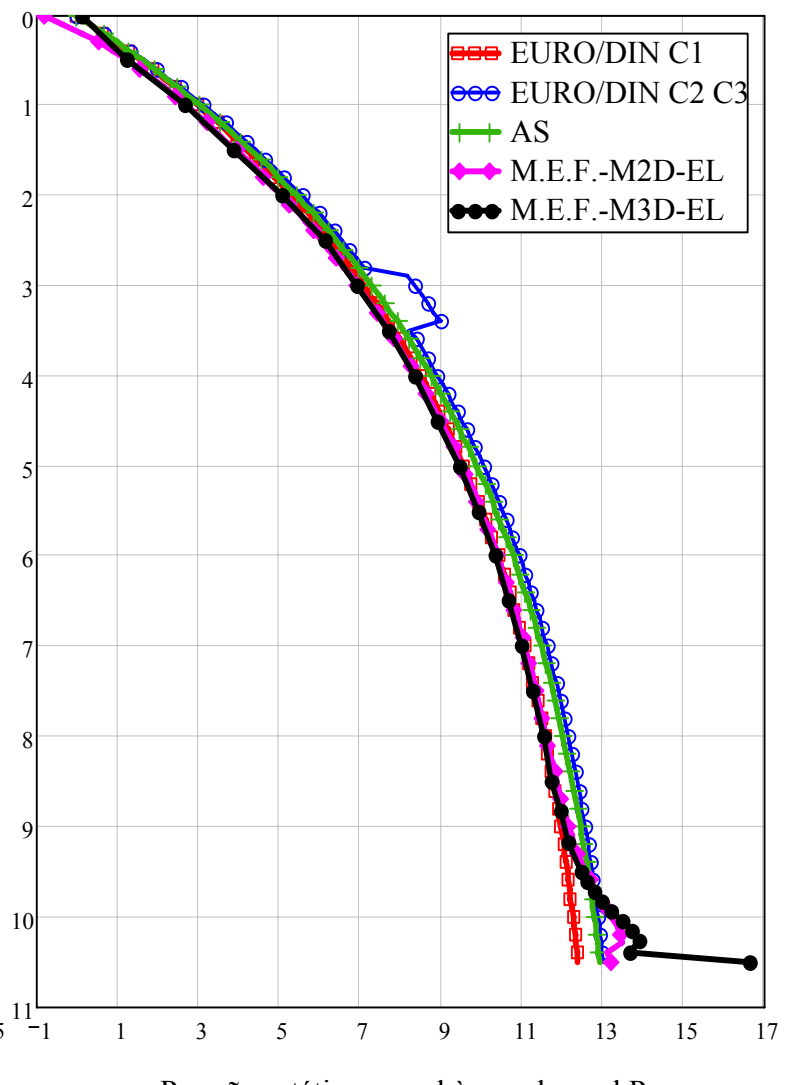

Pressão estática nomal à parede em $\mathrm{kPa}$

Figura 7.15 - Pressão estática normal à parede para farelo de milho (a) e a soja (b) $\operatorname{com} \theta=0^{\circ}$.

A distribuição de pressões normais com a soja (cerca de $13 \mathrm{kPa}$ próximo ao fundo) é superior à do farelo de milho (10 $\mathrm{kPa})$ devido ao maior peso específico da soja. A curva de pressões obtida pelo MEF é quase coincidente com a curva de pressões para os silos da primeira classe de confiabilidade. O motivo principal é que o coeficiente de Poisson e coeficiente de atrito com a parede adotado no modelo numérico foi calculado com base nos valores médios, ou seja, $K_{m}, \mu_{m}$ e $\phi_{m}$ e o peso específico foi considerado com seu valor superior $\left(\gamma_{\mathrm{s}}\right)$. Consequentemente, excluindo a influência da variabilidade das propriedades dos produtos, as pressões obtidas por meio do MEF concordam com as previstas pela equação de Janssen.

A partir dos resultados da pressão estática horizontal na parede e da pressão vertical no produto, podemos avaliar o valor do coeficiente $\mathrm{K}$ resultante da análise numérica e compará-los com os valores médios recomendados pelas normas, conforme a Figura 7.16. 
(a)

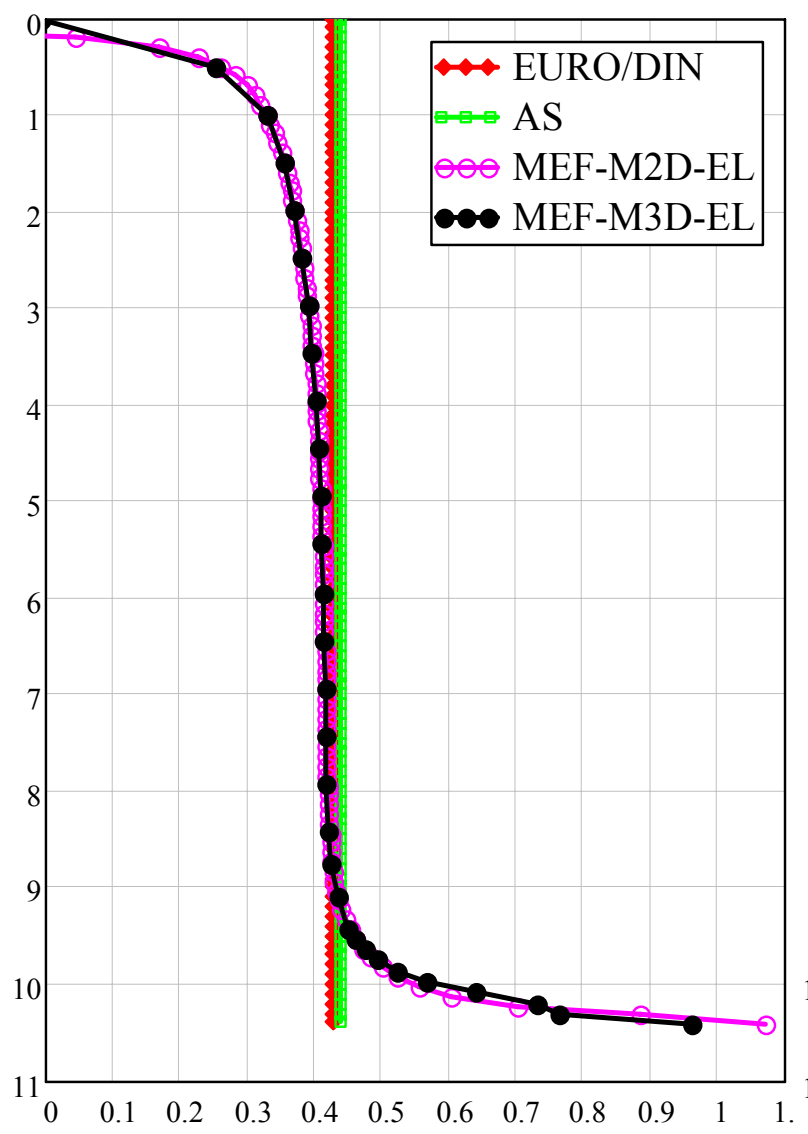

Coeficiente K (b)

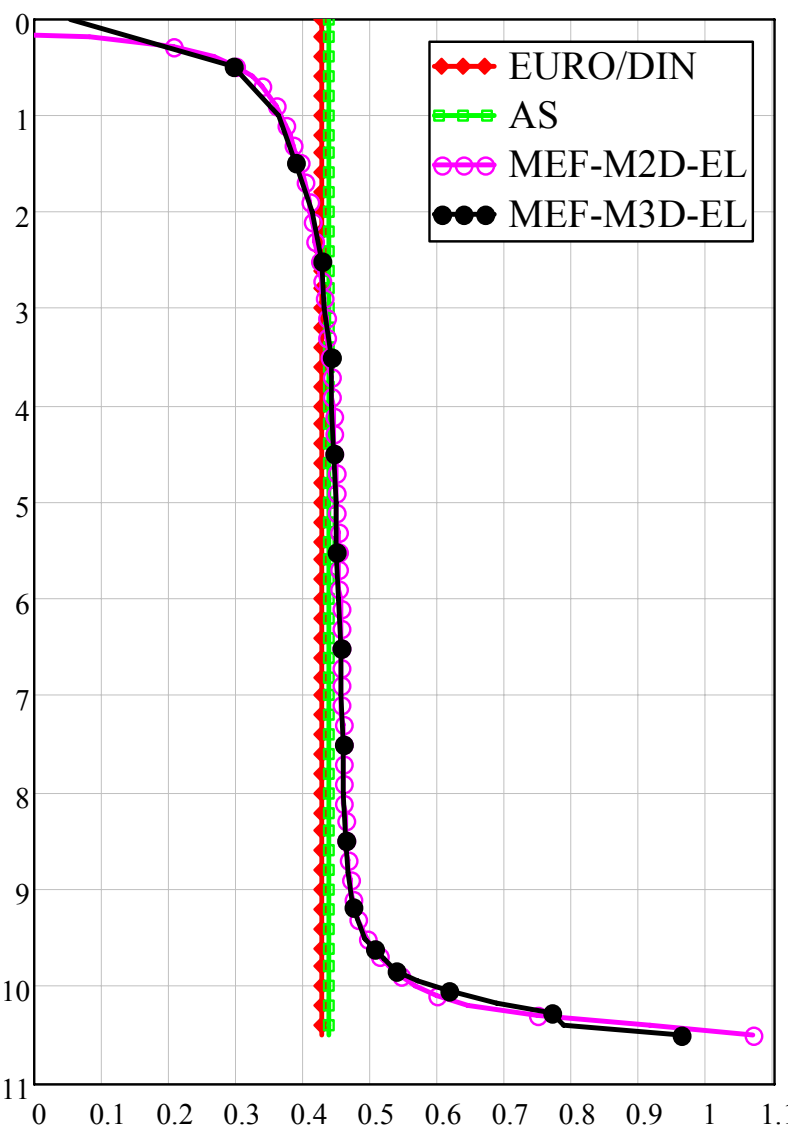

Coeficiente K

Figura 7.16 - Valores dos coeficientes K para o farelo de milho (a) e a soja (b).

Os valores de $\mathrm{K}$ obtidos numericamente aumentam com a profundidade do silo, mas em geral, são muito próximos aos valores adotados pelas normas.

\subsubsection{Pressão estática de atrito}

A pressão estática de atrito está diretamente relacionada com a pressão normal à parede. A pressão estática de atrito para os dois produtos, analisada segundo as três normas e as obtidas pelo MEF é ilustrada na Figura 7.17. 
(a)

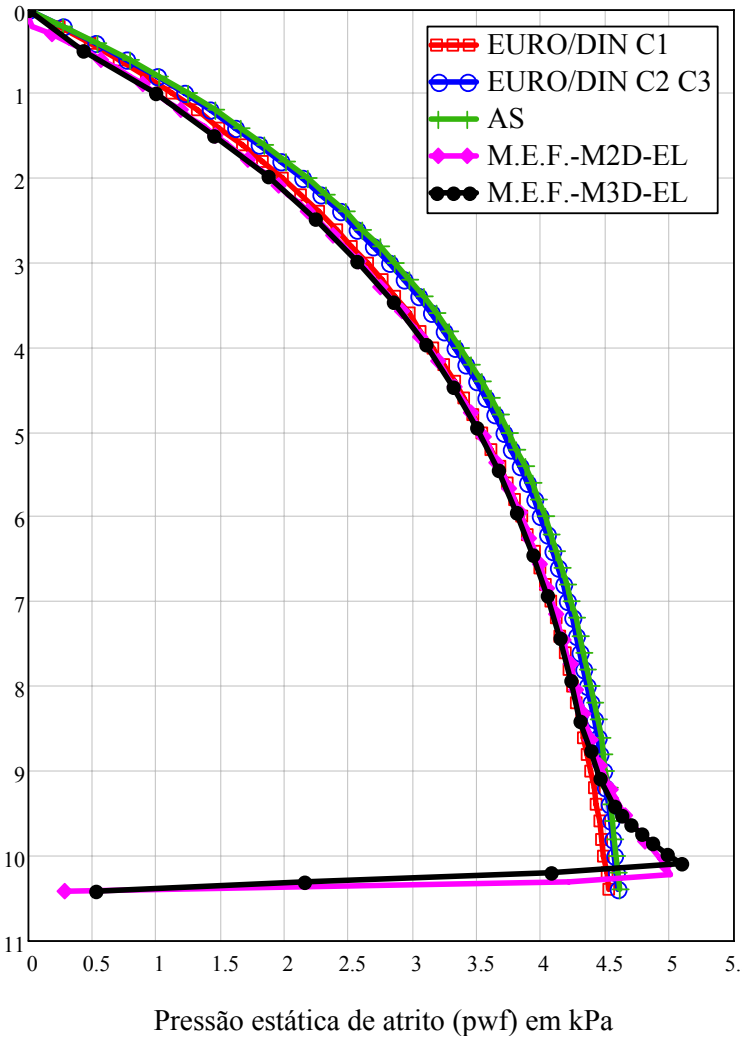

(b)

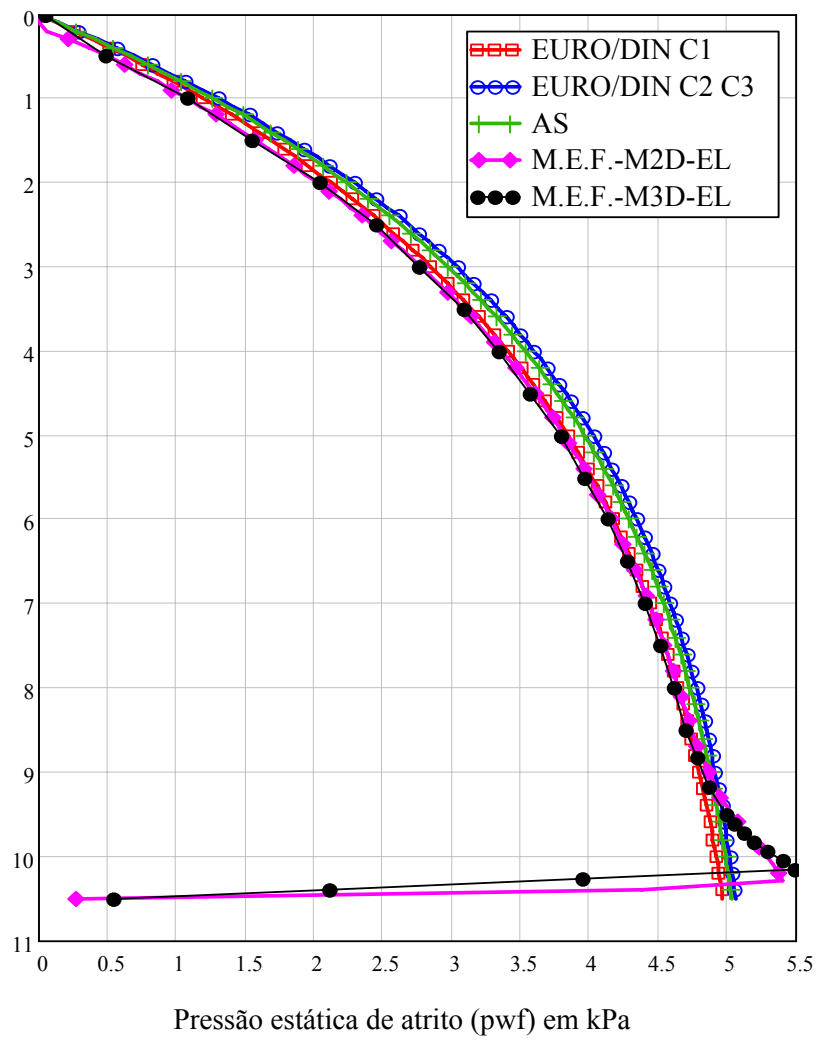

Figura 7.17 - Pressão estática de atrito para o farelo de milho (a) e a soja (b).

O coeficiente de atrito com a parede do farelo de milho é maior que o da soja, porém a pressão de atrito é menor para o farelo de milho devido ao maior peso específico da soja. As pressões em silos da classe 1 de confiabilidade apresentam os menores valores.

Pode ser observado na Figura 7.17 que a interação no contato entre o produto e a parede funciona bem no modelo numérico, respeitando a relação $p_{\mathrm{w}}=\mu_{\mathrm{w}} . \mathrm{p}_{\mathrm{h}}$. Consequentemente, as pressões obtidas por meio do MEF concordam bem com as normativas, ou seja, com a equação de Janssen.

\subsubsection{Pressão dinâmica normal à parede}

O modelo numérico consistiu em aplicar deslocamentos numa área equivalente à área do canal de fluxo excêntrico determinada pela Teoria de Rotter (1986). A evolução das pressões de acordo com o deslocamento no fundo do silo, no lado próximo $\left(\theta=0^{\circ}\right)$ e no lado oposto $\left(\theta=180^{\circ}\right)$ é ilustrado na Figura 7.18 referente ao produto farelo de milho. São ilustrados os valores de deslocamento $0 \mathrm{~cm}$, que corresponde à situação estática, até o valor de $31 \mathrm{~cm}$, o valor a partir do qual as pressões passam a decrescer. 
Lado oposto (180 graus)

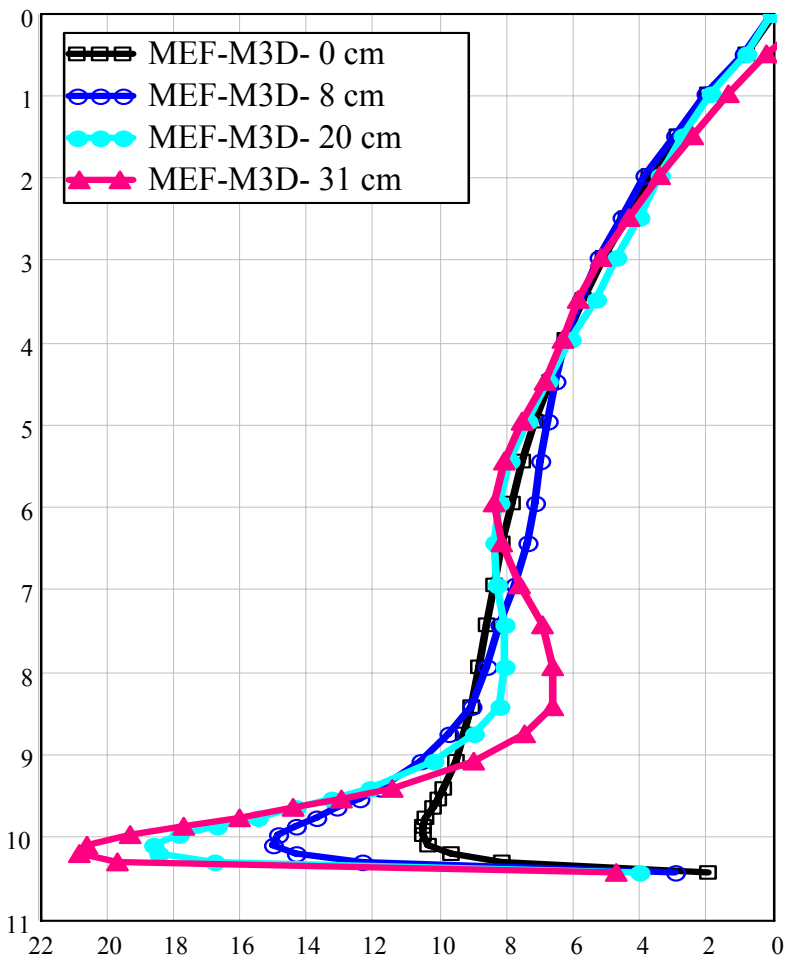

Pressão dinâmica normal à parede em $\mathrm{kPa}$
Lado próximo (0 grau)
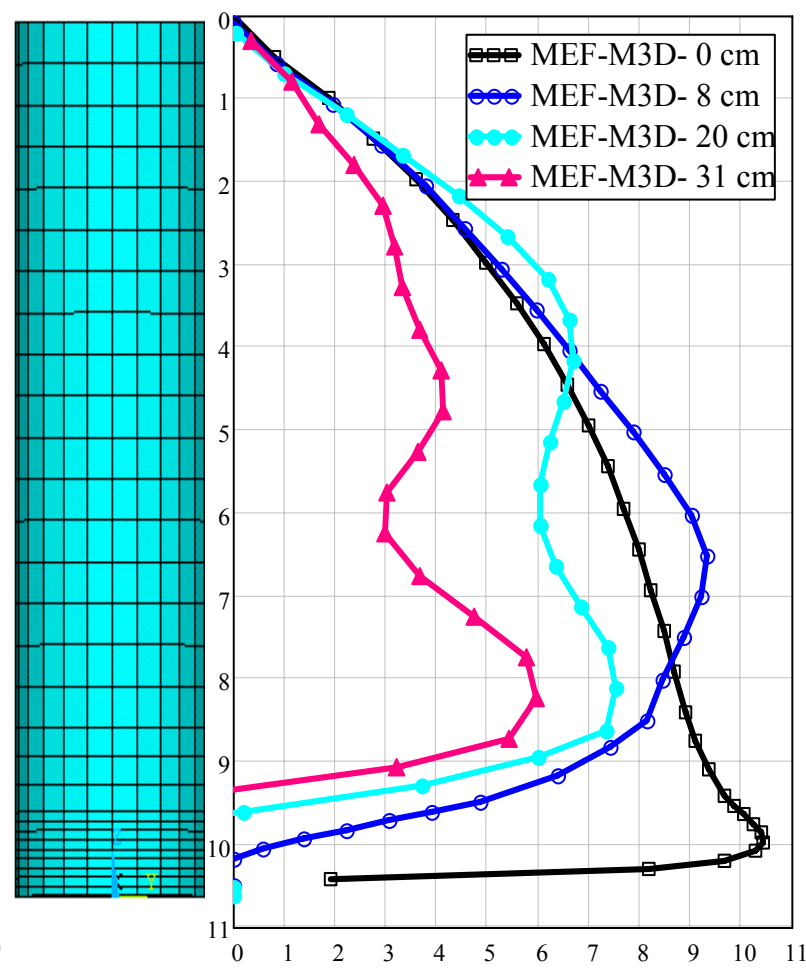

Pressão dinâmica normal à parede em $\mathrm{kPa}$

Figura 7.18 - Pressão dinâmica normal à parede para o farelo de milho de acordo com o deslocamento aplicado e ângulo $\theta$.

Pode ser visto na Figura 7.18 que as pressões no lado próximo à boca de saída apresentam picos na altura intermediária da parede no início do deslocamento e decrescem no fundo do silo conforme aumenta o deslocamento do fundo. No lado oposto, as pressões aumentam na parte mais baixa com o aumento do deslocamento.

Dado a variação das pressões ao longo de toda a circunferência do silo, as pressões máximas não podem ser vistas analisando somente as posições $\theta=0 \mathrm{e}$ $\theta=180$. Por isso, a Figura 7.19 ilustra as curvas de pressão de acordo com o deslocamento aplicado em $\theta=60^{\circ}$ e $\theta=90^{\circ}$. 
90 graus

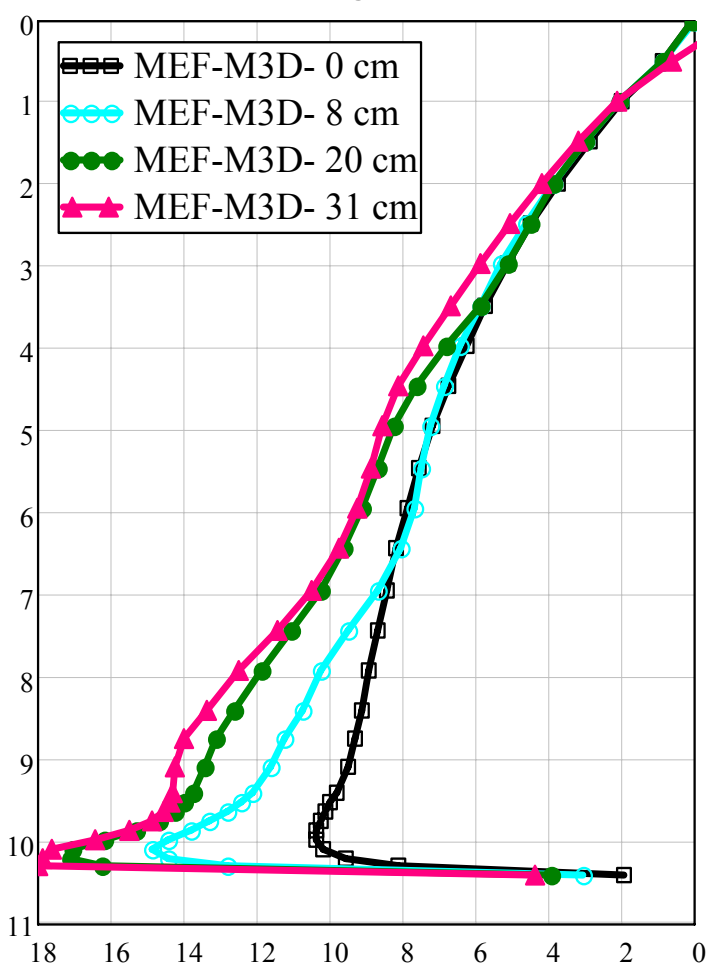

Pressão dinâmica normal à parede em $\mathrm{kPa}$
Lado adjacente (60 graus)
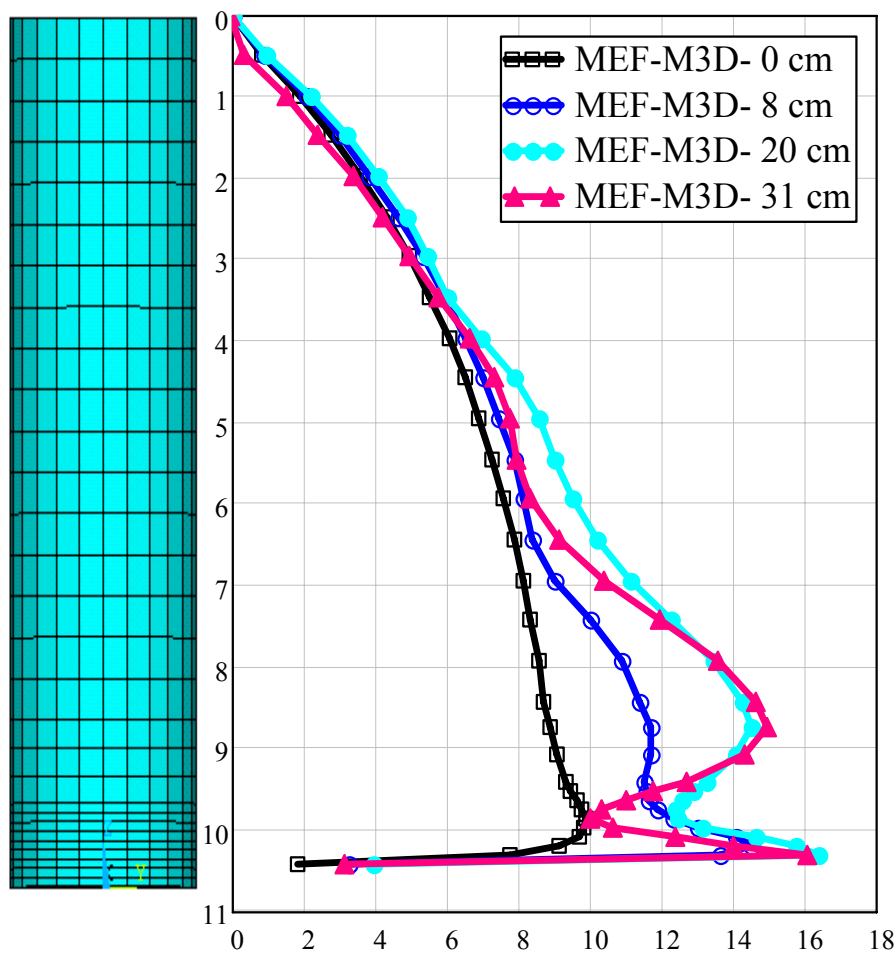

Pressão dinâmica normal à parede em $\mathrm{kPa}$

Figura 7.19 - Pressão dinâmica normal à parede para o farelo de milho de acordo com o deslocamento aplicado e ângulo $\theta$.

Os ângulos $\theta=60^{\circ}$ e $\theta=90^{\circ}$ são os que indicam maiores valores das pressões, alcançando um coeficiente de sobrepressão máximo de 1,7 para $\theta=60^{\circ}$ na altura $z=$ $8,7 \mathrm{~m}$ e 1,5 para $\theta=90^{\circ}$ na altura $z=9,2 \mathrm{~m}$.

Para a soja a mesma tendência é observada. A pressão dinâmica normal para a soja no lado próximo $(\theta=0)$ e no lado oposto $(\theta=180)$ é ilustrada na Figura 7.20. 
Lado oposto (180 graus)

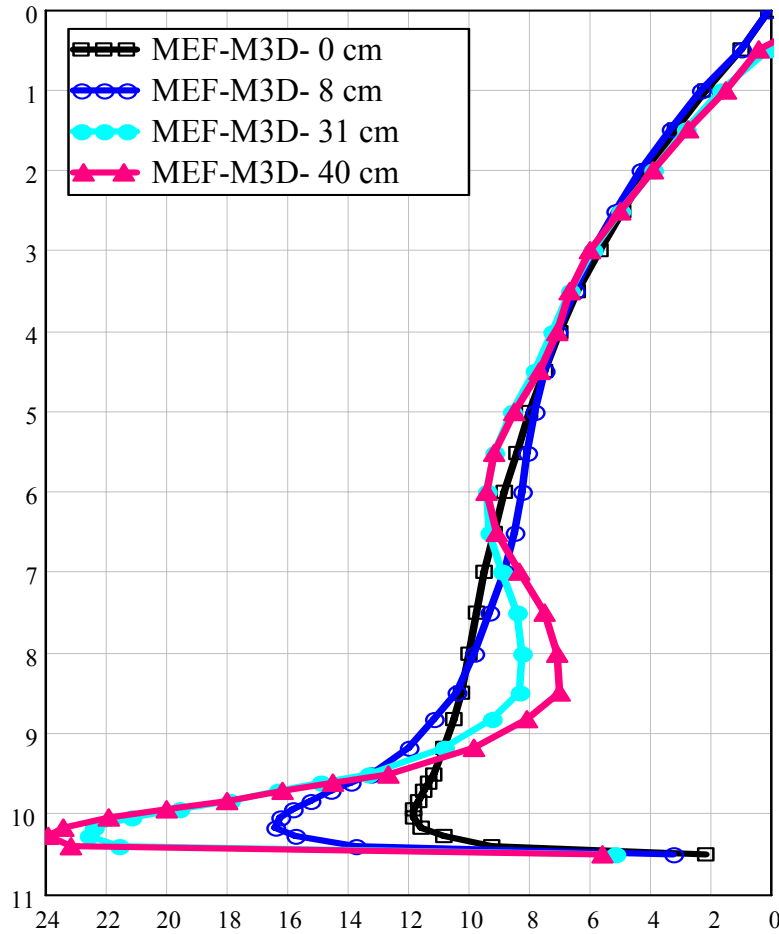

Pressão dinâmica normal à parede em $\mathrm{kPa}$
Lado próximo (0 grau)
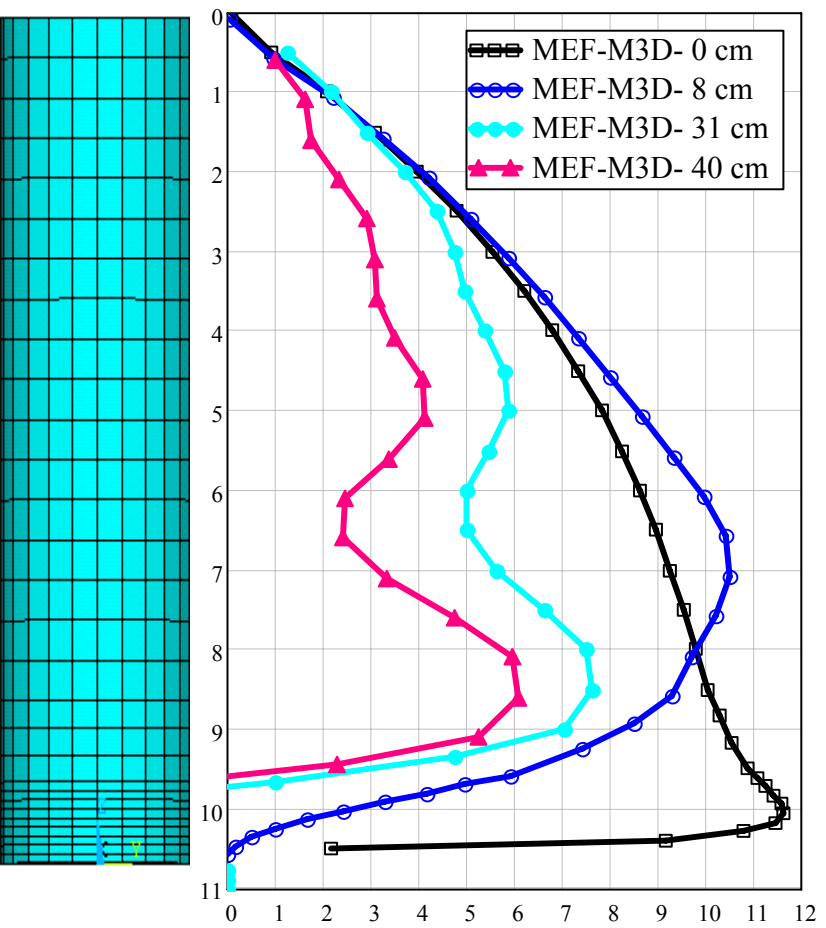

Pressão dinâmica normal à parede em $\mathrm{kPa}$

Figura 7.20 - Pressão dinâmica normal à parede para a soja de acordo com o deslocamento aplicado e ângulo $\theta$.

As curvas em $\theta=60^{\circ}$ e $\theta=90^{\circ}$ com o soja são mostradas na Figura 7.21.

90 graus

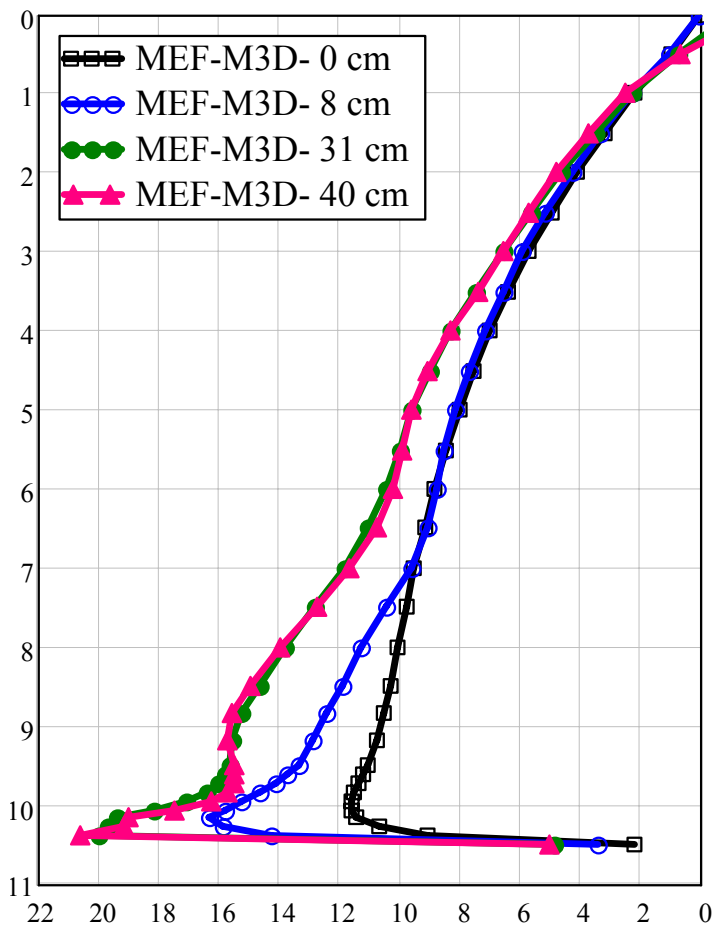

Pressão dinâmica normal à parede em $\mathrm{kPa}$

Figura 7.21 - Pressão dinâmica normal à parede para a soja de acordo com o deslocamento aplicado

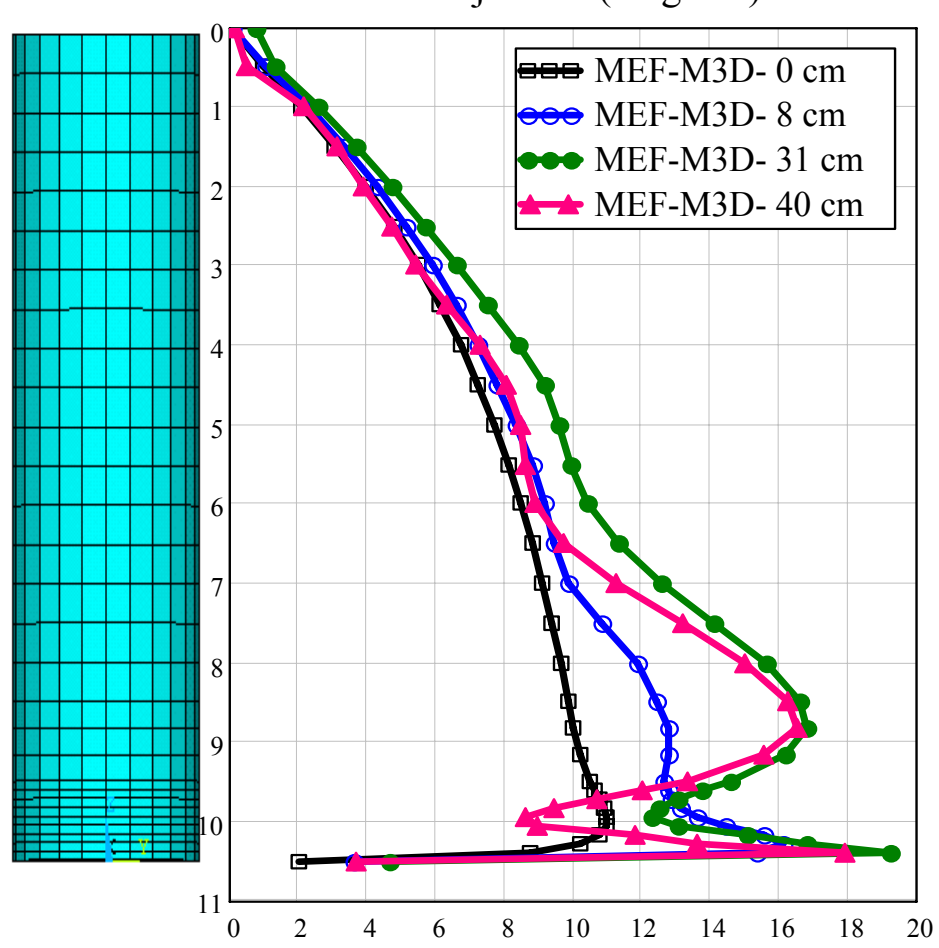

Pressão dinâmica normal à parede em $\mathrm{kPa}$ e ângulo $\theta$. 
Em silos de grande excentricidade, as normas EUROCODE, DIN e AS adotam um caso separado de carregamento para predição das pressões dinâmicas. O EUROCODE admite uma distribuição assimétrica para silos da classe 2 e 3 caracterizada pelo alívio de pressões onde o canal de fluxo intercepta a parede do silo e um acréscimo de pressão adjacente a este local.

A norma australiana também adota uma distribuição assimétrica a partir da redução das pressões no lado próximo à excentricidade e aumento no lado oposto, a partir de uma determinada altura do silo.

Para permitir melhor visualização da distribuição de pressões com o ângulo da circunferência do silo, gráficos tridimensionais ilustram as curvas da pressão dinâmica normal à parede, segundo as normas EUROCODE e DIN, para silos da segunda classe de confiabilidade na Figura 7.22 e os da terceira classe na Figura 7.23 .
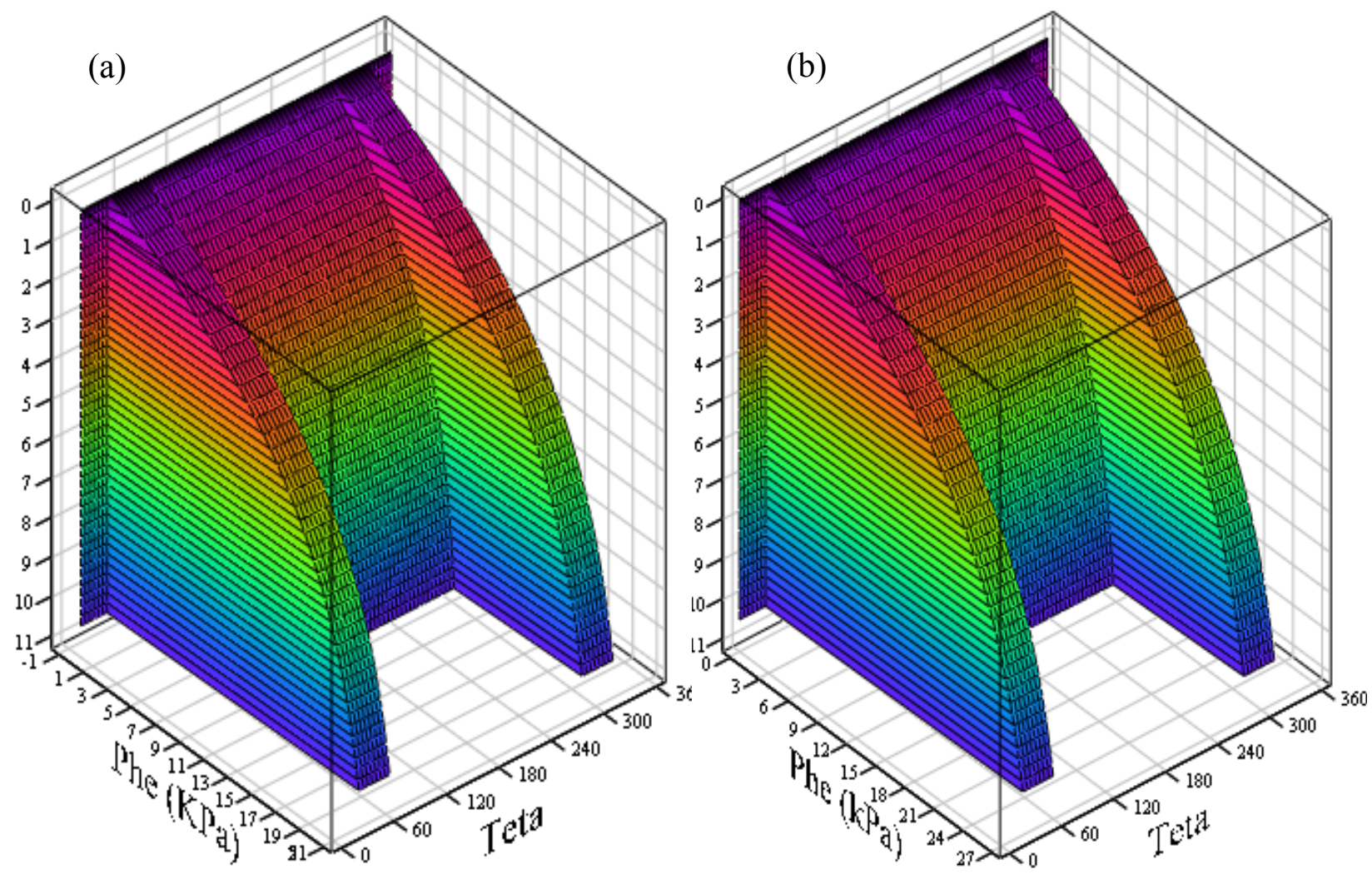

Figura 7.22 - Distribuição assimétrica da pressão dinâmica normal à parede para o farelo de milho (a) e a soja (b) segundo as normas EUROCODE e DIN para silos de classe 2. 

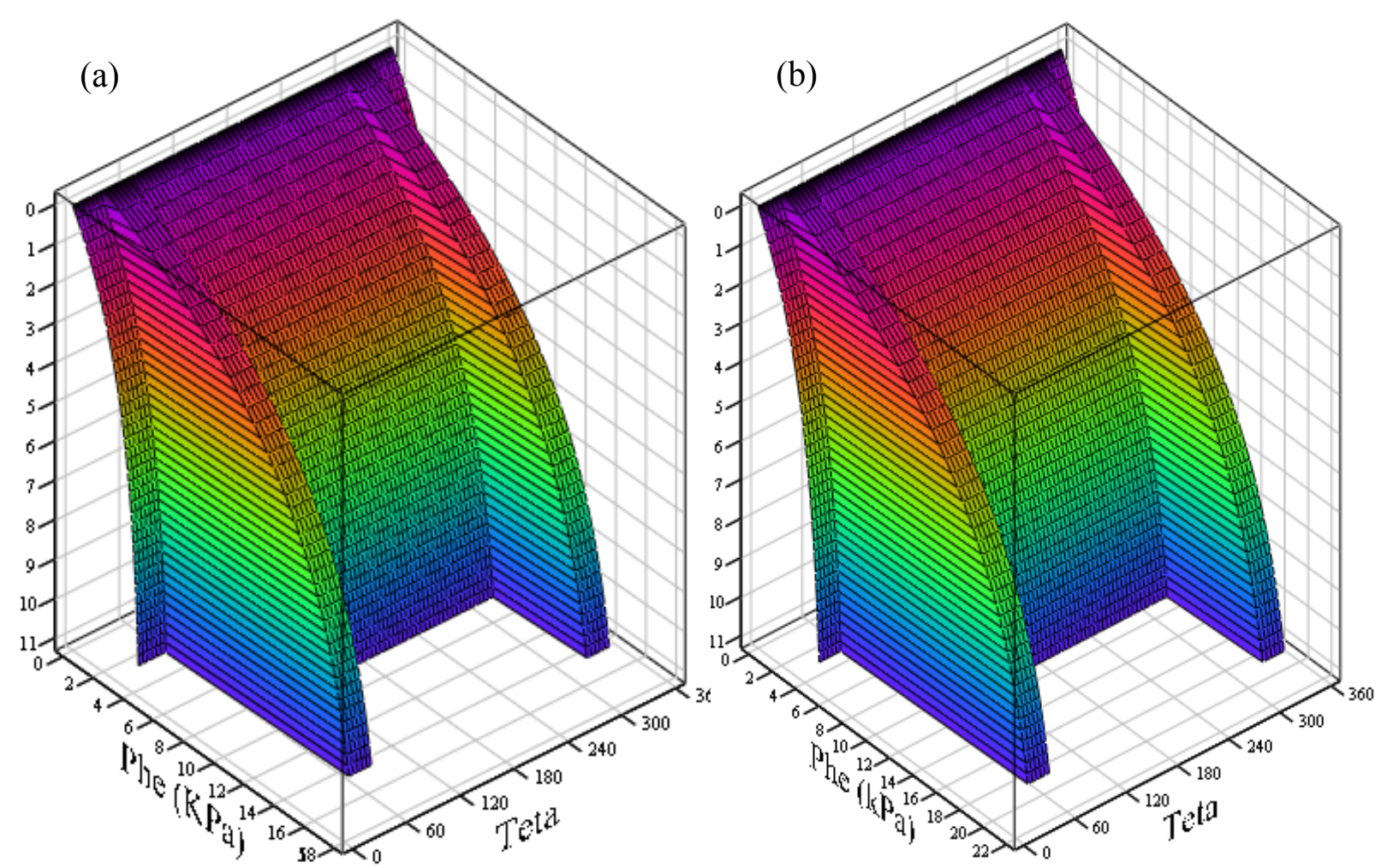

Figura 7.23 - Distribuição assimétrica da pressão dinâmica normal à parede para o farelo de milho (a) e a soja (b) segundo as normas EUROCODE e DIN para silos de classe 3.

Analisando a Figura 7.22 e a Figura 7.23 observa-se que a pressão normal em silos da segunda classe de confiabilidade é nula no local onde o fluxo intercepta a parede e para os silos da terceira classe não. O lado adjacente ao canal de fluxo excêntrico, em ambos os casos, apresenta pressões máximas.

De acordo com a norma australiana, a distribuição tridimensional de pressões horizontais dinâmicas pode ser vista na Figura 7.24. 

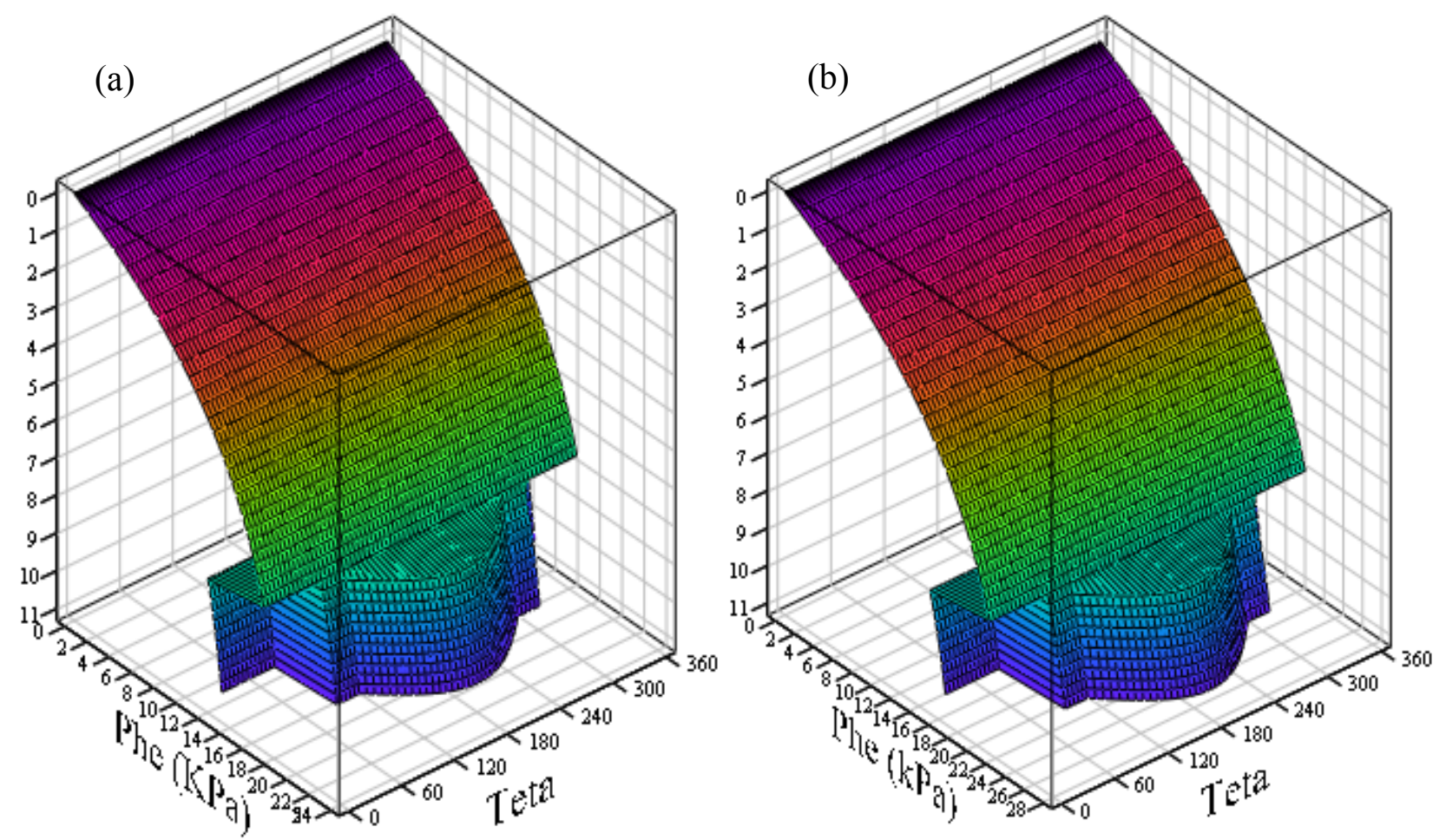

Figura 7.24 - Distribuição assimétrica da pressão dinâmica normal à parede para o farelo de milho (a) e a soja (b) segundo a norma AS.

Pela teoria de Safarian a pressão horizontal também sofre redução no lado próximo e um acréscimo no lado oposto. A distribuição das pressões dinâmicas normais às paredes obtidas pela teoria de Safarian para os dois produtos estudados é mostrada na Figura 7.25.
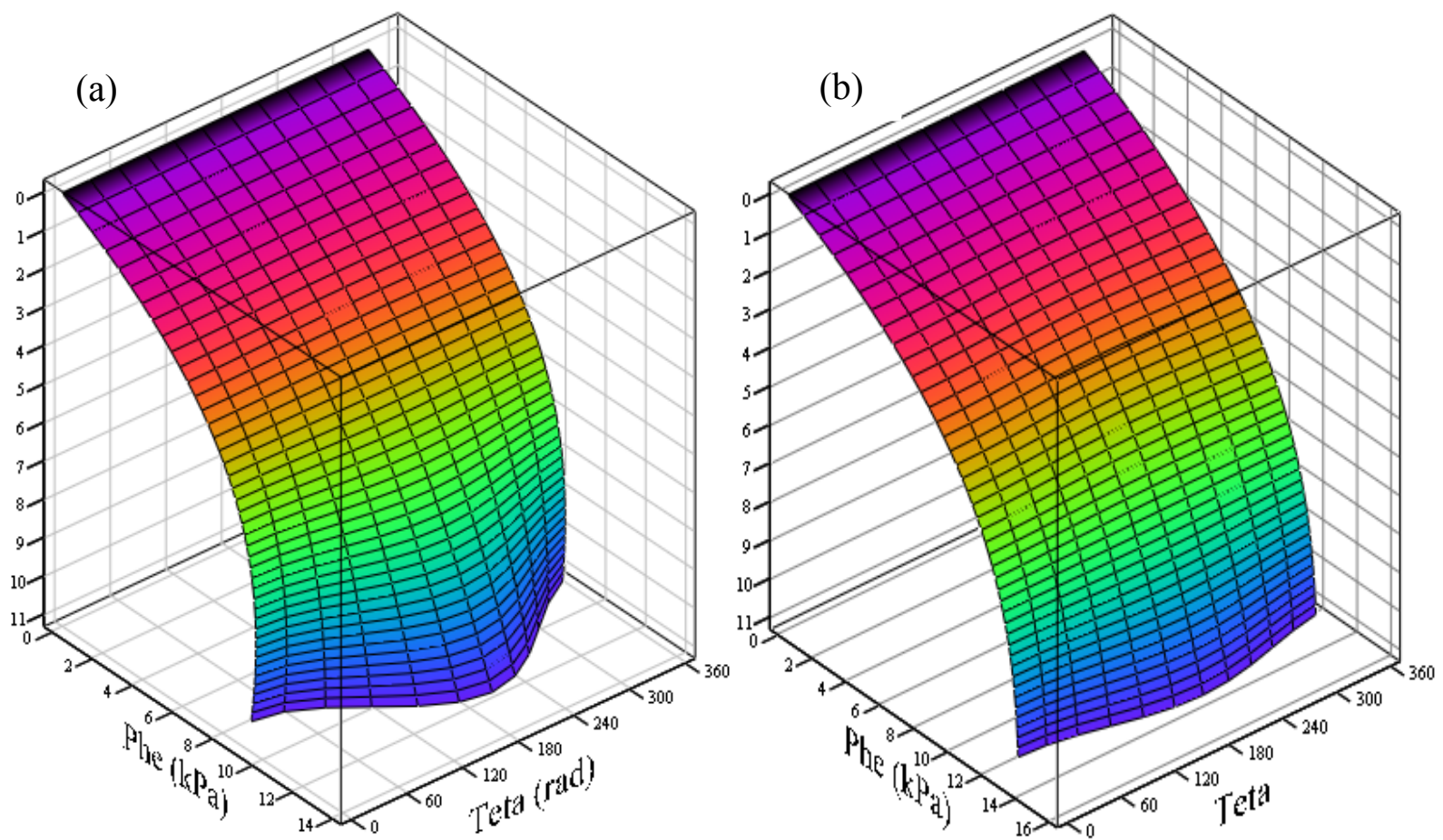

Figura 7.25 - Pressão dinâmica normal à parede para o farelo de milho (a) e a soja (b) de acordo com altura do silo e ângulo $\theta$, calculada de acordo com a teoria de Safarian. 
Para fins de comparação, serão ilustrados gráficos bidimensionais que tornam possível a comparação entre as pressões obtidas numericamente e as normativas, incluindo também a teoria de Safarian. A Figura 7.26 mostra as pressões dinâmicas normais para o farelo de milho sendo os números entre parênteses da Figura 7.26 os intervalos de $\theta$ em que cada curva é válida.

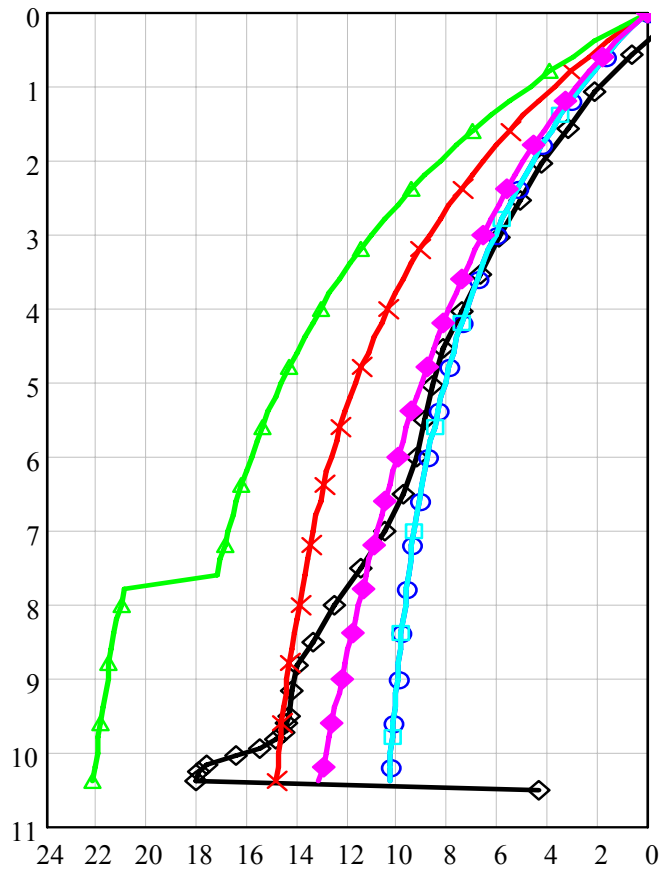

Pressão dinâmica normal em kPa

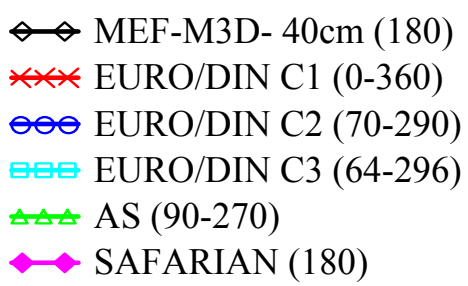

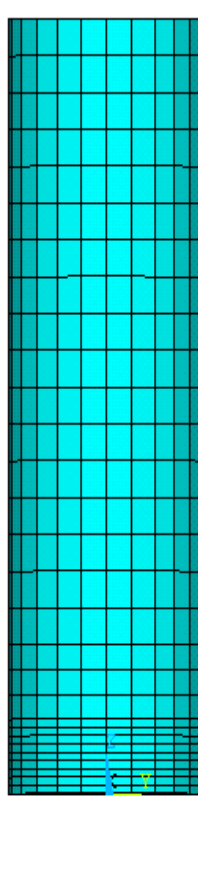

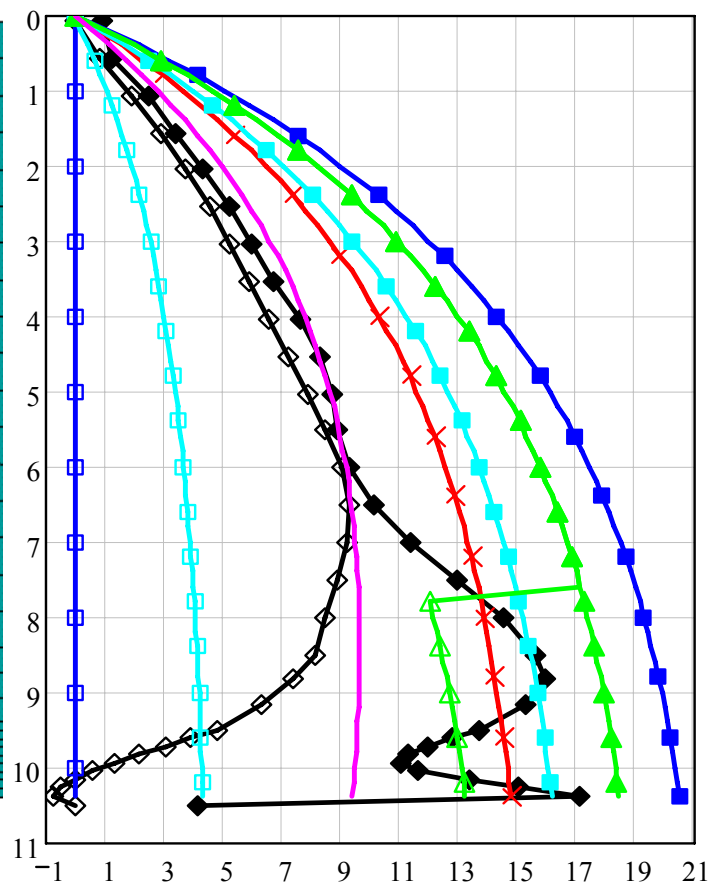

Pressão dinâmica normal em kPa

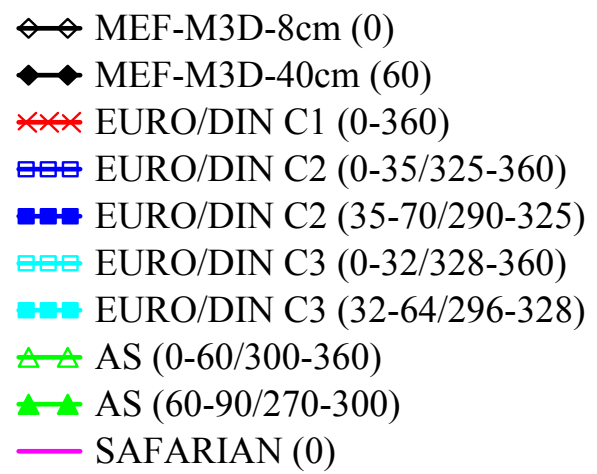

Figura 7.26 - Pressão dinâmica horizontal para o farelo de milho considerando o ângulo $(\theta)$ ao redor da circunferência do silo.

A distribuição de pressões dinâmicas normais para silos da primeira classe de confiabilidade é a única simétrica. Ela é o resultado das pressões estáticas multiplicadas por um coeficiente de sobrepressão que neste caso, depende da excentricidade da boca de saída e é igual a 1,51. Na norma australiana a distribuição inicialmente simétrica foi obtida com o coeficiente de sobrepressão 
equivalente a 1,79. Porém ela torna-se assimétrica a partir da redução de $5,2 \mathrm{kPa}$ no lado próximo da boca de saída e acréscimo de 3,6 kPa no lado oposto para valores de $z$ maiores que 7,7 m. Segundo a Teoria de Safarian, a pressão máxima no lado oposto é de $13 \mathrm{kPa}$ e a mínima no lado próximo é de 9,5 kPa.

Pode-se observar que a distribuição de pressões nos silos das normas EUROCODE e DIN são as que mais se aproximam das pressões obtidas numericamente e o procedimento adotado pela norma AS e a teoria de Safarian são muito simplificados e não cobrem as máximas pressões obtidas numericamente.

Para a soja, pressões dinâmicas normais são ilustradas na Figura 7.27.

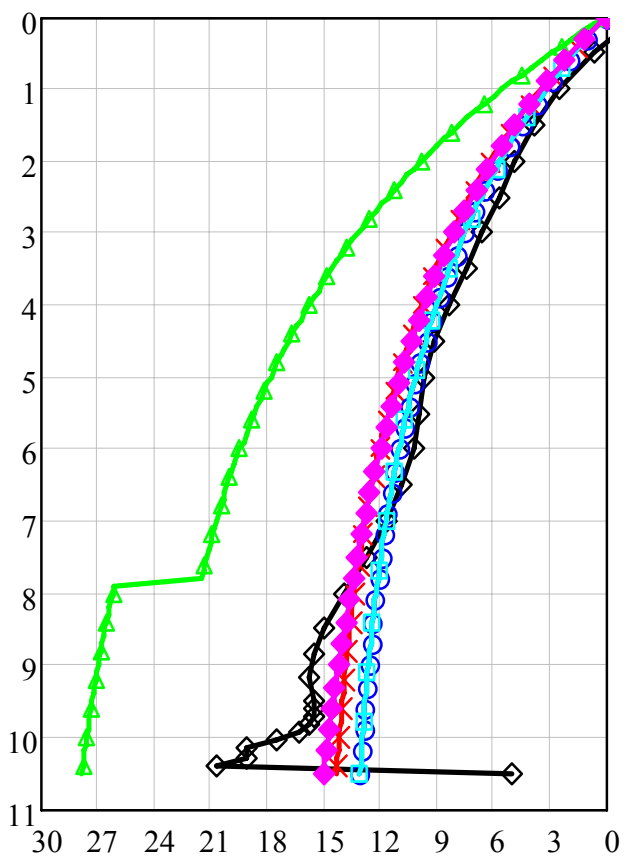

Pressão dinâmica normal em kPa

$$
\begin{aligned}
& \diamond \text { MEF-M3D- 40cm (180) } \\
& \qquad \text { EURO/DIN C1 (0-360) } \\
& \text { EURO/DIN C2 (70-290) } \\
& \triangleq \text { EURO/DIN C3 (64-296) } \\
& \leftrightarrow \text { AS (90-270) }
\end{aligned}
$$
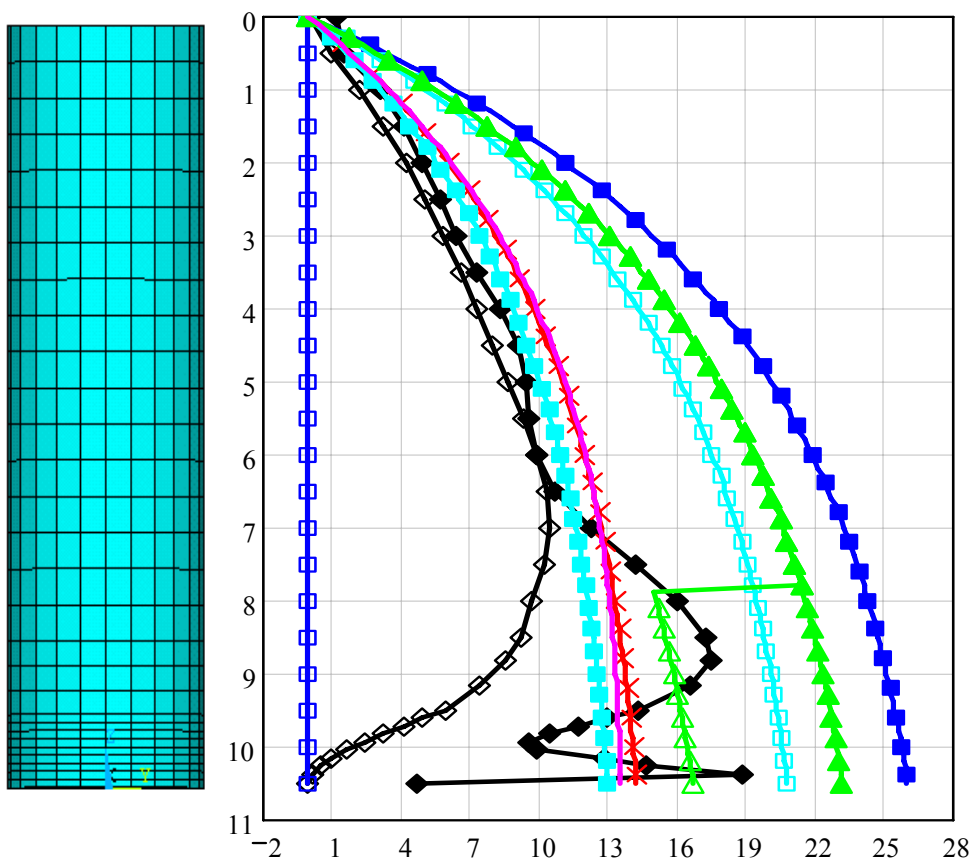

Pressão dinâmica normal em $\mathrm{kPa}$

$$
\begin{aligned}
& \diamond \mathrm{MEF}-\mathrm{M} 3 \mathrm{D}-8 \mathrm{~cm}(0) \\
& \leftrightarrow \text { MEF-M3D-40cm (60) } \\
& \text { *** EURO/DIN C1 (0-360) } \\
& \text { EURO/DIN C2 (0-35/325-360) } \\
& \text { 들 EURO/DIN C2 (35-70/290-325) } \\
& \text { Eם EURO/DIN C3 (0-32/328-360) } \\
& \text { 름븐를 EURO/DIN C3 (32-64/296-328) } \\
& \triangle \triangle \text { AS }(0-60 / 300-360) \\
& \therefore \text { AS (60-90/270-300) } \\
& \text { — SAFARIAN (0) }
\end{aligned}
$$

Figura 7.27 - Pressão dinâmica horizontal para a soja considerando o ângulo ( $\theta)$ ao redor da circunferência do silo.

Um caso interessante ocorreu no cálculo do coeficiente de sobrepressão em silos de classe 1 para o produto soja. Aplicando a equação sugerida pelas normas 
EUROCODE e DIN em silos de classe 1 com o produto soja, foi obtido um valor de 0,84 , valor incoerente de forma que as pressões horizontais dinâmicas resultam menores do que as estáticas. Para contornar este problema foi adotado o coeficiente 1,15. Confirmando a afirmação, tem-se:

$$
C_{h}=1,5 \cdot\left(1+0,4 \cdot \frac{e_{o}}{D}\right) \cdot C_{o p} \Rightarrow C_{h}=1,5 \cdot\left(1+0,4 \cdot \frac{0,9}{3}\right) \cdot 0,5=0,84
$$

O coeficiente de sobrepressão da AS foi de 1,8 no caso da soja com redução de 6,5 kPa no lado próximo da boca de saída e acréscimo de 4,5 kPa no lado oposto para valores de $z$ maiores que $7,8 \mathrm{~m}$. Segundo a Teoria de Safarian, as pressão máxima no lado oposto é de $15 \mathrm{kPa}$ e a mínima no lado próximo é de 13,6 $\mathrm{kPa}$.

Novamente a distribuição de pressões segundo as normas EUROCODE e DIN são as que mais se aproximam das pressões obtidas numericamente, sendo o procedimento adotado pela norma AS e a teoria de Safarian muito simplificados porque não cobrem as máximas pressões obtidas numericamente.

\subsubsection{Pressão dinâmica de atrito}

A pressão assimétrica de atrito em função do ângulo da circunferência do silo e da altura para silos da segunda classe de confiabilidade é ilustrada na Figura 7.28.
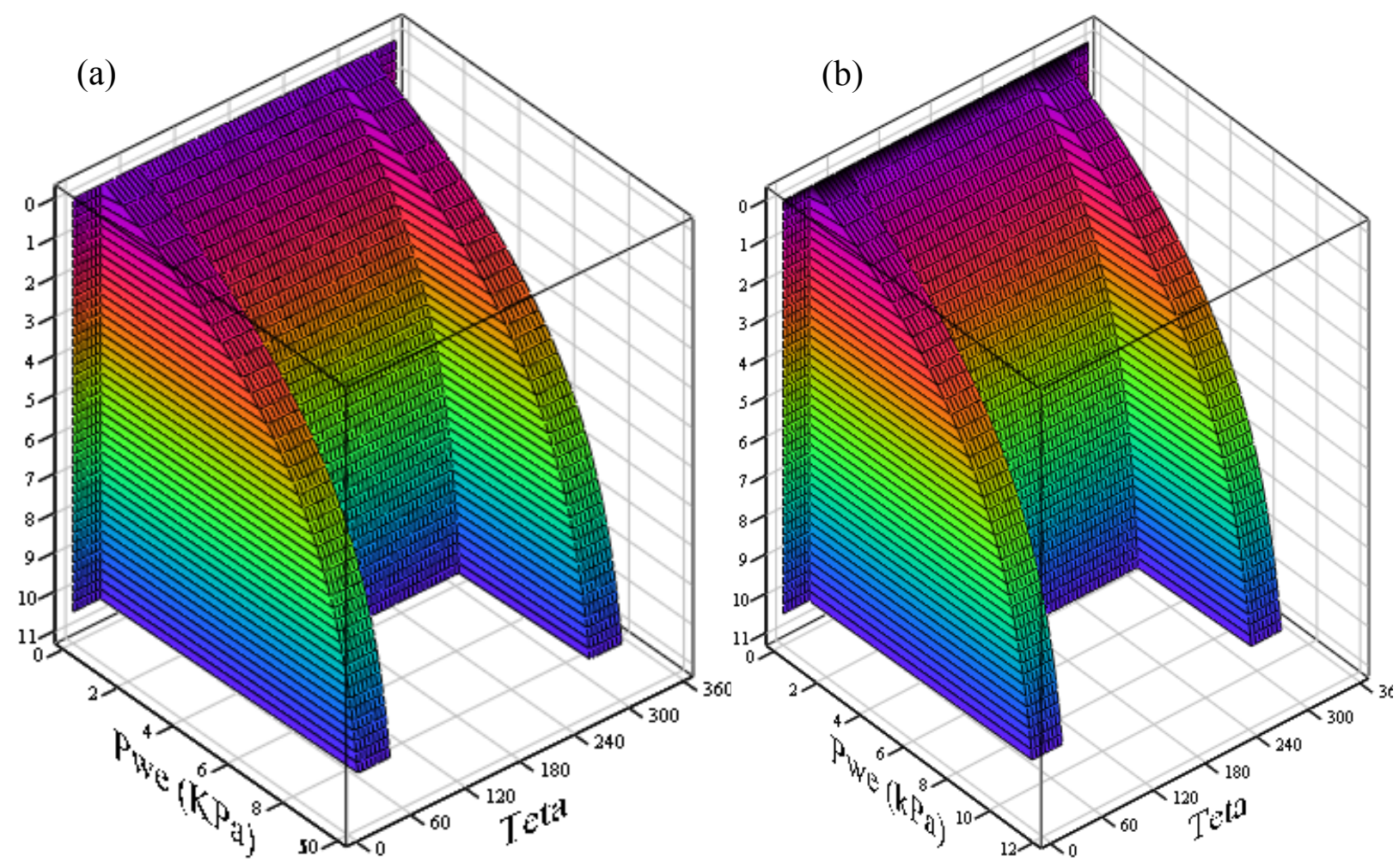

Figura 7.28 - Distribuição assimétrica da pressão dinâmica de atrito, calculada pelas normas EUROCODE e DIN para silos de classe 2 para farelo de milho (a) e a soja (b) 
Observa-se na Figura 7.28 que a pressão de atrito dinâmica em silos de confiabilidade 2 é nula no local onde o fluxo intercepta a parede e no lado adjacente ao canal de fluxo excêntrico, a pressão é máxima. As curvas de pressão de atrito dinâmica para silos da terceira classe de confiabilidade são ilustradas na Figura 7.29.
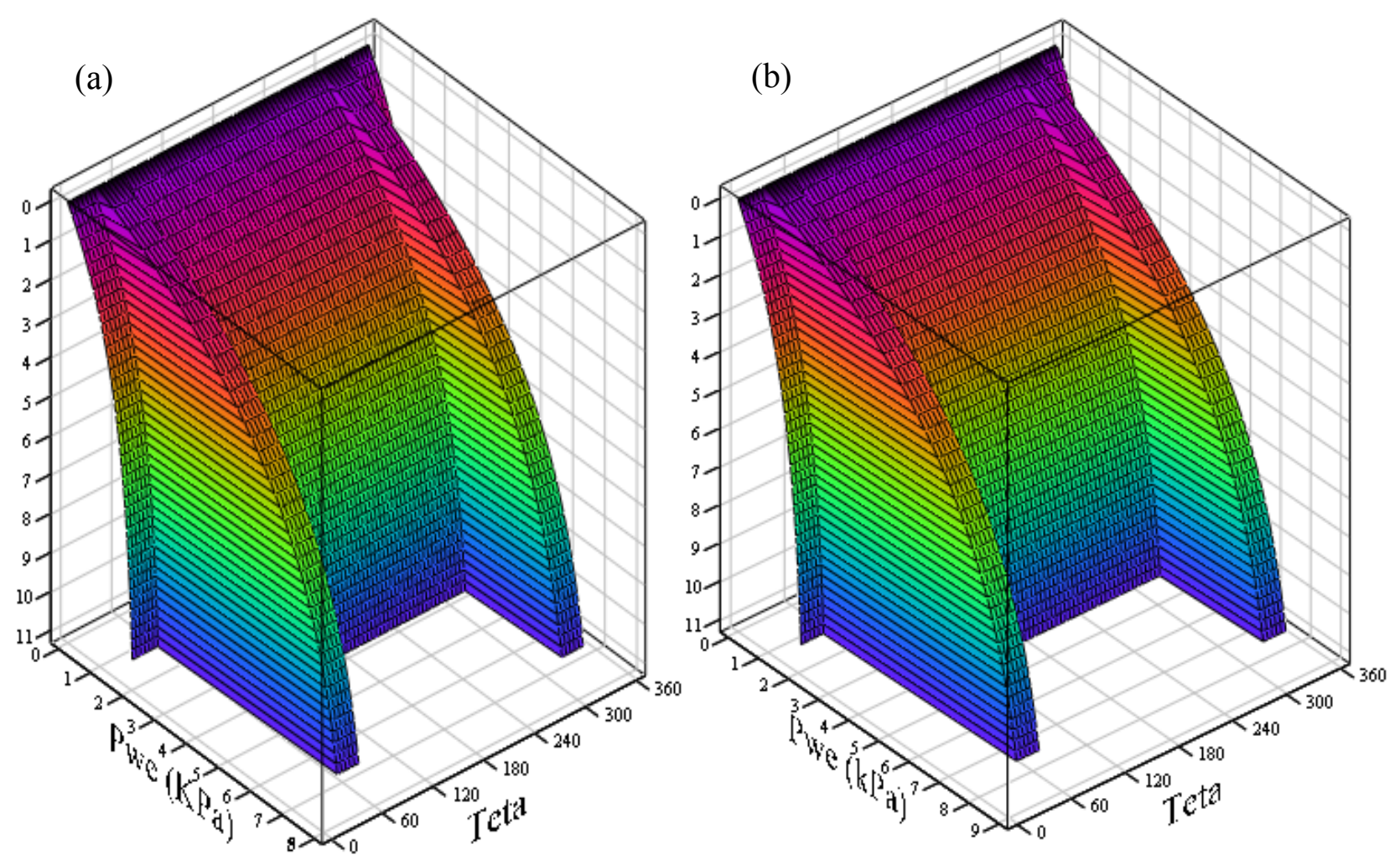

Figura 7.29 - Distribuição assimétrica da pressão de atrito, calculada pelas normas EUROCODE e DIN para silos de classe 3 para o farelo de milho (a) e a soja (b).

A pressão dinâmica de atrito é ilustrada na Figura 7.30 para o farelo de milho. Os valores entre parênteses na legenda de cada curva da Figura 7.30 correspondem aos intervalos do ângulo $\theta$ para os quais cada curva é válida. 


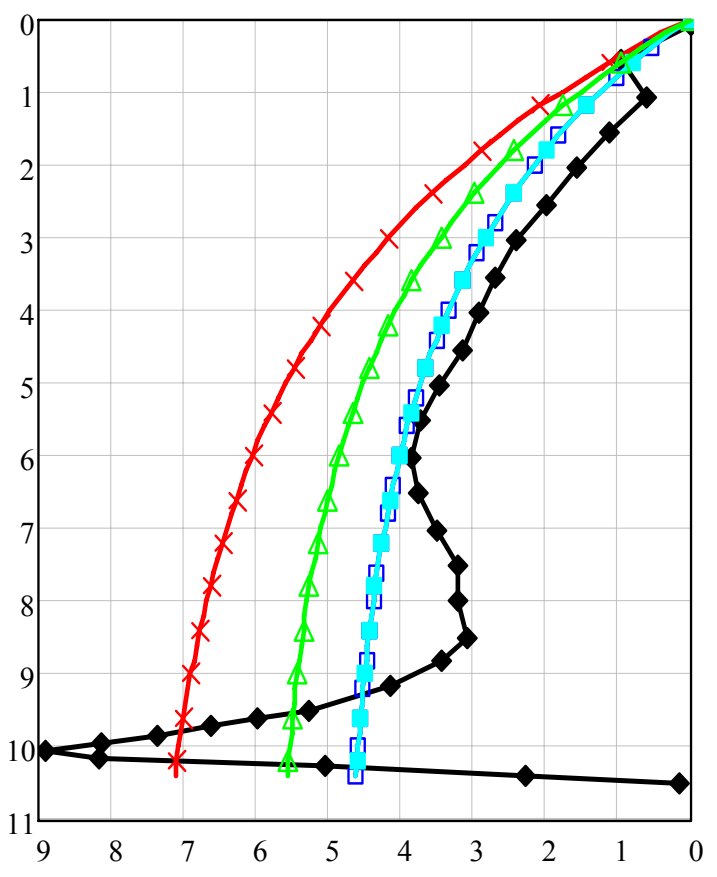

Pressão dinâmica de atrito (pwe) em kPa

$\leftrightarrow$ MEF-M3D-31 cm (180)

EURO/DIN C1 (0-360)

EURO/DIN C2 (70-290)

믄를 EURO/DIN C3 (64-296)

$\Delta \triangle \mathrm{AS}(0-360)$
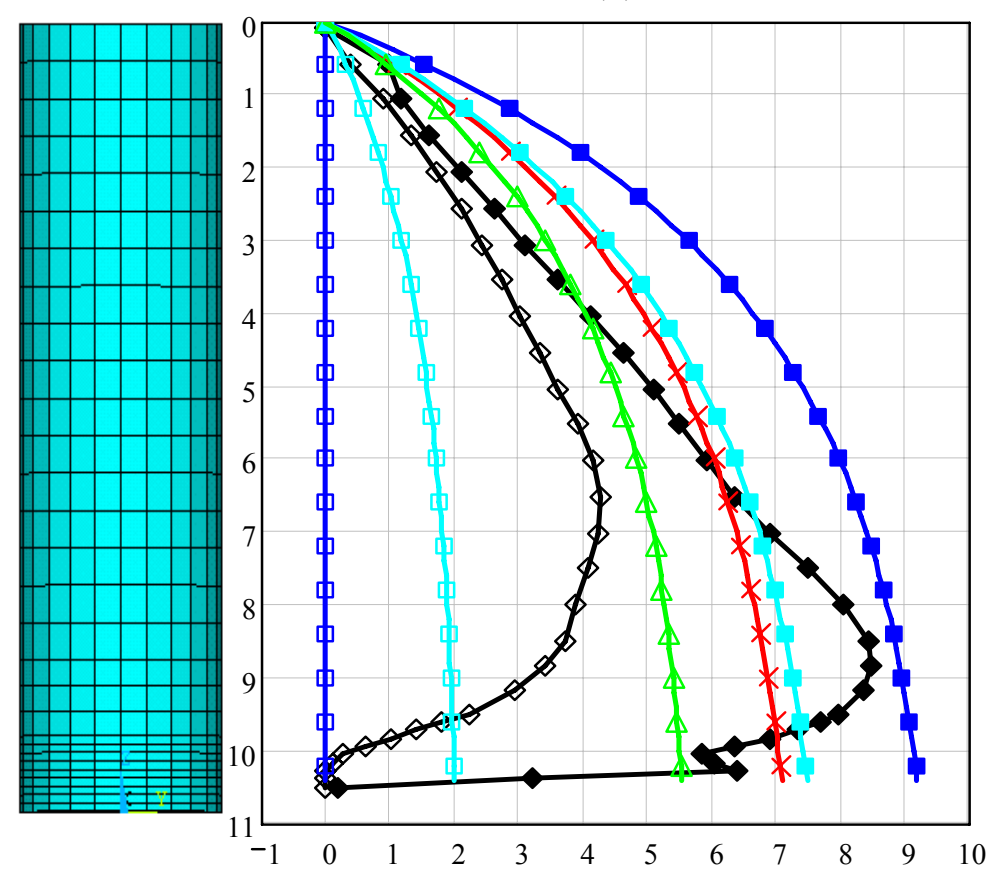

Pressão dinâmica de atrito (pwe) em kPa

$\diamond$ MEF-M3D- 8cm (0)

$\leadsto$ MEF-M3D- $31 \mathrm{~cm}(60)$

EURO/DIN C1 (0-360)

EURO/DIN C2 (0-35/325-360)

EURO/DIN C2 (35-70/290-325)

EURO/DIN C3 (0-32/328-360)

믄른를 EURO/DIN C3 (32-64/296-328)

$\triangle \triangle \mathrm{AS}$

Figura 7.30 - Pressão dinâmica de atrito para o farelo de milho considerando o ângulo $(\theta)$ ao redor da circunferência do silo.

A distribuição de pressões de atrito dinâmicas para silos da classe 1 é simétrica e fornece valores elevados em comparação com as outras curvas obtidas. Isto se deve ao fato de que o coeficiente de sobrepressão neste caso, depende da excentricidade da boca de saída e é igual a 1,57. Na norma australiana a distribuição também é simétrica, porém com um coeficiente de sobrepressão de 1,2.

Os silos da segunda e terceira classe de confiabilidade possuem distribuição assimétrica de pressões, com os menores valores de pressão localizados próximo à boca de saída e maiores nos lados adjacentes. A distribuição das pressões de atrito dinâmicas para a soja é ilustrado na Figura 7.31. 


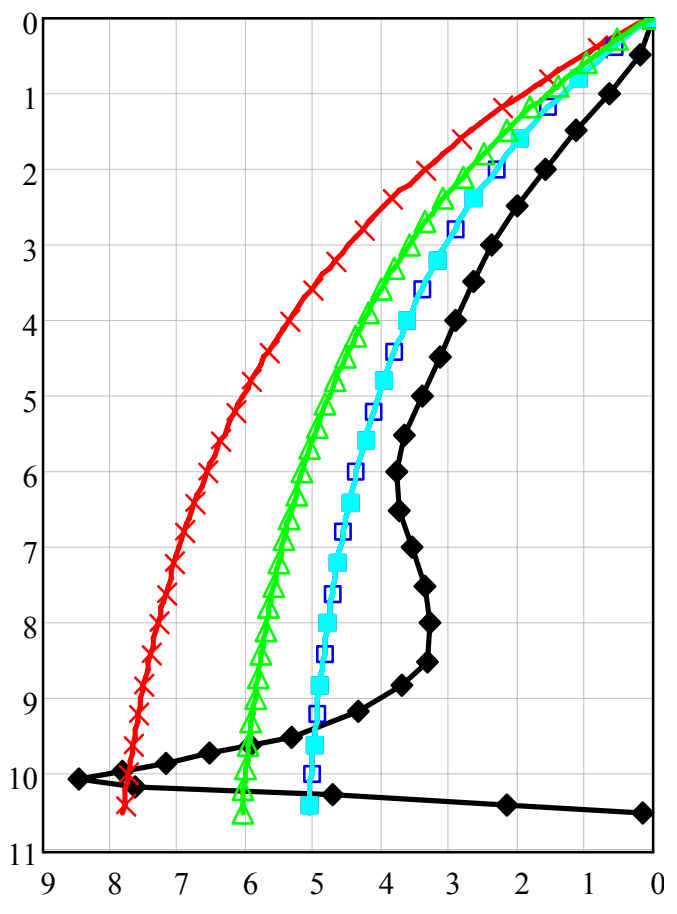

Pressão dinâmica de atrito em $\mathrm{kPa}$

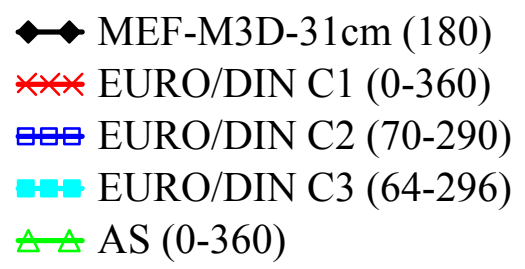

*** EURO/DIN C1 (0-360)

EURO/DIN C2 (70-290)

$\triangle \triangle \mathrm{AS}(0-360)$
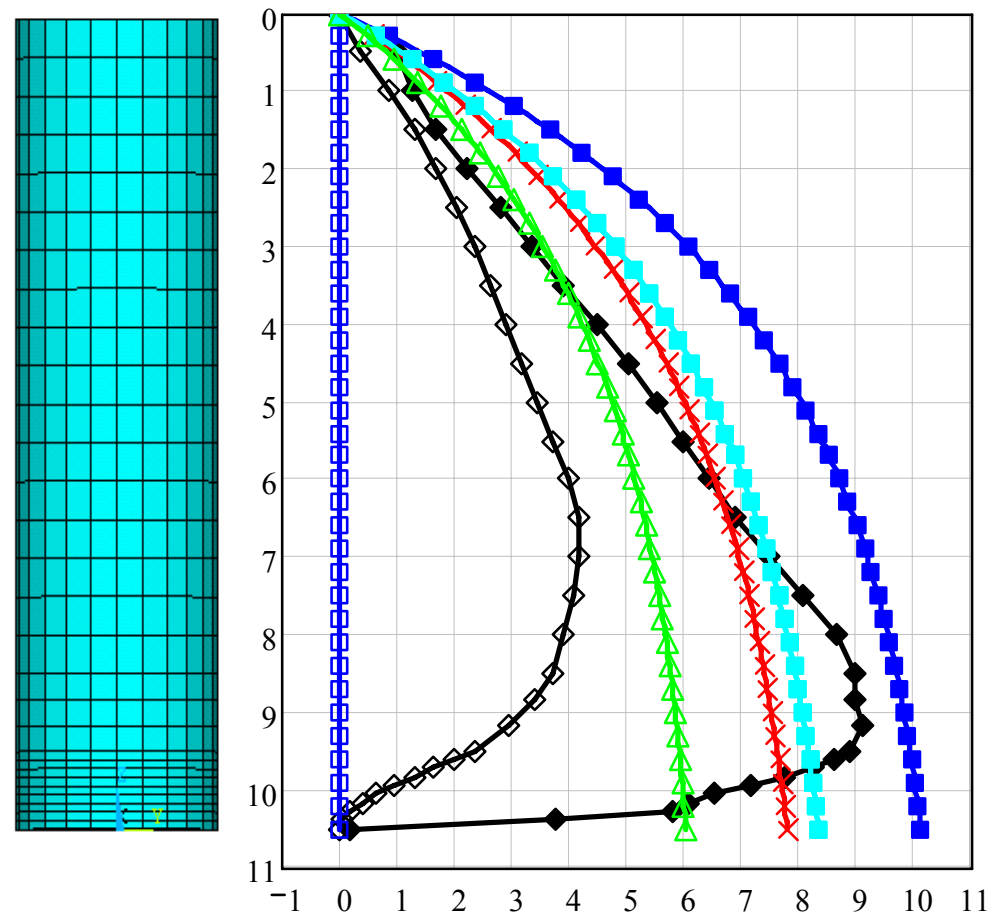

Pressão dinâmica de atrito em $\mathrm{kPa}$

$\diamond$ MEF-M3D- 8cm (0)

$\leadsto$ MEF-M3D- 31cm (60)

*** EURO/DIN C1 $(0-360)$

EURO/DIN C2 (0-35/325-360)

대을 EURO/DIN C2 (35-70/290-325)

EURO/DIN C3 (0-32/328-360)

릅른를 EURO/DIN C3 (32-64/296-328)

$\triangle \triangle \mathrm{AS}$

Figura 7.31 - Pressão dinâmica de atrito para a soja considerando o ângulo $(\theta)$ ao redor da circunferência do silo.

Novamente os valores das pressões de atrito dinâmicas para silos de classe 1 são elevados devido ao alto valor do coeficiente de sobrepressão obtido, igual a 1,6. Na norma australiana a distribuição também é simétrica, porém com um coeficiente de sobrepressão equivalente a 1,2. 


\subsection{Pressões no silo com tremonha concêntrica}

Nenhuma das normas analisadas inclui o cálculo das pressões em tremonhas assimétricas, portanto uma nova geometria foi adotada: o silo com tremonha concêntrica.

\subsubsection{Pressão estática normal à parede}

A pressão estática normal (radial no sistema de coordenadas cilíndricas) no produto armazenado para o soja é ilustrado na Figura 7.32.
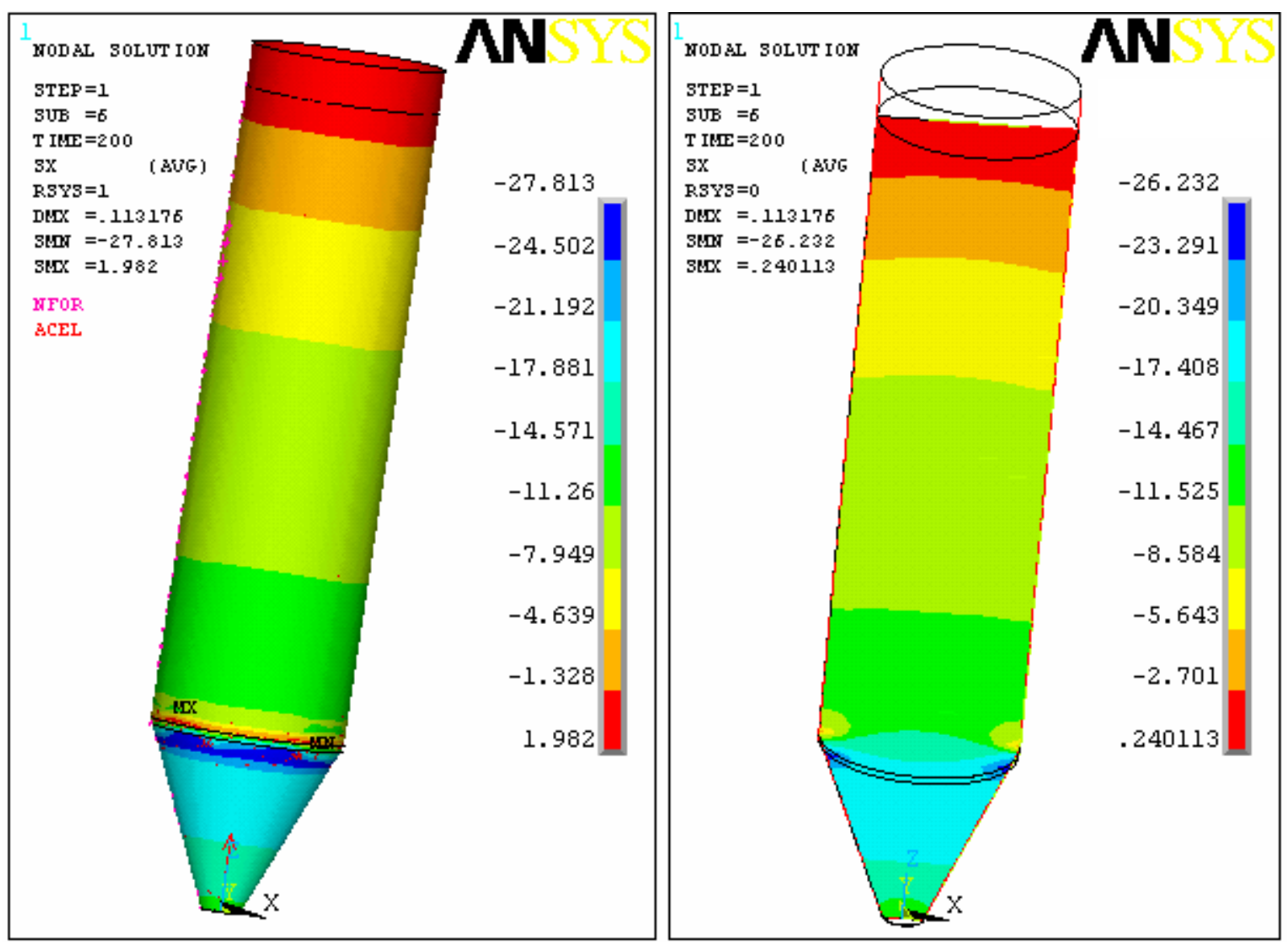

Figura 7.32 - Pressão estática normal (pressão radial em coordenadas cilíndricas) para o soja considerando produto elástico.

A pressão estática normal à parede para os dois produtos, analisada segundo as normas $\left(\operatorname{com} \theta=0^{\circ}\right)$ e o MEF é ilustrada na Figura 7.33. Conforme verificado no capítulo anterior, o fator FKN influencia fortemente a distribuição de pressões. 
Considerando esta influência, os resultados do MEF na Figura 7.33 são de modelos simulados com FKN igual à 2 .

(a)

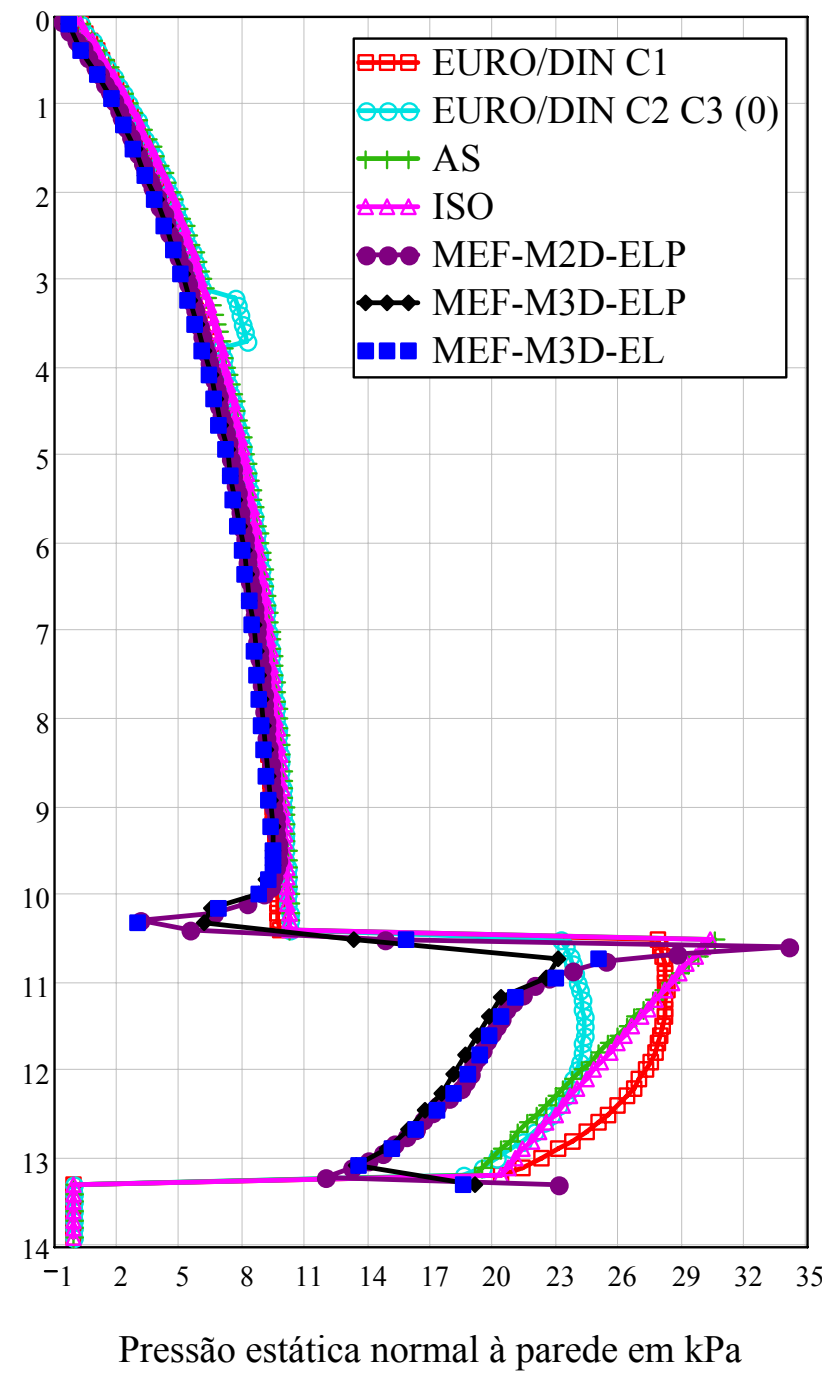

(b)

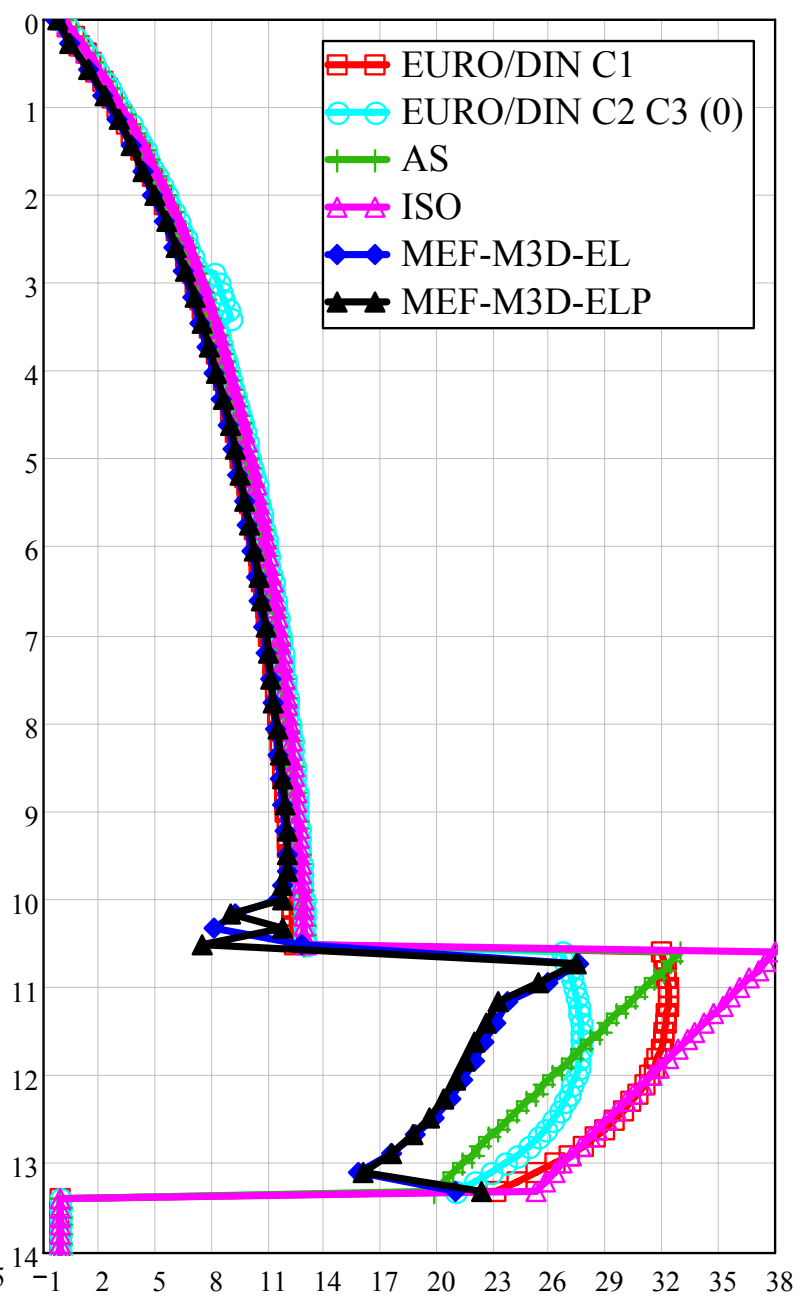

Pressão estática normal à parede em $\mathrm{kPa}$

Figura 7.33 - Pressão estática normal à parede para o farelo de milho (a) e a soja (b).

A pressão normal para a soja é superior à pressão normal com o farelo de milho, tanto no corpo quanto na tremonha. Na transição as pressões normativas são em média iguais a $28 \mathrm{kPa}$ para o farelo de milho e $32 \mathrm{kPa}$ para a soja.

Observa-se que as pressões na tremonha variam muito entre as normas. Isto acontece porque o cálculo das pressões exercidas na tremonha é um fenômeno que ainda não é completamente compreendido.

No corpo do silo, as pressões normais normativas são próximas às obtidas pelo $\mathrm{MEF}$, porém na tremonha as normas indicam pressões superiores ao MEF, sendo que os silos da classe 2 e 3 são os que mais se aproximam com os resultados obtidos com o MEF na tremonha. Entretanto, continuam maiores. 
As maiores pressões obtidas pelas normas ocorrem porque as expressões normativas na tremonha não satisfazem o equilíbrio com as cargas aplicadas (peso próprio do produto) devido ao coeficiente $C_{b}$ majorador da pressão na transição que faz com que o peso do produto na transição seja maior que o peso real do produto armazenado acima dela e também porque as expressões de cálculo para a tremonha são empíricas e, por si só não satisfazem a equação de equilíbrio entre pressões e o peso próprio do produto.

O pico de pressão na transição observada pelas curvas do MEF se deve à descontinuidade do modelo neste local, que causa dificuldade para o programa determinar com exatidão a pressão. Observa-se que a curva de pressões obtidas a partir do modelo bidimensional axissimétrico (curva roxa da Figura 7.33-a), o pico de pressões é maior em relação ao modelo tridimensional (curva preta da Figura 7.33a) que comprova que o pico é realmente um problema numérico.

Em silos da segunda e terceira classe de confiabilidade, pressões adicionais devem ser adotadas para considerar incertezas provenientes de excentricidades acidentais de carregamento, imperfeições geométricas das paredes, entre outras. $A$ distribuição espacial da pressão estática normal à parede para os dois produtos é ilustrada na Figura 7.34.
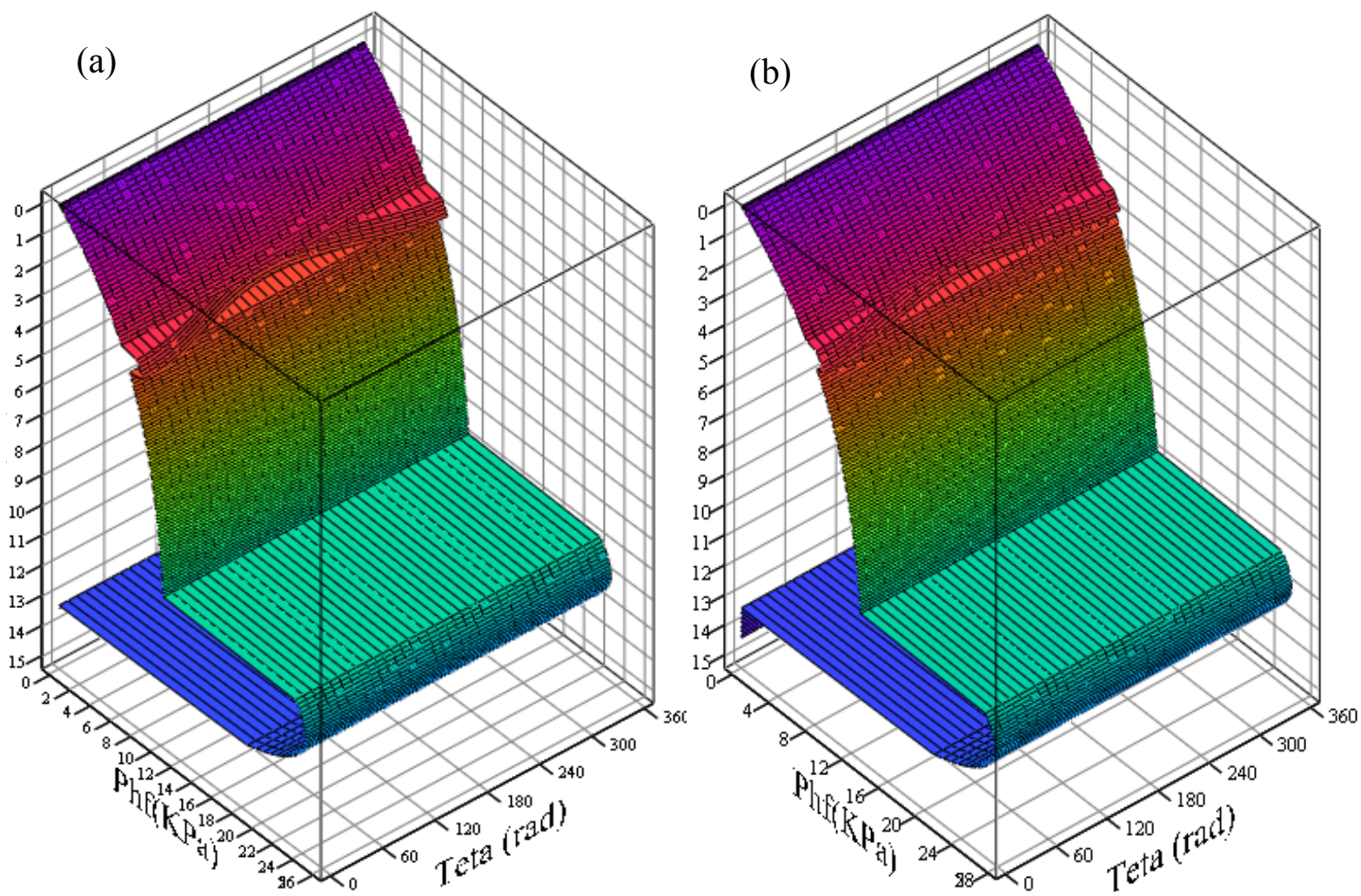
Figura 7.34 - Pressão estática normal às paredes de acordo com as normas EUROCODE e DIN para silos da segunda e terceira classe de confiabilidade para o farelo de milho (a) e a soja (b).

O valor da pressão adicional estática varia de zero a 1,4 kPa para o farelo de milho e de zero a 0,9 kPa para a soja.

A partir dos resultados da pressão estática normal à parede e a pressão vertical no produto, podemos avaliar o valor do coeficiente $\mathrm{K}$ resultante da análise numérica e compará-lo com os valores normativos, conforme a Figura 7.35.

(a)

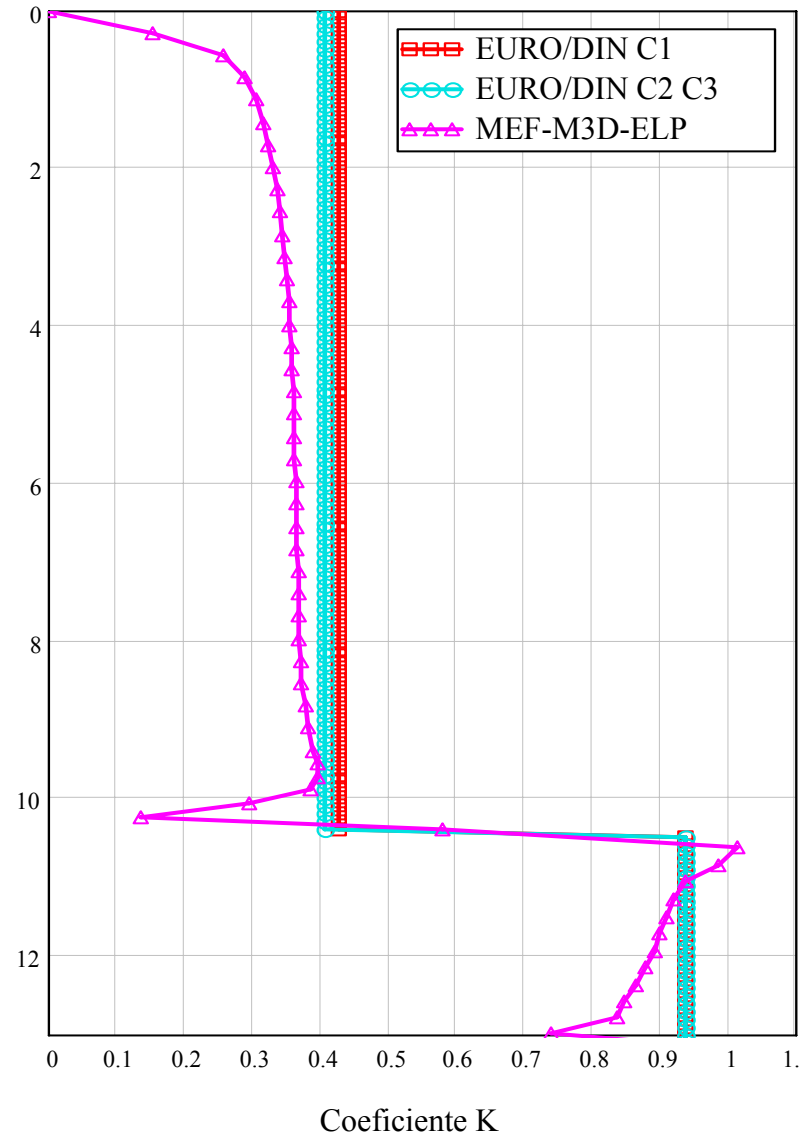

(b)

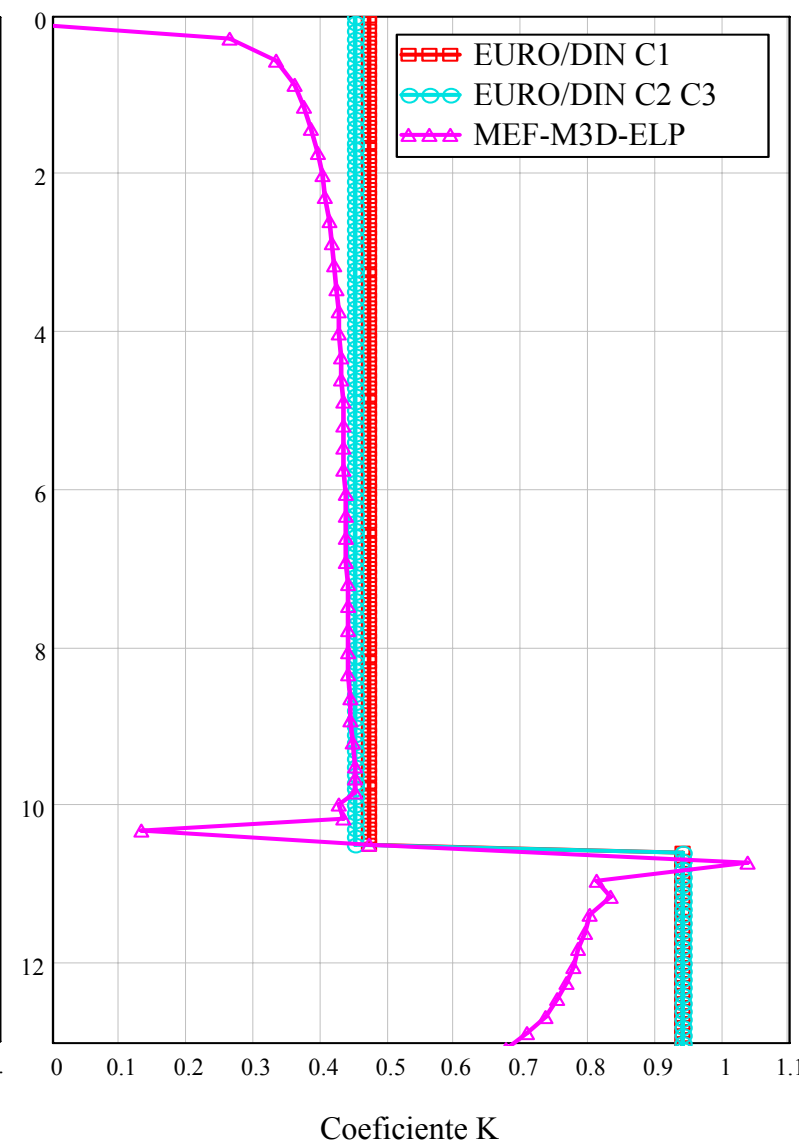

Figura 7.35 - Valores dos coeficientes K para o farelo de milho (a) e a soja (b).

Os valores do coeficiente $\mathrm{K}$ são muito próximos na parede vertical do silo. $\mathrm{O}$ MEF indica uma oscilação desde coeficiente na tremonha e também uma redução de k que não é considerada pelas normas EUROCODE E DIN.

\subsubsection{Pressão estática de atrito}

A pressão estática de atrito de acordo com cada norma analisada e com o método dos elementos finitos é ilustrada na Figura 7.36. 
(a)

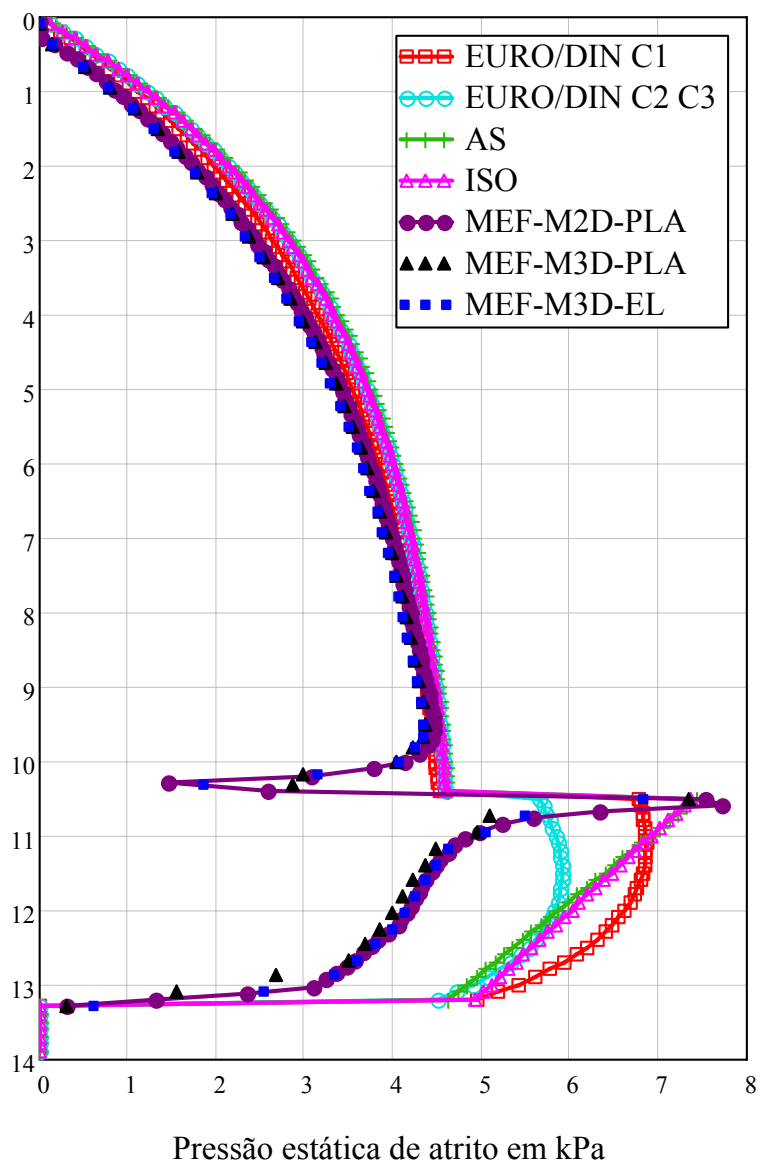

Pressão estática de atrito em $\mathrm{kPa}$ (b)

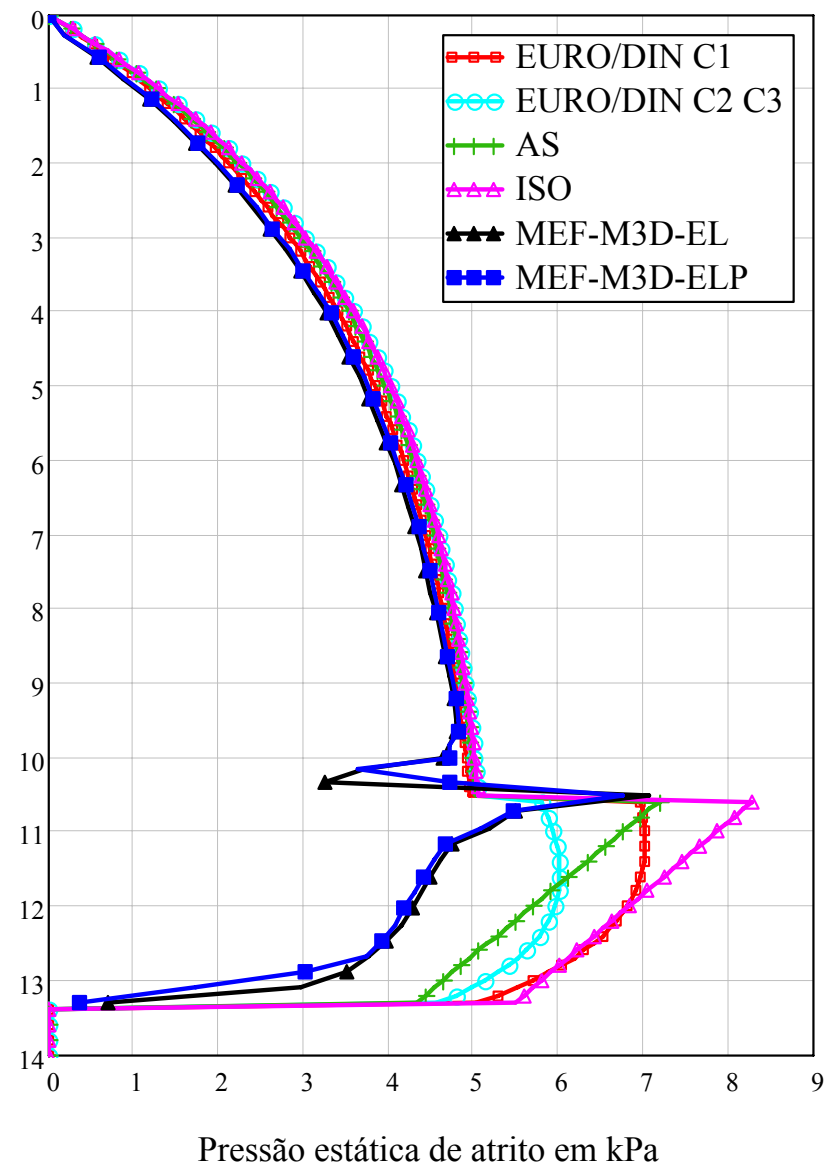

Figura 7.36 - Pressão estática de atrito para o farelo de milho (a) e a soja (b).

A pressão de atrito está diretamente relacionada com a pressão normal à parede e com o coeficiente de atrito entre o produto e a parede. Apesar do coeficiente de atrito entre a parede e o farelo de milho ser maior do que o coeficiente de atrito entre a parede e a soja, a pressão de atrito estática para a soja é superior à pressão de atrito para o farelo de milho, em decorrência do maior peso específico da soja e consequentemente maior pressão normal à parede com a soja.

A redução brusca da pressão de atrito na tremonha, comparado à pressão normal no corpo do silo é decorrente da diminuição do coeficiente de atrito na parede da tremonha (considerada lisa).

$\mathrm{Na}$ transição, as normas apontam um valor médio de 6,5 kPa para o farelo de milho e $7 \mathrm{kPa}$ para a soja. Desprezando-se os picos de pressões e descontinuidades na transição entre o corpo cilíndrico e a tremonha, as pressões obtidas com o MEF na tremonha são inferiores aos valores normativos. 


\subsubsection{Pressão dinâmica normal à parede}

A pressão dinâmica normal à parede para os dois produtos, analisada segundo as quatro normas é ilustrada na Figura 7.37, destacando que os resultados do MEF foram obtidos pela simulação estática com um aumento do coeficiente de Poisson para 0,48 .

(a)

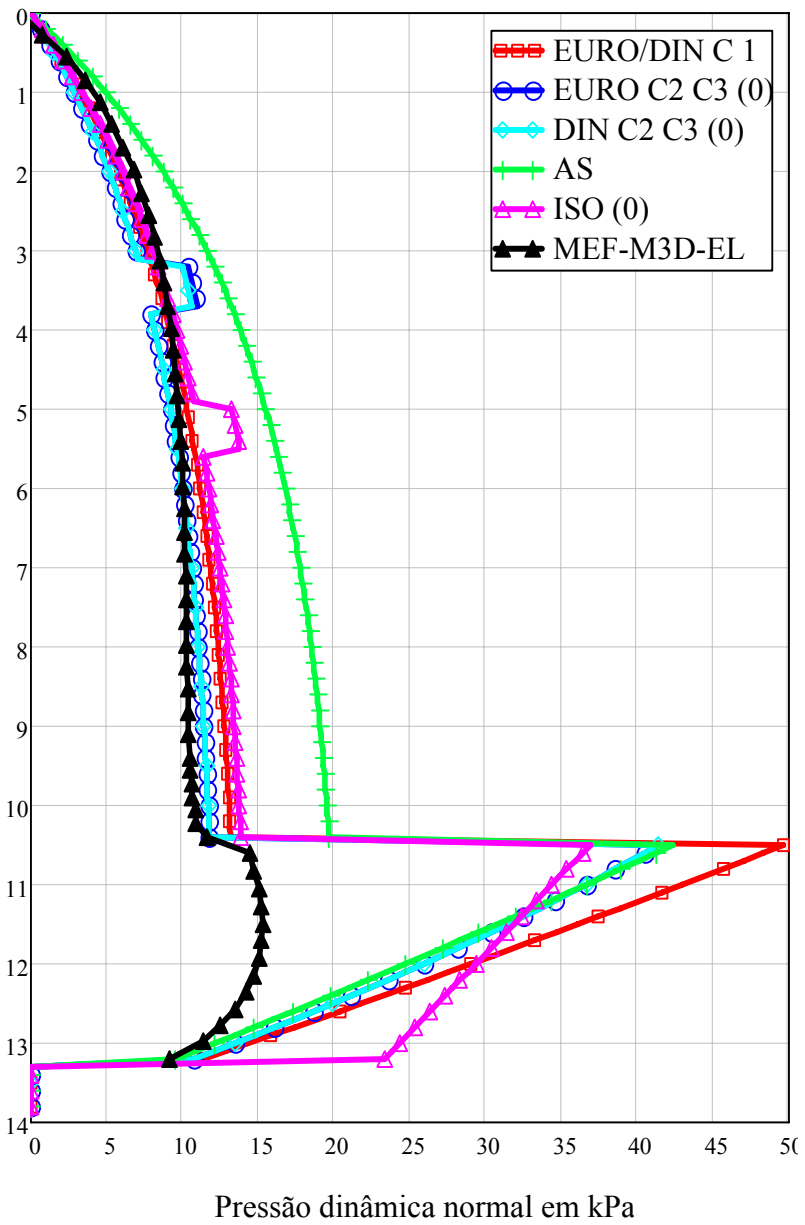

(b)

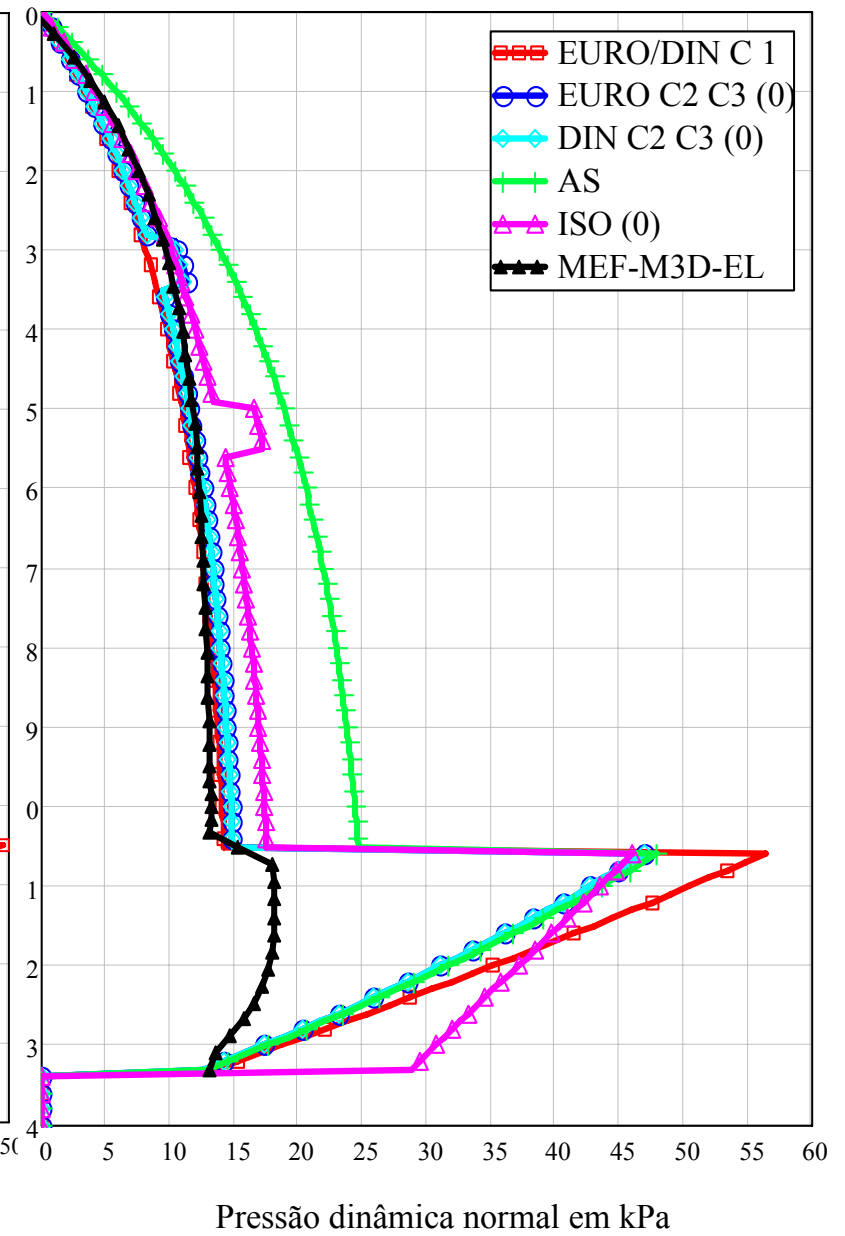

Figura 7.37 - Pressão dinâmica normal à parede para o farelo de milho (a) e a soja (b).

Para o farelo de milho, o coeficiente de sobrepressão aplicado às pressões horizontais estáticas nos silos de classe 1 é igual a 1,4, enquanto que nos silos de classe 2 e 3 este valor é de 1,15, que justifica os valores altos de pressões para aqueles. Com a soja, novamente o coeficiente de sobrepressão aplicado às pressões horizontais estáticas nos silos de classe 1 é menor do que 1 e, portanto adotou-se o valor de 1,15. Nos silos de classe 2 e 3 este valor é de 1,15.

A ISO estabelece o coeficiente de sobrepressão igual a 1,35 para ambos os produtos e a norma AS adotam 1,2 para ambos também. 
As pressões na tremonha obtidas pelo MEF, adotando-se um maior coeficiente de Poisson, são inferiores até mesmo às pressões estáticas obtidas pelo MEF. Portanto, o processo simplificado de aumentar do coeficiente de Poisson do produto fornece uma boa aproximação para as pressões no corpo do silo, porém para a tremonha não. E por isso, as curvas do MEF na tremonha não representam satisfatoriamente a situação de descarga do silo. Considerando as pressões estáticas no corpo do silo obtidas pelo MEF, obtém-se o coeficiente de sobrepressão no corpo do silo de 1,38 para o farelo de milho e 1,3 para a soja.

Nos silos de classe 2 e 3 é adotada uma pressão adicional de descarga para cobrir incertezas provenientes de excentricidades acidentais de descarga, entre outras. A visualização tridimensional da distribuição simétrica de pressões normal à parede com a pressão adicional é ilustrada na Figura 7.38.
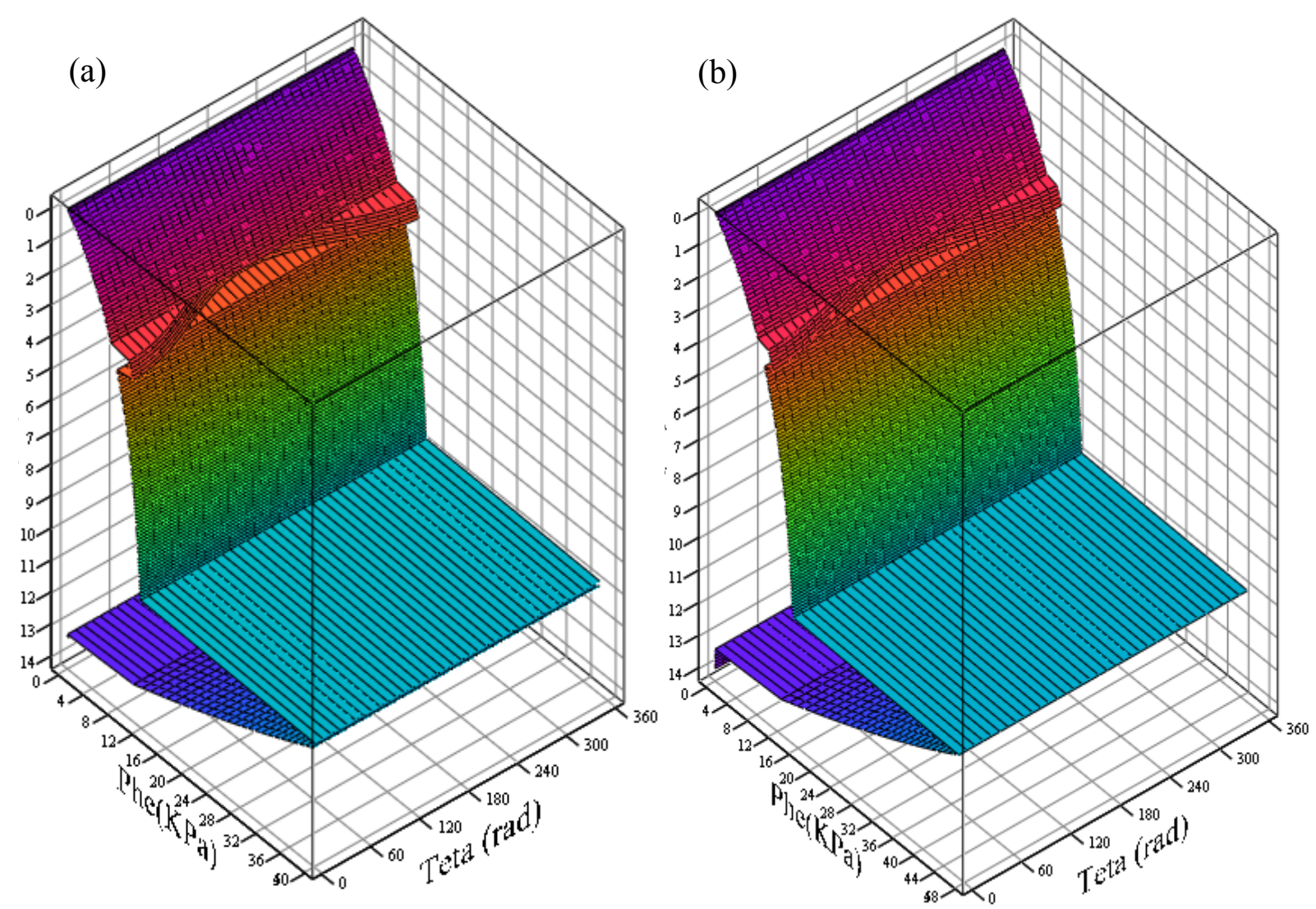

Figura 7.38 - Pressão dinâmica normal à parede de acordo com as normas EUROCODE e DIN para silos da segunda e terceira classe de confiabilidade para o farelo de milho (a) e a soja (b).

A pressão adicional de descarga adotada pelo EUROCODE varia de zero a $3,2 \mathrm{kPa}$ para o farelo de milho e de zero a 2,1 kPa para a soja. Segundo a norma DIN ela varia de zero a 2,8 para o farelo de milho e 2,1 para a soja. 
Como pode ser observado na Figura 7.38, a pressão adicional segundo as normas EUROCODE e DIN atua em uma altura próxima ao topo do silo, em conformidade com a afirmação de Rotter (2001) que diz que as falhas que ocorrem em silos com fluxo excêntrico são geralmente devido à perda de estabilidade por compressão axial na altura média do silo ou nas proximidades do seu topo. Ainda segundo Rotter (2001), as pressões que acarretam a perda de estabilidade do silo atuam numa área quadrada de pequena altura ao longo do perímetro do silo e gera ondulações na parede do silo, podendo ocorrer várias ondas adjacentes.

A norma ISO estabelece que a pressão adicional de descarga deve ser aplicada em áreas quadradas de lados opostos da parede em qualquer altura do silo, conforme a Figura 7.39.
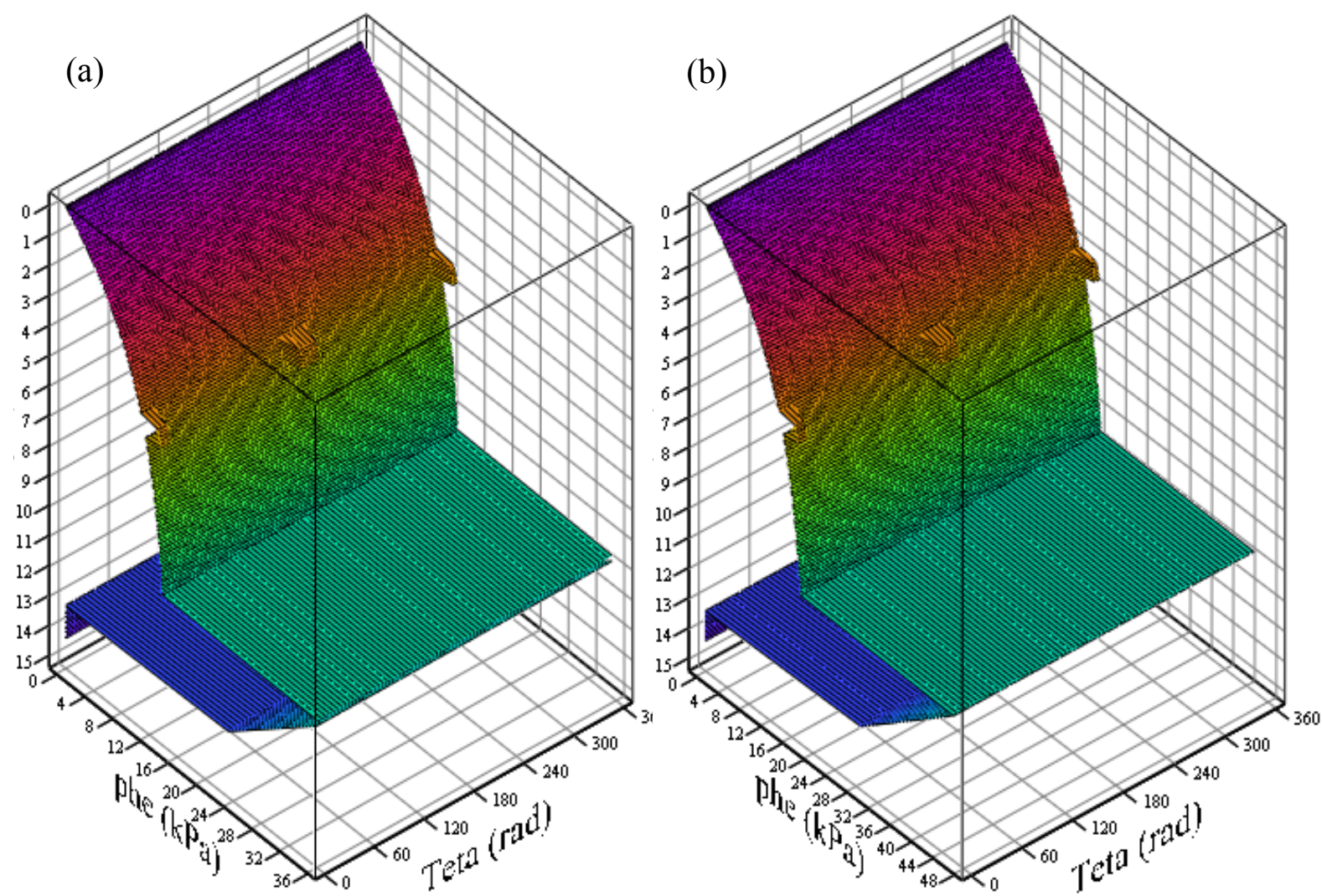

Figura 7.39 - Pressão dinâmica normal à parede de acordo com a norma ISO para silos da segunda e terceira classe de confiabilidade para o farelo de milho (a) e a soja (b).

Portando, de acordo com a ISO, a pressão adicional é constante e igual a 2,45 para o farelo de milho e 3,09 para a soja. 


\subsubsection{Pressão dinâmica de atrito}

A pressão dinâmica de atrito para os dois produtos, analisada segundo as normas é ilustrada na Figura 7.40 .

(a)

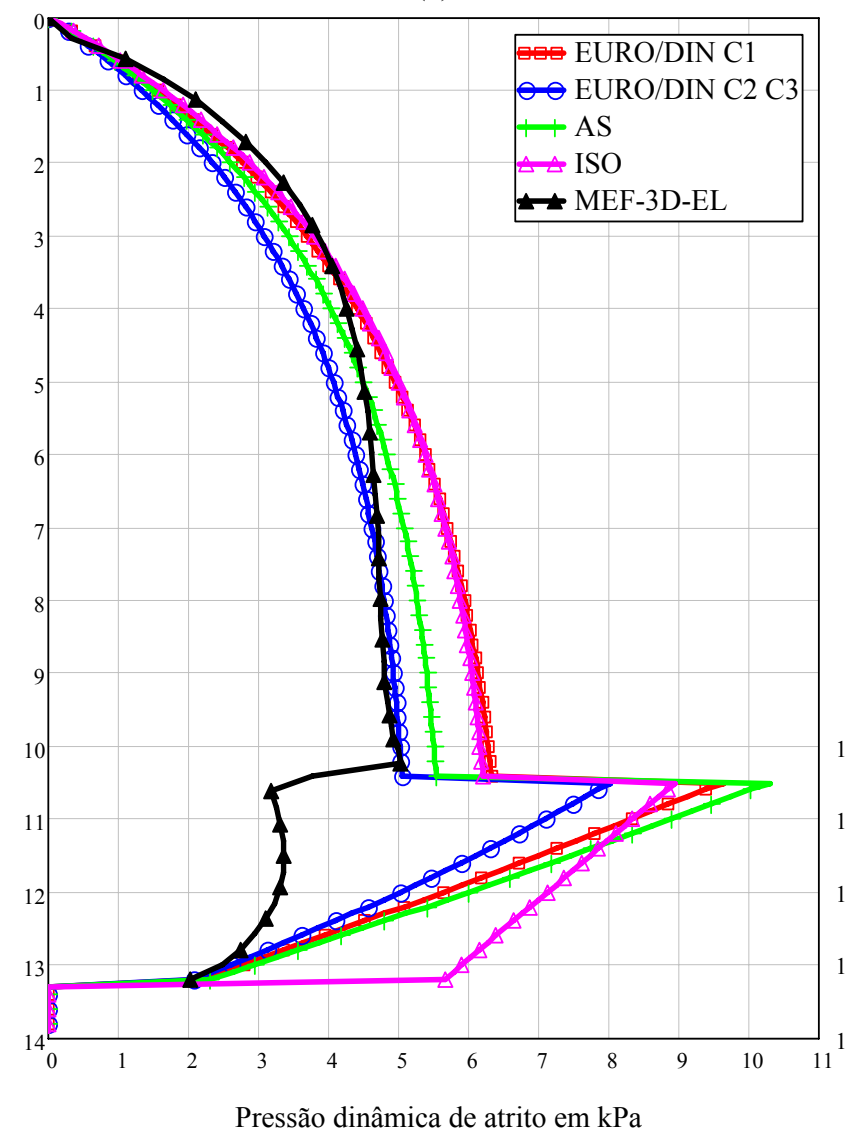

(b)

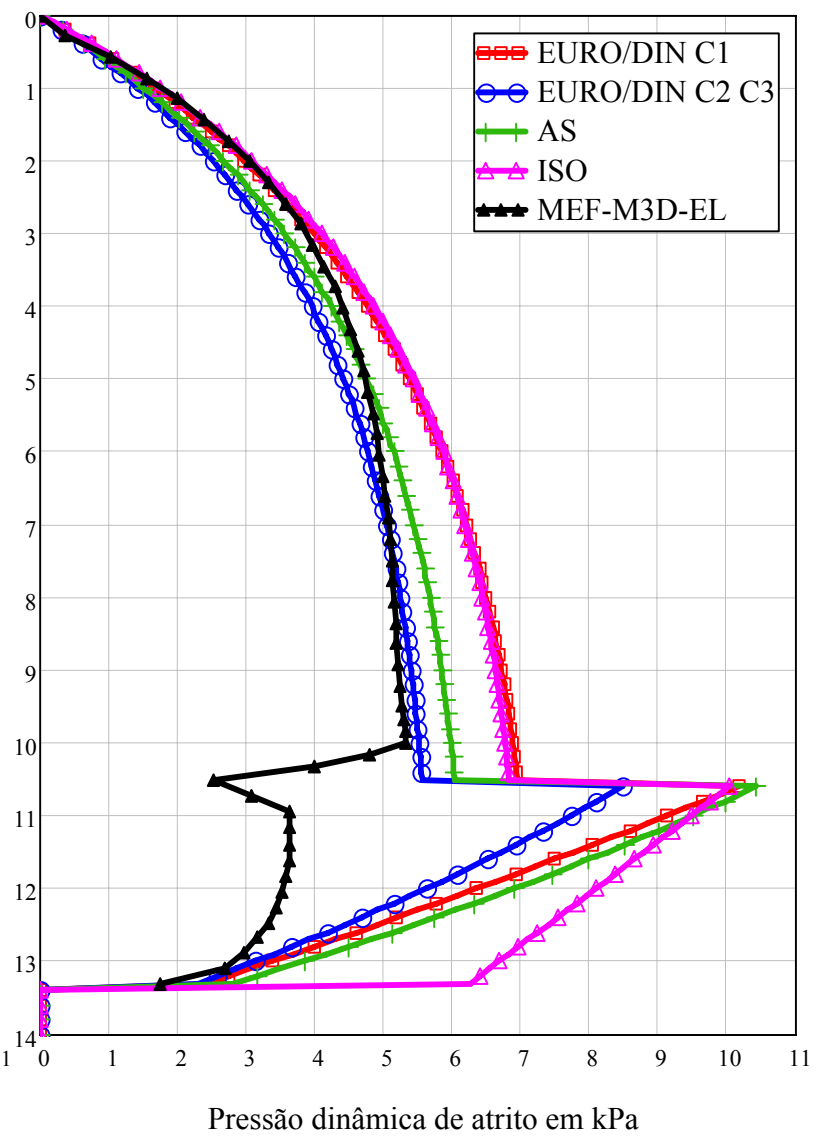

Figura 7.40 - Pressão dinâmica de atrito para o farelo de milho (a) e a soja (b).

Para os dois produtos, o coeficiente de sobrepressão aplicado às pressões de atrito estáticas nos silos de classe 1 é igual a 1,35 e para a ISO também, que justifica os altos valores nestes dois casos. O coeficiente de sobrepressão nos silos de classe 2 e 3 este valor é de 1,1, Enquanto a norma AS adota 1,2.

O processo simplificado de simulação da descarga novamente não fornece uma boa aproximação para as pressões na tremonha com o MEF. A curva numérica indica um acréscimo de pressões na parte superior da parede vertical porque o produto se deforma em direção à superfície livre, local em que as pressões devido ao peso do produto são menores. 


\subsection{Silo com tremonha excêntrica ( $\left.e_{o} / D=25 \%\right)$}

Nenhuma das normas analisadas inclui o cálculo das pressões em tremonhas assimétricas. Portanto, as curvas de distribuição de pressões de acordo com as normas são mostradas neste item apenas para fins de comparação e foram obtidas considerando a tremonha concêntrica.

\subsubsection{Pressão estática normal à parede}

A pressão estática normal na borda do produto e em uma linha de corte dentro do produto para a soja é ilustrada na Figura 7.41.

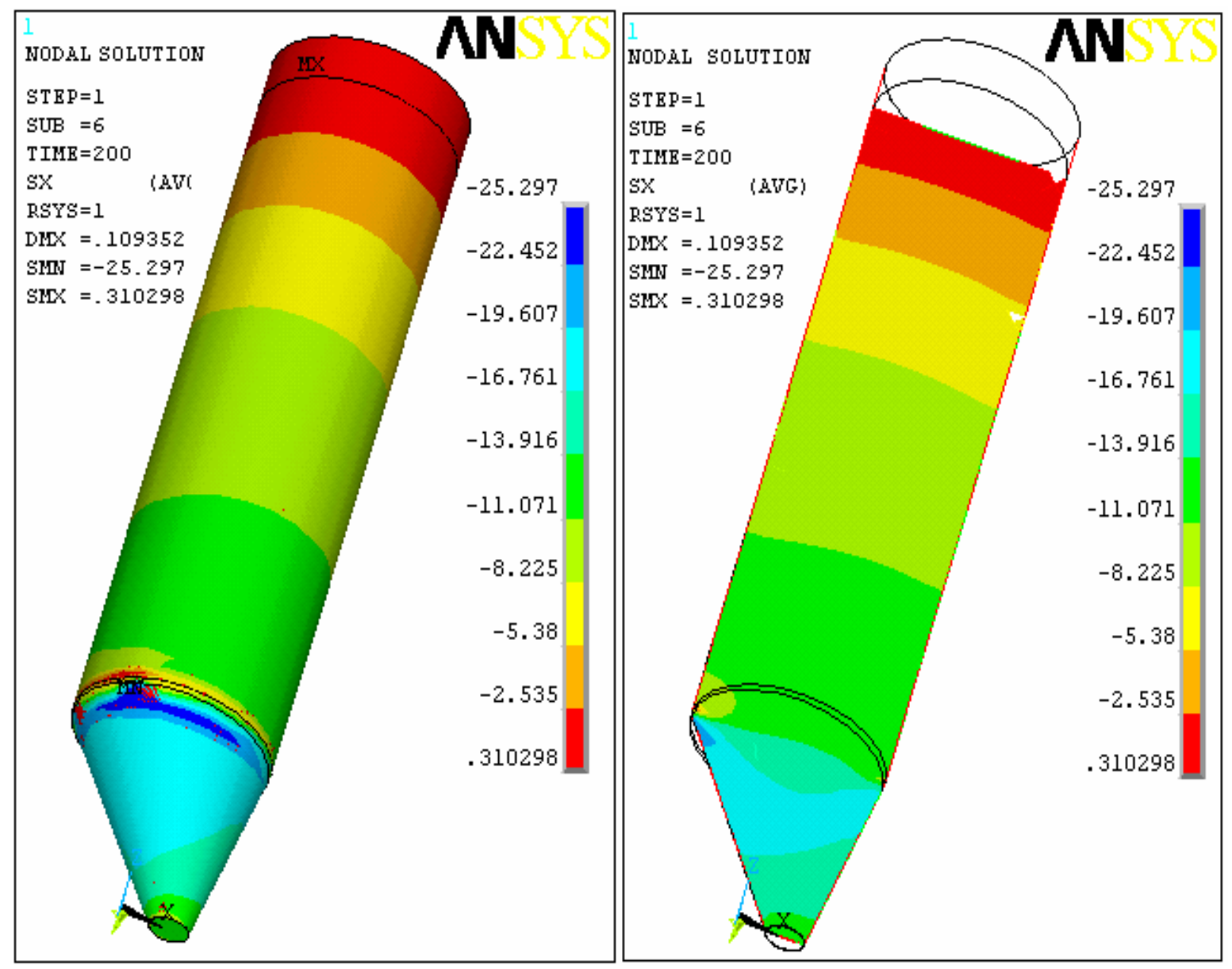

Figura 7.41 - Pressão estática normal para o soja considerando produto elástico.

Analisando a Figura 7.41 é possível observar a variação da pressão normal no produto, sendo que a assimetria da tremonha também ocasiona assimetria das pressões dentro dela. 
A pressão estática normal às paredes de acordo com cada norma analisada e com o método dos elementos finitos é ilustrada na Figura 7.42 para o produto farelo de milho.
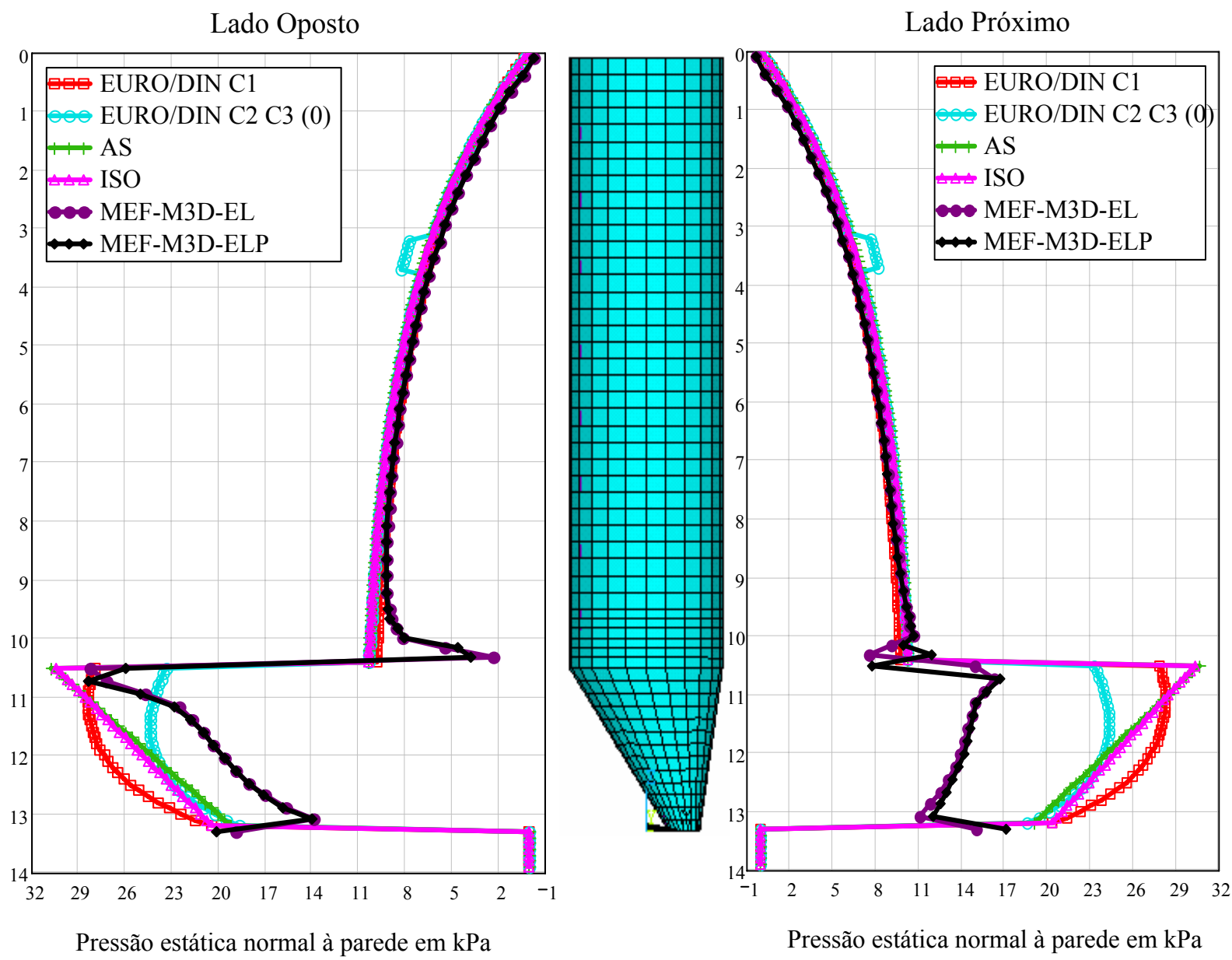

Figura 7.42 - Pressão estática normal à parede para farelo de milho.

No lado oposto à excentricidade são observados os maiores valores de pressão. Entretanto, mesmo no lado oposto os valores obtidos numericamente são inferiores aos recomendados pelas normas com exceção na transição cujos resultados numéricos não podem ser considerados totalmente confiáveis.

Em compensação ao acréscimo de pressões no lado oposto, ocorre um alívio de pressões no lado próximo à excentricidade, respeitando o equilíbrio entre o peso do produto no interior do silo.

Oberva-se também que as normas ISO e AS são as mais conservadoras em relação à determinação das ações na tremonha, que utilizam o processo de soma das parcelas $p_{n 1}, p_{n 2}$ e $p_{n 3}$. 
A mesma conclusão pode ser feita para a soja, cujas curvas das pressões normais estáticas são ilustradas na Figura 7.43.

Lado Oposto

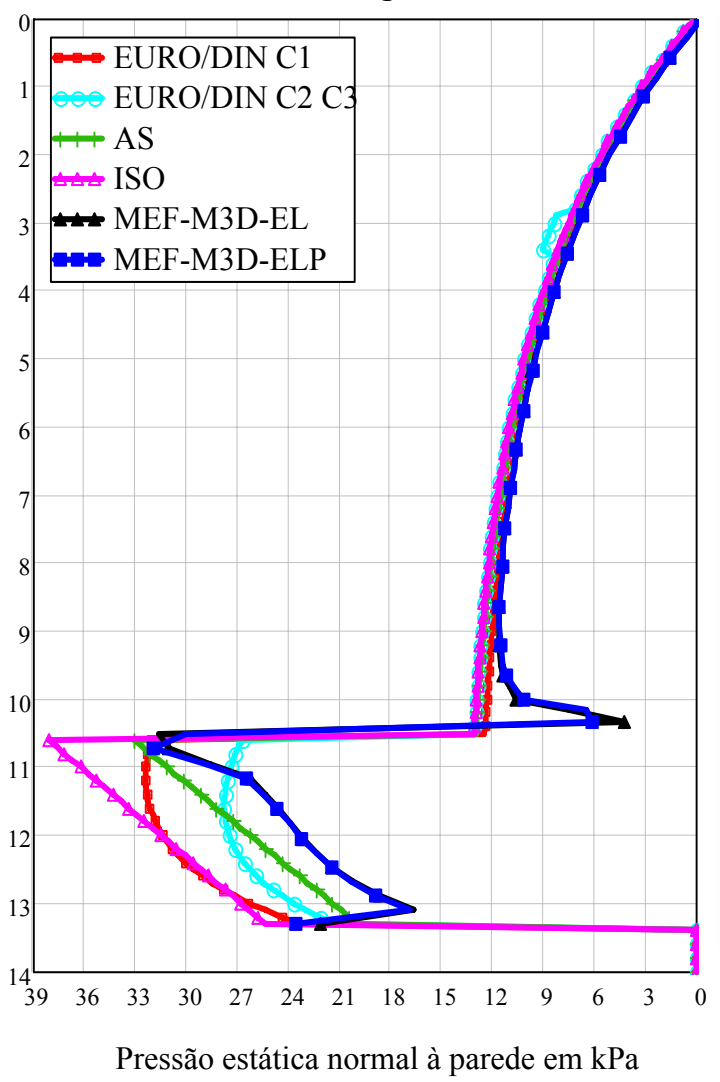

Lado Próximo

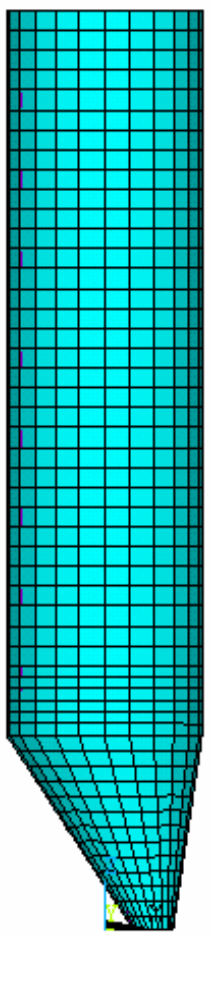

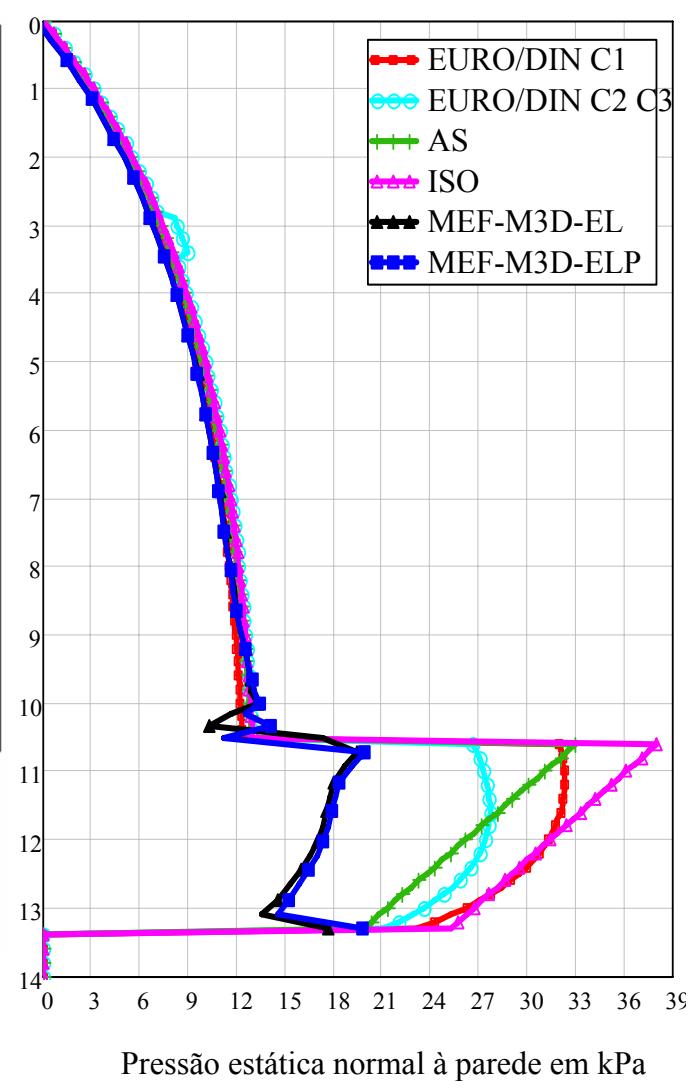

Figura 7.43 - Pressão estática normal à parede para a soja.

Novamente no lado próximo à excentricidade são obtidas pressões menores do que no lado oposto. Cabe destacar que a intensidade das pressões não se altera significativamente em relação à tremonha concêntrica. O problema principal da descarga excêntrica não se encontra nos valores das pressões e sim na assimetria de pressões que gera a ovalização das paredes do silo, efeito que se acentua ainda mais em silos com paredes metálicas devido à elevada esbeltez das paredes.

\subsubsection{Pressão estática de atrito}

A pressão estática de atrito obtida com o método dos elementos finitos é ilustrada na Figura 7.44 e na Figura 7.45 para os produtos farelo de milho e soja, respectivamente. 
Lado Oposto

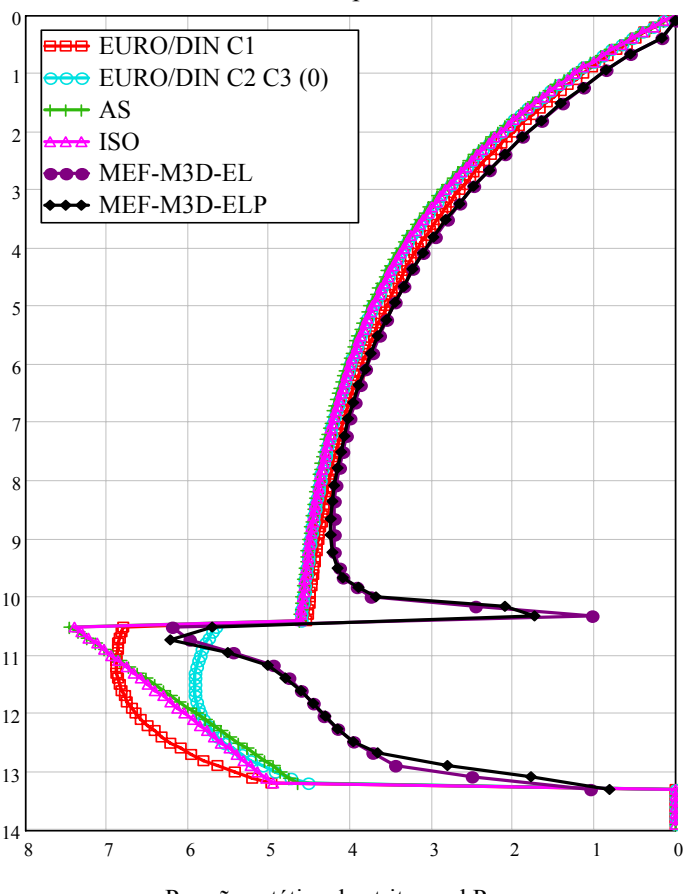

Pressão estática de atrito em $\mathrm{kPa}$
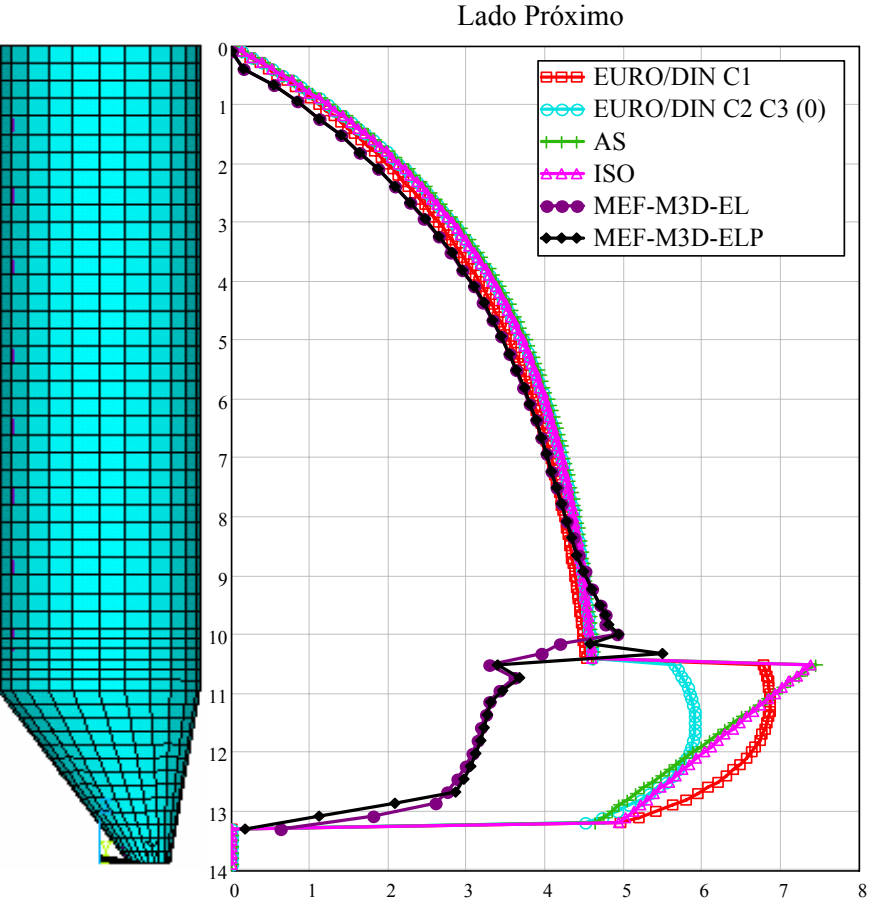

Pressão estática de atrito em $\mathrm{kPa}$

Figura 7.44 - Pressão estática de atrito para o farelo de milho.

No corpo do silo, as pressões não dependem da excentricidade do silo enquanto que na tremonha, observa-se que no lado próximo à excentricidade as pressões são menores do que no lado oposto. O coeficiente de atrito do produto com a parede corrugada é superior ao coeficiente de atrito do produto com a parede lisa da tremonha justificando a redução na pressão de atrito na tremonha.
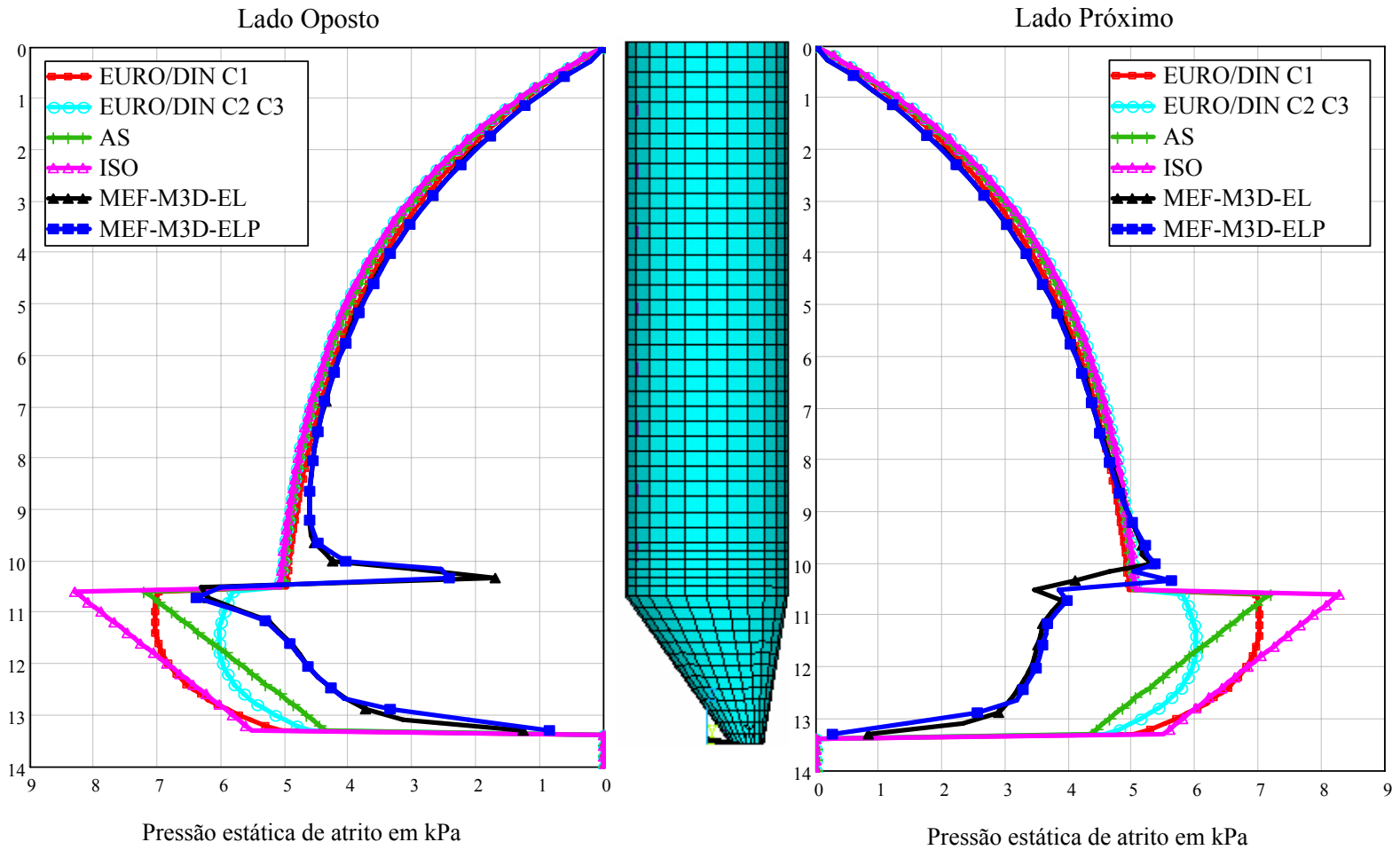

Figura 7.45 - Pressão estática de atrito para a soja. 
Da mesma forma que acontece com o farelo de milho, as pressões no corpo cilíndrico vertical não se altera devido à excentricidade da boca de saída e na tremonha, as pressões são menores no lado próximo à excentricidade as pressões e maiores no lado oposto. Mesmo no lado oposto, as pressões são menores que as recomendadas pelas normas.

\subsubsection{Pressão dinâmica normal à parede}

As curvas da pressão dinâmica nomal à parede do silo para o farelo de milho e para a soja, são ilustradas respectivamente na Figura 7.46 e na Figura 7.47.
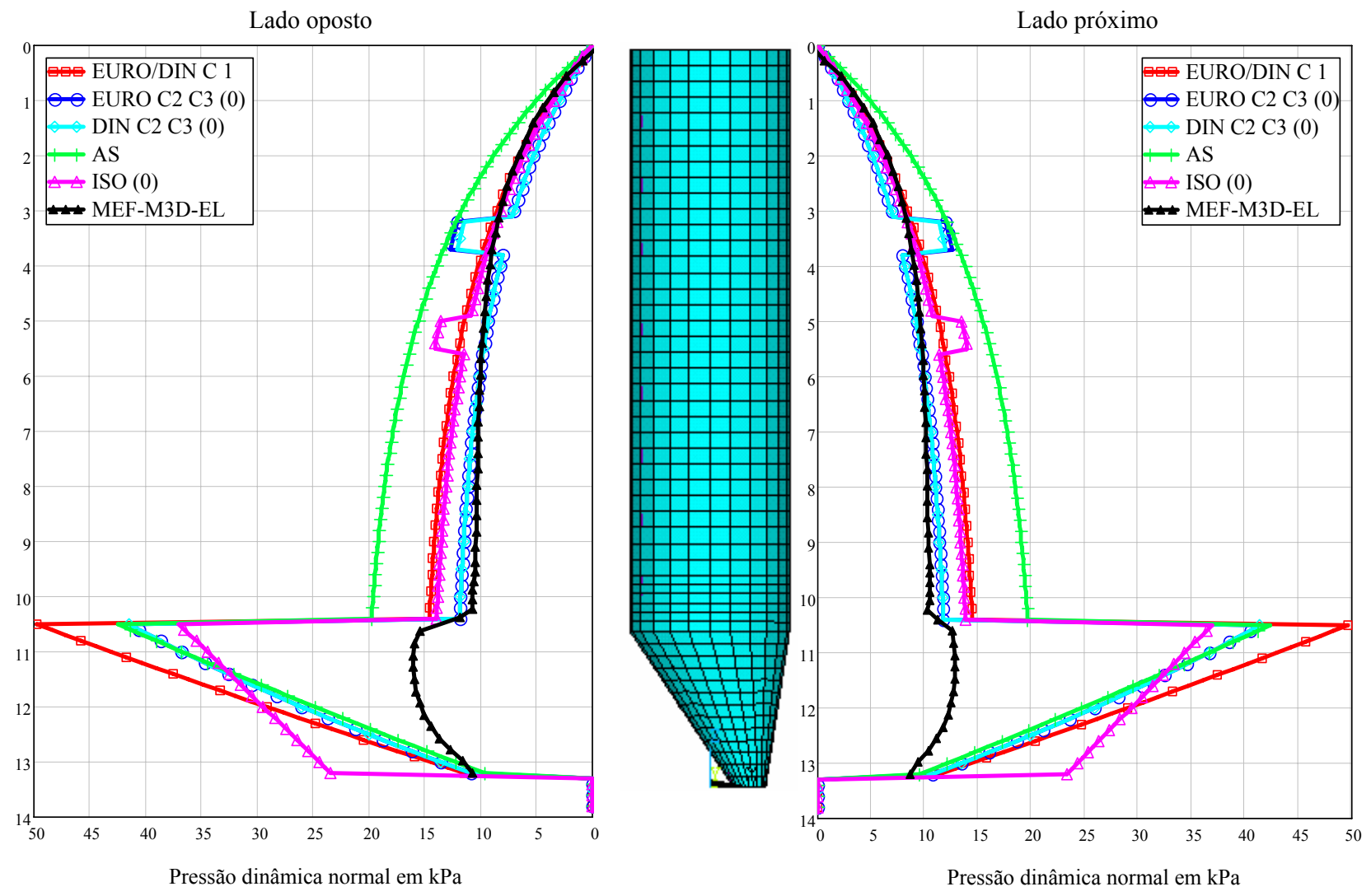

Figura 7.46 - Pressão dinâmica normal à parede para o farelo de milho. 
Lado oposto

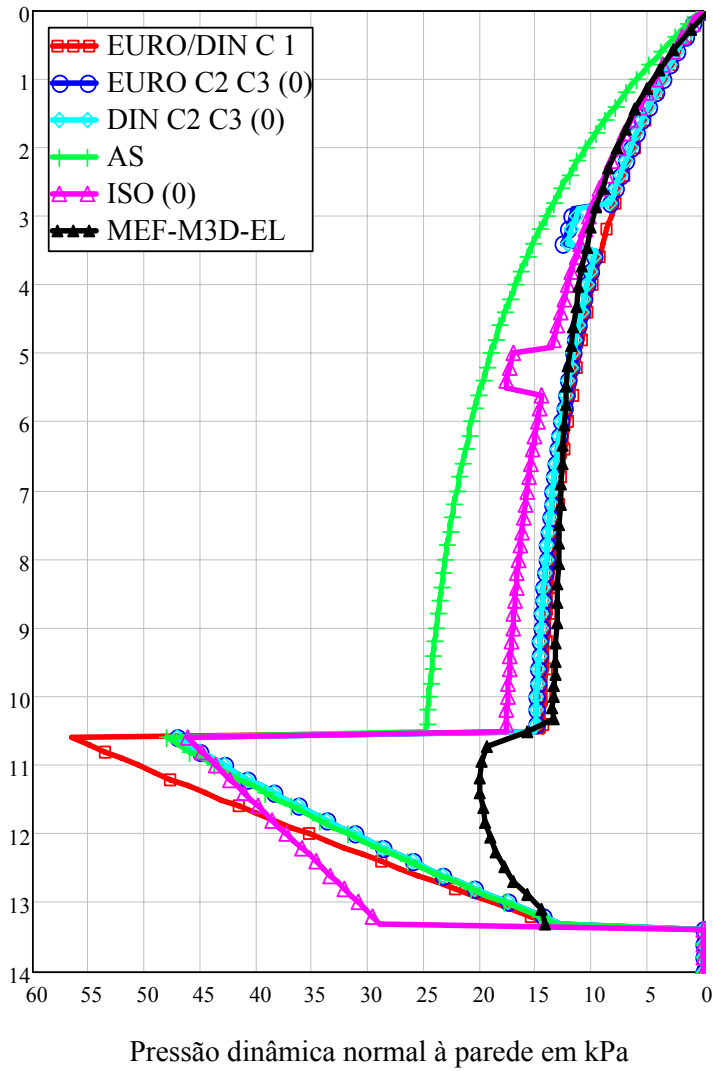

Lado próximo

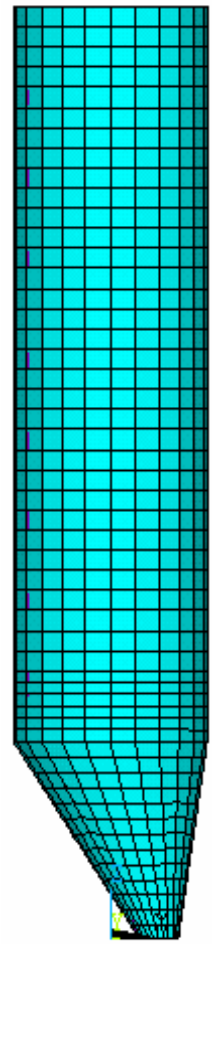

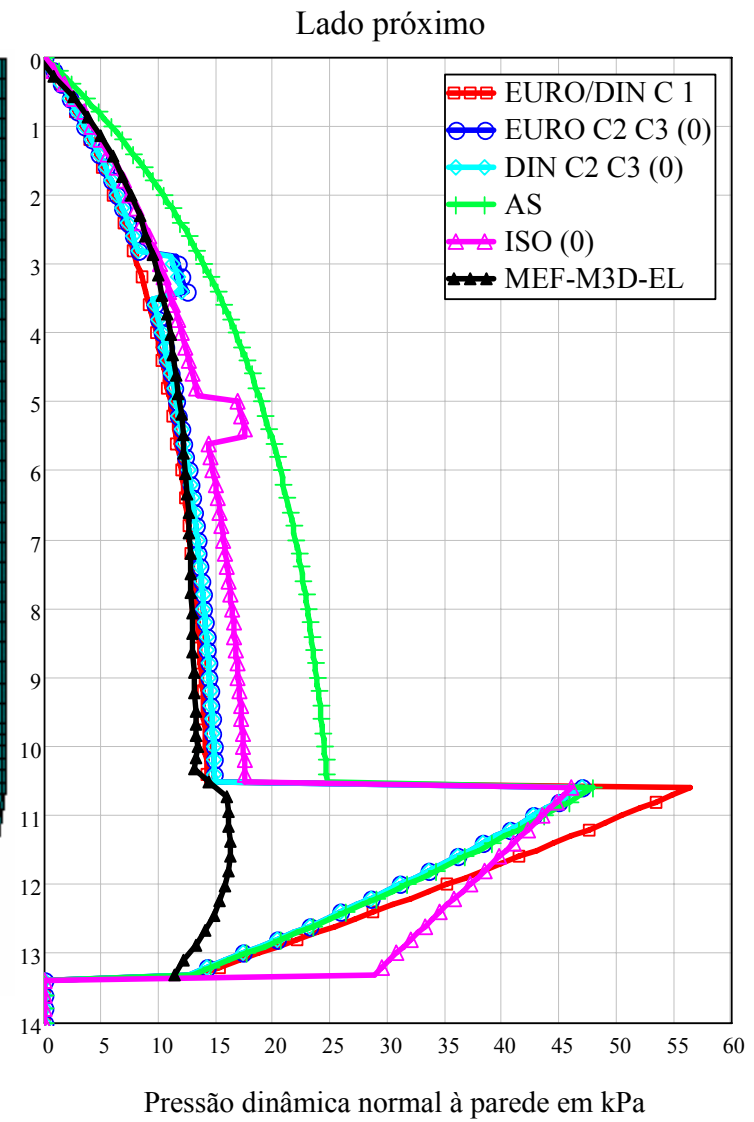

Figura 7.47 - Pressão dinâmica normal à parede para a soja.

Novamente em silos da classe 1 utilizados para o armazenamento de soja, o coeficiente de sobrepressão calculado foi inferior a 1, sendo adotado 1,15. Observase que a norma australiana não adota as pressões adicionais. Em compensação, esta norma é a que apresenta, para os dois produtos, o maior coeficiente de sobrepressão que equivale a 1,91.

O procedimento das normas australiana, européia e alemã (nos silos da classe 1) para cobrir excentricidades com $e_{0} / D$ de até $25 \%$, consiste em majorar os coeficientes de sobrepressão em função do valor da excentricidade da boca de saída. Desta forma, a diferença das pressões normais dinâmicas entre silos excêntricos e concêntricos está apenas na intensidade da distribuição simétrica de pressões.

$\mathrm{Na}$ norma ISO e EUROCODE e DIN para as demais classes, ocorre um acréscimo intensidade das pressões adicionais. Ou seja, a excentricidade para esses casos influi somente na intensidade das pressões adicionais.

A Tabela 7.2 compara os valores das pressões adicionais entre o silo concêntrico e excêntrico. 
Tabela 7.2 - Comparação entre as pressões adicionais dinâmicas, em kPa, para silos concêntricos e excêntricos e ambos os produtos.

\begin{tabular}{|c|c|c|c|c|}
\hline Produto & Norma & $\begin{array}{c}\text { Saída } \\
\text { centrada }\end{array}$ & $\begin{array}{c}\text { Saída } \\
\text { excentrica }\end{array}$ & $\begin{array}{c}\text { Aumento } \\
\text { (\%) }\end{array}$ \\
\hline \multirow{3}{*}{$\begin{array}{c}\text { Farelo } \\
\text { de milho }\end{array}$} & EUROCODE & 3,2 & 4,8 & 50 \\
\cline { 2 - 5 } & DIN & 2,8 & 4,22 & 51 \\
\cline { 2 - 5 } & ISO & 2,45 & 2,69 & 10 \\
\hline \multirow{3}{*}{ Soja } & EUROCODE & 2,08 & 3,12 & 50 \\
\cline { 2 - 5 } & DIN & 1,82 & 2,73 & 50 \\
\cline { 2 - 5 } & ISO & 3,09 & 3,40 & 10 \\
\hline
\end{tabular}

\subsubsection{Pressão dinâmica de atrito à parede}

A pressão dinâmica tangente à parede do silo para o farelo de milho, analisada segundo as quatro normas e pelo MEF é ilustrada na Figura 7.48. A Figura 7.49 refere-se ao produto soja.
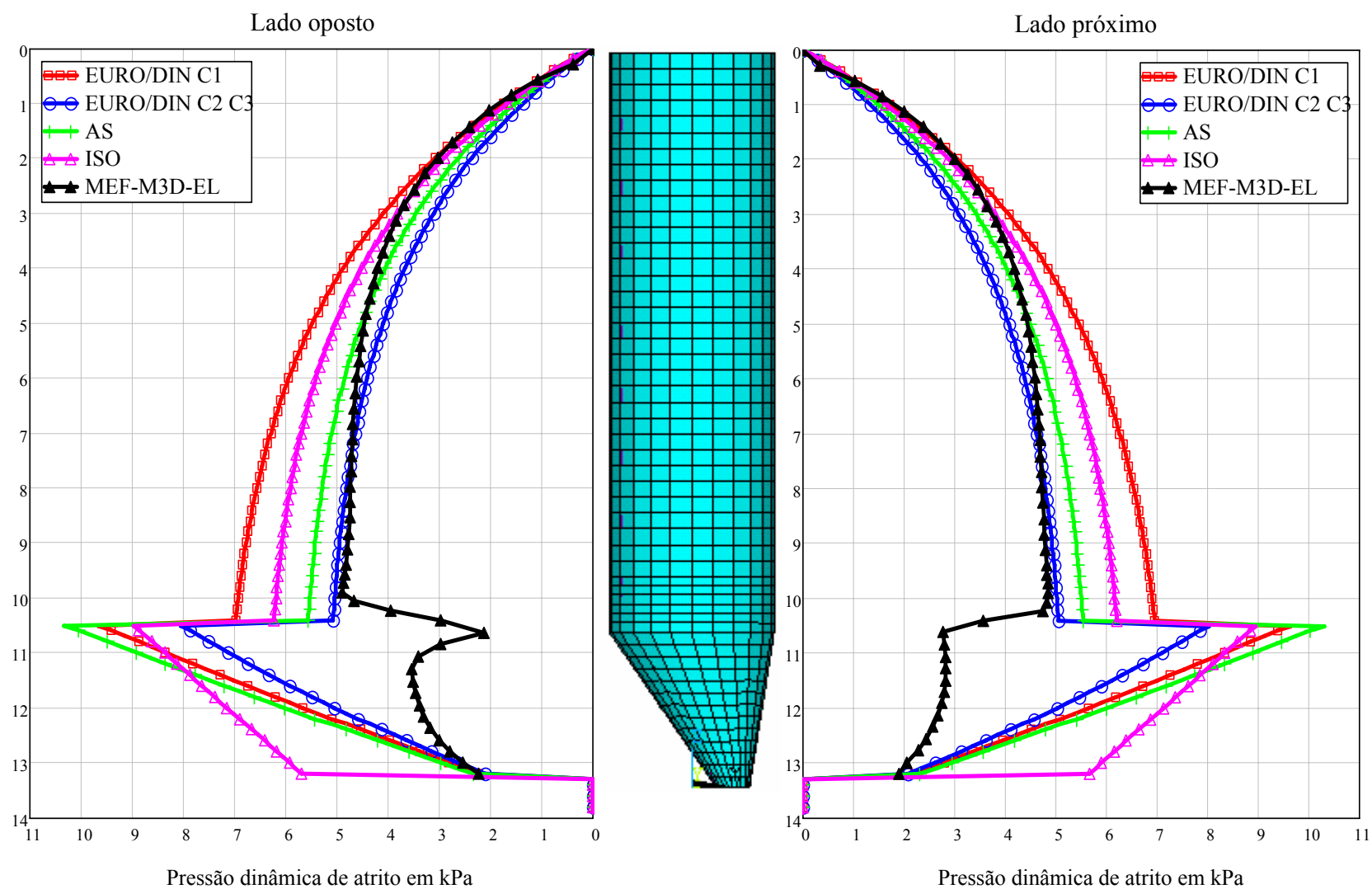

Figura 7.48 - Pressão dinâmica de atrito para o farelo de milho. 
Lado oposto

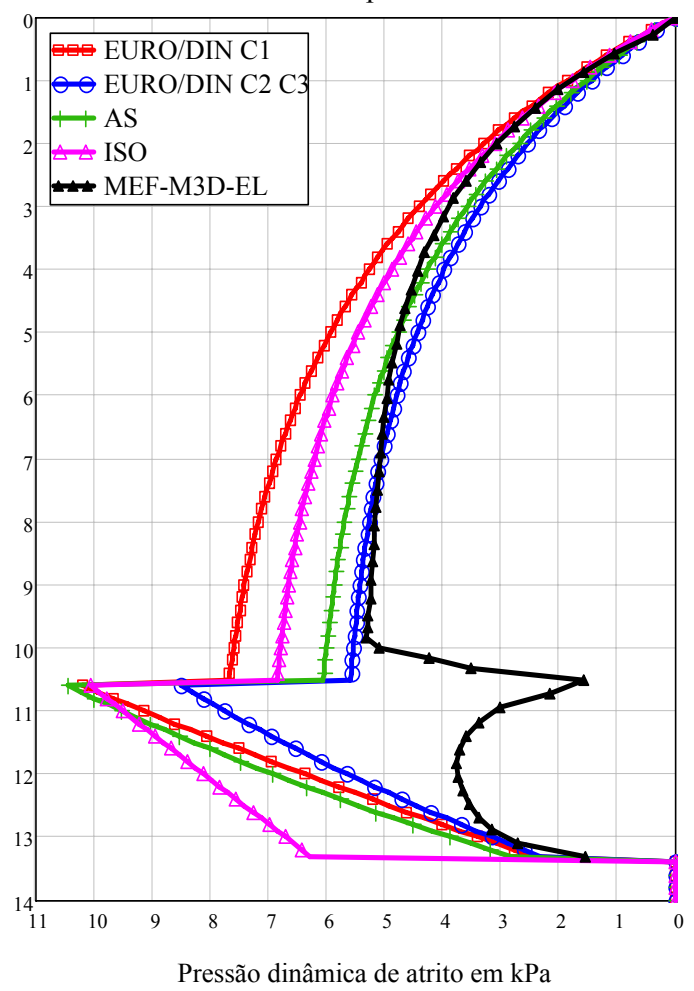

Lado próximo
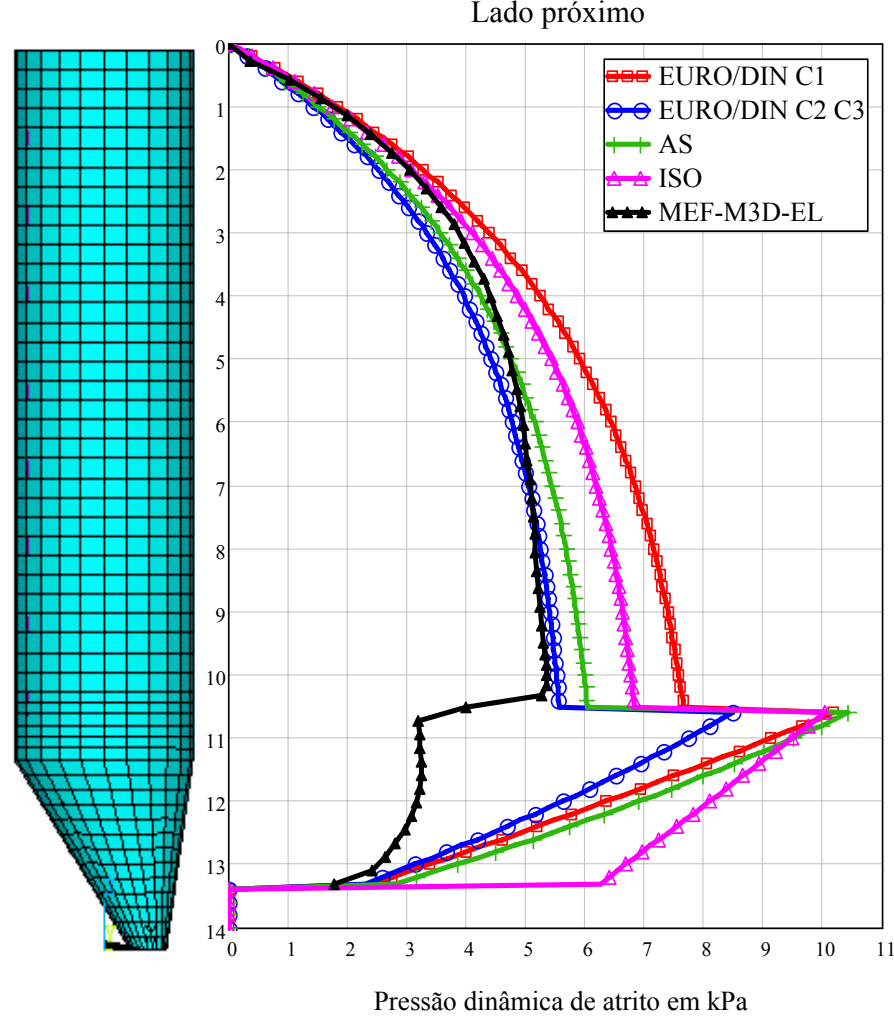

Figura 7.49 - Pressão dinâmica de atrito para a soja.

A diferença da excentricidade na determinação das pressões dinâmicas de atrito aparece apenas para os silos da primeira classe de confiabilidade. Observa-se que Figura 7.48 e na Figura 7.49 que somente os silos da primeira classe apresentam valores superiores em relação às pressões dinâmicas ilustradas na Figura 7.40. Isto acontece porque o cálculo do coeficiente de sobrepressão inclui a variável $e_{0}$, que considera a excentricidade da boca de saída.

\subsection{Análise da excentricicade nas pressões estáticas}

\subsubsection{Pressão estática normal à parede}

Uma forma de avaliar o efeito da excentricidade é utilizar várias relações de $\mathrm{e}_{0} / \mathrm{D}$. A Figura 7.50 ilustra a variação da pressão normal na parede para vários valores de $e_{0} / D$ com o farelo de milho e a Figura 7.51 para a soja. 
Lado Oposto

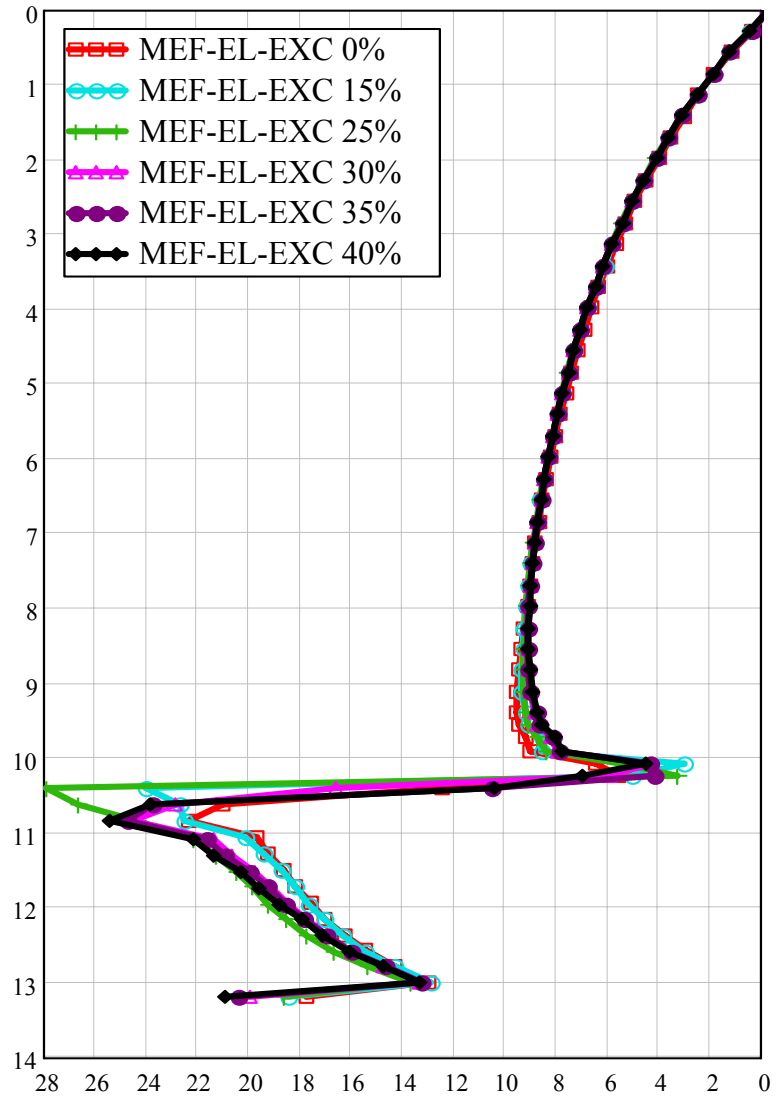

Pressão estática normal à parede em kPa
Lado Próximo
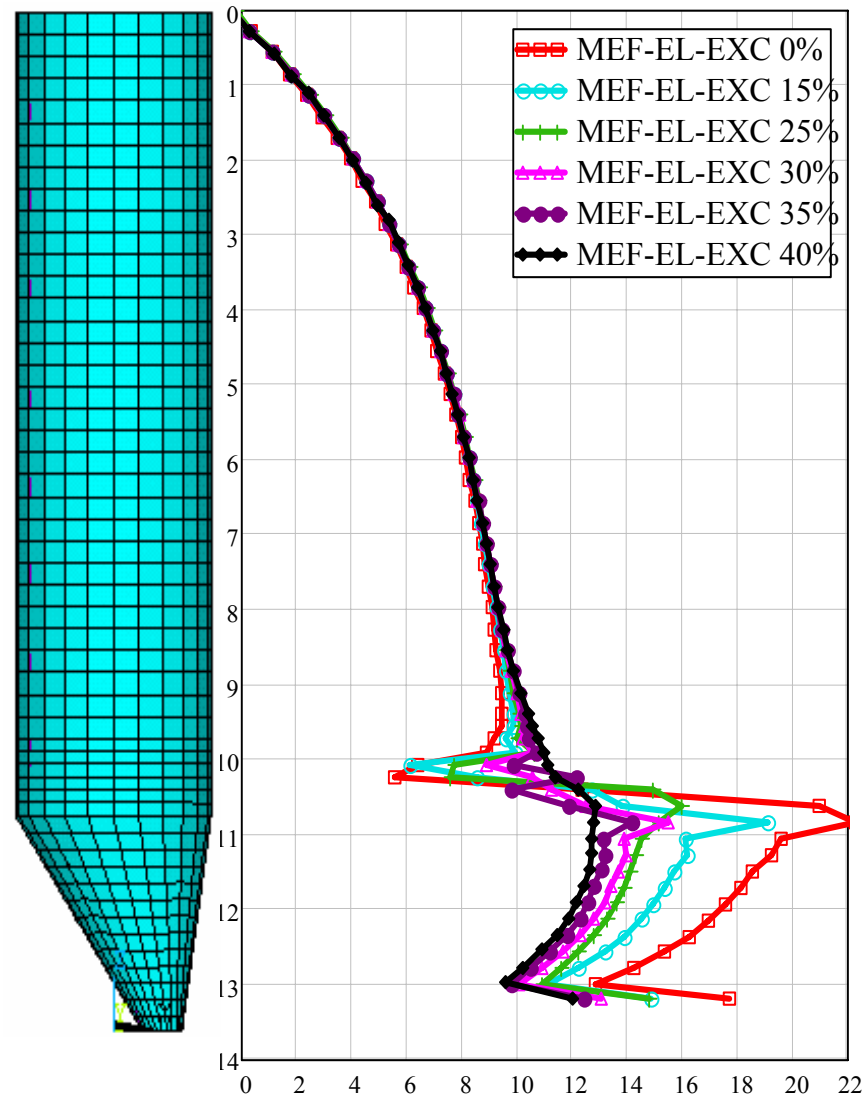

Pressão estática normal à parede em $\mathrm{kPa}$

Figura 7.50 - Pressão estática normal à parede de acordo com a relação $e_{0} / D$ para o farelo de milho. 
Lado Oposto

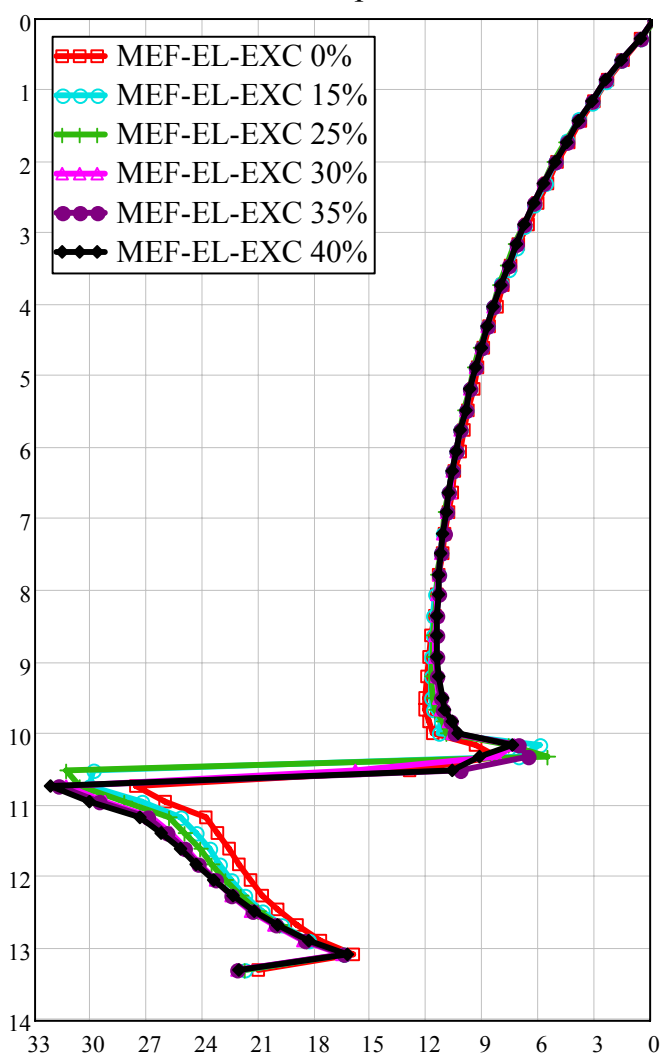

Pressão estática normal à parede em $\mathrm{kPa}$
Lado Próximo
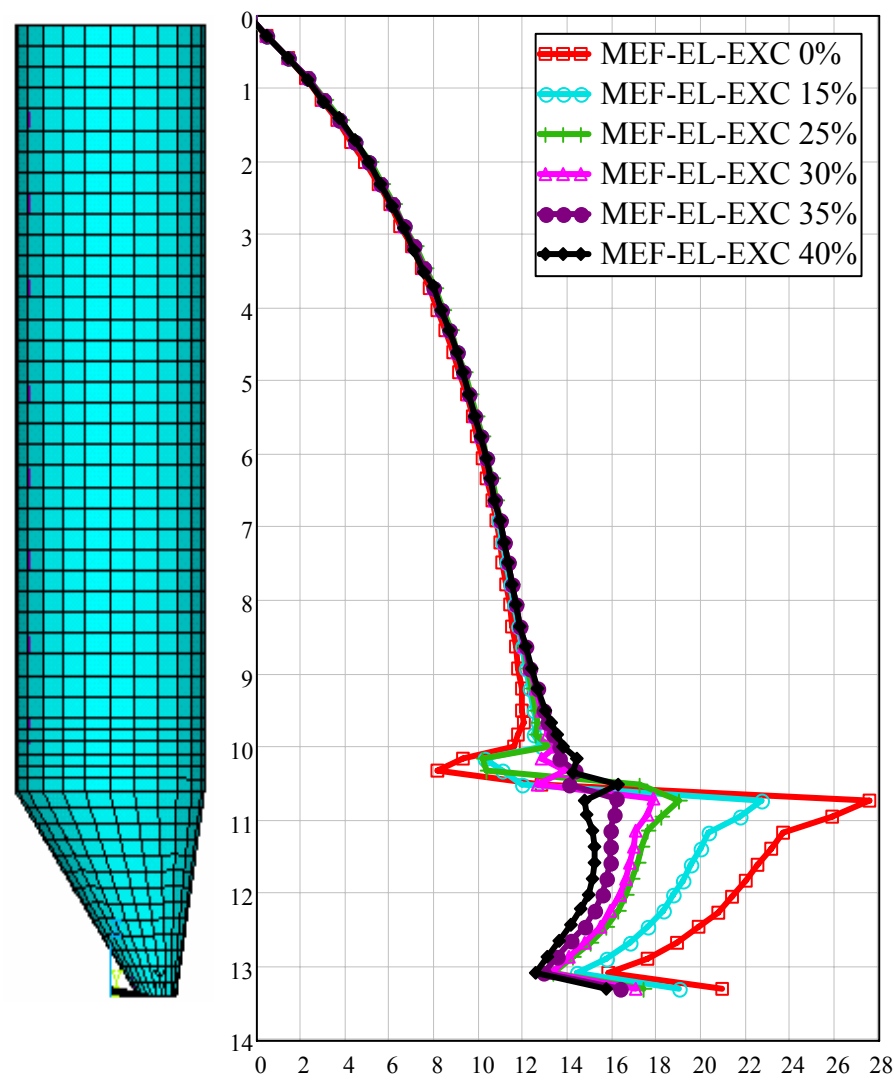

Pressão estática normal à parede em $\mathrm{kPa}$

Figura 7.51 - Pressão estática normal à parede de acordo com a relação e $e_{0} / D$ para a soja.

No lado oposto à excentricidade são obtidas pressões maiores em comparação com o lado próximo. Este efeito é ainda mais acentuado conforme aumenta a relação $e_{0} / D$. No lado próximo observa-se o inverso, ou seja, a pressão sofre redução conforme aumenta a relação $e_{0} / D$.

\subsubsection{Pressão estática de atrito}

Uma forma de avaliar o efeito da excentricidade é utilizar várias relações de $\mathrm{e}_{0} / \mathrm{D}$, definida neste trabalho como excentricidade (EXC). A Figura 7.52 ilustra a variação da pressão de atrito na parede para vários valores de $e_{0} / D$ para o farelo de milho e na Figura 7.53. 
Lado Oposto

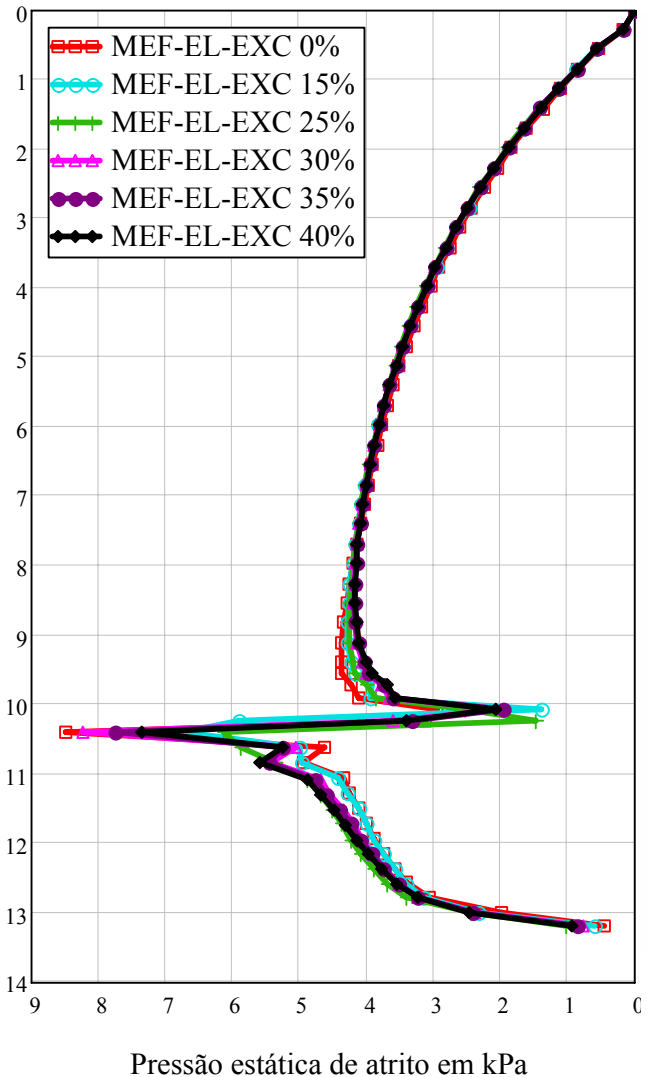

Lado Próximo
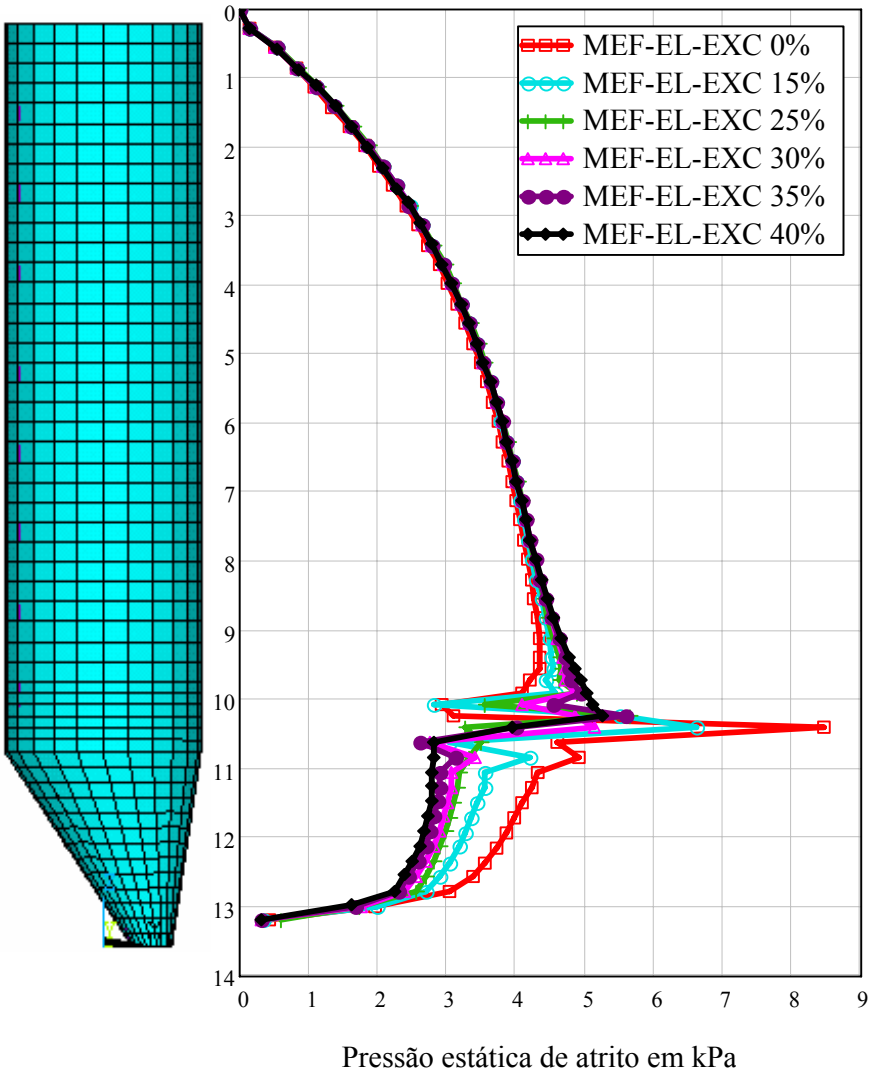

Figura 7.52 - Pressão estática de atrito de acordo com a relação $e_{0} / D$ para o farelo de milho.

Lado Oposto

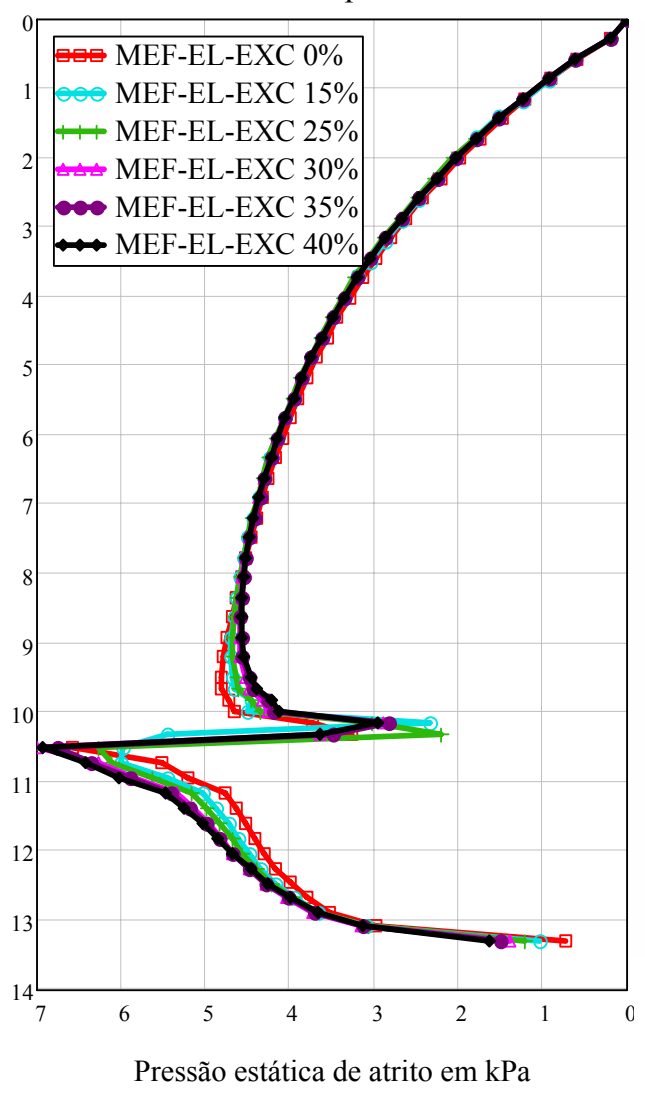

Lado Próximo
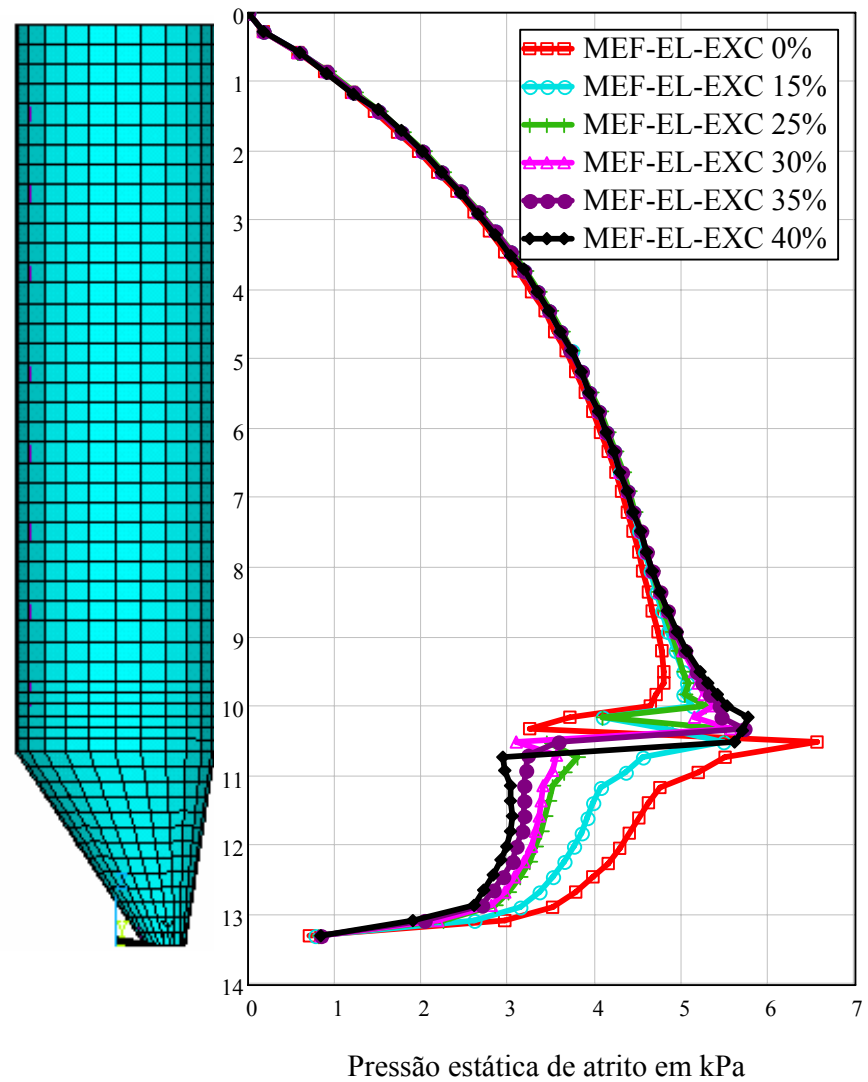

Figura 7.53 - Pressão estática de atrito de acordo com a relação $e_{0} / D$ para a soja. 
Observa-se que no lado oposto à excentricidade são obtidas pressões maiores em comparação com o lado próximo. Este efeito é ainda mais acentuado conforme aumenta a relação $e_{0} / D$. No lado próximo observa-se o inverso, ou seja, a pressão sofre redução conforme aumenta a relação $e_{0} / D$. 



\section{DISCUSSÕES E CONCLUSÕES}

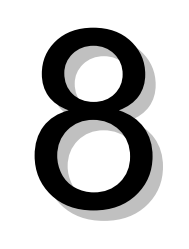

\subsection{Modelo numérico}

\subsubsection{A interação produto-parede}

A modelagem numérica do contado entre dois corpos é importante para simular corretamente a interação entre eles. A escolha do fator de rigidez normal do contato (FKN) deve ser ajustada para que a pressão normal às paredes e consequentemente a força dissipada por atrito em seu perímetro sejam coerentes. Observou-se que quanto maior o valor de $\mathrm{FKN}$, maiores as pressões exercidadas pelo produto sobre a parede vertical do silo, representando paredes rígidas. Nos modelos simulados com valores baixos de FKN ocorre um alívio de tensões nas paredes, compensado por maiores deslocamentos na parede, como nas paredes flexíveis.

No fundo dos silos planos o efeito do FKN é contrário, ou seja, quanto maior FKN, menores as pressões no fundo do silo. Podendo a tremonha ser considerada um fundo inclinado, é importante ajustar o fator FKN para a determinação correta das pressões na tremonha. Analogamente ao fundo plano, foi observado que quanto maior o valor de FKN, menores as pressões na tremonha. Além disso, valores superiores a 5 produziram flutuações nos valores da pressão na altura da transição entre o corpo cilíndrico e a tremonha.

Valores entre 2 e 5 foram os que apresentaram os melhores resultados nos silos com tremonha pois não subestimam as pressões no corpo e em contrapartida não superestimam as pressões na tremonha.

\subsubsection{Comportamento do produto armazenado}

A escolha de um modelo de comportamento para os produtos armazenados é complexa. Soma-se ainda dificuldade de realizar testes para quantificar algumas 
propriedades importantes como o módulo de elasticidade do produto, coeficiente de Poisson, viscosidade, dilatância, entre outras.

O modelo elástico funciona bem para a simulação das pressões estáticas na parede. Os resultados obtidos considerando o modelo elastoplástico são próximos dos resultados obtidos com o produto elástico. Portanto, enquanto o produto se encontra armazenado em repouso no interior do silo a consideração de material elástico é adequada.

Outro fator relacionado ao comportamento do produto que possui fundamental importância nos resultados numéricos é o coeficiente $\mathrm{K}$, que relaciona as pressões horizontais na parede com a pressão vertical no produto. Este parâmetro não é um dado de entrada na confecção do modelo numérico, sendo substituído pelo coeficiente de Poisson.

Os valores de $\mathrm{K}$ obtidos numericamente são parecidos com os adotados pelas normas para a parede vertical do silo, porém na tremonha, o MEF indica uma redução de $\mathrm{K}$, que não é considerada pelas normas estudadas. Constata-se que quanto maior o coeficiente de Poisson, maior a pressão horizontal na parede do silo.

Apesar da funcionalidade para simular as pressões estáticas, os modelos desenvolvidos neste estudo são muito simplificados para simular a situação do produto em fluxo ou na iminência do fluxo dado a dificuldade de adoção de um modelo de comportamento capaz de representar muitas características importantes dos produtos armazenados durante a descarga.

\subsection{Considerações normativas e o MEF}

\subsubsection{Pressões estáticas no corpo dos silos}

As recomendações propostas pelas normas internacionais analisadas são, em sua totalidade, baseadas na teoria Janssen (1895) para as estimativas das pressões iniciais ou de carregamento para o corpo do silo. Além de ter a simplicidade de uma equação analítica, o equacionamento de Janssen é apontado por muitos pesquisadores como Jenike \& Johanson (1973), Arnold et al. (1980), Benink (1989), Carson \& Jenkin (1993) e Calil (1993) como o que melhor descreve as pressões de carregamento no corpo do silo.

A validade da teoria de Janssen foi comprovada também pelo MEF, dado que as pressões estáticas no corpo do silo obtidas pelo MEF concordam muito bem com 
as obtidas a partir da teoria de Janssen, desde que efeito da variabilidade das propriedades físicas dos produtos seja excluída.

\subsubsection{Pressões estáticas na tremonha}

\subsubsection{Tremonhas concêntricas}

O cálculo das pressões exercidas na tremonha é um fenômeno que ainda não é completamente compreendido, portanto não existe uma concordância até mesmo entre os valores normativos, observando-se que as normas são conservadoras neste caso. As pressões obtidas pelo MEF na tremonha são inferiores em comparação com as normas analisadas. Isto se deve ao fato de que as expressões adotadas pelas normas não satisfazem o equilíbrio com as cargas aplicadas, enquanto o MEF satisfaz.

\subsubsection{Tremonhas excêntricas}

As normas não abordam uma metodologia para o cálculo das pressões em tremonhas excêntricas. Somente mencionam que para este tipo de situação deve ser utilizado um método de cálculo apropriado, não especificando qual.

A partir dos resultados melo MEF podemos concluir que as pressões estáticas em tremonhas excêntricas são maiores no lado oposto à excentricidade e menores no lado próximo, fenômeno ainda mais acentuado conforme aumenta o valor da excentricidade.

Cabe destacar que a intensidade das pressões não é muito maior em relação à tremonha concêntrica devido à condição de conservação do equilíbrio de forças, de forma que o acréscimo de pressão observado na lado oposto é compensado por uma redução da pressão no lado próximo. Por isso, o problema principal da descarga excêntrica não se encontra nos valores das pressões e sim na assimetria de pressões que gera ovalização das paredes do silo, efeito que se acentua devido à elevada esbeltez das paredes.

Um método de adoção de coeficientes que majoram a pressão no lado oposto à excentricidade e que minoram as pressões no lado próximo é uma alternativa adequada para a cobrir maiores excentricidades em silos com tremonha excêntrica. 


\subsubsection{Pressões dinâmicas no corpo dos silos}

\subsubsection{Boca de saída centrada}

Dado a complexidade das teorias para a determinação das pressões de descarga, as normas estudadas utilizam coeficientes de sobrepressão que, aplicados às pressões estáticas fornecem as pressões dinâmicas no corpo do silo. Além disso, algumas normas recomendam também a adoção de pressões adicionais a fim de levar em conta o efeito de possíveis pressões assimétricas, mesmo em silos concêntricos.

Os coeficientes de sobrepressão em silos com saída concêntrica são mostrados na Tabela 8.1.

Tabela 8.1 - Coeficientes de sobrepressão para silos concêntricos e pressão adicional.

\begin{tabular}{|c|c|c|c|c|c|}
\hline Protuto & Método & $\begin{array}{c}\text { Classe de } \\
\text { confiabilidade }\end{array}$ & $C_{h}$ & $\mathrm{C}_{\mathrm{w}}$ & $\begin{array}{c}\text { Pressão } \\
\text { adicional (kPa) }\end{array}$ \\
\hline \multirow{7}{*}{$\begin{array}{l}\text { Farelo de } \\
\text { milho }\end{array}$} & \multirow{2}{*}{ EUROCODE } & 1 & 1,35 & 1,4 & - \\
\hline & & 2 e 3 & 1,15 & 1,1 & 3,2 (máximo) \\
\hline & \multirow{2}{*}{ DIN } & 1 & 1,35 & 1,4 & - \\
\hline & & 2 e 3 & 1,15 & 1,1 & 2,8 (máximo) \\
\hline & AS & - & 1,9 & 1,2 & - \\
\hline & ISO & - & 1,35 & 1,35 & 2,45 (constante) \\
\hline & MEF & - & 1,38 & 1,38 & - \\
\hline \multirow{7}{*}{ Soja } & \multirow{2}{*}{ EUROCODE } & 1 & $0,75^{*}$ & 1,4 & - \\
\hline & & 2 e 3 & 1,15 & 1,1 & 2,1 (máximo) \\
\hline & \multirow{2}{*}{ DIN } & 1 & $0,75^{*}$ & 1,4 & - \\
\hline & & 2 e 3 & 1,15 & 1,1 & 1,8 (máximo) \\
\hline & AS & - & 1,9 & 1,2 & - \\
\hline & ISO & - & 1,35 & 1,35 & 2,45 (constante) \\
\hline & MEF & - & 1,30 & 1,30 & - \\
\hline
\end{tabular}

* Valor menor do que 1.

Pode ser observado que os coeficientes de sobrepressão variam muito entre as normas, de maneira que as pressões de descarga resultam bastante diferentes entre elas. Nos silos da classe 1, o coeficiente de sobrepressão obtido a partir da fórmula empírica adotada foi menor do que 1.

O procedimento para determinação das pressões dinâmicas por meio do MEF foi simplificado. Apesar da simplicidade do modelo, os resultados mostram que as pressões no corpo do silo são maiores quando existe um acréscimo do coeficiente K. 


\subsubsection{Boca de saída com excentricidade $e_{0} / D$ de $25 \%$}

A diferença no cálculo das pressões dinâmicas entre silos com tremonha concêntrica e excêntrica é o acréscimo dos coeficientes de sobrepressão e/ou acréscimo das pressões adicionais, conforme pode ser observado na Tabela 8.2.

Tabela 8.2 - Coeficientes de sobrepressão para silos de pequena excentricidade e pressão adicional.

\begin{tabular}{|c|c|c|c|c|c|}
\hline Produto & Método & $\begin{array}{c}\text { Classe de } \\
\text { confiabilida } \\
\text { de }\end{array}$ & $C_{h}$ & $\mathrm{C}_{\mathrm{w}}$ & $\begin{array}{c}\text { Pressão } \\
\text { adicional (kPa) }\end{array}$ \\
\hline \multirow{8}{*}{$\begin{array}{l}\text { Farelo de } \\
\text { milho }\end{array}$} & \multirow{2}{*}{ EUROCODE } & 1 & 1,5 & 1,54 & - \\
\hline & & 2 e 3 & 1,15 & 1,1 & 4,8 (máximo) \\
\hline & \multirow{2}{*}{ DIN } & 1 & 1,5 & 1,54 & - \\
\hline & & 2 e 3 & 1,15 & 1,1 & 4,2 (máximo) \\
\hline & AS & - & 1,9 & 1,2 & - \\
\hline & ISO & - & 1,35 & 1,35 & 2,7 (constante) \\
\hline & MEF (lado próximo) & - & 1,35 & 1,35 & \\
\hline & MEF (lado oposto) & - & 1,40 & 1,40 & - \\
\hline \multirow{8}{*}{ Soja } & \multirow{2}{*}{ EUROCODE } & 1 & $0,82^{*}$ & 1,54 & - \\
\hline & & 2 e 3 & 1,15 & 1,1 & 3,1 (máximo) \\
\hline & \multirow{2}{*}{ DIN } & 1 & 0,82 & 1,54 & - \\
\hline & & 2 e 3 & 1,15 & 1,1 & 2,7 (máximo) \\
\hline & AS & - & 1,9 & 1,2 & - \\
\hline & ISO & - & 1,35 & 1,35 & 3,4 (constante) \\
\hline & MEF (lado próximo) & & 1,25 & 1,25 & \\
\hline & MEF (lado oposto) & - & 1,35 & 1,35 & - \\
\hline
\end{tabular}

* Valor menor do que 1.

Somente a norma australiana não adota o conceito de pressões adicionais. Para compensar a ausência da pressão adicional, ela é a norma que adota os maiores coeficientes de sobrepressão.

Em algumas normas como a ISO e EUROCODE e DIN (silos da classe 1), o coeficiente de sobrepressão também sofre acréscimo de acordo com a relação $e_{0} / D$, porém a fórmula empírica aplicada deve ser utilizada com muita cautela porque pode acontecer de o coeficiente de sobrepressão ser menor do que 1.

Apesar da simplicidade do modelo numérico, os resultados com o MEF, neste caso, também mostram que as pressões no corpo do silo são maiores quando existe um acréscimo do parâmetro $\mathrm{K}$.

\subsubsection{Boca de saída com grande excentricidade}

Segundo as normas EUTOCODE e DIN, nos silos da segunda e terceira classe de confiabilidade que possuem grande excentricidade de descarga, uma distribuição assimétrica de pressões deve ser adotada. 
Esta distribuição é baseada na teoria de Rotter e é caracterizada pela redução da pressão em locais onde o fluxo excêntrico está em contato com a parede, aumento das pressões (com coeficiente de sobrepressão próximo de 2) no local onde o fluxo e a parede se interceptam e valores intermediários no lado oposto.

Os resultados numéricos obtidos a partir da aplicação de deslocamento no fundo do silo mostram que a distribuição de pressões obtidas pela teoria de Rotter é satisfatória e é capaz de prever as máximas pressões em casos de fluxo excêntrico.

Em contrapartida, o procedimento da norma AS para considerar maiores excentricidades e a Teoria de Safarian não cobrem as faixas de máximas pressões nos silos.

\subsubsection{Pressões dinâmicas na tremonha}

O processo simplificado de aumentar o coeficiente de Poisson do produto para simular as pressões fornece uma boa aproximação para as pressões no corpo do silo, porém na tremonha não. Portanto, o modelo numérico utilizado neste trabalho não permitiu analisar as pressões dinâmicas na tremonha.

\subsection{Conclusão}

$\mathrm{Na}$ maioria dos casos estudados neste trabalho, as normas EUROCODE e DIN foram as que apresentaram resultados de pressões mais próximos dos obtidos numericamente. Essas normas oferecem um melhor balanço entre segurança e economia da estrutura por considerar diferentes níveis de rigor de projeto em função de suas características e complexidade.

Além disso, são as normas de publicação mais recentes que incluíram as mais novas teorias desenvolvidas no estudo dos silos. Também são as normas mais específicas, separando metodologias de cálculo de acordo com elbeltez, confiabilidade, tipo de tremonha, tipo de fluxo, que parece ser mais razoável no estudo dos silos dado a complexidade e interdependência de inúmeros fatores envolvidos na determinação das pressões.

Portanto, para a determinação das ações em silos esbeltos para o armazenamento de produtos de fluxo livre uma boa alternativa é a utilização dos métodos recomendados pelas normas EUROCODE e DIN, com algumas ressalvas: pressão no fundo do silo segundo a AS e estabelecimento de coeficiente de 
sobrepressão mínimo de 1,2 e porcentagem mínima de variabilidade das propriedades dos produtos, mesmo quando elas forem obtidas por meio de testes experimentais.

Finalmente, para a normalização brasileira de silos com descarga excêntrica recomenda-se os valores adotados pelas normas EUROCODE e DIN.

\subsection{Sugestões para trabalhos futuros}

1) Realização de ensaios experimentais em silos excêntricos;

2) Simulação do carregamento progressivo com a atualização do módulo de elasticidade e densidade em cada camada;

3) Desenvolvimento de um modelo de comportamento que possibilite incorporar parâmetros como viscosidade, variação de densidade e dilatação volumétrica;

4) Simulação dinâmica do descarregamento do silo, considerando uma nova variável no modelo: o tempo;

5) Desenvolvimento e validação de modelos baseados no MED;

6) Aprofundar estudos a respeito das pressões adicionais e seu efeito estrutural na parede do silo;

7) Estudo do efeito estrutural nas paredes devido às pressões assimétricas de descarga excêntrica;

8) Estudo numérico das pressões em silos baixos. 



\section{REFERÊNCIAS BIBLIOGRÁFICAS}

AMERICAN SOCIETY OF AGRICULTURAL ENGINEERS (ANSI/ASAE) EP 433 DEC2001 Approved SEP 1991; reaffirmed JUN 2000 by American National Standards Institute.

AUSTRALIAN STANDARD. AS 3774 Supplement 1: Loads on bulk containers. Sydney, 1997.

AUSTRALIAN STANDARD. AS 3774: Loads on bulk containers. Sydney,1996.

AYUGA, F.; GUAITA M.; AGUADO P. Static and dynamic silo loads using finite element models. J. Agric. Eng. Res., v. 78, n. 3, p. 299-308, 2001a.

AYUGA, F; GUAITA M.; AGUADO P; COUTO A. Discharge and the Eccentricity of the Hopper Influence on the Silo Wall Pressures. Journal of Engineering Mechanics ASCE, $v$. 127, n. 10, p. 1067-1074, 2001b.

AYUGA, F. Los empujes del material almacenado en silos. Informes de la construcción, v. 46, n. 436, p. 27-34, 1995.

AYUGA, F; AGUADO P; GALLEGO E; RAMÍREZ A. 2006. Experimental tests to validate numerical models in silos design. ASABE Paper No. 064002. St. Joseph, Mich.: ASABE.

BUCKLIN, R. A., S. A. THOMPPSON, and I. J. ROSS. 1990. Bin-wall failure caused by eccentric discharge of free-flowing grain. J. Structural Eng. 116(11): 3175 B 3190.

CALIL, C. J. Recomendações de fluxo e de cargas para o projeto de silos verticais. 1990. 198 p. Tese (Livre Docência) - Escola de Engenharia de São Carlos, Universidade de São Paulo, São Carlos, 1990'.

CALIL, C. J. Sobrepresiones en las paredes de los silos para almacenamientode productos pulverulentos cohesivos. 1984. 184 p. Tese (Doutorado). Escola Politécnica de Barcelona, Espanha. Publicação do Departamento de Engenharia de Estruturas da Escola de Engenharia de São Carlos, Universidade de São Paulo, 1984.

CALIL Jr., C. (1997). A relação entre as pressões horizontais e verticais em silos. In: XXVI Congresso Brasileiro de Engenharia Agrícola, Campina Grande, 1997. (CD ROM). Paraíba, UFP.

CARSON, J. W.; JENKYN, R. T. Load Development and StructuralConsiderations in Silo Design. Reliable Flow of Particulate Solids II, Oslo, Norway, 1993.

CARSON, J. W. Silos failures: case histories and lessons learned. Third Israeli Conference for Conveying and handling of partivulate solids, Dead Sea, 2000.

CESCOTTO S.; CHARILIER R. Frictional Contact Finite Elements Based on Mixed Variational Principles. International Journal for Numerical Methods in Engineering, v. 36, p. 1681- 1701, 1992.

CHEUNG, A. B. Modelo estocástico de pressões de produtos armazenados para a estimativa da confiabilidade estrutural de silos esbeltos. 2007. $305 \mathrm{f}$. Tese (Doutorado) Escola de Engenharia de São Carlos, Universidade de São Paulo, 2007. 
COMPANHIA NACIONAL DE ABASTECIMENTO - CONAB (2007). http://www.conab.com.br/

COULOMB, C.A. (1773). "Essai sur une application des régles de maximis et minimis à quelques problémes de statique relatifs a l'architecture". Mémoires de Mathématique et de Physique, présentés à l'Académie Royale des Sciences par Divers Savants et lus dans ses Assemblées, 7, Paris, France, 343-382.

COUTO, A; GUAITA, M.; AYUGA, F.; AGUADO, P. Analysis of Static Pressures in Cylindrical Silos With Eccentric Outlet Hopper Using F.E.M. Models. Thin-Walled Struct, v.5, p. $98-101,2000$.

COUTO, A. Métodos avanzados de cálculo de presiones estáticas en silos cilíndricos y prismáticos con tolva excéntrica mediante el método de los elementos finitos. 2000. Tese (Doutorado). Politechnic University of Madrid, 2000.

COUTO A; VIDAL P; MOYA M. 2003. INFLUENCIA DE LOS PARÁMETROS ELÁSTICOS EN LA ESTIMACIÓN DE EMPUJES EN LAS PAREDES DE LOS SILOS CON TOLVA EXCÉNTRICA Y SU COMPARACIÓN CON EL EUROCÓDIGO- 1. ANÁLISIS EN 3-D MEDIANTE EL M.E.F.

DEUTSCH, G P; CLYDE D H. 1967. Flow and pressure of granular materials in silos. Proceedings of the ASCE 93 (EM6); 103-125.

DEUTSCHE NORM DIN 1055 Part 6 - Design loads for buildings; Loads in silos bins. Berlin, Verlaz, 1987.

DRUCKER, D.C.; PRAGER, W. Soil mechanics and plastic analysis or limit design. Quarterly of Applied Mathematics, v. 7, n. 411-418, pp 157-165, 1952.

Eibl J., Landahl H., Häußler U., and Gladen W., 1982. Zur fragedes silodrucks. Beton- und Stahlbetonbau, 77, 104-110.

EUROPEAN COMMITTEE OF STANDARDIZATION. PrEN 1991-4: Actions on silos and tanks, CEN, Brussels. 2002.

ENSTAD G.G., 1983. The ultimate critical outlet width for flow in mass-flow hoppers. Chemie Ingenieur Technik, 55(2), 154-155.

FREITAS, E. G. Estudo teórico e experimental das pressões em silos cilíndricos de baixa relação altura/diâmetro e fundo plano. 2001. 175p. Tese (Doutorado) - Escola de Engenharia de São Carlos, Universidade de São Paulo, São Carlos, 2001.

GALLEGO 2006. Numerical Simulation of Loads Exerted by Stored Materials in Silos with non-Elastic Material Models. Polytechnic University of Madrid.. Escuela Técnica Superior de Ingenieros Agrónomos. Department of Construction and Rural Roads. PhD Thesis.

GALLEGO, E.; GOODEY, R. J.; AYUGA, F.; BROWN, C. J. Some practical features in modelling silos with finite elements. ASAE Paper No. 044150. St. Joseph, Mich.: ASAE. Proc. of the 2004 ASAE/CSAE Annual International Meeting. Ottawa, August 2004.

GILLIE M., ROTTER J.M.. The effects of patch loads on thin-walled steel silos. Thin-Walled Struct 2002;40:835-52.

GIUNTA, J S. Flow patterns of granular materials in flat-bottom bins. Transactions of the ASME, Journal of Engineering for Industry, 1991. Ser. B, No. 2, pp. 406-413. 
GOMES, F.C. Estudo teórico e experimental das ações em silos horizontais. 2000, 205p. Tese (Doutorado em Engenharia Civil) - Escola de Engenharia de São Carlos. São Carlos. 2000.

GUAITA M.; COUTO A.; AYUGA F. Numerical Simulation of Wall Pressure during Discharge of Granular Material from Cylindrical Silos with Eccentric Hoppers. Biosystems Engineering, v. 85, n. 1, p. 101-109, 2003.

GUAITA, M. Creación de modelos para la simulación de silos por el método de elementos finitos y análisis de los empujes estáticos del material almacenado. 1995. Tese (Doutorado) Department of Construction and Rural Roads, Polytechnic University of Madrid, 1995.

HÄUßLER, U; EIBL, J. 1984 Numerical investigations on discharging silos. Journal of Engineering Mechanics (110) 6; 957-971

HARDIN B. O.; HARDIN K. O.; ROSS I. J.; SCHWAB C. V. (1990). Triaxial compression, simple shear, and strength of wheat en masse. Transactions of the ASAE, 33(3), 933\}943

HARTLEN, J., NIELSEN, J., LJUNGGREN, L., MERTENSSON, G. E WIGRAM, S. (1984), "The Wall Pressure in Large Grain Silos", Swedish Council for Building Research, Stockholm, D2:1984.

INTERNATIONAL ORGANIZATION FOR STANDART ISO - 11697: Bases for design of structures: Loads due to bulk materials, London, 1995.

JAMIELSON, J A Grain pressures in deep bins. Engineering News. Montreal 1904.

JANSSEN, H. A. Versuche Über Getreidedruck in Silozellen. Zeitschrift, Verein Deutscher Ingeniure, v. 39, pp. 1045-1049, 1895.

JENIKE, A. W. (1964). Storage and Flow of Solids. Bulletin 123. Utah Engineering Experiment Station. University of Utah. Salt Lake City. Utah. Estados Unidos. 197 p.

JENIKE, A. W.; JOHANSON, J. R. Bin Loads. Journal of the Structural Division, ASCE, v.95, nST4, 1968.

JENIKE A. W., JOHANSON J. R. On the theory of bin loads. Journal of Engineering for Industry, ASME, Series B 1969;94(2):339-44.

JOFRIET, J. C.; LELIEVRE, B. e FWA, T. F. 1977. Friction model for Finite Element Analises of silos. Transactions of the American Soc. Ag. Eng. 20(4): 735-744.

JOFRIET, J. C. e CZAJKOWSKI. 1980. A parametric study of whole plant corn silage pressures and loads in tower silos. Canadian Agricultural Engineering (22) 1.

JOFRIET J. C.; NEGI S. C.; LU Z. 1997. A Numerical Model for Flow of Granular Materials in Silos. Part 3: Parametric Study. Journal of Agricultural Engineering Research, 68 (3), 237246

JOFRIET, J.C.; MENG, Q.G.; NEGI, S.C.1997. Finite-element analysis of bulk solids flow. Part 1. Development of a model-based on a secant constitutive relationship. Journal of Agricultural Engineering. Research; 67(2):141-50.

KAMINSKI, M.; WIRSKA, E. 1998. Variation of pressures in flexible walled silo model. Powder Handling \& Processing. V.10 n.4, p.349-355. October/December. 
KIM, V.S. 1959. Davlenie Zerna I Sovershenstvovanie Konstrukstii Silosov (Presión del grano y mejoras en la construcción de silos). Moscow: Khleboissdat.

KOTCHANOVA, I J 1970. Experiments and theoretical investigations on discharge of granular materials from bins. Powder Technology 4: 32-37

LOHNES R.A. (1993). Lateral stress ratios for particulate materials. Powder Handling \& Processing. V 5 n.4 p 331-336

Lu Z ; Negi S C ; Jofriet J C A hybrid FEM and DEM model for numerical analysis of granular material flow .1995 Annual Meeting American Society of Agricultural Engineering, Chicago , IL , Paper no . $95-4450$

LU, Z; NEGI, S.C; JOFRIET, J. 1997. A numerical model for flow of granular materials in silos. Part 1: Model Development. J. Agric. Engng. Res. 68: 223-229.

McCABE, R. P. 1974. Flow Patterns in granular materials in circular silos. Geotechnique 1: 45-62.

MAHMOUD, M. H. 1975. Silage silo interaction using material characterization and finite element techiniques. PhD thesis. Ohio, State University, $164 \mathrm{p}$.

MAHMOUD, M. H. e ABDEL-SAYED, G. 1981. Loading on shallow cylindrical flexibe grain bins. Journal of powder \& bulk solids technology 5(3): 12-19.

MARTÍNEZ, M.A.; ALFARO, I.; DOBLARÉ, M. (2002). Simulation of axisymmetric discharging in metallic silos. Analysis of the induced pressure distribuition and comparison with different standards. Engineering Structures. V. 24. p 1561-1574.

McLEAN, A. G. (1986). Empirical Critical Flow Factor Equations. Bulk Solids Handling, V.6, $\mathrm{N}^{\circ} 4$.

MENG Q.; JOFRIET J. C.; NEGI S. C. Finite Element Analysis of Bulk Solids Flow : Part 1 , Development of a Model Based on a Secant Constitutive Relationship. Journal of agricultural Engineering Res Ontario, Canada. 67, p. 141 - 150, 1997.

MILANI, A. P. Determinação das propriedades de produtos armazenados para o projeto de pressões e fluxo em silos. 1993, 272f. Tese (Doutorado em Engenharia Civil) - Escola de Engenharia de São Carlos. São Carlos. 1993.

MOLENDA M.; HORABIK J.; THOMPSON S. A.; ROSS I. J.; BIN LOADS INDUCED BY ECCENTRIC FILLING AND DISCHARGE OF GRAIN. Structures \& Environment Division of ASAE, v. 45, n. 3, p. 781-785, 2001.

MUNCH-ANDERSEN, J. e NIELSEN, J. 1986 Size efects in slender grain silos. Int. J. Storing Handling Bulk Mater. 6, 885-889.

NIELSEN, J. 1972 Silo pressure. PhD thesis, Structural Research Laboratory, Technical University of Denmark, Report R26. (In Danish.)

NIELSEN, J. 1977 Model laws for granular media and powders with a special view to silo models. Arch. Mech. 29(4), 547-560.

NIELSEN, J. e KRISTIANSEN, N.O. (1979), Trykmaling pa silo i Karpalund. (Pressure measurements on silo at Karpalund.) Dept. Struct. Engg, Tech. Univ. Denmark, Lyngby. 
NIELSEN, J. e ANDERSEN, E.Y. (1981), Silotrykmalinger i Karpalund 1980. (Measurements of silo pressure at Karpalund in 1980.) Dept. Struct. Engg, Tech. Univ. Denmark, Lyngby.

NIELSEN, J. 1983. Load distributions in silos influenced by anisotropic grain behavior. In Int. Conf. on Bulk Materials, Storage, Handling and Transportation, Newcastle, NSW, Australia, 22-24 August 1983, pp. 226-230 The Institution of Engineers, Australia.

NIELSEN, J. e ASKEGAARD, V. 1977. Scale errors in model tests on granular media with special reference to silo models. Powder Technol. 16, 123-130.

NIELSEN, J. e KRISTIANSEN, N. 1980. Related measurements of pressure conditions in full-scale barley silo and in model silo. In Int. Conf. on Design of Silos for Strength and Flow, Lancaster, UK, 2-4 September 1980.

OOI, J.Y., ROTTER, J.M. e PHAM, L.. 1990. Systematic and Random Features of Measured Pressures on Full-Scale Silo Walls, Engineering Structures, Vol. 12, No. 2, April 1990, pp 7487.

PALMA, G. Pressões e fluxo em silos esbeltos ( $h / d \geq 1,5)$. 2005.109 p. Dissertação (Mestrado) - Escola de Engenharia de São Carlos, Universidade de São Paulo, São Carlos, 2005

PETROV, B. A. 1958. Experimentalnoe Opredeleinie Davlenia Cementa na Stenki Zhelezobetonnich Silosov (Determinação experimental das pressões do cimento sobre as paredes de silos de concreto). Cement 2: 21-25.

Pieper, K. (1969), Investigation of Silo Loads in Measuring Models. Jnl of Engg for Ind., ASME, May, pp 365-72. New York.

PIEPER, K., e WAGNER, K. 1969. "Der Einfluss Verscheidener Auslaufarten auf die Seitendrucke in Silozellen [The influence of different types of discharge on the silo cells loads]." Aufbereitungs-Technik, Wiesbaden, Germany (in German).

RAMIREZ, A. NIESEN, J., AYAGUGA, F., MUNICH-ANDERSEN, J. 2006. On the Use of Plate-Type Normal Pressure Cells for Silos. Fifth World Congress on Particle Technology. Orlando, 2006.

RAVENET, J. 1977. Silos, teoria investigacion, construccion. Editores Tecnicos Asociados, S. A. Barcelona, Spain.

RAVENET, J. Sobrepresiones en las paredes de los silos debidos al vaciado y efectos producidos por la forma de la tolva y excentricidad del vaciado- Tesis Doctoral- Universidad Politecnica de Barcelona. Barcelona. 1974

ROMBACH, G. A. 1991. Schüttguteinwirkungen auf Silozellen -Exzentrische Entleerung-, thesis, University of Karlsruhe, Germany, report no. 14 of Institute 'Massivbau und Baustofftechnologie'

ROMBACH G., EIBL J.: Granular Flow of Materials in Silos - Numerical Results. Bulk solids handling 1995, pp. 65-70

ROBERTS, A. W. (1998). Basic Principles of Bulk Solids: Storage, Flow and Handling. Centre for Bulk Solids and Particulate Technologies. Callaghan, NSW. Australia. 
ROBERTS, I. 1884. Pressure of stored grain. Engineering, Vol.34, pp.399, Oct. 27.

Roberts, A.W. Storage, flow and handling of bulk solids. The University of Newcastle. Australia, v.único, p.103-135, 1987.

ROMBACH G; NEUMANN F. 3-D finite element modeling of granular flow in silos. 17 th ASCE Engineering Mechanics Conference June 13-16, 2004, University of Delaware, Newark, DE

ROMBACH, G.A.; AYUGA, F.; GALLEGO, E.; NEUMANN, F. 2005. Filling and discharging simulations with different Finite Element programmes - ANSYS VS. SILO.

RONG, G. H. 1994. Discrete element modeling for flow of particulate material in bins. PhD diss. Guelph, Ontario, Canada: University of Guelph, School of Engineering.

ROTTER J. M., OOI, J. K., CHEN, J. F., TILEY, P. J., MACKINTOSH, I. e BENNET, F. R. (1995) "Flow Pattern Measurement in Full Scale Silos", British Materials Handling Board. London, 230pp.

ROTTER, J. M. (1986), The Analysis of Steel Bins Subject to Eccentric Discharge, Proc., Second Int. Conf. Bulk Materials Storage Handling and Transportation, IEAust., Wollongong, pp 264-271

ROTTER, J. M.; HOLST, F.G.; OOI, J. Y.; SANAD, M. (1998). Silo pressures predictions using discreteelement and finite-element analyses. Phil. Trans. R. Soc. of London: Philosophical Transaction: Mathematical, Physical and Engineering Sciences. Series A. (356). pp. 2685-2712.

ROTTER J. M. The analysis of steel bins subject to eccentric discharge. Proceedings of the Second International Conference on Bulk Material Storage, Handling and Transportation, Wollongong, 7-9 Jul.; 1986. p. 264-71.

ROTTER J. M; TENG J. G. Elastic stability of cylindrical shells with weld depressions. J. Struct. Eng., ASCE 1989;115(5):1244-63.

J. M. ROTTER, J. M. F. G. HOLST, J. Y. OOI e A. M. SANADY (1998). Silo pressure predictions using discrete-element and Finite-element analyses Phil. Trans. R. Soc. Lond. A 356, 2685-2712.

ROTTER, J.M. (2001) Pressures, stresses and buckling in metal silos containing eccentrically discharging solids. 60th Birthday Celebration for Univ-Prof Dipl-Ing Dr.techn. Richard Greiner, Oct. 12, Institute for Steel, Timber and Shell Structures, Technical University Graz, Austria. 2001.

RONG, G. 1994. "Discrete element modeling for flow of particulate materials in bins." PhD thesis, University of Guelph, Ont., Canada.

RONG G H; NEGI S C; JOFRIET J C. 1995. Simulation of ßow behavior of bulk solids in bins. Part 1: model development and validation. Journal of Agricultural Engineering Research, 62, 247-256

SAFARIAN, S S Design pressures of granular materials in silos. ACI Journal New York. 1969

SCHULZE, D. 1996: Flowability of bulk solids - Definition and measuring techniques, Part I and II, Powder and Bulk Engineering 10 4, pp. 45-61, and 10 (1996) 6, pp. 17-28 
SMITH D.L.O. e LOHNES R.A., 1983. Bulk strength and stress strain behaviour of four agricultural grains. J. Powder \& Bulk Solids Technology, 7(4), 1-7.

SONG, C.Y.; TENG, J.G. (2003) Buckling of circular steel silos subject to code-specified eccentric discharge pressures. Engineering Structures v.25, p. 1397-1417.

SUGITA M. 1972. Flow and pressures of non-cohesive granular materials in funnel \#ow bin. ASME No. 72-MH-20, pp 1\}8

VIDAL, P. L. Advanced models for finite element numerical simulation of actions in the discharge of cylindrical silos with concentric and eccentric hoppers. 2003. Tese (Doutorado).

VIDAL, P.; GUAITA M.; AYUGA F. 2005a Discharge from cylindrical slender steel silos: Finite element simulation and comparison with Eurocode 1. Trans. ASAE 48(6): 2315-2321.

VIDAL, P.; GUAITA M.; AYUGA F. 2005b. Analysis of discharge pressures in cylindrical slender silos with a flat bottom or with a hopper: Comparison with Eurocode 1. Biosystems Eng. 91(3): 335-348.

VIDAL, P.; COUTO A.; AYUGA F.; GUAITA M. 2006. Influence of hopper eccentricity on discharge of cylindrical mass flow silos with rigid walls. J. Eng. Mechanics ASCE 132(9): 1026-1033

ZHANG Q. M., BRITTON G., e JAREMIK R. 1993. Dynamic loads during discharge for wheat, barley and canola in a smooth and a corrugated-walled model bin. J. Agric. Eng. Res., 56, 111-119.

ZHANG Q; BRITTON M G; XU S. 1994. Using dilatancy angle to predict dynamic loads during discharge in bulk solid storage structures. Proceeding of Powder and Bulk Solids'94, Rosemont, IL 383-390

WALKER, D. M. (1966). An Approximate Theory for Pressures and Arching in Hoppers. Chem. Eng. Sci., V. 21, p. 975-997. WPMPS (1989) Standart Shear Testing Technique for Particulate Solids Using the Jenike Shear Cell“. The Institution of Chemical Engineers. England.

WPMPS (1989) Standart Shear Testing Technique for Particulate Solids Using the Jenike Shear Cell“. The Institution of Chemical Engineers. England. 